\title{
Unifying Concepts in Electro- and Thermocatalysis towards Hydrogen Peroxide Production
}

Jason S. Adams, ${ }^{1, *}$ Matthew L. Kromer, ${ }^{2, *}$ Joaquín Rodríguez-López, ${ }^{2, *}$ David W. Flaherty, ${ }^{1, *}$

${ }^{1}$ Department of Chemical and Biomolecular Engineering, University of Illinois at Urbana-Champaign, IL, 61801, USA

${ }^{2}$ Department of Chemistry, University of Illinois at Urbana-Champaign, IL, 61801, USA $\$$ Authors contributed equally

Table of Contents:

S1. Discussion of Material Synthesis and Characterization..........................................

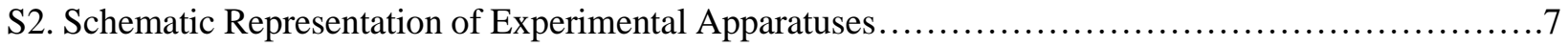

S3. Development of Electrochemical Cell and Open-Circuit Measurement Results......................9

S4. Derivation of the Nernst Equations for Hydrogen Oxidation and Oxygen Reduction.................25

S5. Koutcky-Levich Analysis to Correct Mass Transfer Limitations in Electrochemical Measurements....27

S6. Derivation of Hydrogen Coverage by Adsorption, Oxidation, and Reduction Paths..................56

S7. Derivation of $\mathrm{H}_{2} \mathrm{O}_{2}$ and $\mathrm{H}_{2} \mathrm{O}$ Rate expressions via Proton-electron Transfer Paths.................61

S7.1 Theoretical Consideration of Low-barrier Proton-electron Transfer Pathways...............61

S7.2 Derivation of Rate Expressions for $\mathrm{H}_{2} \mathrm{O}_{2}$ and $\mathrm{H}_{2} \mathrm{O}$ Formation Rates...................63

S7.3 Derivation of $\mathrm{H}_{2} \mathrm{O}_{2}$ Selectivity and Average Electrons Transmitted During the ORR........70

S7.4 Derivation of Operating Potential and Turnover Rates of ORR During Thermocatalysis......72

S7.5 Considerations of Electron Activity and Influence of Coupled ORR and HOR..............75

S8. Changes in the Selectivity of $\mathrm{H}_{2} \mathrm{O}_{2}$ as a Function of the Electrode Potential......................77

S8.1 Analysis of $\mathrm{H}_{2} \mathrm{O}_{2}$ Selectivity as a Function of Electrode Potential and Optimization.........77

S8.2 Experimental Comparisons of Selectivity and Optimal Potentials of Catalytic Materials......80

S9. Mathematical Interpretations of Selectivity with Reactant Activity and Temperature ...............97

S9.1 Selectivity of $\mathrm{H}_{2} \mathrm{O}_{2}$ Formation as a Function of Hydrogen activity $\ldots \ldots \ldots \ldots \ldots \ldots \ldots \ldots \ldots . \ldots 7$

S9.2 Selectivity of $\mathrm{H}_{2} \mathrm{O}_{2}$ Formation as a Function of Temperature.........................98

S9.3 Activation Barriers of $\mathrm{H}_{2} \mathrm{O}_{2}$ Formation Comparted to Experimental Measurements.........100

S10. Comparisons of Rates and Selectivities Between Thermo- and Electrochemical Systems...........116

S10.1 Comparisons of $\mathrm{H}_{2} \mathrm{O}_{2}$ Selectivity Under Thermo- and Electrocatalytic Conditions........116

S10.1 Comparisons of Oxygen Reduction Rates and Consideration of Error Propagation........116

References... 


\section{Supporting Information}

\section{S1. Discussion of Material Synthesis and Characterization}

In this subsection, we discuss the precursor materials used to synthesize the supported nanoparticle catalysts and report their particle sizes and metal content. Materials were prepared by strong electrostatic adsorption by mixing Vulcan XC-72 with the metal nitrate precursors and aqueous ammonium hydroxide $\left(\mathrm{NH}_{4} \mathrm{OH}\right.$, Macron 6665) with a target loading of $1 \mathrm{wt} \%$ for each metal (discussed in the main text Section 2.1). Each batch used $\sim 5 \mathrm{~g}$ of Vulcan XC-72 with the $300 \mathrm{~mL}$ of $\mathrm{NH}_{4} \mathrm{OH}$ solution with the following anhydrous concentrations of metal salts: $0.72 \mathrm{mM}$ palladium (II) nitrate $\left(\mathrm{Pd}\left(\mathrm{NO}_{3}\right)_{2}\right.$, Sigma Aldrich), $0.43 \mathrm{mM}$ tetraamine platinum (II) nitrate $\left(\left(\mathrm{NH}_{3}\right)_{4}\left[\mathrm{Pt}\left(\mathrm{NO}_{3}\right)_{2}\right]\right.$, Sigma Aldrich), gold (III) chloride, $\left(\mathrm{HAuCl}_{4}\right.$, Sigma Aldrich), $0.91 \mathrm{mM}$ cobalt nitrate (II) $\left(\mathrm{Co}\left(\mathrm{NO}_{3}\right)_{2}\right.$, Sigma Aldrich), $0.88 \mathrm{mM}$ zinc (II) nitrate $\left(\mathrm{Zn}\left(\mathrm{NO}_{3}\right)_{2}\right.$, Sigma Aldrich), 0.91 $\mathrm{mM}$ nickel (II) nitrate $\left(\mathrm{Ni}\left(\mathrm{NO}_{3}\right)_{2}\right.$, Sigma Aldrich), $0.89 \mathrm{mM}$ copper nitrate $\left(\mathrm{Cu}\left(\mathrm{NO}_{3}\right)_{2}\right.$, Sigma Aldrich) (precursors reported in Table S1).

The metal content in these catalysts was measured by energy dispersive X-ray fluorescence (Shimadzu, EDX-7000), in which $\mathrm{La}_{2} \mathrm{O}_{3}$ was intentionally mixed into the carbon materials as an internal standard. Metal content was also measured by inductively coupled plasma optical emission spectrometry using a PerkinElmer Optima 2000DV (Table S1) to complement EDXRF measurements. Figure S1 shows representative TEM images and histograms of the particle size distribution and morphology of Pd nanoparticles that were measured by bright-field transmission electron microscopic imaging (JEOL $2010 \mathrm{LaB} 6$ ) of more than 100 nanoparticles. Table S1 reports the average diameter $\left(\left\langle d_{\text {avg, TEM }}\right\rangle\right)$ and the surface area normalized average diameter $\left(\left\langle d_{s, \mathrm{TEM}}\right\rangle\right.$, calculated using equation S1.1) for each catalyst material.

$$
<d_{S, T E M}>=\frac{\sum_{i} n_{i} d_{i}^{3}}{\sum_{i} n_{i} d_{i}^{2}}
$$

Overall, the materials showed heterogeneous particle size distributions with a large variance in the average nanoparticle diameters. Moreover, the extent of alloying between metals and their bimetallic morphologies are unclear with these measurements alone. The metal content measurements generally showed agreement between the EDXRF and ICP techniques. Still, the EDXRF measurements were more precise and showed better agreement with the target metal loadings of each material. Thus, all rates reported throughout this article are normalized by the metal content of Pd and/or Pt, determined by EDXRF. Rates were not normalized by estimations of dispersion due to the nanoparticle heterogeneity and unclear morphology of the metal alloys. Nevertheless, the characterization presented here is sufficient for drawing comparisons between electrocatalytic and thermocatalytic measurements since the same materials are used in either case. 

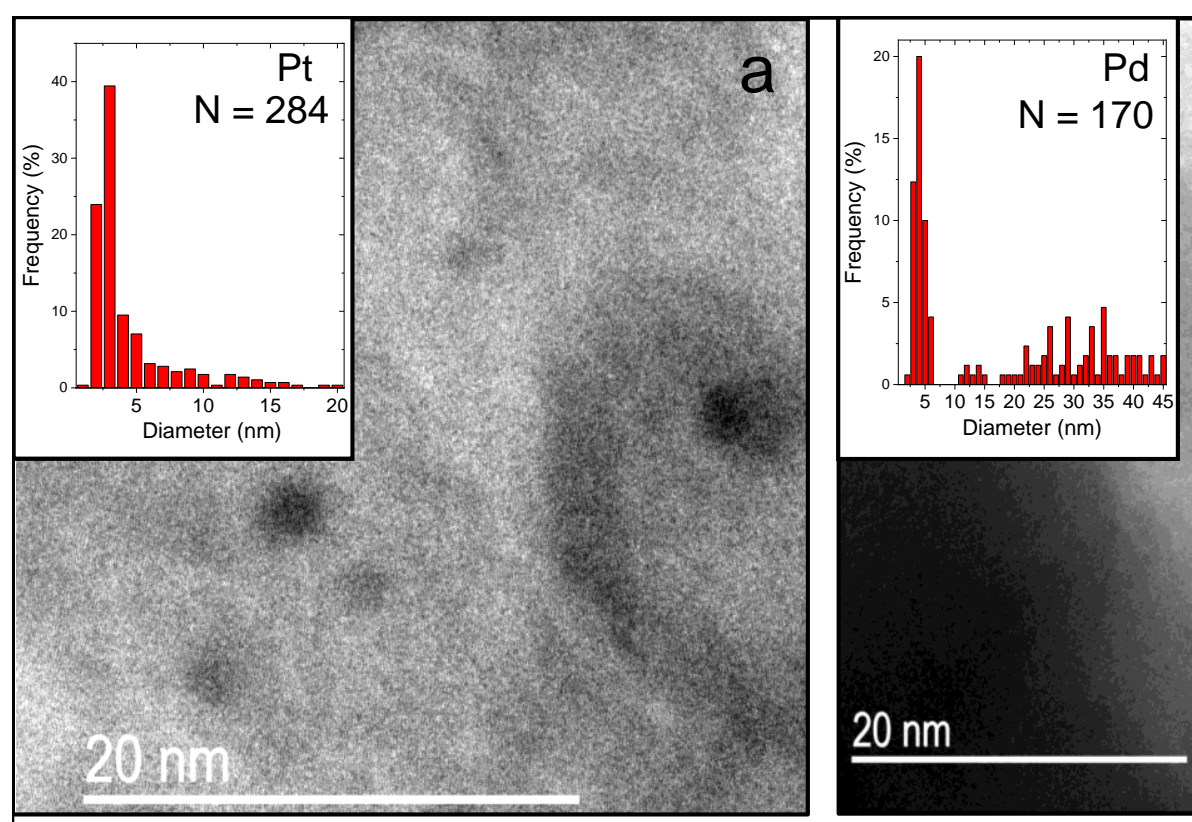

b

$20 \mathrm{~nm}$

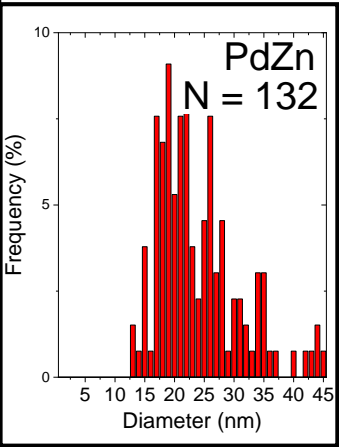

C

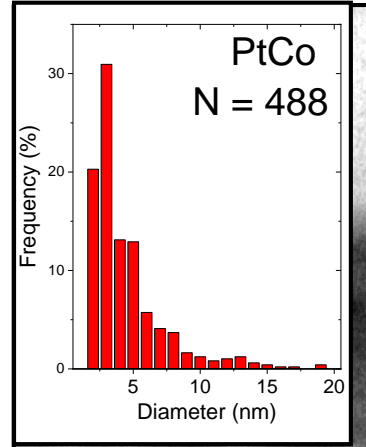

$20 \mathrm{~nm}$

\section{$20 \mathrm{~nm}$}




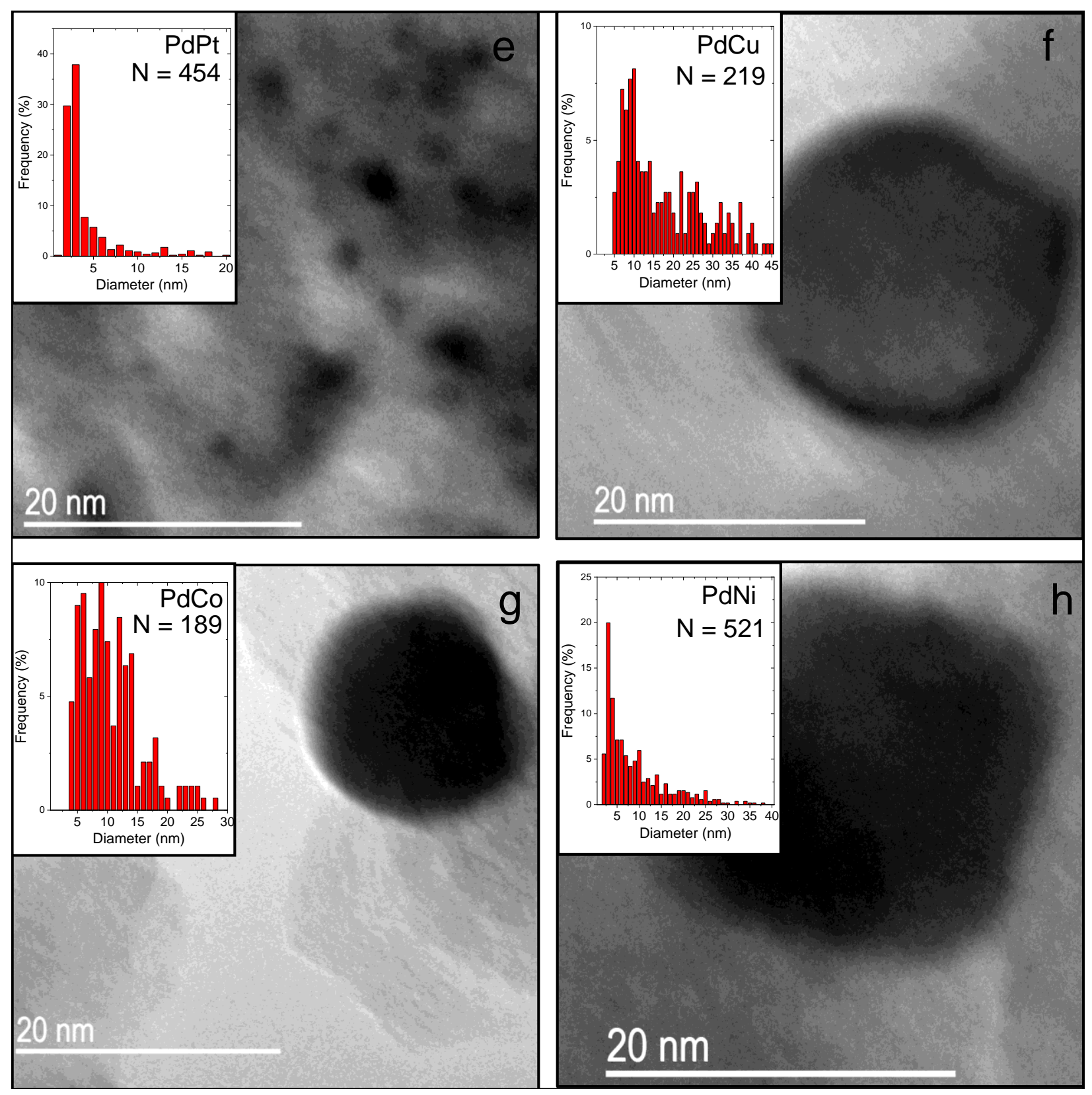



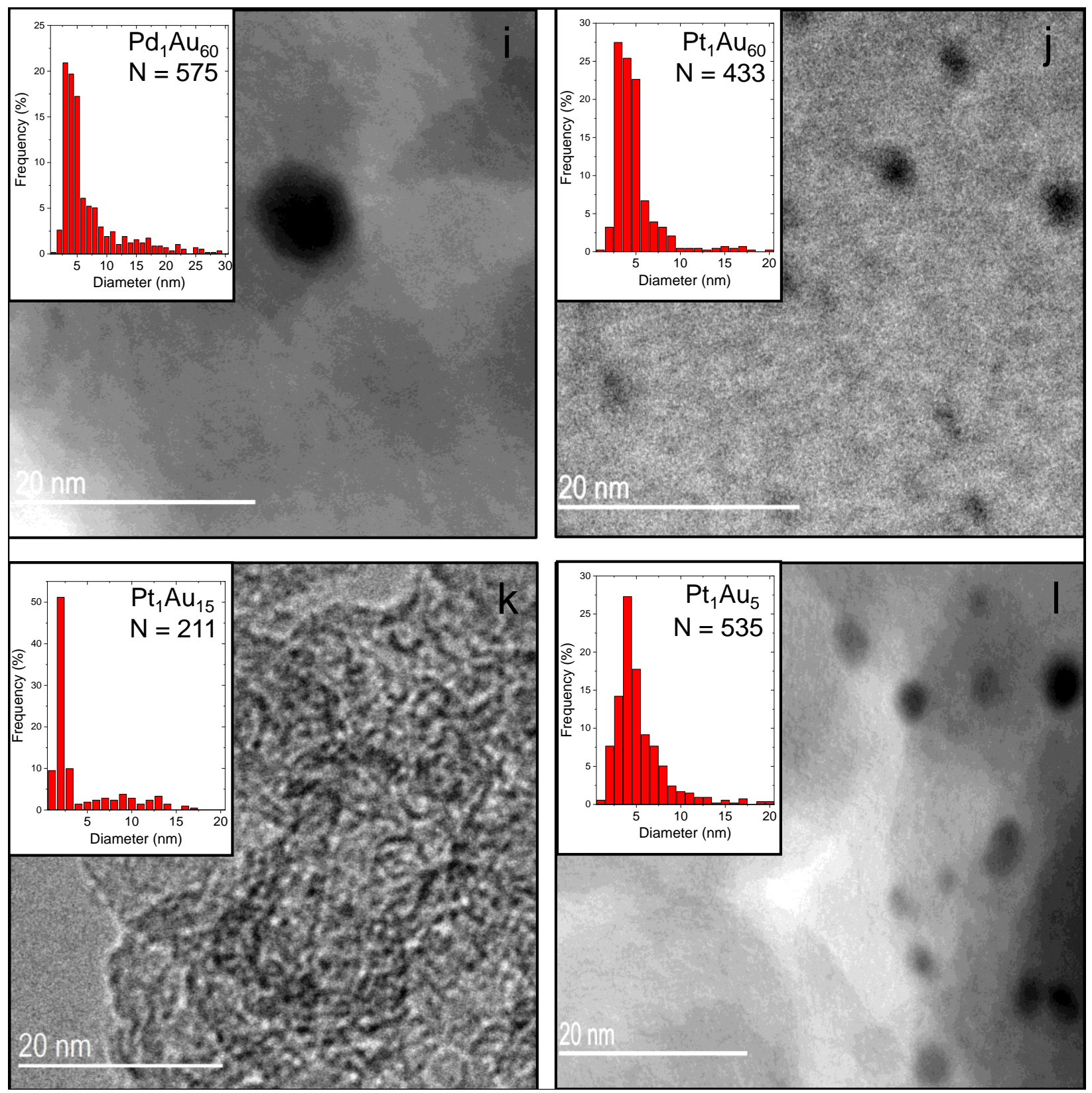

Figures S1. Representative TEM image of (a) Pt, (b) Pd, (c) PdZn, (d) PtCo, (e) PdPt, (f) PdCu, (g) PdCo, (h) PdNi, (i) $\mathrm{Pd}_{1} \mathrm{Au}_{60}$, (j) $\mathrm{Pt}_{1} \mathrm{Au}_{60}$, (k) $\mathrm{Pt}_{1} \mathrm{Au}_{15}$, and (l) $\mathrm{Pt}_{1} \mathrm{Au}_{5}$ nanoparticles supported on Vulcan XC-72 with an inset histogram of the particle size distribution. More than 100 particles were measured to calculate the value of $\left\langle d_{s, \mathrm{TEM}}\right\rangle$ and $\left\langle d_{a v g, \mathrm{TEM}}\right\rangle$, which are the surface areaaveraged and averaged diameters, respectively, found in table S1. 
Table S1:

\begin{tabular}{|c|c|c|c|c|c|}
\hline Material & $\begin{array}{l}\text { Precursor } \\
\text { Salts }\end{array}$ & $\begin{array}{l}\text { Metal Content } \\
\text { (EDXRF, wt\%) }\end{array}$ & $\begin{array}{c}\text { Metal } \\
\text { Content } \\
(\mathrm{ICP}, \text { wt\%) }\end{array}$ & $\left\langle d_{s, \mathrm{TEM}}\right\rangle$ & $\left\langle d_{\text {avg,TEM }}\right\rangle$ \\
\hline $\mathrm{Pt}$ & $\mathrm{Pt}\left(\mathrm{NH}_{3}\right)_{4}\left(\mathrm{NO}_{3}\right)_{2}$ & Pt: $0.87 \pm 0.03$ & Pt: 0.48 & $11.3 \pm 3.5$ & $3.9 \pm 3.5$ \\
\hline $\mathrm{Pd}$ & $\mathrm{Pd}\left(\mathrm{NO}_{3}\right)_{2}$ & Pd: $0.34 \pm 0.02$ & Pd: 0.33 & $37.1 \pm 15.8$ & $18.4 \pm 15.8$ \\
\hline $\mathrm{PdZn}$ & $\begin{array}{l}\mathrm{Pd}\left(\mathrm{NO}_{3}\right)_{2} \\
\mathrm{Zn}\left(\mathrm{NO}_{3}\right)_{2}\end{array}$ & $\begin{array}{l}\text { Pd: } 0.22 \pm 0.02 \\
\text { Zn: } 0.09 \pm 0.01\end{array}$ & $\begin{array}{l}\text { Pd: } 0.23 \\
\text { Zn: } 0.06\end{array}$ & $30.6 \pm 8.3$ & $24.2 \pm 8.3$ \\
\hline PtCo & $\begin{array}{c}\mathrm{Pt}\left(\mathrm{NH}_{3}\right)_{4}\left(\mathrm{NO}_{3}\right)_{2} \\
\mathrm{Co}\left(\mathrm{NO}_{3}\right)_{2}\end{array}$ & $\begin{array}{l}\text { Pt: } 0.61 \pm 0.06 \\
\text { Co: } 0.25 \pm 0.02\end{array}$ & $\begin{array}{l}\text { Pt: } 0.46 \\
\text { Co: } 0.14\end{array}$ & $17.8 \pm 4.2$ & $4.5 \pm 4.2$ \\
\hline $\mathrm{PdPt}$ & $\begin{array}{c}\mathrm{Pd}\left(\mathrm{NO}_{3}\right)_{2} \\
\mathrm{Pt}\left(\mathrm{NH}_{3}\right)_{4}\left(\mathrm{NO}_{3}\right)_{2}\end{array}$ & $\begin{array}{l}\text { Pd: } 0.29 \pm 0.02 \\
\text { Pt: } 0.88 \pm 0.02\end{array}$ & $\begin{array}{l}\text { Pd: } 0.19 \\
\text { Pt: } 0.26\end{array}$ & $27.5 \pm 6.3$ & $3.6 \pm 6.3$ \\
\hline $\mathrm{PdCu}$ & $\begin{array}{l}\mathrm{Pd}\left(\mathrm{NO}_{3}\right)_{2} \\
\mathrm{Cu}\left(\mathrm{NO}_{3}\right)_{2}\end{array}$ & $\begin{array}{l}\mathrm{Pd}: 0.60 \pm 0.03 \\
\mathrm{Cu}: 0.58 \pm 0.01\end{array}$ & $\begin{array}{l}\text { Pd: } 0.56 \\
\text { Pt: } 0.45\end{array}$ & $30.4 \pm 11.0$ & $17.4 \pm 11.0$ \\
\hline PdCo & $\begin{array}{l}\mathrm{Pd}\left(\mathrm{NO}_{3}\right)_{2} \\
\mathrm{Co}\left(\mathrm{NO}_{3}\right)_{2}\end{array}$ & $\begin{array}{l}\mathrm{Pd}: 0.56 \pm 0.05 \\
\mathrm{Co}: 0.58 \pm 0.01\end{array}$ & $\begin{array}{l}\mathrm{Pd}: 0.51 \\
\mathrm{Co}: 0.28\end{array}$ & $16.3 \pm 5.3$ & $10.2 \pm 5.3$ \\
\hline $\mathrm{PdNi}$ & $\begin{array}{l}\mathrm{Pd}\left(\mathrm{NO}_{3}\right)_{2} \\
\mathrm{Ni}\left(\mathrm{NO}_{3}\right)_{2}\end{array}$ & $\begin{array}{l}\mathrm{Pd}: 0.36 \pm 0.01 \\
\mathrm{Ni}: 0.25 \pm 0.01\end{array}$ & $\begin{array}{l}\text { Pd: } 0.36 \\
\text { Ni: } 0.17\end{array}$ & $18.7 \pm 6.9$ & $7.5 \pm 6.9$ \\
\hline $\mathrm{Pd}_{1} \mathrm{Au}_{60}$ & $\begin{array}{c}\mathrm{Pd}\left(\mathrm{NO}_{3}\right)_{2} \\
\mathrm{HAuCl}_{4}\end{array}$ & $\begin{array}{l}\text { Pd: } 0.03 \pm 0.01 \\
\text { Au: } 3.59 \pm 0.11\end{array}$ & $\begin{array}{l}\text { Pd: } 0.03 \\
\text { Au: } 2.81 \\
\end{array}$ & $20.1 \pm 6.0$ & $6.6 \pm 6.0$ \\
\hline $\mathrm{Pt}_{1} \mathrm{Au}_{60}$ & $\begin{array}{c}\mathrm{Pt}\left(\mathrm{NH}_{3}\right)_{4}\left(\mathrm{NO}_{3}\right)_{2} \\
\mathrm{HAuCl}_{4}\end{array}$ & $\begin{array}{c}\text { Pt: } 0.07 \pm 0.01 \\
\text { Au: } 3.61 \pm 0.14\end{array}$ & $\begin{array}{l}\text { Pt: } 0.06 \\
\text { Au: } 2.83\end{array}$ & $11.8 \pm 3.2$ & $4.7 \pm 3.2$ \\
\hline $\mathrm{Pt}_{1} \mathrm{Au}_{15}$ & $\begin{array}{c}\mathrm{Pt}\left(\mathrm{NH}_{3}\right)_{4}\left(\mathrm{NO}_{3}\right)_{2} \\
\mathrm{HAuCl}_{4}\end{array}$ & $\begin{array}{l}\text { Pt: } 0.08 \pm 0.01 \\
\text { Au: } 1.23 \pm 0.01\end{array}$ & - & $13.9 \pm 4.6$ & $4.0 \pm 4.6$ \\
\hline $\mathrm{Pt}_{1} \mathrm{Au}_{5}$ & $\begin{array}{c}\mathrm{Pt}\left(\mathrm{NH}_{3}\right)_{4}\left(\mathrm{NO}_{3}\right)_{2} \\
\mathrm{HAuCl}_{4}\end{array}$ & $\begin{array}{l}\text { Pt: } 0.09 \pm 0.01 \\
\text { Au: } 0.51 \pm 0.02\end{array}$ & - & $11.2 \pm 3.4$ & $5.1 \pm 3.4$ \\
\hline
\end{tabular}




\section{S2. Schematic Representation of Experimental Apparatuses}

In this section, we discuss the custom instrumentation that was used for the measurement carried out in this study. Thermal catalytic measurements of $\mathrm{H}_{2} \mathrm{O}_{2}$ and $\mathrm{H}_{2} \mathrm{O}$ formation from $\mathrm{H}_{2}$ and $\mathrm{O}_{2}$ gas were conducted in a trickle bed reactor, as shown in Figure S2. The electrocatalytic measurement of the ORR and HOR were conducted with a rotating ring disk electrode connected to a potentiostat, as described in Figure S3. Finally, Figure S4 shows the pressurized electrochemical cell used to measure open circuit potentials on materials. This design is analogous to a combination of the trickle bed reactor and a typical electrochemical cell.

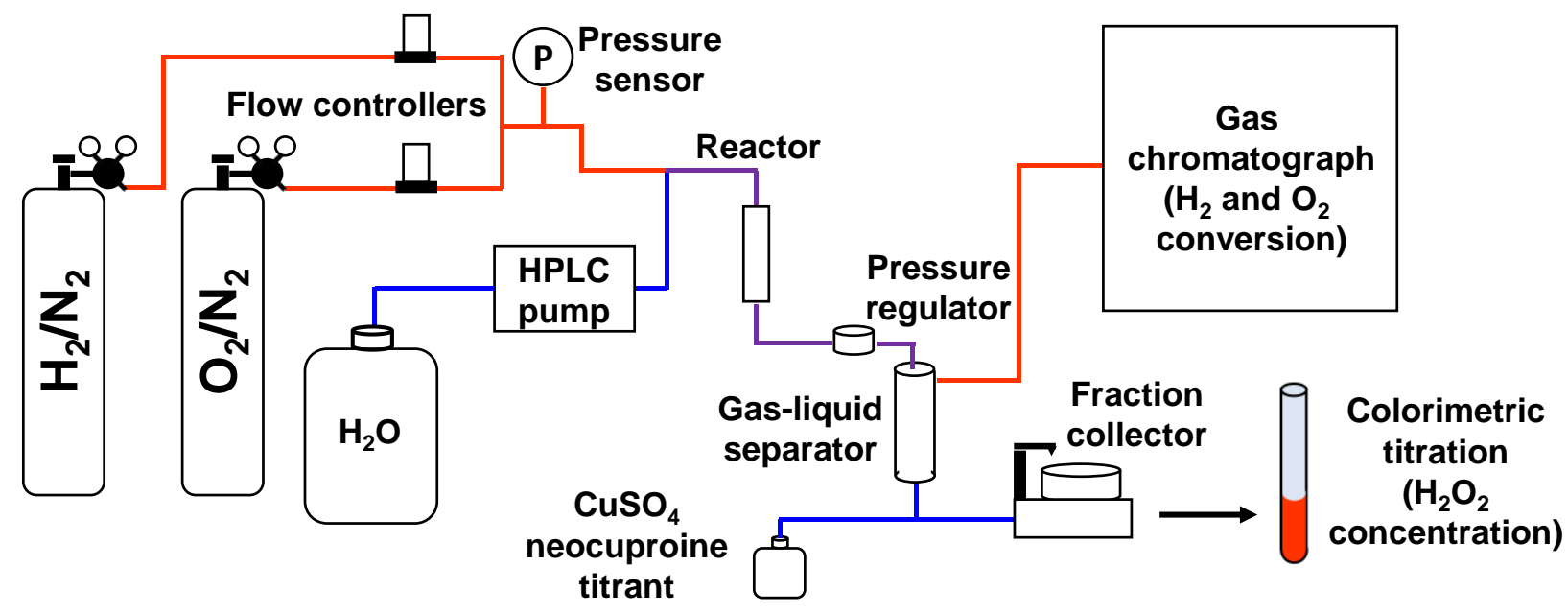

Figure S2. A schematic of the trickle bed reactor used for the continuous measurements in this study. In this system, a mixture of $\mathrm{H}_{2}, \mathrm{O}_{2}$, and $\mathrm{N}_{2}$ flow into the system from mass flow controllers, and this gas mixes with solvent pumped from the liquid carboy. This mixture was passed over the catalyst bed at the desired reactant pressure, maintained by a back-pressure regulator. The mixture was separated in a gas-liquid separator, after which the gas composition was analyzed to determine $\mathrm{H}_{2}$ and $\mathrm{O}_{2}$ conversion, while the liquid was calorimetrically titrated to determine the $\mathrm{H}_{2} \mathrm{O}_{2}$ concentration. 


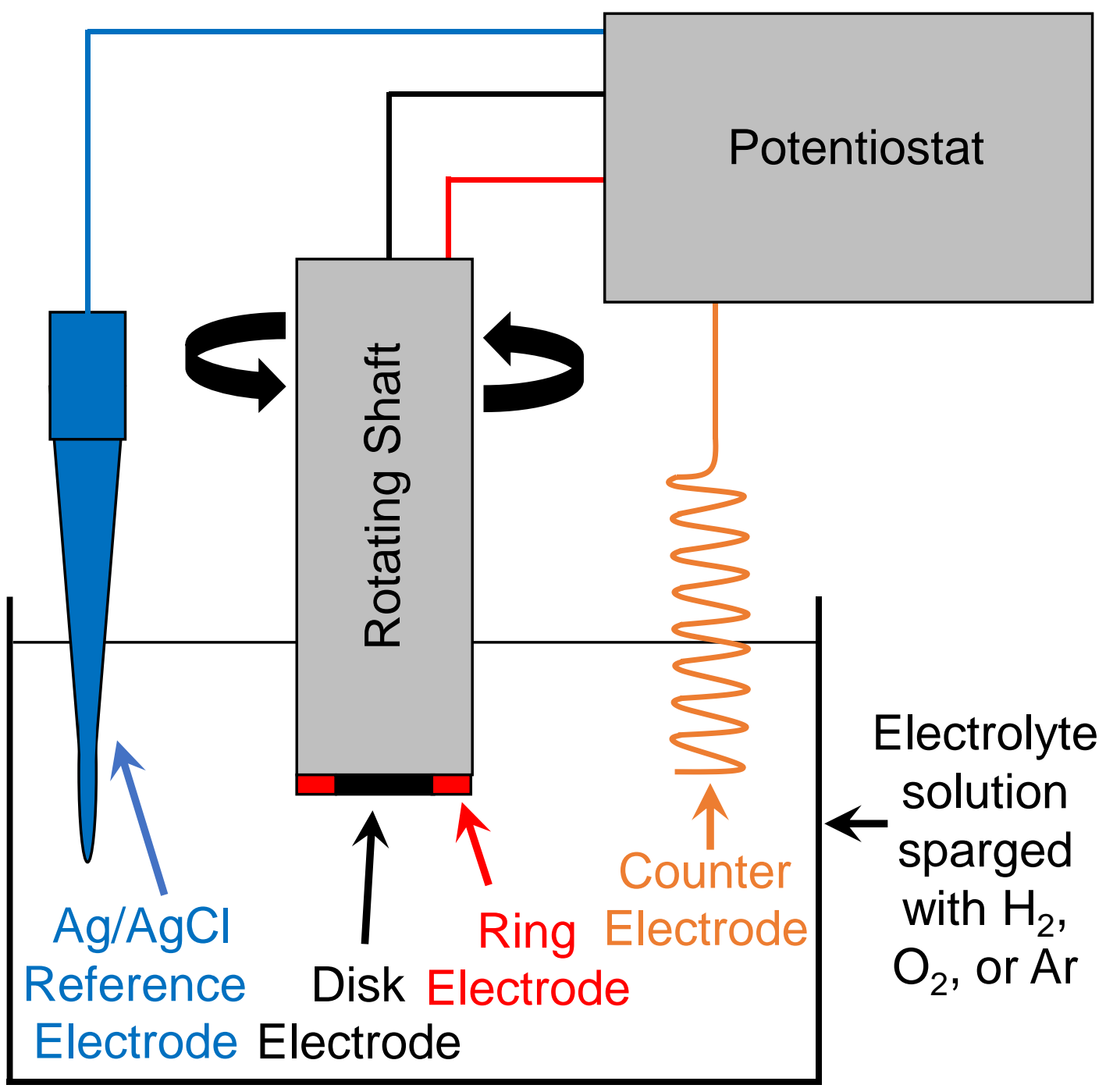

Figure S3. Schematic of electrode set up, in which a rotating ring-disk electrode, a $\mathrm{Ag} / \mathrm{AgCl}$ reference electrode, and a counter electrode are placed in an electrolyte solution that is sparged with $\mathrm{H}_{2}, \mathrm{O}_{2}$, or Ar for HOR and ORR measurements. Here, the potentiostat controls the potential between the ring and disk electrodes relative to the $\mathrm{Ag} / \mathrm{AgCl}$ reference and measures the current. 
Compression fittings for electrodes (1/4"

for working/reference, $1 / 16^{\prime \prime}$ for counter)
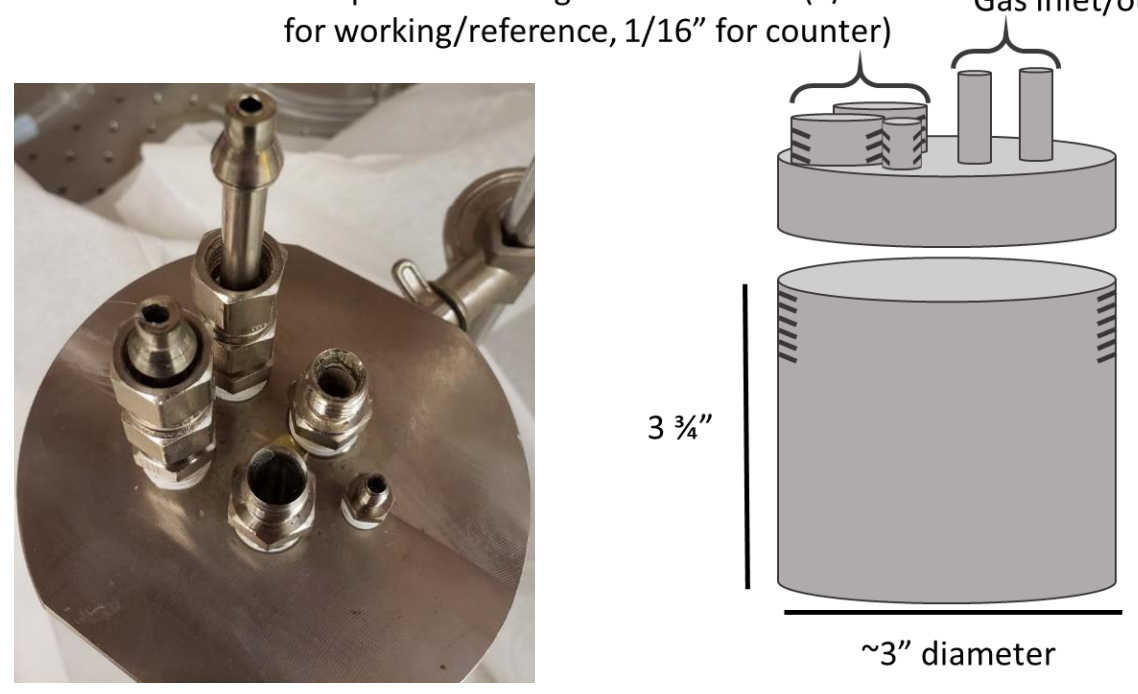

Threaded cap with orifices for electrodes

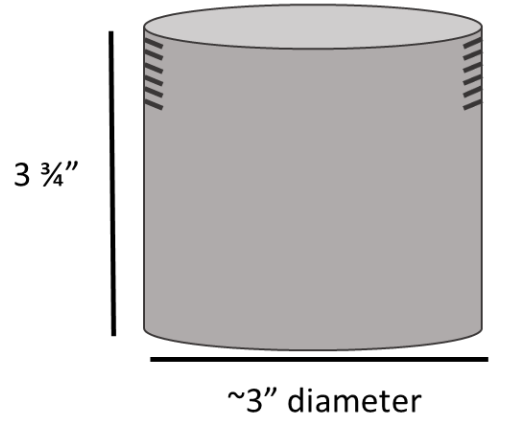

Wall thickness $=1 / 4 "$ Teflon liner inside of cell (to prevent shorting)
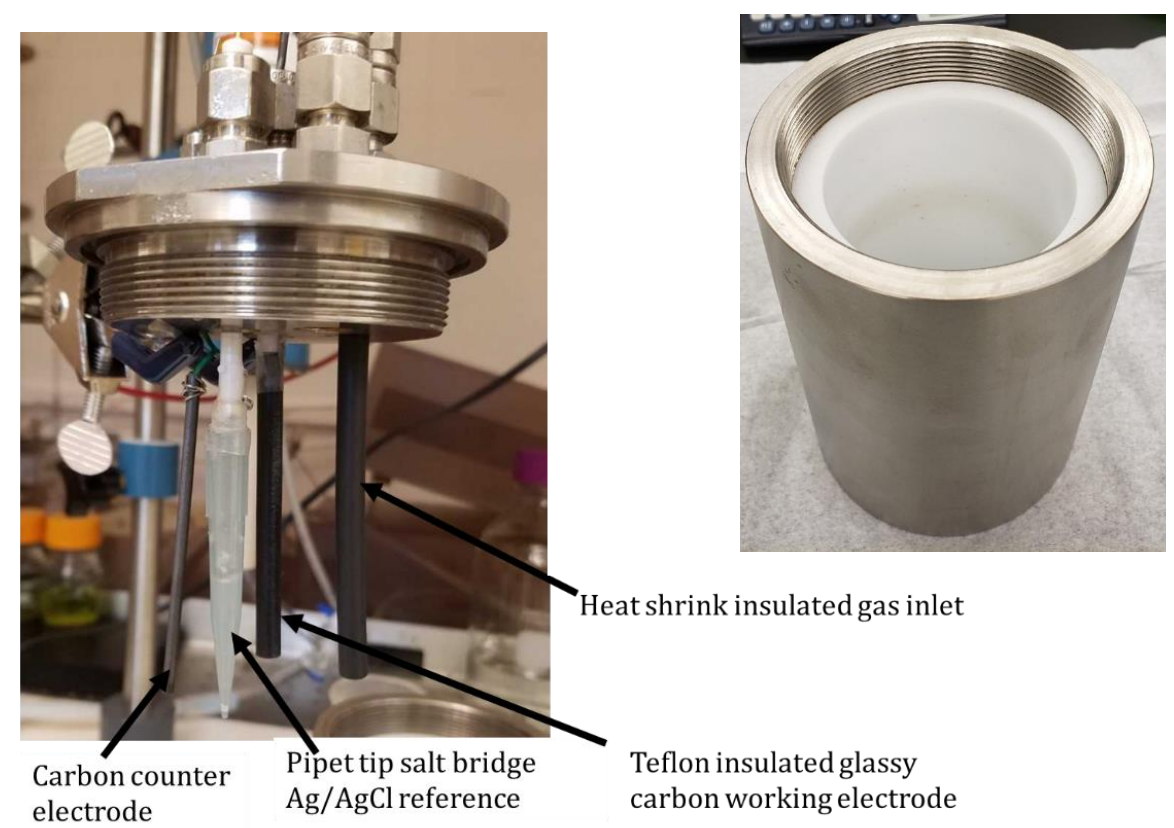

Heat shrink insulated gas inlet

Figure S4. Schematic and images of pressurized cell setup, in which the cap contains 5 orifices for electrodes and gas flow. This design accommodates a working electrode, a $\mathrm{Ag} / \mathrm{AgCl}$ reference electrode, and a carbon counter electrode that are sealed by compression fittings. These electrodes are submerged in DI water that is insulated by a Teflon liner, while the inlet tube sparges a $\mathrm{H}_{2}$ and $\mathrm{O}_{2}$ gas mixture into this solution. The configuration of gas flow is analogous to that of the trickle bed reactor shown in Figure S2, while the open circuit potential with the cell is monitored through a potentiostat, as described in Figure S3. 


\section{S3. Development of Electrochemical Cell and Open-Circuit Measurement Results}

In this section, we discuss measurements in a pressurized electrochemical cell to determine the open circuit potential of nanoparticle materials under direct synthesis conditions. We first consider the possibility that the pressurized conditions may indirectly influence our electrochemical measurements. Figure S5a shows the current generated from a $0.5 \mathrm{mM}$ ferrocenemethanol solution as a function of potential $(0.1-0.55 \mathrm{~V}$ vs. $\mathrm{Ag} / \mathrm{AgCl})$ at $100 \mathrm{kPa}$ and at $2750 \mathrm{kPa}$ Ar. Here, we observe no appreciable difference between these voltammograms, which indicates that the highpressure conditions do not lead to artifacts in the apparent behavior of the electrode. Figure S5b shows the transient open circuit potential on Pd catalyst at a constant $\mathrm{O}_{2}$ pressure $(60 \mathrm{kPa})$ as the $\mathrm{H}_{2}$ pressure decreases from 400 to $60 \mathrm{kPa} \mathrm{H}_{2}$. Here, the electrode potential steadily increases and approaches a steady-state for each condition, as reported in Figures S6-S17. Figure S5c shows a voltammogram for hydrogen oxidation at various $\mathrm{H}_{2}$ pressures $\left(60-400 \mathrm{kPa} \mathrm{H}_{2}\right)$ on a $\mathrm{Pd}$ catalyst. The apparent onset of reaction occurs at more negative potentials as the pressure of $\mathrm{H}_{2}$ increases, suggesting a more negative intersection of the zero-current condition for the HOR/HER which corroborates the trends in Figure S5b over a broad range of electrode potentials.

a

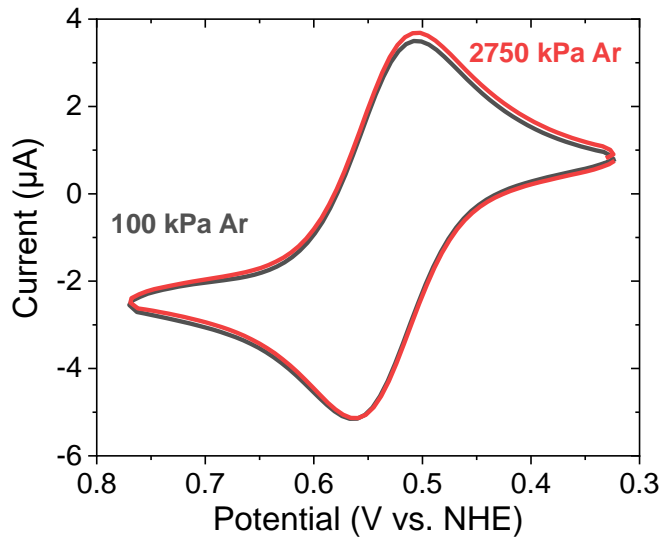

b

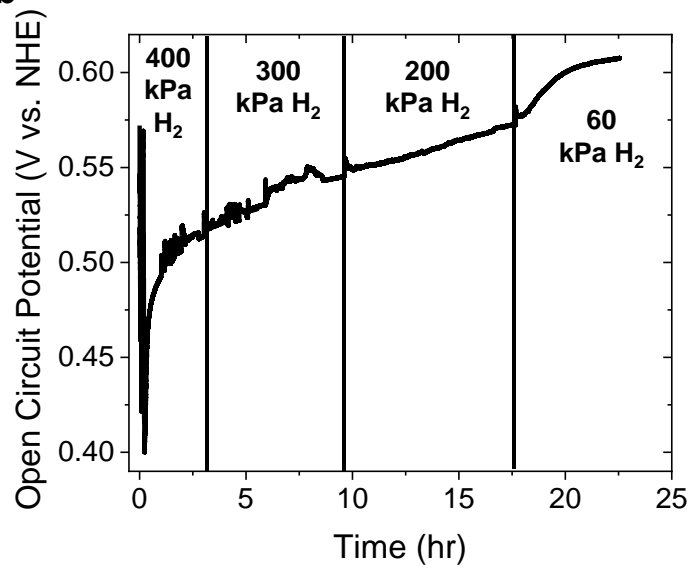

C

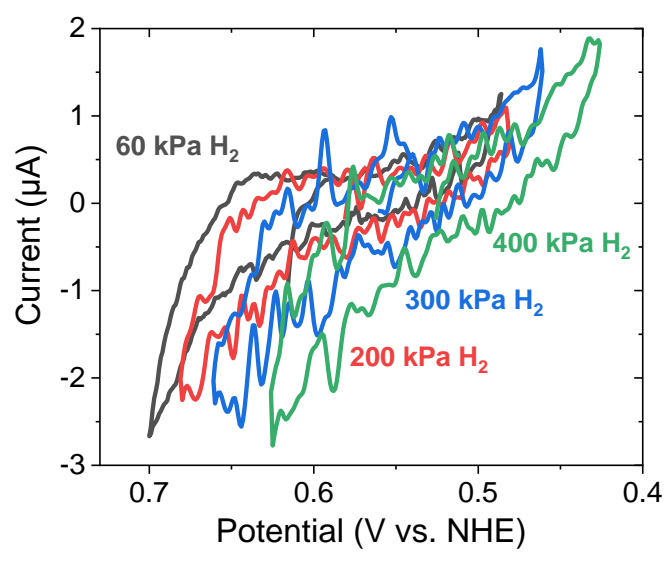

Figure S5: Pressurized amperometric measurements of current as a function of potential on (a) $0.5 \mathrm{M}$ ferrocenemethanol and (c) $\mathrm{Pd} / \mathrm{Vulcan}$ at $\mathrm{H}_{2}$ pressures between $60-400 \mathrm{kPa} \mathrm{H}_{2}$. (b) 
Measurements of the open circuit electrode potential as a function of $\mathrm{H}_{2}$ pressures $\left(60-400 \mathrm{kPa} \mathrm{H}_{2}\right.$ ) on $\mathrm{Pd} / \mathrm{Vulcan}$ at a constant $60 \mathrm{kPa} \mathrm{O}_{2}$ at 298. Measurements were conducted in the pressurized cell described in Figure S4.

We repeated the measurements shown in Figure 5c on all of the catalytic materials in this study. Figures S6-S17 show the open circuit potentials of these materials under direct synthesis conditions $\left(60-400 \mathrm{kPa} \mathrm{H}_{2}, 60 \mathrm{kPa} \mathrm{O}_{2}\right)$ that are analogous to those used in trickle-bed reactor measurements. Generally, these materials show a diverse range of open-circuit potentials (0.30$0.65 \mathrm{~V}$ vs. NHE) and noticeable differences in the slope of the potential with respect to hydrogen pressure. In general, Pt-based materials showed a more significant decrease in potential with $\mathrm{H}_{2}$ pressure when compared to Pd-based materials. As discussed in section S7.2, this change in potential may result from the low charge transfer coefficients on the Pt materials versus the Pd materials.

Figure S18 shows the open circuit potential of blank carbon support electrode under analogous direct synthesis conditions, which shows a much more positive potential ( $0.75 \mathrm{~V}$ vs. NHE) than on any of the test materials at the most reducing conditiosn $(400 \mathrm{kPa} \mathrm{H}, 60 \mathrm{kPa} \mathrm{O}$ ), thus displaying insensitivity to the HOR. These results indicate that the rate of hydrogen oxidation is much slower than the rate of oxygen reduction on this surface. However, the rate of oxygen reduction is still significantly slower than on the nanoparticle catalysts, such that the electrode negligibly contributes to the other OCP measurements. 


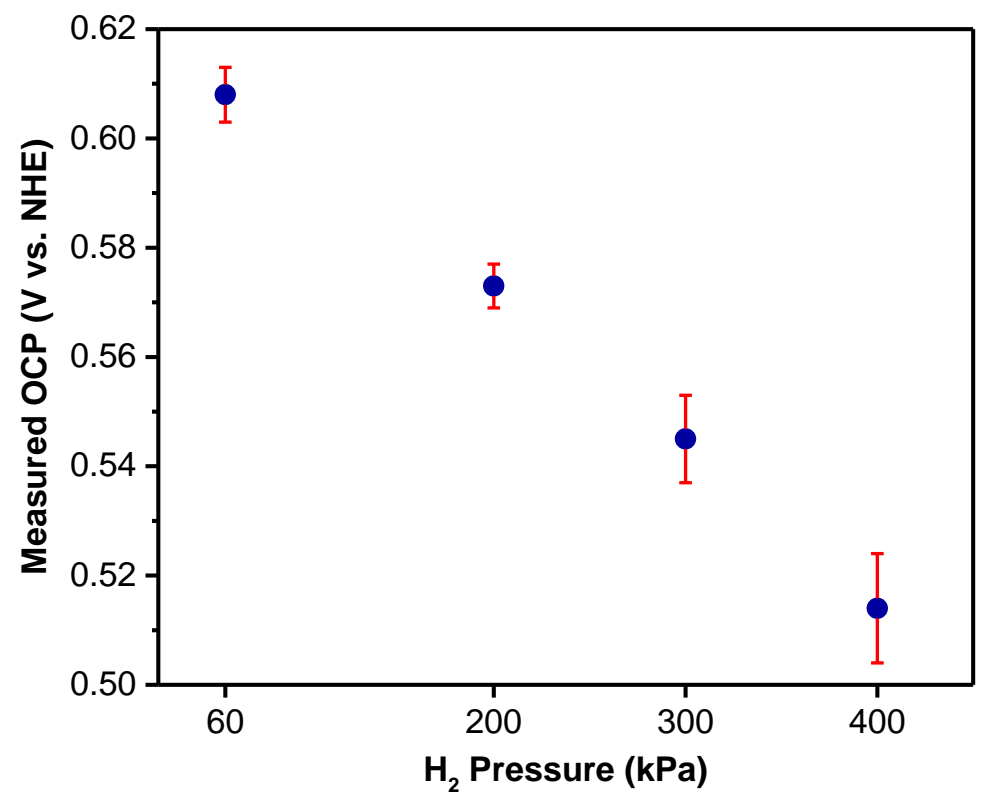

Figure S6: Pressurized OCP measurements for Pd/Vulcan with water as a solvent. Glassy carbon working electrode was modified with $5 \mu \mathrm{L}$ of a catalyst slurry $(5 \mathrm{mg}$ catalyst, $1 \mathrm{~mL}$ water, $0.6 \mathrm{~mL}$ ethanol) and $1 \mu \mathrm{L}$ of $0.5 \mathrm{wt} \%$ Nafion solution. Potentials were measured as a function of $\mathrm{H}_{2}$ pressures $(60-400 \mathrm{kPa})$ with a constant $\mathrm{O}_{2}$ pressure of $60 \mathrm{kPa}$ at $298 \mathrm{~K}$. 


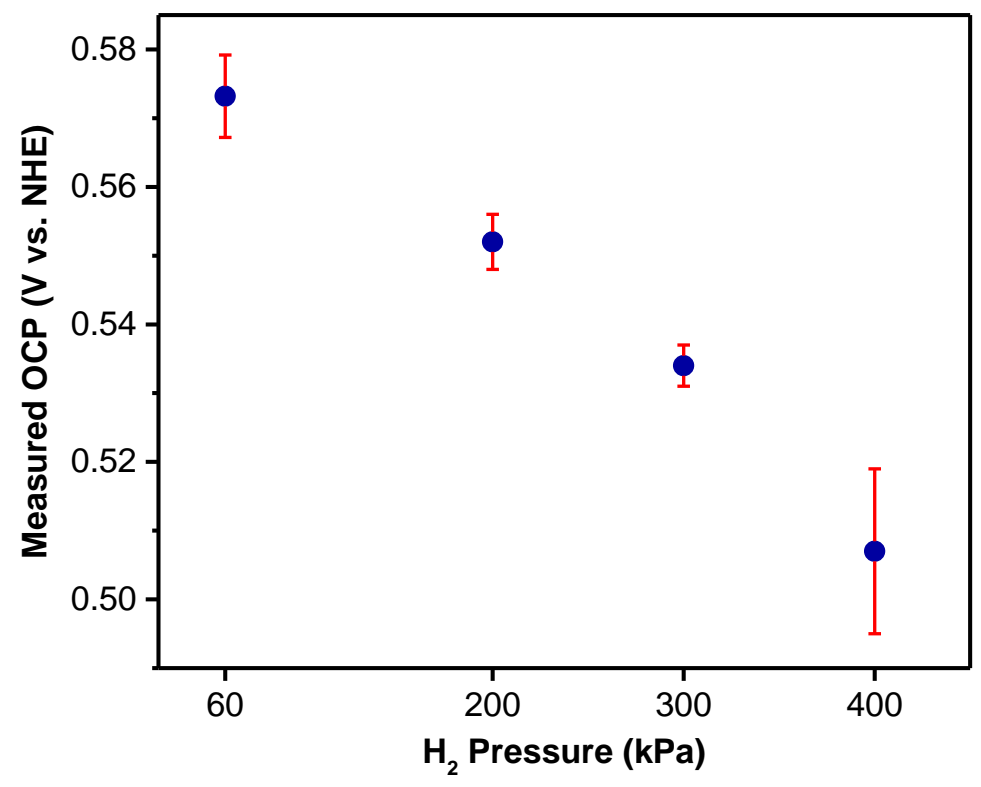

Figure S7: Pressurized OCP measurements for $\mathrm{PdCo} /$ Vulcan with water as a solvent. Glassy carbon working electrode was modified with $5 \mu \mathrm{L}$ of a catalyst slurry $(5 \mathrm{mg}$ catalyst, $1 \mathrm{~mL}$ water, $0.6 \mathrm{~mL}$ ethanol) and $1 \mu \mathrm{L}$ of $0.5 \mathrm{wt} \%$ Nafion solution. Potentials were measured as a function of $\mathrm{H}_{2}$ pressures $(60-400 \mathrm{kPa})$ with a constant $\mathrm{O}_{2}$ pressure of $60 \mathrm{kPa}$ at $298 \mathrm{~K}$. 


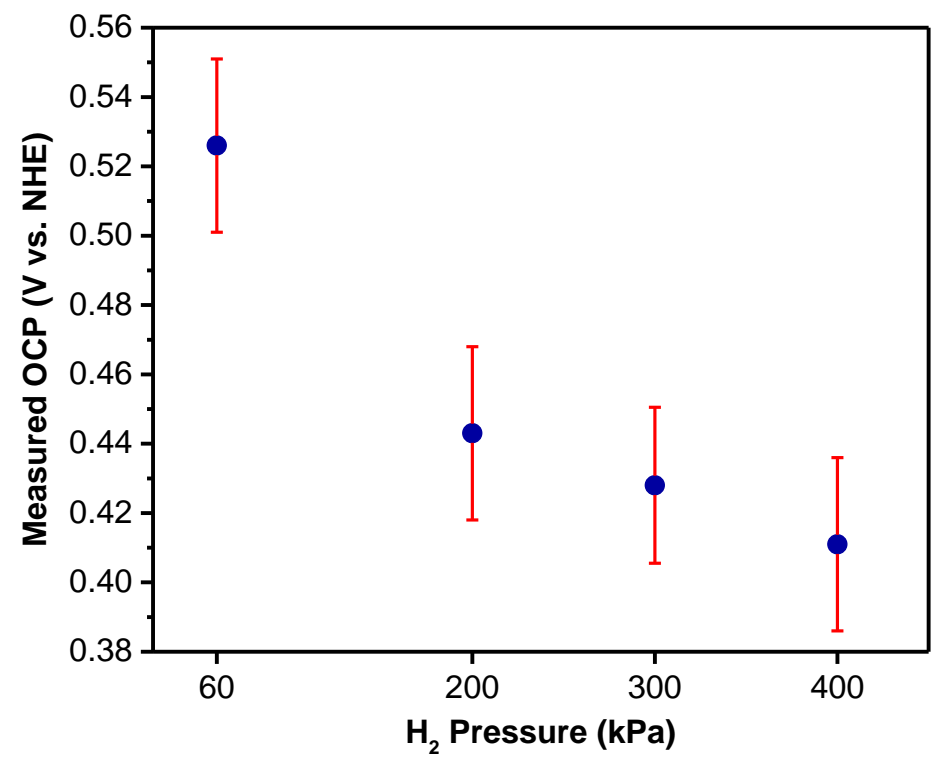

Figure S8: Pressurized OCP measurements for PdNi/Vulcan with water as a solvent. Glassy carbon working electrode was modified with $5 \mu \mathrm{L}$ of a catalyst slurry $(5 \mathrm{mg}$ catalyst, $1 \mathrm{~mL}$ water, $0.6 \mathrm{~mL}$ ethanol) and $1 \mu \mathrm{L}$ of $0.5 \mathrm{wt} \%$ Nafion solution. Potentials were measured as a function of $\mathrm{H}_{2}$ pressures $(60-400 \mathrm{kPa})$ with a constant $\mathrm{O}_{2}$ pressure of $60 \mathrm{kPa}$ at $298 \mathrm{~K}$. 


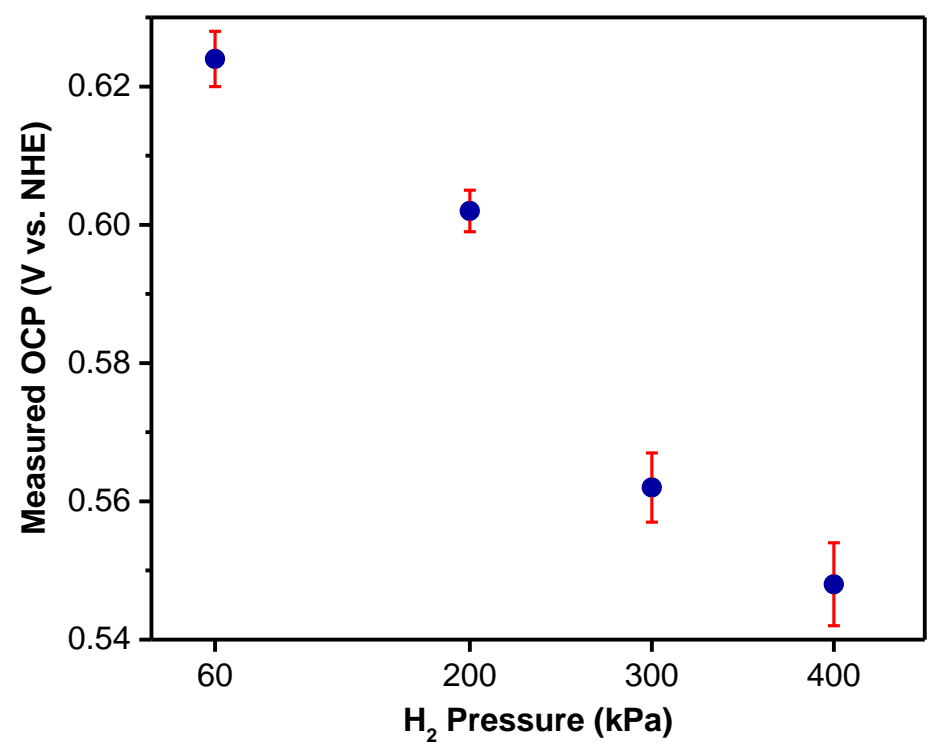

Figure S9: Pressurized OCP measurements for PdZn/Vulcan with water as a solvent. Glassy carbon working electrode was modified with $5 \mu \mathrm{L}$ of a catalyst slurry ( $5 \mathrm{mg}$ catalyst, $1 \mathrm{~mL}$ water, $0.6 \mathrm{~mL}$ ethanol) and $1 \mu \mathrm{L}$ of $0.5 \mathrm{wt} \%$ Nafion solution. Potentials were measured as a function of $\mathrm{H}_{2}$ pressures $(60-400 \mathrm{kPa})$ with a constant $\mathrm{O}_{2}$ pressure of $60 \mathrm{kPa}$ at $298 \mathrm{~K}$. 


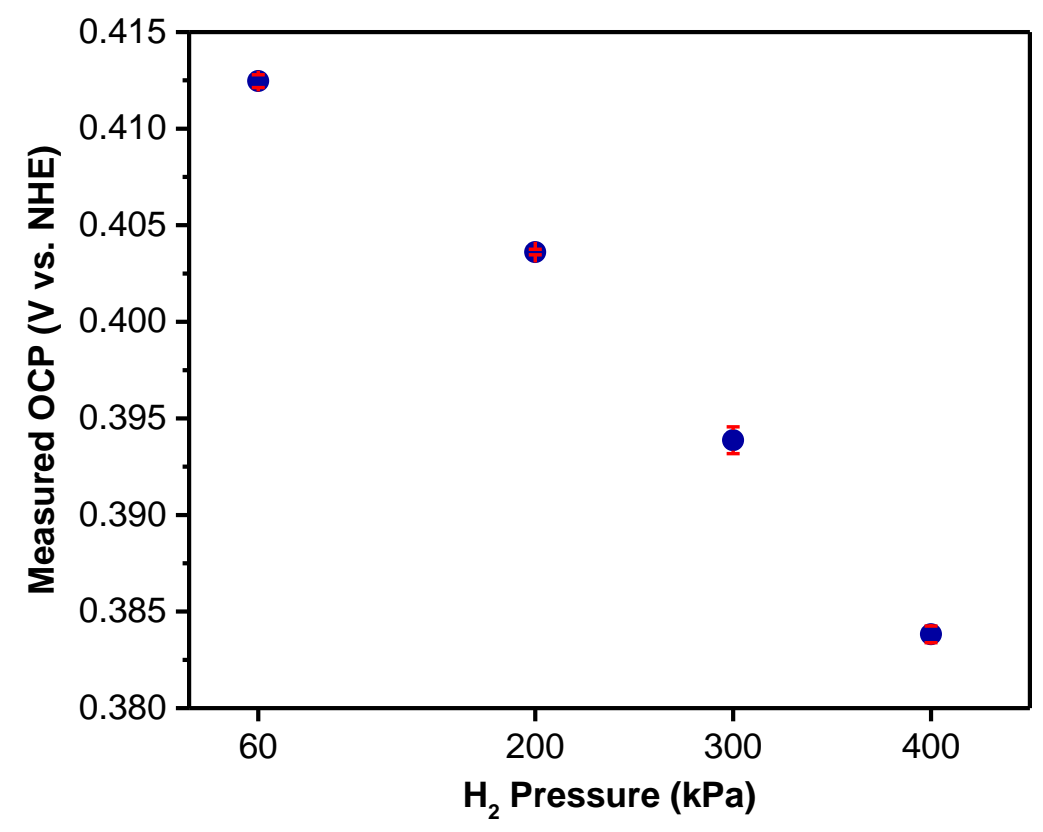

Figure S10: Pressurized OCP measurements for $\mathrm{PdAu}_{60} / V_{\text {Vulcan }}$ with water as a solvent. Glassy carbon working electrode was modified with $5 \mu \mathrm{L}$ of a catalyst slurry $(5 \mathrm{mg}$ catalyst, $1 \mathrm{~mL}$ water, $0.6 \mathrm{~mL}$ ethanol) and $1 \mu \mathrm{L}$ of $0.5 \mathrm{wt} \%$ Nafion solution. Potentials were measured as a function of $\mathrm{H}_{2}$ pressures $(60-400 \mathrm{kPa})$ with a constant $\mathrm{O}_{2}$ pressure of $60 \mathrm{kPa}$ at $298 \mathrm{~K}$. 


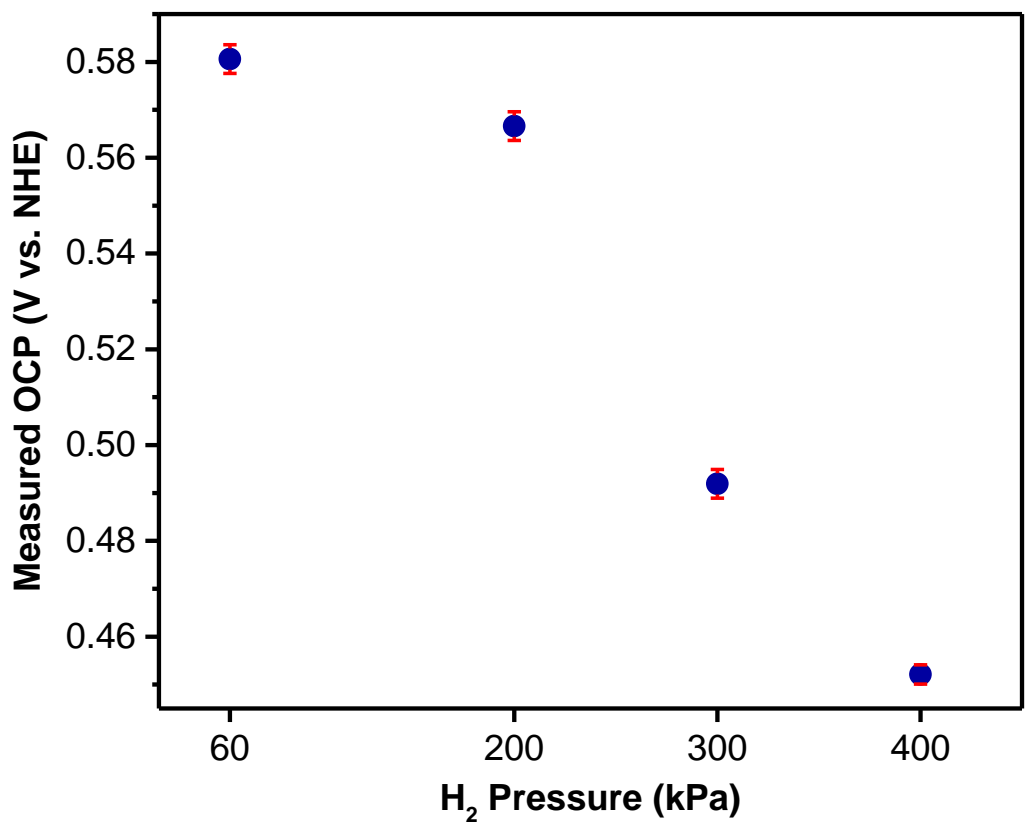

Figure S11: Pressurized OCP measurements for $\mathrm{PdCu} / \mathrm{Vulcan}$ with water as a solvent. Glassy carbon working electrode was modified with $5 \mu \mathrm{L}$ of a catalyst slurry $(5 \mathrm{mg}$ catalyst, $1 \mathrm{~mL}$ water, $0.6 \mathrm{~mL}$ ethanol) and $1 \mu \mathrm{L}$ of $0.5 \mathrm{wt} \%$ Nafion solution. Potentials were measured as a function of $\mathrm{H}_{2}$ pressures $(60-400 \mathrm{kPa})$ with a constant $\mathrm{O}_{2}$ pressure of $60 \mathrm{kPa}$ at $298 \mathrm{~K}$. 


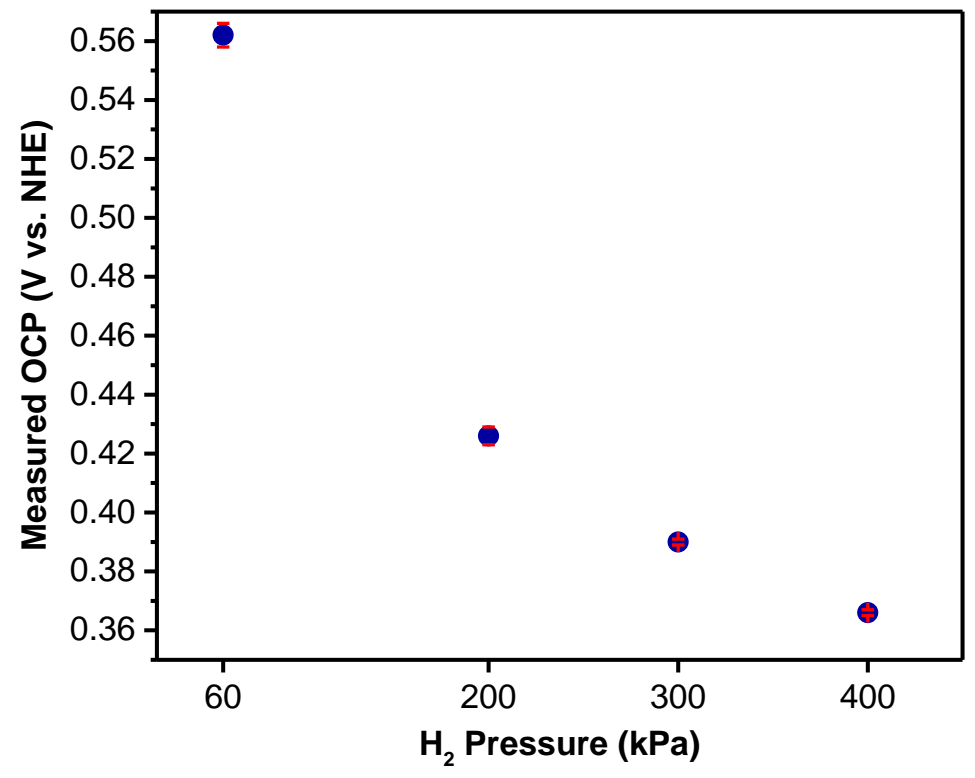

Figure S12: Pressurized OCP measurements for PdPt/Vulcan with water as a solvent. Glassy carbon working electrode was modified with $5 \mu \mathrm{L}$ of a catalyst slurry $(5 \mathrm{mg}$ catalyst, $1 \mathrm{~mL}$ water, $0.6 \mathrm{~mL}$ ethanol) and $1 \mu \mathrm{L}$ of $0.5 \mathrm{wt} \%$ Nafion solution. Potentials were measured as a function of $\mathrm{H}_{2}$ pressures $(60-400 \mathrm{kPa})$ with a constant $\mathrm{O}_{2}$ pressure of $60 \mathrm{kPa}$ at $298 \mathrm{~K}$. 


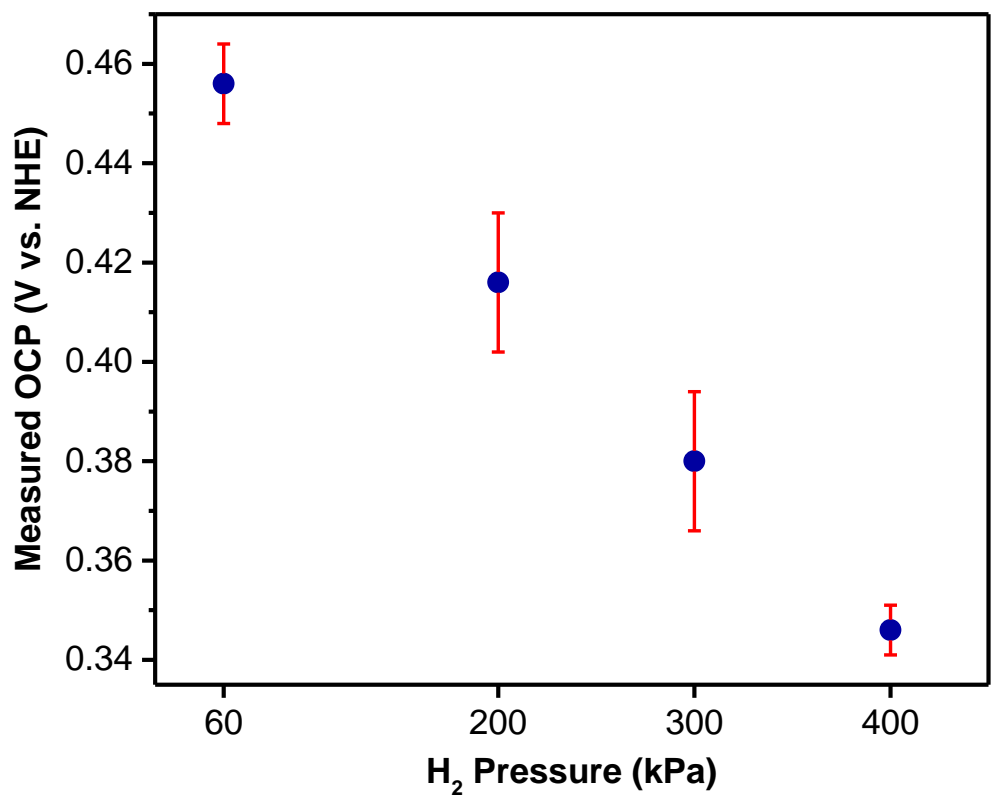

Figure S13: Pressurized OCP measurements for $\mathrm{PtAu}_{60} /$ Vulcan with water as a solvent. Glassy carbon working electrode was modified with $5 \mu \mathrm{L}$ of a catalyst slurry $(5 \mathrm{mg}$ catalyst, $1 \mathrm{~mL}$ water, $0.6 \mathrm{~mL}$ ethanol) and $1 \mu \mathrm{L}$ of $0.5 \mathrm{wt} \%$ Nafion solution. Potentials were measured as a function of $\mathrm{H}_{2}$ pressures $(60-400 \mathrm{kPa})$ with a constant $\mathrm{O}_{2}$ pressure of $60 \mathrm{kPa}$ at $298 \mathrm{~K}$. 


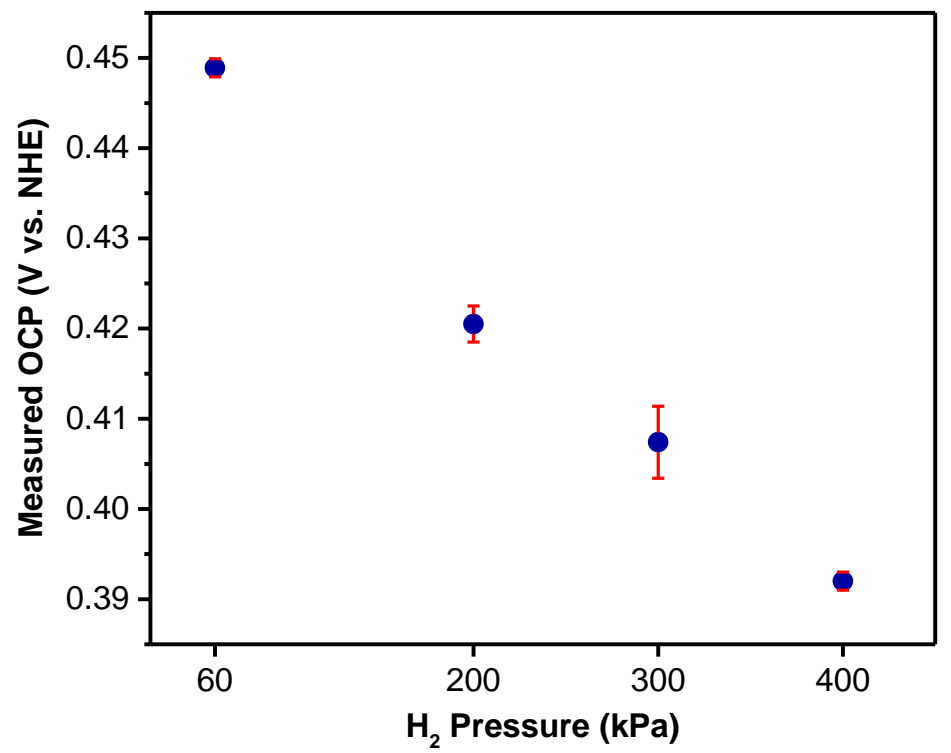

Figure S14: Pressurized OCP measurements for $\mathrm{PtAu}_{15} /$ Vulcan with water as a solvent. Glassy carbon working electrode was modified with $5 \mu \mathrm{L}$ of a catalyst slurry $(5 \mathrm{mg}$ catalyst, $1 \mathrm{~mL}$ water, $0.6 \mathrm{~mL}$ ethanol) and $1 \mu \mathrm{L}$ of $0.5 \mathrm{wt} \%$ Nafion solution. Potentials were measured as a function of $\mathrm{H}_{2}$ pressures $(60-400 \mathrm{kPa})$ with a constant $\mathrm{O}_{2}$ pressure of $60 \mathrm{kPa}$ at $298 \mathrm{~K}$. 


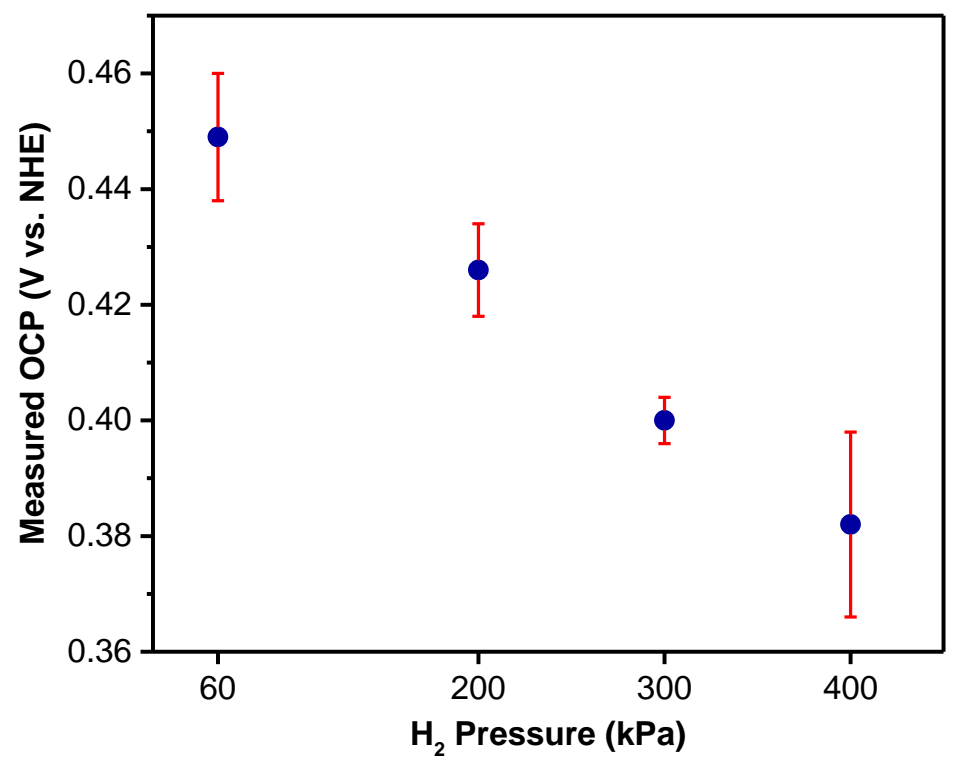

Figure S15: Pressurized OCP measurements for $\mathrm{PtAu}_{5} / \mathrm{Vulcan}$ with water as a solvent. Glassy carbon working electrode was modified with $5 \mu \mathrm{L}$ of a catalyst slurry ( $5 \mathrm{mg}$ catalyst, $1 \mathrm{~mL}$ water, $0.6 \mathrm{~mL}$ ethanol) and $1 \mu \mathrm{L}$ of $0.5 \mathrm{wt} \%$ Nafion solution. Potentials were measured as a function of $\mathrm{H}_{2}$ pressures $(60-400 \mathrm{kPa})$ with a constant $\mathrm{O}_{2}$ pressure of $60 \mathrm{kPa}$ at $298 \mathrm{~K}$. 


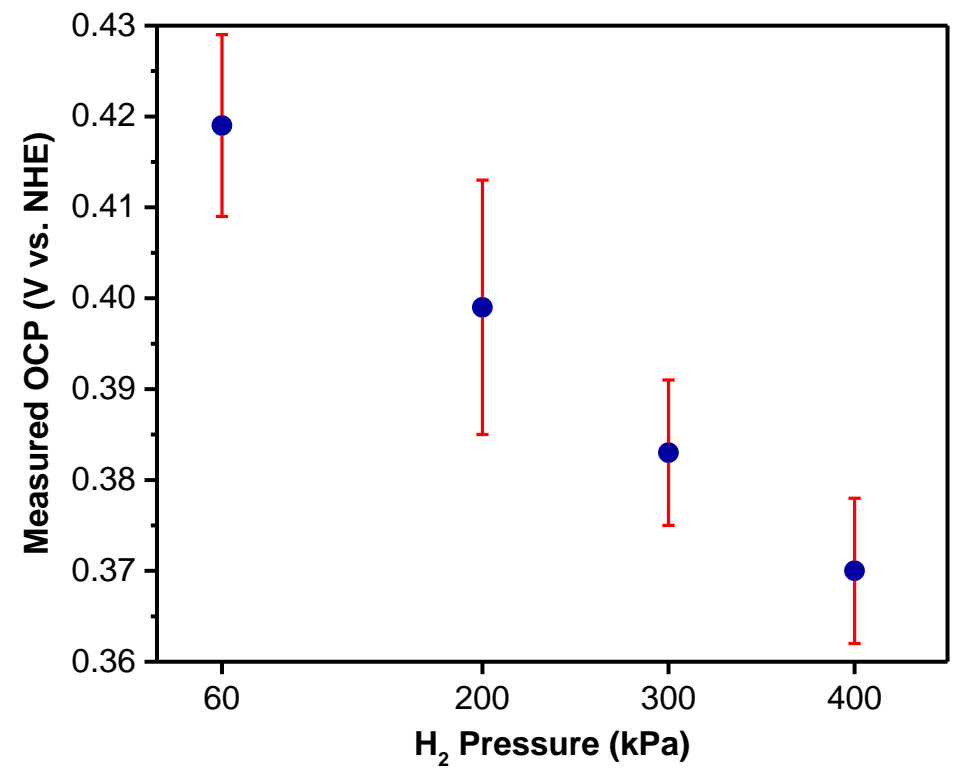

Figure S16: Pressurized OCP measurements for Pt/Vulcan with water as a solvent. Glassy carbon working electrode was modified with $5 \mu \mathrm{L}$ of a catalyst slurry $(5 \mathrm{mg}$ catalyst, $1 \mathrm{~mL}$ water, $0.6 \mathrm{~mL}$ ethanol) and $1 \mu \mathrm{L}$ of $0.5 \mathrm{wt} \%$ Nafion solution. Potentials were measured as a function of $\mathrm{H}_{2}$ pressures $(60-400 \mathrm{kPa})$ with a constant $\mathrm{O}_{2}$ pressure of $60 \mathrm{kPa}$ at $298 \mathrm{~K}$. 


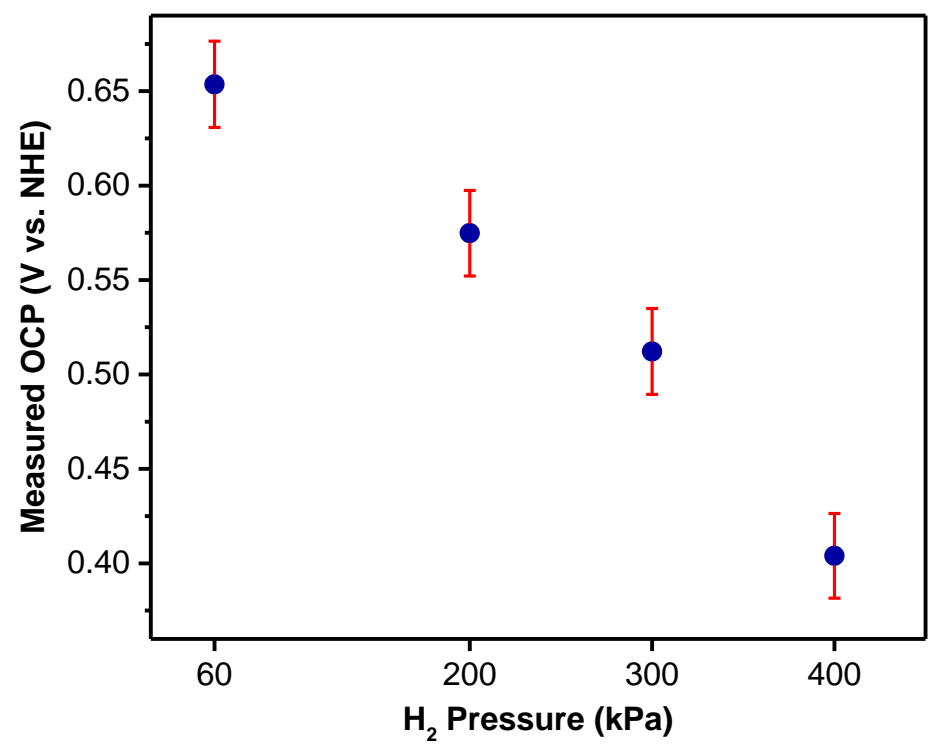

Figure S17: Pressurized OCP measurements for $\mathrm{PtCo} /$ Vulcan with water as a solvent. Glassy carbon working electrode was modified with $5 \mu \mathrm{L}$ of a catalyst slurry $(5 \mathrm{mg}$ catalyst, $1 \mathrm{~mL}$ water, $0.6 \mathrm{~mL}$ ethanol) and $1 \mu \mathrm{L}$ of $0.5 \mathrm{wt} \%$ Nafion solution. Potentials were measured as a function of $\mathrm{H}_{2}$ pressures $(60-400 \mathrm{kPa})$ with a constant $\mathrm{O}_{2}$ pressure of $60 \mathrm{kPa}$ at $298 \mathrm{~K}$. 


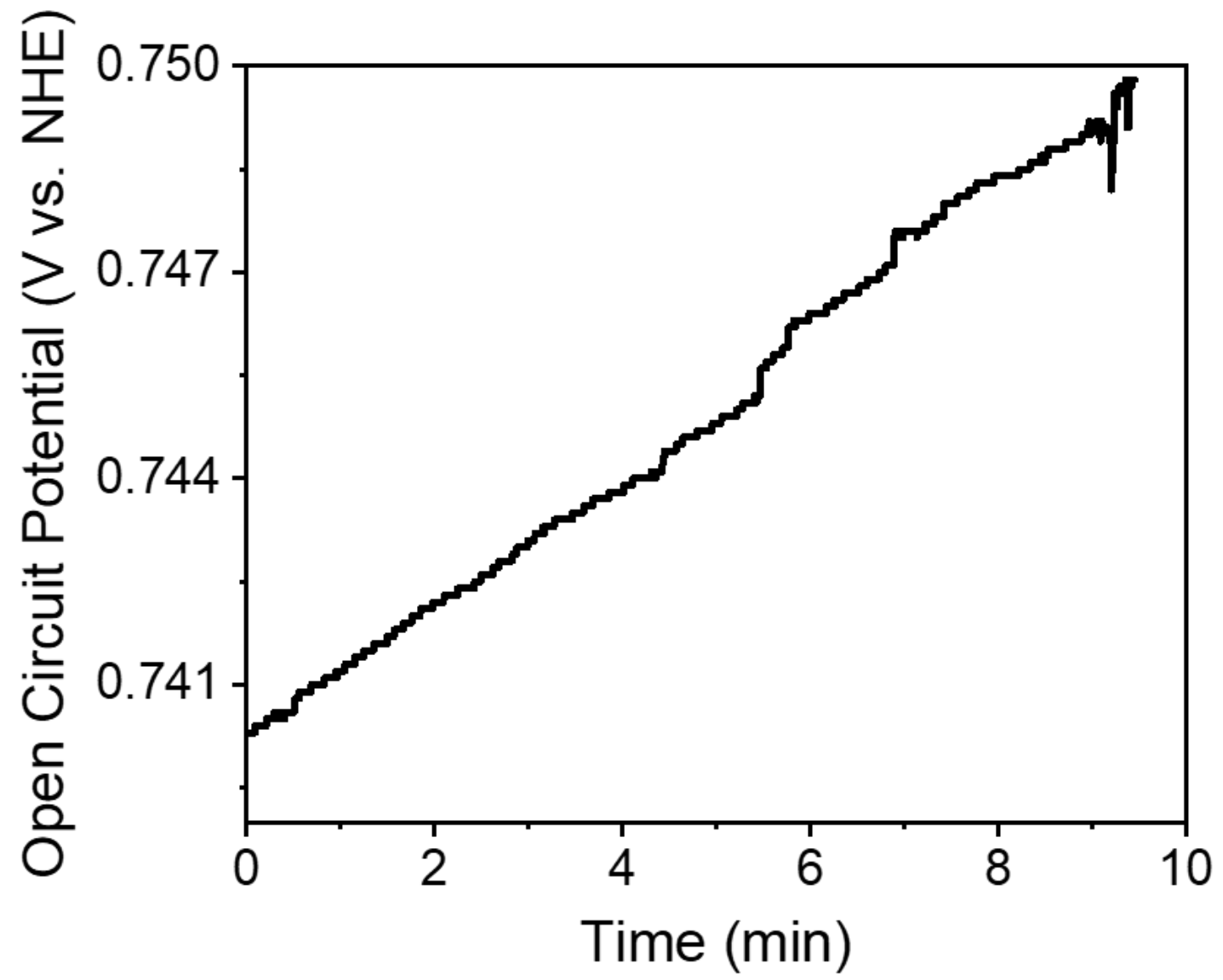

Figure S18: Open circuit potential on the glassy carbon electrode as a function of time at $400 \mathrm{kPa}$ $\mathrm{H}_{2}$ and $60 \mathrm{kPa} \mathrm{O}_{2}$ at $298 \mathrm{~K}$. 


\section{S4. Derivation of the Nernst Equations for Hydrogen Oxidation and Oxygen Reduction}

In this section, we derive a Nernstian model for the direct synthesis of $\mathrm{H}_{2} \mathrm{O}_{2}$ through coupled $\mathrm{H}_{2}$ oxidation and $\mathrm{O}_{2}$ reduction. Below we show expressions describing the thermodynamic potentials of species $j:{ }^{1}$

$$
\begin{gathered}
\bar{\mu}^{\alpha}{ }_{\mathrm{j}}=\left(\frac{\partial \bar{G}}{\partial n_{j}}\right)_{T, P}=\mu_{\mathrm{j}}^{\alpha}+\mathrm{z}_{\mathrm{j}} \mathrm{F} \phi^{\alpha} \\
\mu_{\mathrm{j}}^{\alpha}=\mu_{j}^{0, \alpha}+R T \cdot \ln \left([j]^{\alpha}\right)
\end{gathered}
$$

Where F is Faraday's constant, and $R$ is the universal gas constant. Here, the electrochemical $\left(\bar{\mu}^{\alpha}{ }_{\mathrm{j}}\right)$ potential depends on the chemical potential $\left(\mu_{j}^{\alpha}\right)$, the inner electrical potential $\left(\phi^{\alpha}\right)$, and the charge of species $j\left(\mathrm{z}_{\mathrm{j}}\right)$ within the phase $\alpha$. The chemical potential is defined as the derivative of the electrochemical Gibb's free energy $(G)$ with respect to the number of species $n_{j}$, which depends on the standard state potential $\left(\mu_{\mathrm{j}}^{\alpha}\right)$, the temperature $(T)$, and the activity $\left([j]^{\alpha}\right)$ of species $j$ in phase $\alpha$. By integrating equation S4.1 and substituting equation S4.2 in this expression, we derive the change in electrochemical Gibb's free energy ${ }^{1}$ for a given reaction:

$$
\Delta(n \bar{G})=\sum_{j} v_{j} \mu_{j}^{0}+\sum_{j} v_{j} R T \cdot \ln ([j])+\sum_{j} v_{j} \mathrm{z}_{\mathrm{j}} \mathrm{F} \phi
$$

Where $v_{j}$ is the stoichiometric coefficient for reactant $j$. Here, we have generalized each of the parameters to sum over all phases. Note that the term on the right-hand side is proportional to the number of electrons transmitted. Moreover, at equilibrium, the net change in free energy equals zero, which results in a direct relationship between the inner electrical potentials and the reactant activity:

$$
\begin{gathered}
\Delta(n G)=0 \\
\sum_{j} v_{j} \mathrm{z}_{\mathrm{j}} \mathrm{F} \phi=-\frac{\sum_{j} v_{j} \mu_{j}^{0}+\sum_{j} v_{j} R T \cdot \ln ([j])}{\mathrm{F}}
\end{gathered}
$$

To simplify this expression, we can redefine the summation of $v_{j} \mu_{j}^{0}$ as the Gibb's free energy change at standard state conditions $\left(\Delta G_{R x n}^{0}\right)$ under equilibrium. This term is directly related to the standard potential of reaction $\left(\phi_{R x n}^{0}\right)$, which reflects the difference in inner potential between both junctions of a given electrode and its reference electrode (treated as different phases) for some reaction at standard state conditions, as shown below:

$$
\sum_{j} v_{j} \mathrm{z}_{\mathrm{j}} \mathrm{F} \phi=-\frac{\Delta G_{R x n}^{0}+\sum_{j} v_{j} R T \cdot \ln ([j])}{\mathrm{F} \sum_{j} v_{j} \mathrm{z}_{\mathrm{j}}}=\phi_{R x n}^{0}-\frac{\sum_{j} v_{j} R T \cdot \ln ([j])}{\mathrm{F} \sum_{j} v_{j} \mathrm{z}_{\mathrm{j}}}
$$


Next, we define the terms in equation $\mathrm{S} 4.6$ for the hydrogen oxidation reaction $\left(\mathrm{H}_{2}+2 \mathrm{H}_{2} \mathrm{O} \rightarrow\right.$ $2 \mathrm{H}_{3} \mathrm{O}^{+}+2 \mathrm{e}^{-}$) in the solution phase using equations $\mathrm{S} 4.7-8$ :

$$
\begin{gathered}
\sum_{j} v_{j} R T \cdot \ln ([j])=R T\left(2 \ln \left(\left[\mathrm{H}_{3} \mathrm{O}^{+}\right]\right)-\ln \left(\left[\mathrm{H}_{2}\right]\right)-2 \ln \left(\left[\mathrm{H}_{2} \mathrm{O}\right]\right)\right) \\
=R T \ln \left(\frac{\left[\mathrm{H}_{3} \mathrm{O}^{+}\right]^{2}}{\left[\mathrm{H}_{2}\right]\left[\mathrm{H}_{2} \mathrm{O}\right]^{2}}\right)
\end{gathered}
$$

where the activity of hydronium ions $\left(\left[\mathrm{H}_{3} \mathrm{O}^{+}\right]\right)$, hydrogen $\left(\left[\mathrm{H}_{2}\right]\right)$, and water $\left(\left[\mathrm{H}_{2} \mathrm{O}\right]\right)$ exist within the solution phase and influence the potential of the cell. Substituting equation S4.7, the standard potential of the HOR $\left(\phi_{H O R}^{0}\right)$, and the transfer of two electrons to the electrode into equation S4.6, we derive the Nernst equation for the HOR:

$$
\phi^{0}=\phi_{H O R}^{0}+\frac{R T}{2 \mathrm{~F}} \ln \left(\frac{\left[\mathrm{H}_{3} \mathrm{O}^{+}\right]^{2}}{\left[\mathrm{H}_{2}\right]\left[\mathrm{H}_{2} \mathrm{O}\right]^{2}}\right)
$$

Here, the equilibrium potential $\left(\phi^{0}\right)$ reflects the difference in inner potential between both junctions of a given electrode and its reference electrode (treated as different phases), which is influenced by the activity of the solution phase reactants. The same definition applies to all Nernst equations reported henceforth, but precise reactions differ in the following derivations.

Next, we define the terms in equation $\mathrm{S} 4.6$ for the $2 \mathrm{e}^{-}$oxygen reduction reaction $\left(2 \mathrm{H}_{3} \mathrm{O}^{+}+\mathrm{O}_{2}+\right.$ $2 \mathrm{e}^{-} \rightarrow \mathrm{H}_{2} \mathrm{O}_{2}+2 \mathrm{H}_{2} \mathrm{O}$ ) in the solution phase using equations $\mathrm{S} 4.9-11$ :

$$
\begin{aligned}
\sum_{j} n_{j} R T \cdot \ln ([j]) & \\
& =R T\left(2 \ln \left(\left[\mathrm{H}_{2} \mathrm{O}\right]\right)+\ln \left(\left[\mathrm{H}_{2} \mathrm{O}_{2}\right]\right)+-2 \ln \left(\left[\mathrm{H}_{3} \mathrm{O}^{+}\right]\right)-\ln \left(\left[\mathrm{O}_{2}\right]\right)\right) \\
& =R T \ln \left(\frac{\left[\mathrm{H}_{2} \mathrm{O}_{2}\right]\left[\mathrm{H}_{2} \mathrm{O}\right]^{2}}{\left[\mathrm{H}_{3} \mathrm{O}^{+}\right]^{2}\left[\mathrm{O}_{2}\right]}\right)
\end{aligned}
$$

Where the activity of hydrogen peroxide $\left(\left[\mathrm{H}_{2} \mathrm{O}_{2}\right]\right)$, water $\left(\left[\mathrm{H}_{2} \mathrm{O}\right]\right)$, oxygen $\left(\left[\mathrm{O}_{2}\right]\right)$, and hydronium ions $\left(\left[\mathrm{H}_{3} \mathrm{O}^{+}\right]\right)$influence the potential of the cell. Substituting equation $\mathrm{S} 4.9$, the standard potential of the 2e- ORR $\left(\phi_{2 e^{-}, O R R}^{0}\right)$, and the transfer of two electrons from the electrode into equation S4.6, we derive the Nernst equation for the $2 \mathrm{e}-\mathrm{ORR}$ :

$$
\phi=\phi_{2 e^{-}, O R R}^{0}-\frac{R T}{2 \mathrm{~F}} \ln \left(\frac{\left[\mathrm{H}_{2} \mathrm{O}_{2}\right]\left[\mathrm{H}_{2} \mathrm{O}\right]^{2}}{\left[\mathrm{H}_{3} \mathrm{O}^{+}\right]^{2}\left[\mathrm{O}_{2}\right]}\right)
$$

Finally, we define an analogous equation for the $4 \mathrm{e}^{-}$oxygen reduction reaction $\left(4 \mathrm{H}_{3} \mathrm{O}^{+}+\mathrm{O}_{2}+4 \mathrm{e}^{-}\right.$ $\rightarrow 6 \mathrm{H}_{2} \mathrm{O}$ ) in the solution phase using equations $\mathrm{S} 4.11-12$ : 


$$
\begin{gathered}
\sum_{j} n_{j} R T \cdot \ln ([j])=R T\left(6 \ln \left(\left[\mathrm{H}_{2} \mathrm{O}\right]\right)-4 \ln \left(\left[\mathrm{H}_{3} \mathrm{O}^{+}\right]\right)-\ln \left(\left[\mathrm{O}_{2}\right]\right)\right) \\
=R T \ln \left(\frac{\left[\mathrm{H}_{2} \mathrm{O}\right]^{6}}{\left[\mathrm{H}_{3} \mathrm{O}^{+}\right]^{4}\left[\mathrm{O}_{2}\right]}\right)
\end{gathered}
$$

Where the activity of water $\left(\left[\mathrm{H}_{2} \mathrm{O}\right]\right)$, oxygen $\left(\left[\mathrm{O}_{2}\right]\right)$, and hydronium ions $\left(\left[\mathrm{H}_{3} \mathrm{O}^{+}\right]\right)$influence the potential of the cell. Substituting equation S4.9, the standard potential of the $4 \mathrm{e}-\mathrm{ORR}\left(\phi_{4 e^{-}, O R R}^{0}\right)$, and the transfer of four electrons from the electrode into equation S4.6, we derive the Nernst equation for the 4e- ORR:

$$
\phi=\phi_{4 e^{-}, O R R}^{0}-\frac{R T}{4 \mathrm{~F}} \ln \left(\frac{\left[\mathrm{H}_{2} \mathrm{O}\right]^{6}}{\left[\mathrm{H}_{3} \mathrm{O}^{+}\right]^{4}\left[\mathrm{O}_{2}\right]}\right)
$$

The combined half-reactions of the $\mathrm{HOR}$ and 2e- ORR relate to the equilibrium cell potential for the direct synthesis of $\mathrm{H}_{2} \mathrm{O}_{2}\left(\mathrm{H}_{2}+\mathrm{O}_{2} \rightarrow \mathrm{H}_{2} \mathrm{O}_{2}\right)$. Thus, the standard electrode potential for $\mathrm{H}_{2} \mathrm{O}_{2}$ formation $\left(\phi_{\mathrm{H}_{2} \mathrm{O}_{2}}^{0}\right)$ is equivalent to subtracting the standard potential of the two half-reactions in the system:

$$
\phi_{\mathrm{H}_{2} \mathrm{O}_{2}}^{0}=\phi_{2 e^{-}, \mathrm{ORR}}^{0}-\phi_{\mathrm{HOR}}^{0}
$$

Similarly, we derive the complete Nernst equation for the direct synthesis of $\mathrm{H}_{2} \mathrm{O}_{2}$ by subtracting the Nernst equation of the HOR (equation S4.8) from the Nernst equation of the 2e- ORR (equation S4.10) to derive:

$$
\phi=\phi_{\mathrm{H}_{2} \mathrm{O}_{2}}^{0}-\frac{R T}{2 \mathrm{~F}} \ln \left(\frac{\left[\mathrm{H}_{2} \mathrm{O}_{2}\right]}{\left[\mathrm{H}_{2}\right]\left[\mathrm{O}_{2}\right]}\right)
$$

Analogously, the combined half-reactions of the $\mathrm{HOR}$ and 4e- ORR relate to the equilibrium cell potential for the direct synthesis of $\mathrm{H}_{2} \mathrm{O}\left(\mathrm{H}_{2}+1 / 2 \mathrm{O}_{2} \rightarrow \mathrm{H}_{2} \mathrm{O}\right)$. Thus, the standard electrode potential for $\mathrm{H}_{2} \mathrm{O}$ formation $\left(\phi_{\mathrm{H}_{2} \mathrm{O}}^{0}\right)$ is equivalent to subtracting the standard potential of the two halfreactions in the system:

$$
\phi_{\mathrm{H}_{2} \mathrm{O}}^{0}=\phi_{4 e^{-}, \mathrm{ORR}}^{0}-\phi_{\mathrm{HOR}}^{0}
$$

Again, we derive the complete Nernst equation for the direct synthesis of $\mathrm{H}_{2} \mathrm{O}$ by subtracting the Nernst equation of the HOR (equation S4.8) from the Nernst equation of the 4e- ORR (equation S4.12) to derive:

$$
\phi=\phi_{\mathrm{H}_{2} \mathrm{O}}^{0}-\frac{R T}{4 \mathrm{~F}} \ln \left(\frac{\left[\mathrm{H}_{2} \mathrm{O}\right]^{2}}{\left[\mathrm{H}_{2}\right]^{2}\left[\mathrm{O}_{2}\right]}\right)
$$




\section{S5. Koutcky-Levich Analysis to Correct Mass Transfer Limitations in Electrochemical Measurements}

In this section, we discuss the analysis of electrochemical measurements on a rotating ring disk electrode (RRDE). Here, we use Koutcky-Levich analysis to determine rate constants and charge transfer coefficients of the HOR and ORR in the kinetic regime for the corresponding voltammograms. In other words, we report data points below the half-wave potential of the steadystate voltammograms in order to avoid contributions from mass transfer. Figure S19a shows the ORR current on a carbon-supported Pt material at potentials between -0.2-0.8 V vs. NHE at multiple rotation rates between 150-1500 RPM.
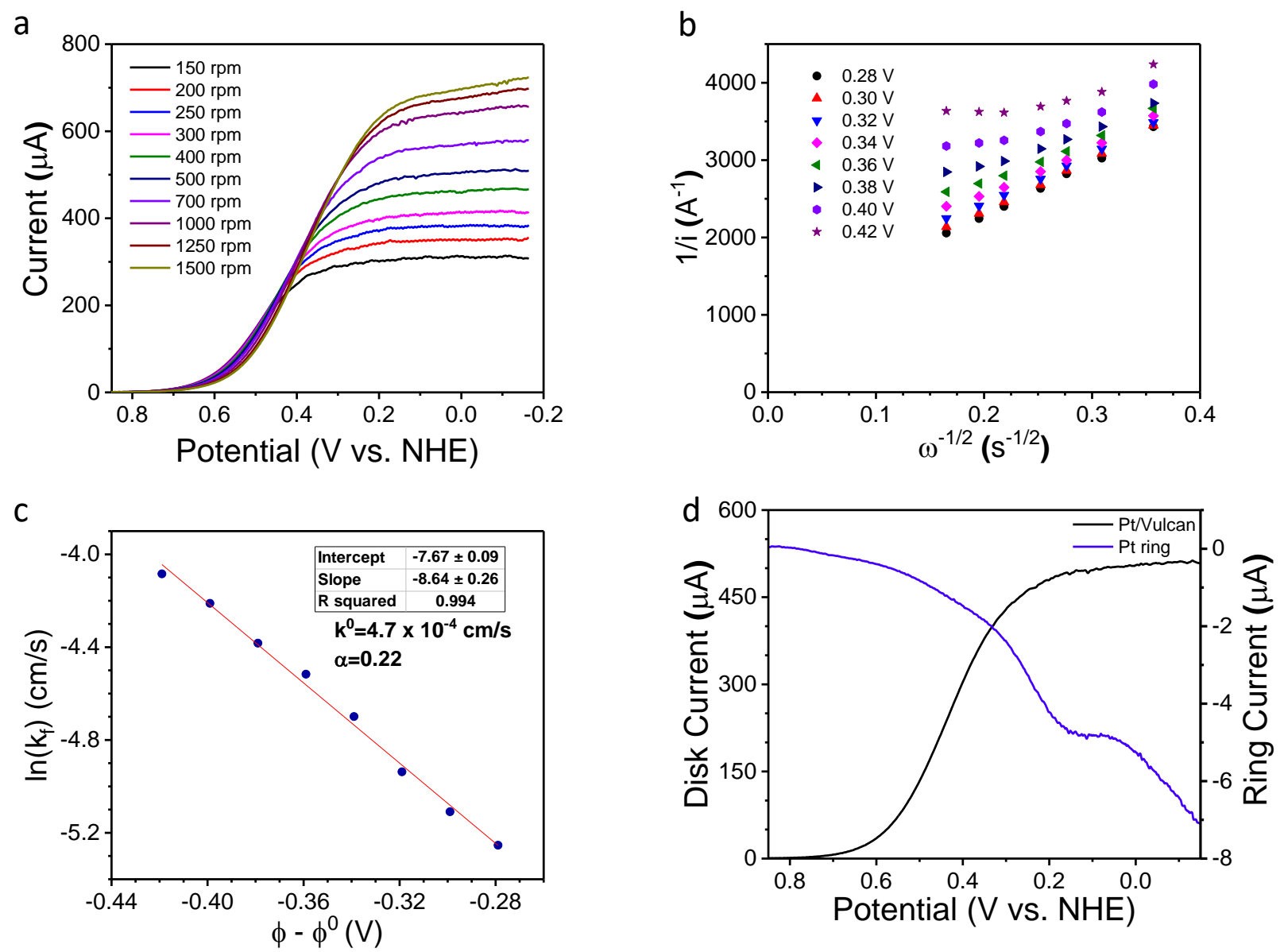

Figure S19. Electrochemical measurements of Pt nanoparticles supported on Vulcan XC-72 using a rotating ring disk electrode (RRDE). (a) Disk current of the oxygen reduction reaction (ORR) as a function of potential (-0.2-0.8 V vs NHE) at rotation rates between 150-1500 RPM. (b) The inverse of these disk currents $(1 / \mathrm{i})$ as a function of the inverse squared rotation rate $\left(\omega^{-1 / 2}\right)$, which were used to extrapolate ORR current densities in the absence of mass transfer limitations at the y-intercept. (c) Apparent rate constants of the ORR as a function of the potential difference $\Phi-$ $\Phi^{0}$ in the absence of mass transfer. (d) Disk and ring currents of the ORR as a function of potential (-0.2-0.8 V vs NHE) at a rotation rate of $500 \mathrm{rpm}$, which shows the relative rate of $\mathrm{H}_{2} \mathrm{O}_{2}$ and $\mathrm{H}_{2} \mathrm{O}$ 
formation. All RRDE measurements were conducted in an aqueous $0.1 \mathrm{M} \mathrm{NaClO}_{4}$ solution sparged with $\mathrm{O}_{2}$ gas $(101 \mathrm{kPa}, 298 \mathrm{~K})$.

The RRDE measurements of all materials (Figures S20-S43) show a similar functional form to the complete Butler-Volmer equation, ${ }^{1}$ which we show for a general reaction below:

$$
i=\frac{i_{l c} i^{0} \mathrm{e}^{\frac{\alpha \mathrm{zF}\left(\Phi-\Phi^{0}\right)}{\mathrm{RT}}}}{i_{l c}+i^{0} \mathrm{e}^{\frac{\alpha \mathrm{zF}\left(\Phi-\Phi^{0}\right)}{\mathrm{RT}}}}
$$

Where the overall current $(i)$ depends on the intrinsic current of reaction $\left(i^{0}\right)$, the limiting current $\left(i_{l c}\right)$, the charge transfer coefficient $(\alpha)$, the direction of electron transfer $(\mathrm{z})$, the electrical potential $(\Phi)$, the standard potential of reaction $\left(\Phi^{0}\right)$, the universal gas constant $(\mathrm{R})$, Faraday's constant $(\mathrm{F})$, and the temperature (T). In this form, the value $i_{0}$ accounts for the number of electrons transferred (n), the intrinsic rate constant of reaction $\left(\mathrm{k}^{0}\right)$, and the reactant activity of species $j([j])$ in the absence of mass transfer constraints. In contrast, the value $i_{l c}$ assumes that the rate of reaction equals the rate of mass transfer $\left(r_{M T}\right)$ of species $j$ at the catalyst surface. The value $r_{M T}$ depends on the mass transfer coefficient $\left(\mathrm{k}_{M T}\right)$, the activity of species $j$ in solution $\left([j]_{s o l}\right)$, and its activity at the catalyst surface $\left([j]_{\text {sur }}\right)$. Under such mass transfer limitations, however, the activity of reactants near the surface become small relative to the bulk $\left([j]_{\text {sol }} \gg[j]_{\text {sur }}\right)$.

$$
\begin{gathered}
i^{0}=\mathrm{nFk}^{0}[j] \\
i_{l c}=\mathrm{nFr}_{M T}=\mathrm{nFk}_{M T}\left([j]_{\text {sol }}-[j]_{\text {sur }}\right) \approx \mathrm{nFk}_{M T}[j]_{s o l}
\end{gathered}
$$

These expressions imply that the current increases exponentially with the applied overpotential until the rate of reaction equal the rate of mass transfer to the catalyst. Thus, equation S5.1 explains the sigmoidal dependence of current with potential shown in Figure S19a. To fit constants to this data, however, we must extrapolate to the current in the absence of mass transfer, which we analyzed through the Levich equation. ${ }^{1}$

$$
i_{l c}=0.62 \mathrm{nFD}_{j}^{2 / 3} v^{-1 / 6} C_{j}^{*} \omega^{1 / 2} i_{l c}=i_{l c}^{0} \omega^{1 / 2}
$$

Where the limiting current $\left(i_{l c}\right)$ depends on the diffusion coefficient $\left(\mathrm{D}_{j}\right)$ and bulk concentration $\left(C_{j}^{*}\right)$ of species $j$ in solution, the kinematic viscosity $(v)$ of the liquid, and the rotation rate $(\omega)$ of the electrode. For simplicity, we have grouped these terms into a single proportionality constant $i_{l c}^{0}$. In Figure S19a, the Levich equation explains the sublinear increase in the limiting current at increasing rotation rates (150-1500 RPM). At the highest rotation rates (1250-1500), however, this relation breaks down as the rate of reaction is limited more by the rate of electron transfer rather than mass transfer. To explain this behavior, we substitute equation S5.4 into equation S5.1 to derive the Koutecky-Levich equation: 


$$
\frac{1}{i}=\frac{1}{i^{0} \mathrm{e}^{\frac{\alpha \mathrm{zF}\left(\Phi-\Phi^{0}\right)}{\mathrm{RT}}}}+\frac{1}{i_{l c}^{0}} \omega^{-1 / 2}
$$

This expression shows that the measured current approaches an ideal Butler-Volmer behavior as the rotation rate increases, and the rate of mass transfer exceeds the rate of reaction. Under these conditions, the concentration of species $j$ at the catalyst surfaces equals the concentration of species $j$ in the bulk solution, and we derive:

$$
\lim _{\omega \rightarrow \infty} i=i^{0} \mathrm{e}^{\frac{\alpha \mathrm{zF}\left(\Phi-\Phi^{0}\right)}{\mathrm{RT}}}
$$

Thus, we linearized the voltammograms in Figure S19a by plotting the inverse current $(1 / i)$ with respect to $\omega^{-1 / 2}$, as shown in Figure $S 19 b$. Then, we determined the current in the absence of mass transfer limitations by extrapolating to the current at the y-intercept $\left(\omega^{-1 / 2}=0\right)$ of these plots. In Figure S19c, we plot the extrapolated currents as a function of potential, which we fit to the linearized version of equation S5.6:

$$
\ln (i)=\ln \left(i^{0}\right)+\frac{\alpha z \mathrm{~F}\left(\Phi-\Phi^{0}\right)}{\mathrm{RT}}
$$

With this equation, we calculated $\alpha$ from the slope of Figure S19c and determined $i^{0}$ from the yintercept of the plot, and values of $\mathrm{k}^{0}$ were calculated from $i^{0}$ using equation S5.7. A similar

\begin{tabular}{|c|c|c|c|c|}
\hline Materials & $\operatorname{ORR~k}^{0}(\mathrm{~cm} / \mathrm{s})$ & ORR $\alpha$ & $\operatorname{HOR~k}^{0}(\mathrm{~cm} / \mathrm{s})$ & $\begin{array}{l}\text { HOR } \\
(1-\alpha)\end{array}$ \\
\hline $\mathrm{Pd}$ & $2.8 \times 10^{-4} \pm 1.3 \times 10^{-4}$ & $\begin{array}{ll}0.27 & \pm \\
0.03 & \end{array}$ & $1.1 \times 10^{-4} \pm 0.4 \times 10^{-4}$ & $\begin{array}{ll}0.91 & \pm \\
0.01 & \end{array}$ \\
\hline $\mathrm{PdZn}$ & $3.3 \times 10^{-4} \pm 0.9 \times 10^{-4}$ & $\begin{array}{l}0.24 \\
0.05\end{array}$ & $2.8 \times 10^{-5} \pm 0.4 \times 10^{-5}$ & $\begin{array}{l}0.86 \pm \\
0.01\end{array}$ \\
\hline $\mathrm{Pt}$ & $2.5 \times 10^{-4} \pm 1.9 \times 10^{-4}$ & $\begin{array}{l}0.28 \\
0.05\end{array}$ & $1.0 \times 10^{-5} \pm 2.5 \times 10^{-6}$ & $\begin{array}{l}0.34 \\
0.03\end{array}$ \\
\hline $\mathrm{PtCo}$ & $4.3 \times 10^{-4} \pm 2.6 \times 10^{-4}$ & $\begin{array}{l}0.30 \\
0.06\end{array}$ & $4.1 \times 10^{-6} \pm 9.0 \times 10^{-7}$ & $\begin{array}{l}0.25 \\
0.02\end{array}$ \\
\hline $\mathrm{PdCo}$ & $2.9 \times 10^{-4} \pm 0.5 \times 10^{-4}$ & $\begin{array}{l}0.24 \\
0.04\end{array}$ & $6.2 \times 10^{-5} \pm 2.0 \times 10^{-5}$ & $\begin{array}{l}0.82 \pm \\
0.01\end{array}$ \\
\hline $\mathrm{PdPt}$ & $4.1 \times 10^{-4} \pm 2.4 \times 10^{-4}$ & $\begin{array}{l}0.32 \\
0.08\end{array}$ & $2.0 \times 10^{-6} \pm 1.0 \times 10^{-6}$ & $\begin{array}{l}0.23 \\
0.06\end{array}$ \\
\hline $\mathrm{PdNi}$ & $4.7 \times 10^{-4} \pm 6.0 \times 10^{-5}$ & $\begin{array}{l}0.21 \\
0.05\end{array}$ & $1.1 \times 10^{-4} \pm 0.4 \times 10^{-4}$ & $\begin{array}{l}0.88 \\
0.02\end{array}$ \\
\hline $\mathrm{PdCu}$ & $2.4 \times 10^{-4} \pm 0.2 \times 10^{-4}$ & $\begin{array}{l}0.21 \\
0.02\end{array}$ & $2.7 \times 10^{-5} \pm 0.6 \times 10^{-5}$ & $\begin{array}{l}0.82 \pm \\
0.02\end{array}$ \\
\hline
\end{tabular}
analysis was completed on each material in Figures S19-S43 and the values of $\alpha$ and $\mathrm{k}^{0}$ were tabulated in Table $\mathrm{S} 2$ below: 


\begin{tabular}{|l|l|ll|l|l|}
\hline $\mathrm{Pd}_{1} \mathrm{Au}_{60}$ & $4.3 \times 10^{-5} \pm 1.7 \times 10^{-5}$ & 0.37 & $3.3 \times 10^{-5} \pm 0.5 \times 10^{-5}$ & $0.93 \pm$ \\
& & 0.04 & & 0.01 \\
\hline $\mathrm{Au}$ & $3.1 \times 10^{-5} \pm 0.5 \times 10^{-5}$ & 0.37 & \pm & $($ too slow to measure w/ & - \\
& & 0.01 & $\mathrm{RDE})$ & \\
\hline $\mathrm{Pt}_{1} \mathrm{Au}_{60}$ & $2.0 \times 10^{-5} \pm 0.4 \times 10^{-5}$ & $0.36 \pm$ & $4.1 \times 10^{-5} \pm 2.8 \times 10^{-5}$ & $0.72 \pm$ \\
& & 0.02 & & 0.05 \\
\hline $\mathrm{Pt}_{1} \mathrm{Au}_{15}$ & $1.6 \times 10^{-5} \pm 0.8 \times 10^{-5}$ & $0.41 \pm$ & $1.2 \times 10^{-5} \pm 3.0 \times 10^{-6}$ & $0.73 \pm$ \\
& & 0.03 & & 0.02 \\
\hline $\mathrm{Pt}_{1} \mathrm{Au}_{5}$ & $2.2 \times 10^{-5} \pm 0.4 \times 10^{-5}$ & $0.46 \pm$ & $7.6 \times 10^{-5} \pm 4.3 \times 10^{-5}$ & $0.77 \pm$ \\
& & 0.02 & 0.08 \\
\hline
\end{tabular}

Table S2: Average $\mathrm{k}^{0}$ and $\alpha$ values for the ORR and HOR from three measurements performed on each of the catalysts investigated. These parameters correspond to data shown in Figures S19-S43.

Table $\mathrm{S} 2$ shows the distinct trends in the values of $\alpha$ and $\mathrm{k}^{0}$ for each of the materials tested. Generally, Au-based materials show greater ORR charge transfer coefficients $(\alpha)$ than the other Pt- and Pd-based materials, but the Au materials show lower ORR intrinsic rate constants $\left(\mathrm{k}^{0}\right)$. Similarly, the Pt-based materials tend to show lower HOR charge transfer coefficients than the Pd and Au-based materials, while the PtAu alloys show an intermediate charge transfer coefficient that is more like those of the Au-based materials. The intrinsic rate constants of the HOR, however, show no clear trend between all the materials.

FigureS19d shows the disk and ring current overlaid with one another at a constant rotation rate (500 RPM). In an RRDE system, the ring operates at a different potential than the disk, and it collects products generated on the disk. In the HOR, the current is monitored on the disk electrode since there are no secondary products to monitor at the ring. For the ORR, however, the disk current $\left(i_{d}\right)$ reflects the total rate of oxygen reduction, while the ring current $\left(i_{r}\right)$ reflects the rate of $\mathrm{H}_{2} \mathrm{O}_{2}$ formed on the disk multiplied by the collection efficiency $(C E)$ of the ring. ${ }^{2}$ Thus, the ratio of disk and ring currents determines the total number electrons $(n)$ consumed by the catalyst, which is related to the $\mathrm{H}_{2} \mathrm{O}_{2}$ selectivity $\left(\mathrm{S}_{\mathrm{H}_{2} \mathrm{O}_{2}}\right)$ of the catalyst.

$$
\begin{gathered}
n=\frac{4 i_{d}}{i_{d}+\frac{i_{r}}{C E}} \\
S_{H_{2} O_{2}}=\frac{(4-n)}{2}
\end{gathered}
$$

Here, the selectivity of $\mathrm{H}_{2} \mathrm{O}_{2}$ increases if the $2 \mathrm{e}^{-}$ORR pathway dominates over the $4 \mathrm{e}^{-}$pathway. In Figures S44-S56, we show the selectivity of each material as a function of potential, and we discuss these profiles in more detail in supporting information S8. 

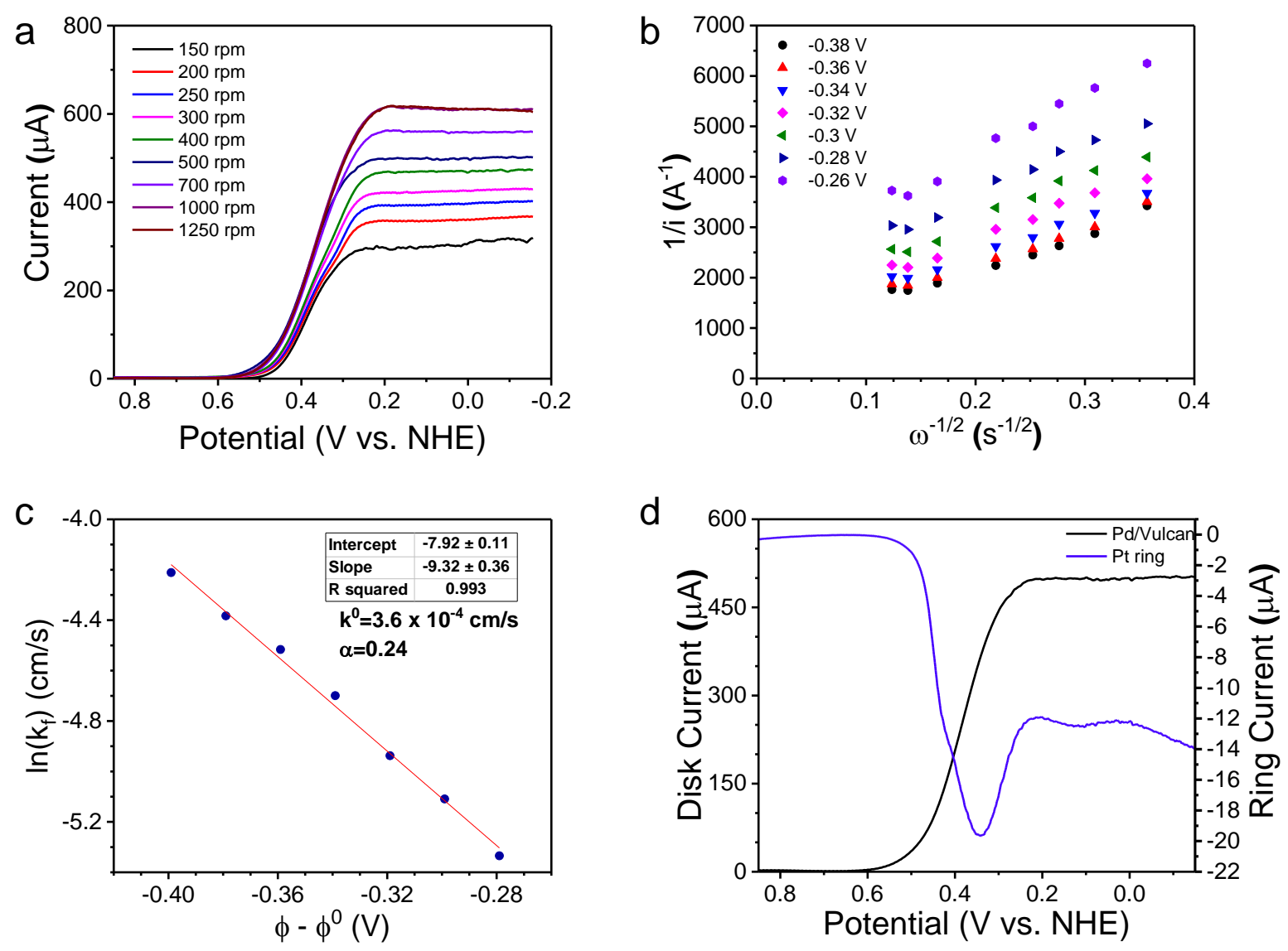

Figure S20. Electrochemical measurements of Pd nanoparticles supported on Vulcan XC-72 using a rotating ring disk electrode (RRDE). (a) Disk current of the oxygen reduction reaction (ORR) as a function of potential (-0.2-0.8 V vs NHE) at rotation rates between 150-1500 RPM. (b) The inverse of these disk currents $(1 / \mathrm{i})$ as a function of the inverse squared rotation rate $\left(\omega^{-1 / 2}\right)$, which were used to extrapolate ORR current densities in the absence of mass transfer limitations at the y-intercept. (c) Apparent rate constants of the ORR as a function of the potential difference $\Phi-$ $\Phi^{0}$ in the absence of mass transfer. (d) Disk and ring currents of the ORR as a function of potential (-0.2-0.8 V vs NHE) at a rotation rate of $500 \mathrm{rpm}$, which shows the relative rate of $\mathrm{H}_{2} \mathrm{O}_{2}$ and $\mathrm{H}_{2} \mathrm{O}$ formation. All RRDE measurements were conducted in an aqueous $0.1 \mathrm{M} \mathrm{NaClO}_{4}$ solution sparged with $\mathrm{O}_{2}$ gas $(101 \mathrm{kPa}, 298 \mathrm{~K})$. 

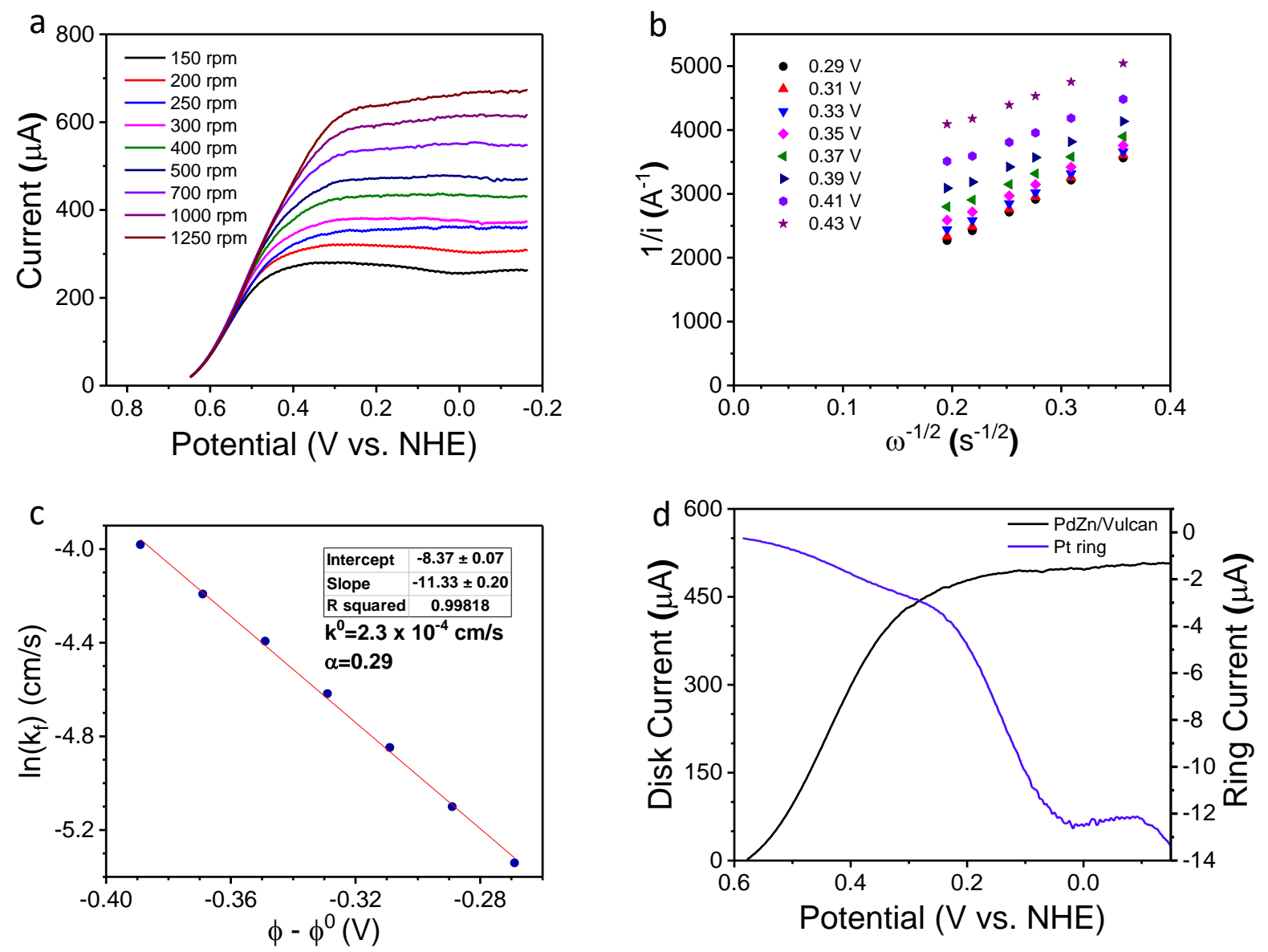

Figure S21: Electrochemical measurements of PdZn nanoparticles supported on Vulcan XC-72 using a rotating ring disk electrode (RRDE). (a) Disk current of the oxygen reduction reaction (ORR) as a function of potential (-0.2-0.65 V vs NHE) at rotation rates between 150-1250 RPM. (b) The inverse of these disk currents (1/i) as a function of the inverse squared rotation rate $\left(\omega^{-1 / 2}\right)$, which were used to extrapolate ORR current densities in the absence of mass transfer limitations at the y-intercept. (c) Apparent rate constants of the ORR as a function of the potential difference $\left(\Phi-\Phi^{0}\right)$ in the absence of mass transfer. (d) Disk and ring currents of the ORR as a function of potential (-0.2-0.65 V vs NHE) at a rotation rate of $500 \mathrm{rpm}$, which shows the relative rate of $\mathrm{H}_{2} \mathrm{O}_{2}$ and $\mathrm{H}_{2} \mathrm{O}$ formation. All RRDE measurements were conducted in an aqueous $0.1 \mathrm{M}$ $\mathrm{NaClO}_{4}$ solution sparged with $\mathrm{O}_{2}$ gas $(101 \mathrm{kPa}, 298 \mathrm{~K})$. 

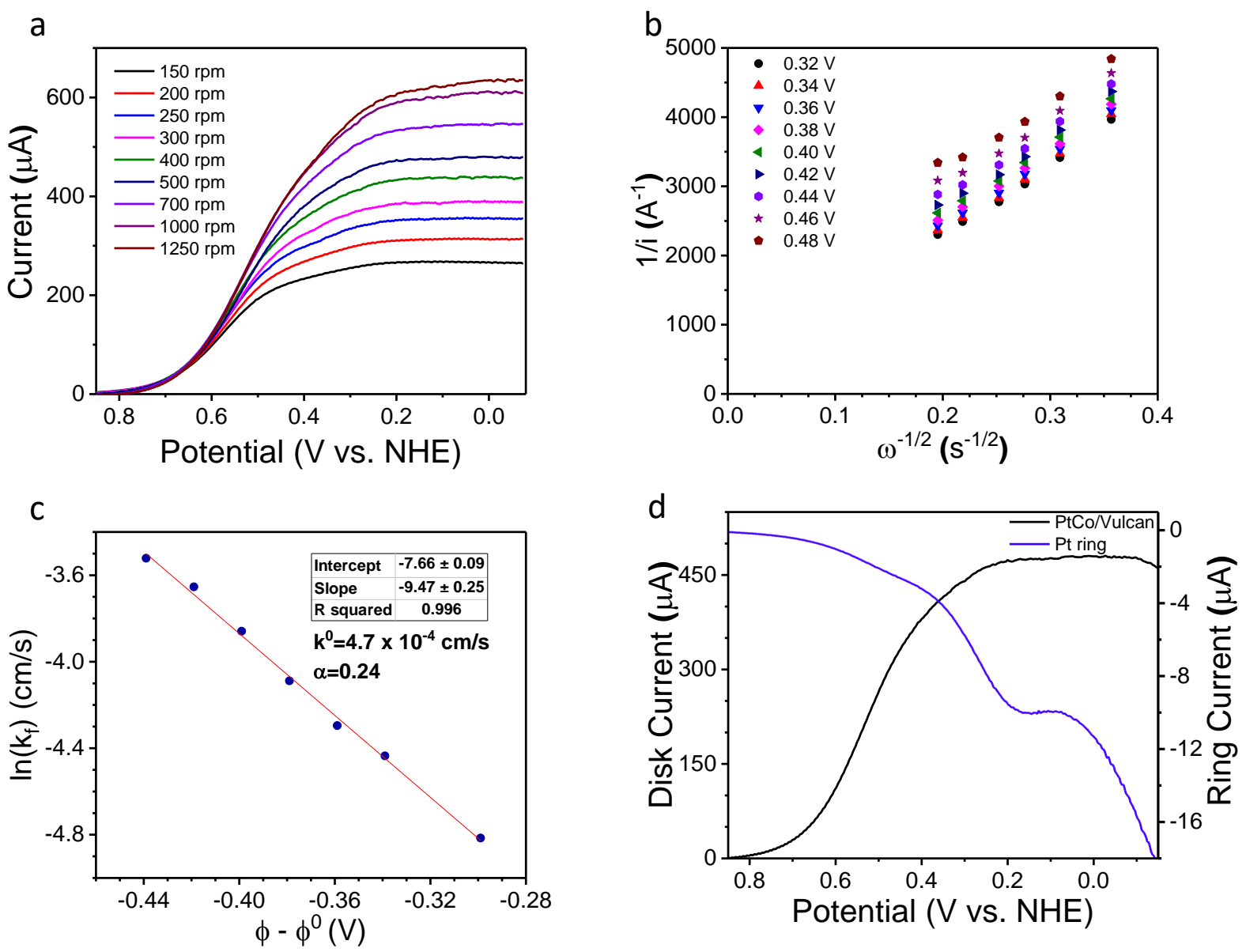

Figure S22: Electrochemical measurements of PtCo nanoparticles supported on Vulcan XC-72 using a rotating ring disk electrode (RRDE). (a) Disk current of the oxygen reduction reaction (ORR) as a function of potential (-0.2-0.8 V vs NHE) at rotation rates between 150-1250 RPM. (b) The inverse of these disk currents (1/i) as a function of the inverse squared rotation rate $\left(\omega^{-1 / 2}\right)$, which were used to extrapolate ORR current densities in the absence of mass transfer limitations at the $y$-intercept. (c) Apparent rate constants of the ORR as a function of the potential difference $\left(\Phi-\Phi^{0}\right)$ in the absence of mass transfer. (d) Disk and ring currents of the ORR as a function of potential (-0.2-0.8 V vs NHE) at a rotation rate of $500 \mathrm{rpm}$, which shows the relative rate of $\mathrm{H}_{2} \mathrm{O}_{2}$ and $\mathrm{H}_{2} \mathrm{O}$ formation. All RRDE measurements were conducted in an aqueous $0.1 \mathrm{M}$ $\mathrm{NaClO}_{4}$ solution sparged with $\mathrm{O}_{2}$ gas $(101 \mathrm{kPa}, 298 \mathrm{~K})$. 

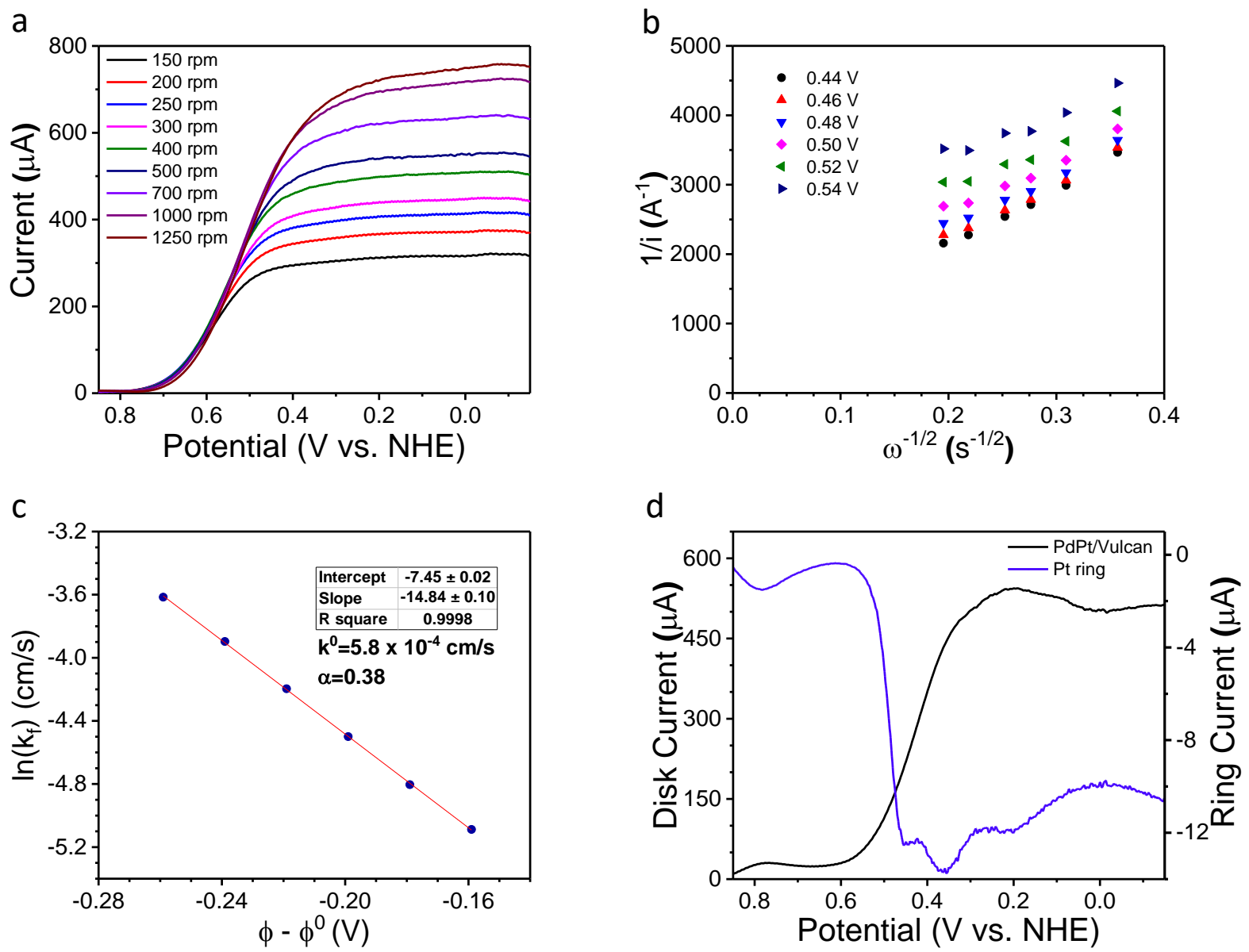

Figure S23: Electrochemical measurements of PdPt nanoparticles supported on Vulcan XC-72 using a rotating ring disk electrode (RRDE). (a) Disk current of the oxygen reduction reaction (ORR) as a function of potential (-0.2-0.8 V vs NHE) at rotation rates between 150-1250 RPM. (b) The inverse of these disk currents (1/i) as a function of the inverse squared rotation rate $\left(\omega^{-1 / 2}\right)$, which were used to extrapolate ORR current densities in the absence of mass transfer limitations at the y-intercept. (c) Apparent rate constants of the ORR as a function of the potential difference $\left(\Phi-\Phi^{0}\right)$ in the absence of mass transfer. (d) Disk and ring currents of the ORR as a function of potential (-0.2-0.8 V vs NHE) at a rotation rate of $500 \mathrm{rpm}$, which shows the relative rate of $\mathrm{H}_{2} \mathrm{O}_{2}$ and $\mathrm{H}_{2} \mathrm{O}$ formation. All RRDE measurements were conducted in an aqueous $0.1 \mathrm{M}$ $\mathrm{NaClO}_{4}$ solution sparged with $\mathrm{O}_{2}$ gas $(101 \mathrm{kPa}, 298 \mathrm{~K})$. 

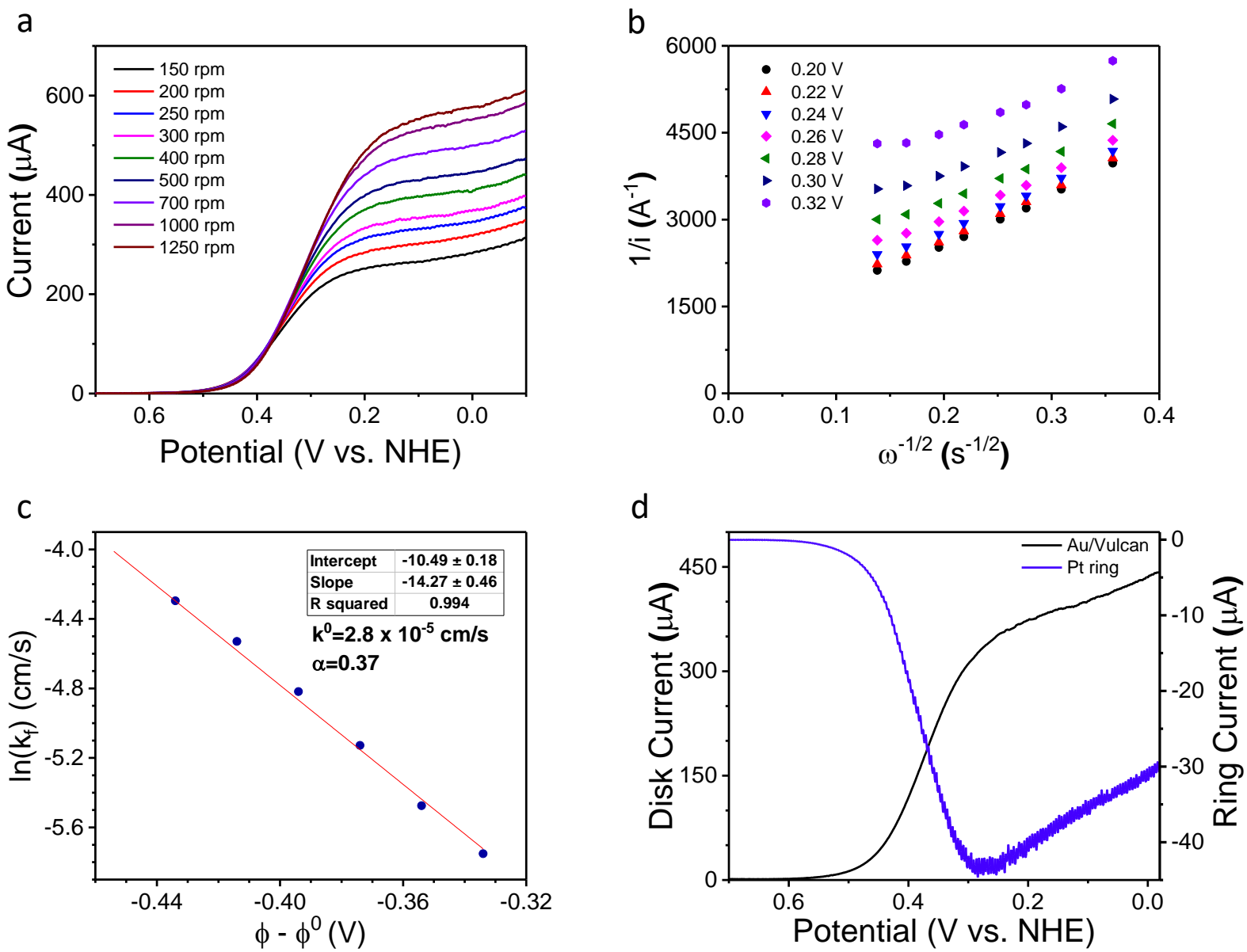

Figure S24: Electrochemical measurements of Au nanoparticles supported on Vulcan XC-72 using a rotating ring disk electrode (RRDE). (a) Disk current of the oxygen reduction reaction (ORR) as a function of potential (-0.2-0.8 V vs NHE) at rotation rates between 150-1250 RPM. (b) The inverse of these disk currents (1/i) as a function of the inverse squared rotation rate $\left(\omega^{-1 / 2}\right)$, which were used to extrapolate ORR current densities in the absence of mass transfer limitations at the y-intercept. (c) Apparent rate constants of the ORR as a function of the potential difference $\left(\Phi-\Phi^{0}\right)$ in the absence of mass transfer. (d) Disk and ring currents of the ORR as a function of potential (-0.2-0.8 V vs NHE) at a rotation rate of $500 \mathrm{rpm}$, which shows the relative rate of $\mathrm{H}_{2} \mathrm{O}_{2}$ and $\mathrm{H}_{2} \mathrm{O}$ formation. All RRDE measurements were conducted in an aqueous $0.1 \mathrm{M}$ $\mathrm{NaClO}_{4}$ solution sparged with $\mathrm{O}_{2}$ gas $(101 \mathrm{kPa}, 298 \mathrm{~K})$. 
a

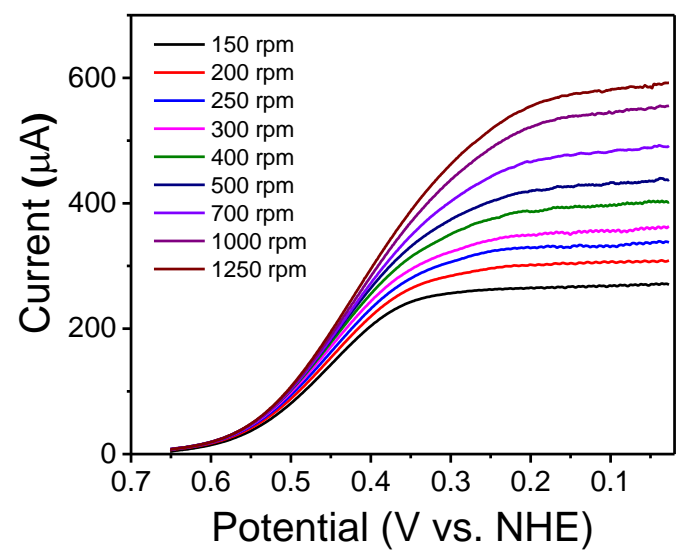

C

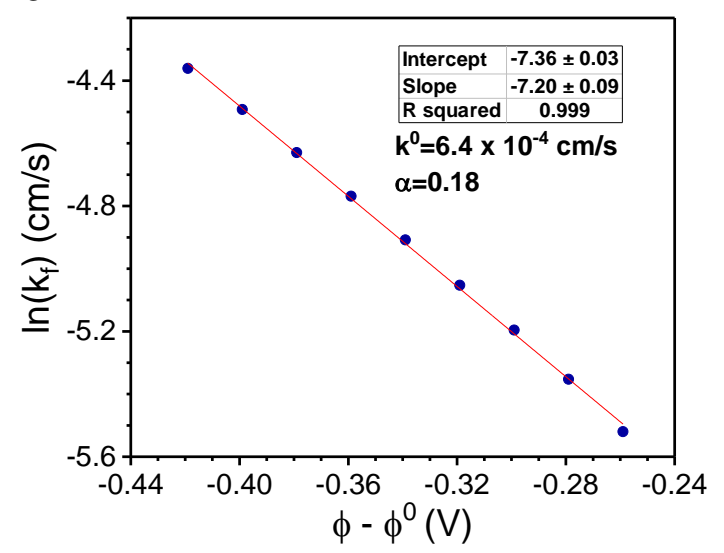

b

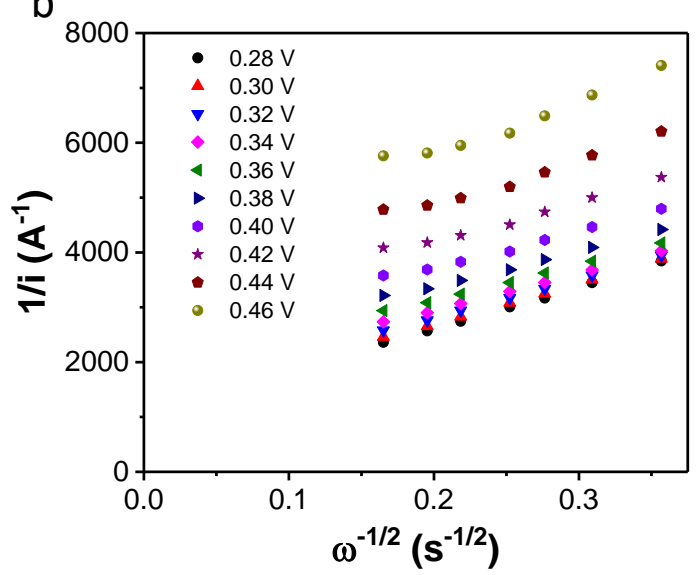

d

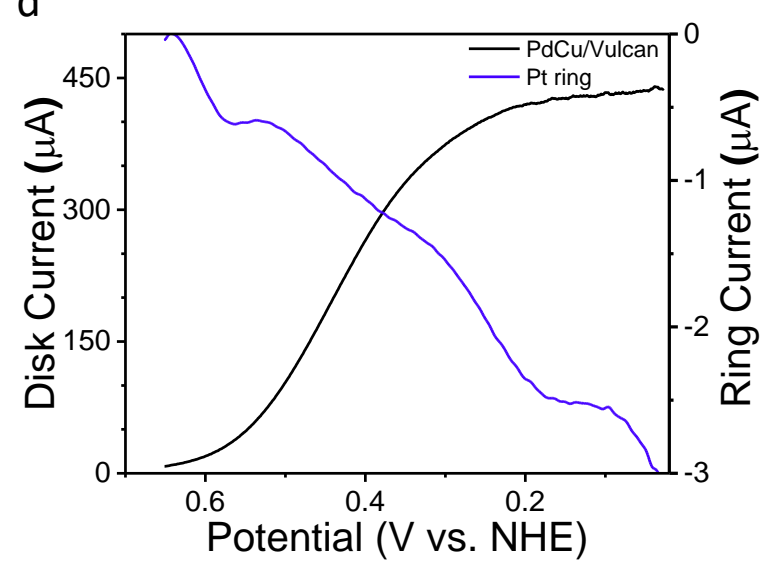

Figure S25: Electrochemical measurements of $\mathrm{PdCu}$ nanoparticles supported on Vulcan XC-72 using a rotating ring disk electrode (RRDE). (a) Disk current of the oxygen reduction reaction (ORR) as a function of potential (-0.2-0.7 V vs NHE) at rotation rates between 150-1250 RPM. (b) The inverse of these disk currents (1/i) as a function of the inverse squared rotation rate $\left(\omega^{-1 / 2}\right)$, which were used to extrapolate ORR current densities in the absence of mass transfer limitations at the $y$-intercept. (c) Apparent rate constants of the ORR as a function of the potential difference $\left(\Phi-\Phi^{0}\right)$ in the absence of mass transfer. (d) Disk and ring currents of the ORR as a function of potential (-0.2-0.7 V vs NHE) at a rotation rate of $500 \mathrm{rpm}$, which shows the relative rate of $\mathrm{H}_{2} \mathrm{O}_{2}$ and $\mathrm{H}_{2} \mathrm{O}$ formation. All RRDE measurements were conducted in an aqueous $0.1 \mathrm{M}$ $\mathrm{NaClO}_{4}$ solution sparged with $\mathrm{O}_{2}$ gas $(101 \mathrm{kPa}, 298 \mathrm{~K})$. 

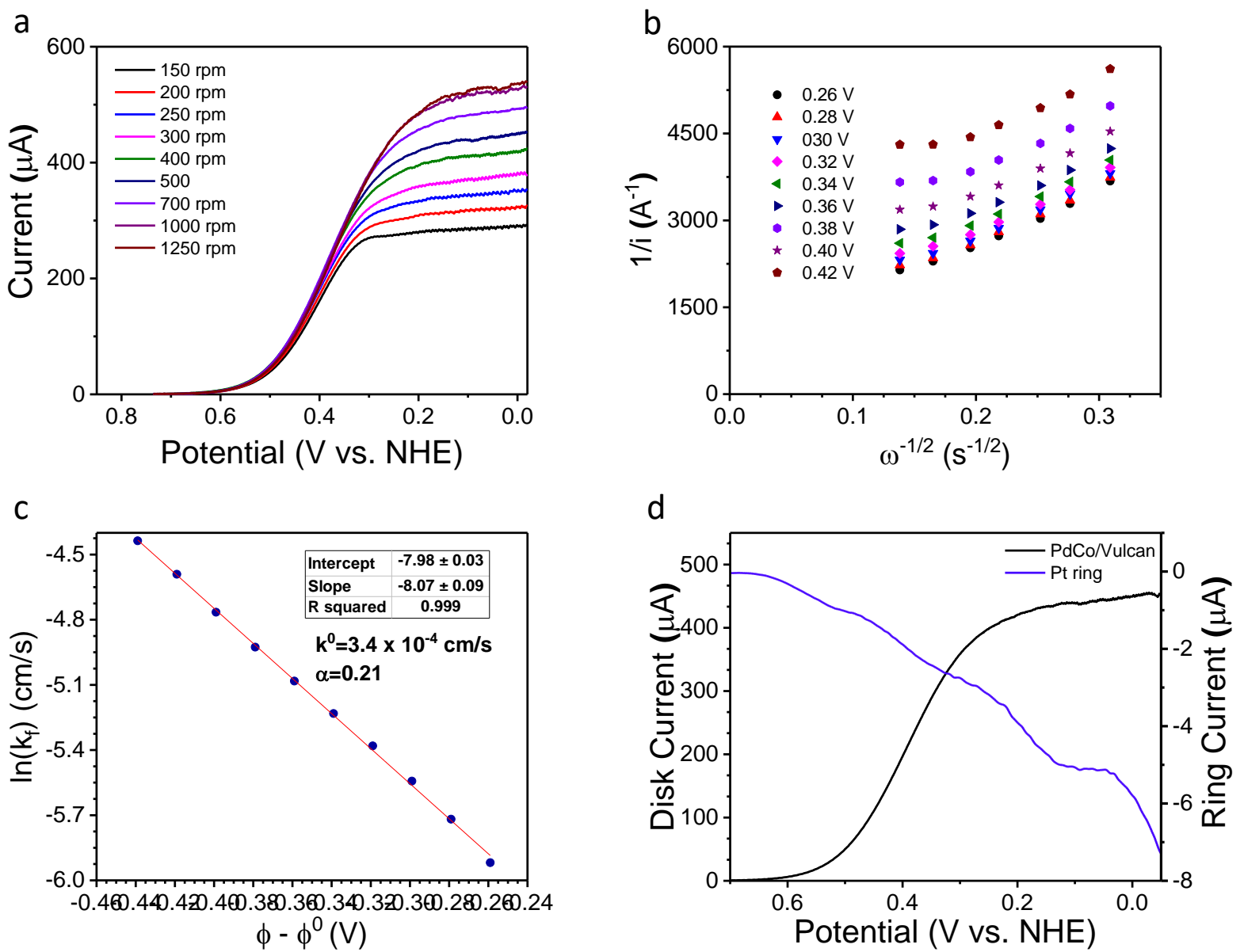

Figure S26: Electrochemical measurements of PdCo nanoparticles supported on Vulcan XC-72 using a rotating ring disk electrode (RRDE). (a) Disk current of the oxygen reduction reaction (ORR) as a function of potential (-0.2-0.8 V vs NHE) at rotation rates between 150-1500 RPM. (b) The inverse of these disk currents (1/i) as a function of the inverse squared rotation rate $\left(\omega^{-1 / 2}\right)$, which were used to extrapolate ORR current densities in the absence of mass transfer limitations at the y-intercept. (c) Apparent rate constants of the ORR as a function of the potential difference $\left(\Phi-\Phi^{0}\right)$ in the absence of mass transfer. (d) Disk and ring currents of the ORR as a function of potential (-0.2-0.8 V vs NHE) at a rotation rate of $500 \mathrm{rpm}$, which shows the relative rate of $\mathrm{H}_{2} \mathrm{O}_{2}$ and $\mathrm{H}_{2} \mathrm{O}$ formation. All RRDE measurements were conducted in an aqueous $0.1 \mathrm{M}$ $\mathrm{NaClO}_{4}$ solution sparged with $\mathrm{O}_{2}$ gas $(101 \mathrm{kPa}, 298 \mathrm{~K})$. 


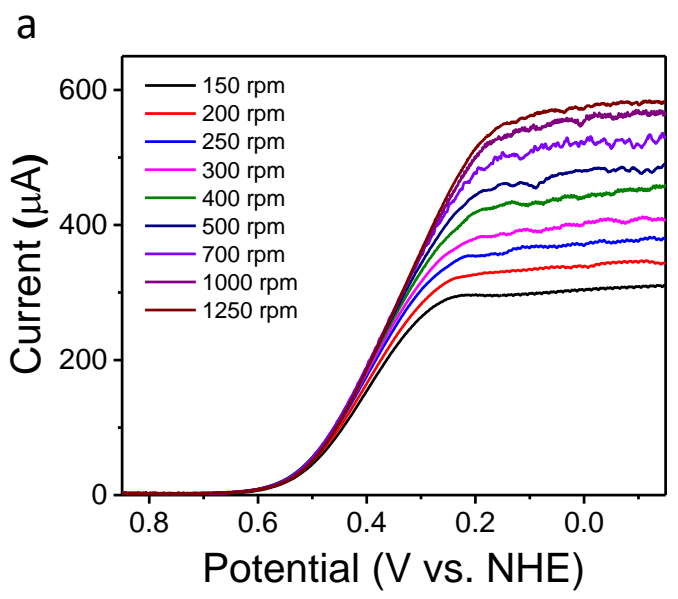

C

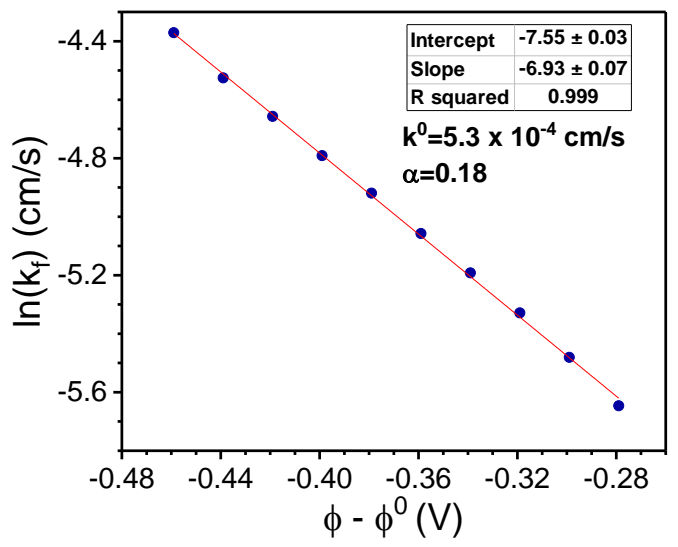

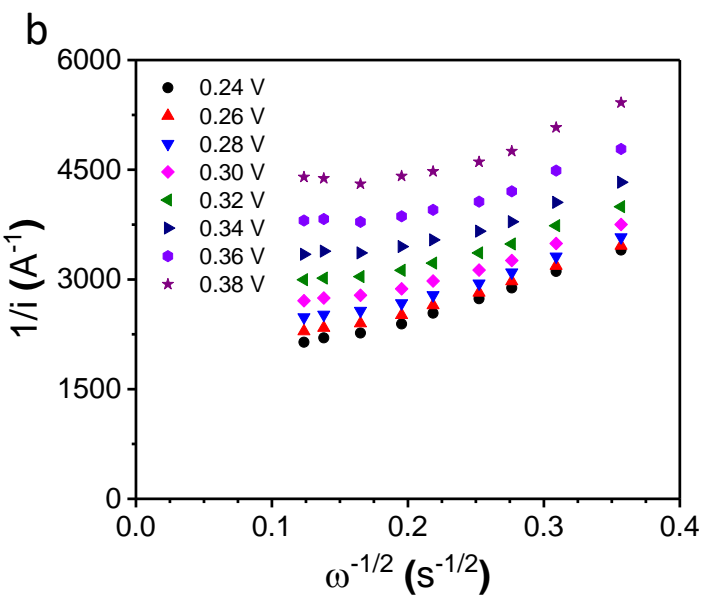

d

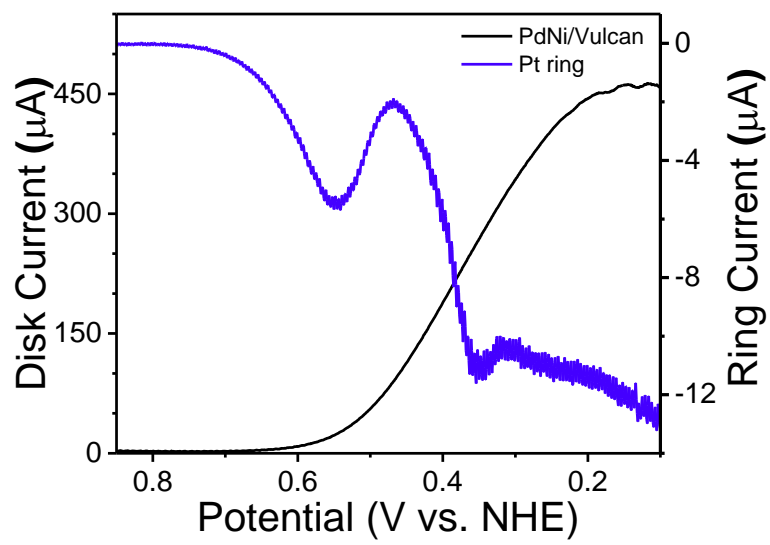

Figure S27: Electrochemical measurements of PdNi nanoparticles supported on Vulcan XC-72 using a rotating ring disk electrode (RRDE). (a) Disk current of the oxygen reduction reaction (ORR) as a function of potential (-0.2-0.8 V vs NHE) at rotation rates between 150-1250 RPM. (b) The inverse of these disk currents (1/i) as a function of the inverse squared rotation rate $\left(\omega^{-1 / 2}\right)$, which were used to extrapolate ORR current densities in the absence of mass transfer limitations at the y-intercept. (c) Apparent rate constants of the ORR as a function of the potential difference $\left(\Phi-\Phi^{0}\right)$ in the absence of mass transfer. (d) Disk and ring currents of the ORR as a function of potential (-0.2-0.8 V vs NHE) at a rotation rate of $500 \mathrm{rpm}$, which shows the relative rate of $\mathrm{H}_{2} \mathrm{O}_{2}$ and $\mathrm{H}_{2} \mathrm{O}$ formation. All RRDE measurements were conducted in an aqueous $0.1 \mathrm{M}$ $\mathrm{NaClO}_{4}$ solution sparged with $\mathrm{O}_{2}$ gas $(101 \mathrm{kPa}, 298 \mathrm{~K})$. 

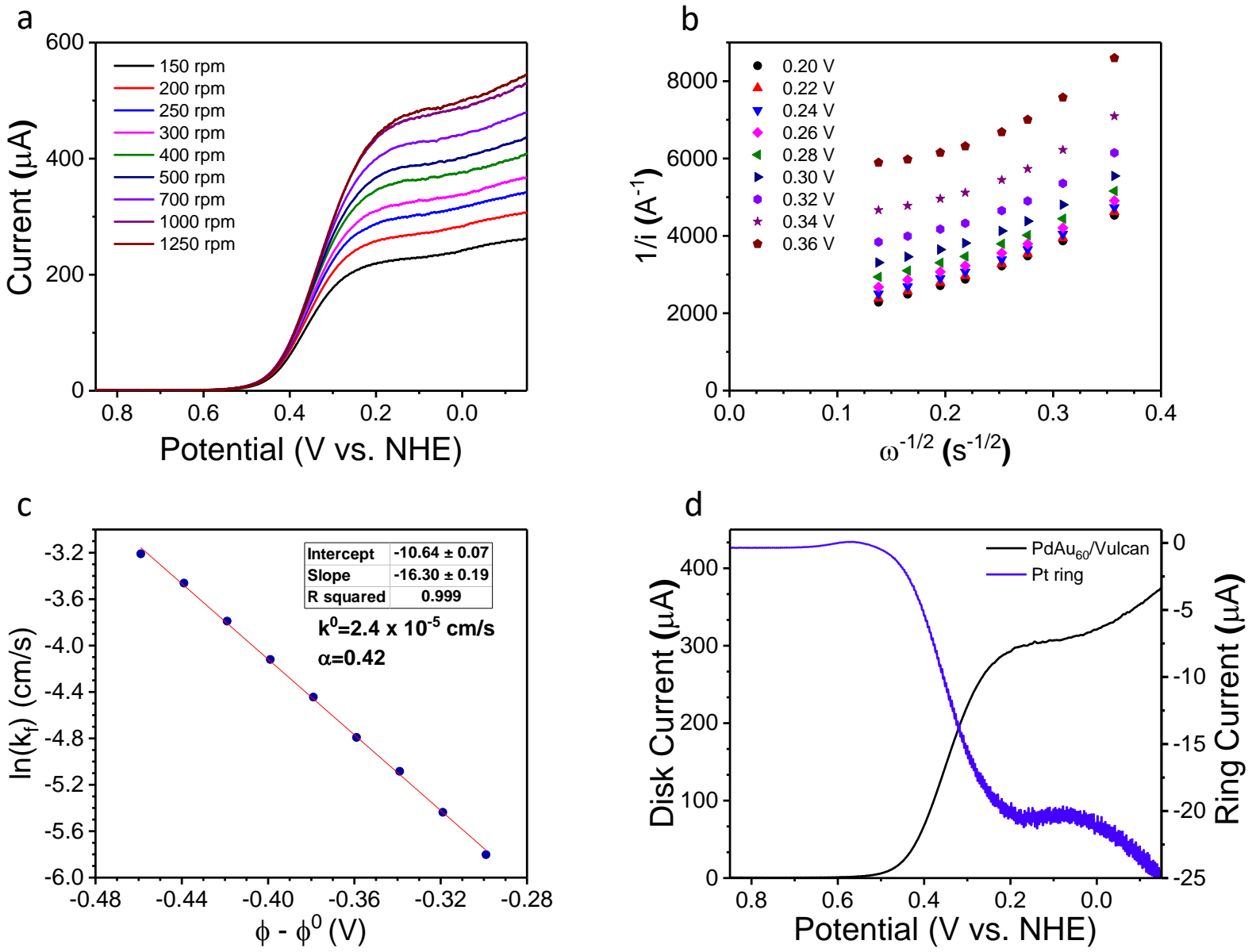

Figure S28: Electrochemical measurements of $\mathrm{Pd}_{1} \mathrm{Au}_{60}$ nanoparticles supported on Vulcan $\mathrm{XC}$ 72 using a rotating ring disk electrode (RRDE). (a) Disk current of the oxygen reduction reaction (ORR) as a function of potential (-0.2-0.8 V vs NHE) at rotation rates between 150-1250 RPM. (b) The inverse of these disk currents (1/i) as a function of the inverse squared rotation rate $\left(\omega^{-1 / 2}\right)$, which were used to extrapolate ORR current densities in the absence of mass transfer limitations at the $y$-intercept. (c) Apparent rate constants of the ORR as a function of the potential difference $\left(\Phi-\Phi^{0}\right)$ in the absence of mass transfer. (d) Disk and ring currents of the ORR as a function of potential (-0.2-0.8 V vs NHE) at a rotation rate of $500 \mathrm{rpm}$, which shows the relative rate of $\mathrm{H}_{2} \mathrm{O}_{2}$ and $\mathrm{H}_{2} \mathrm{O}$ formation. All RRDE measurements were conducted in an aqueous $0.1 \mathrm{M}$ $\mathrm{NaClO}_{4}$ solution sparged with $\mathrm{O}_{2}$ gas $(101 \mathrm{kPa}, 298 \mathrm{~K})$. 
a

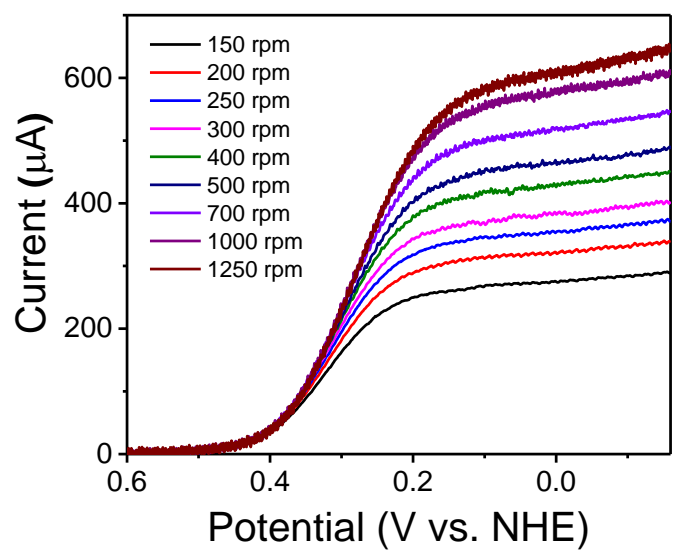

C

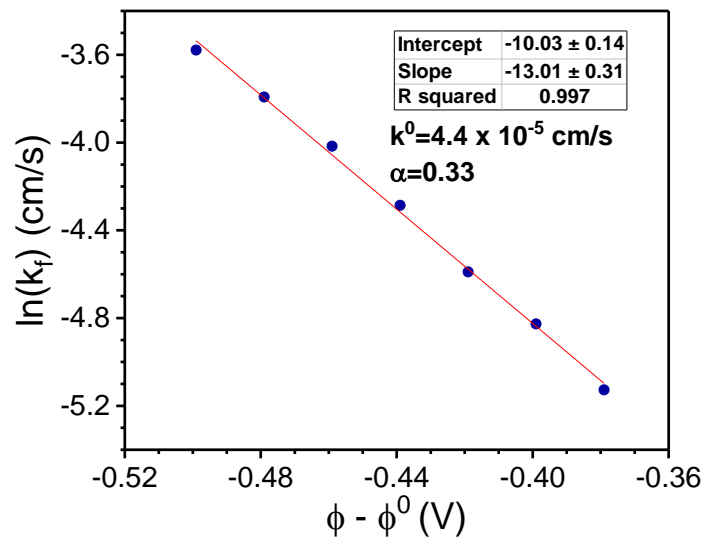

b

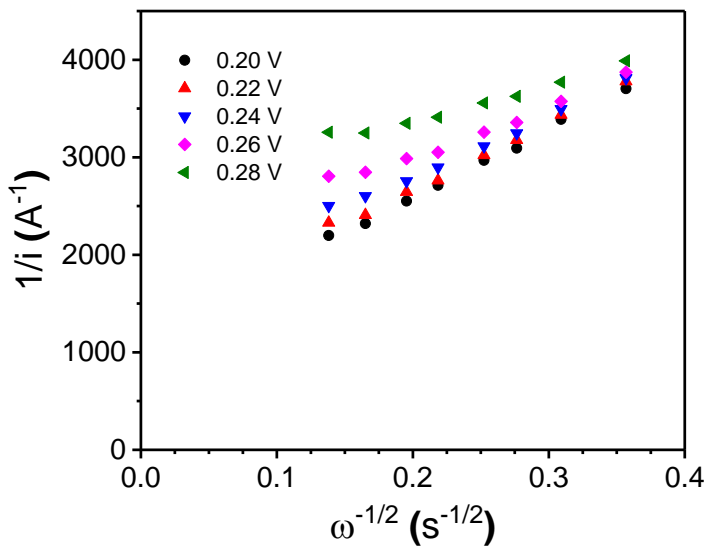

d

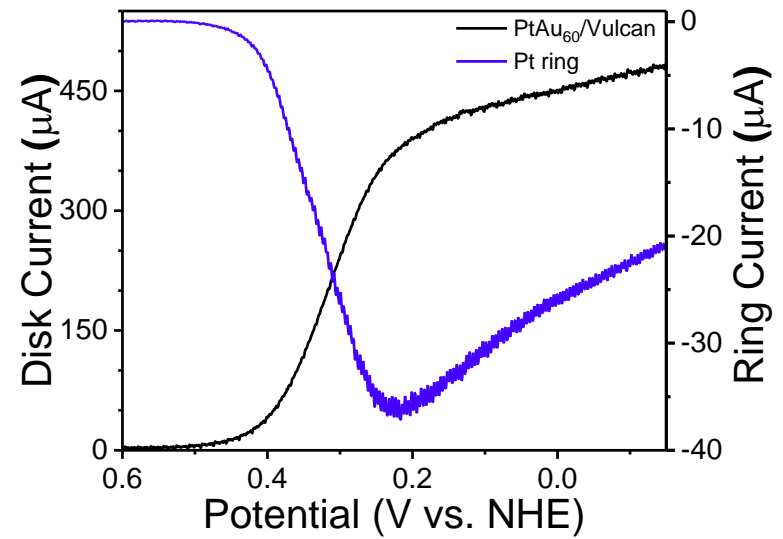

Figure S29: Electrochemical measurements of $\mathrm{Pt}_{1} \mathrm{Au}_{60}$ nanoparticles supported on Vulcan XC-72 using a rotating ring disk electrode (RRDE). (a) Disk current of the oxygen reduction reaction (ORR) as a function of potential (-0.2-0.8 V vs NHE) at rotation rates between 150-1250 RPM. (b) The inverse of these disk currents (1/i) as a function of the inverse squared rotation rate $\left(\omega^{-1 / 2}\right)$, which were used to extrapolate ORR current densities in the absence of mass transfer limitations at the y-intercept. (c) Apparent rate constants of the ORR as a function of the potential difference $\left(\Phi-\Phi^{0}\right)$ in the absence of mass transfer. (d) Disk and ring currents of the ORR as a function of potential (-0.2-0.8 V vs NHE) at a rotation rate of $500 \mathrm{rpm}$, which shows the relative rate of $\mathrm{H}_{2} \mathrm{O}_{2}$ and $\mathrm{H}_{2} \mathrm{O}$ formation. All RRDE measurements were conducted in an aqueous $0.1 \mathrm{M}$ $\mathrm{NaClO}_{4}$ solution sparged with $\mathrm{O}_{2}$ gas $(101 \mathrm{kPa}, 298 \mathrm{~K})$. 


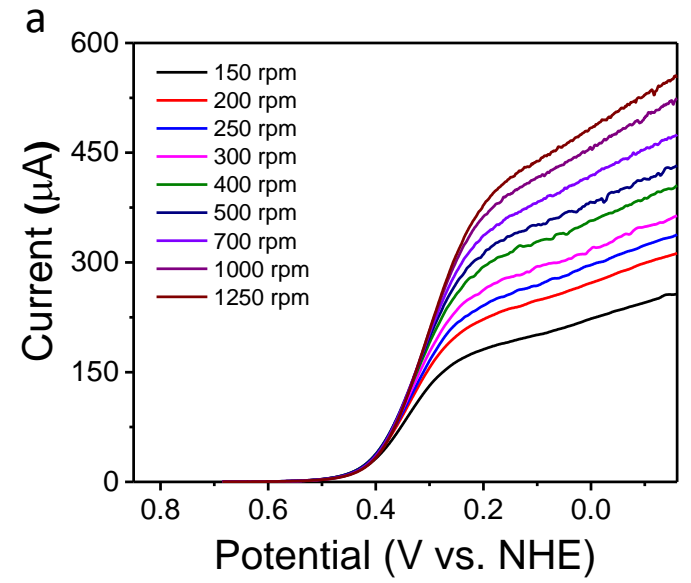

C

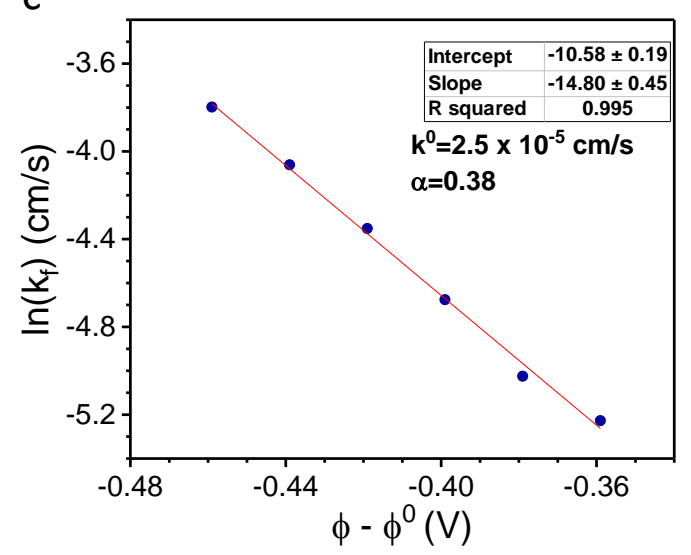

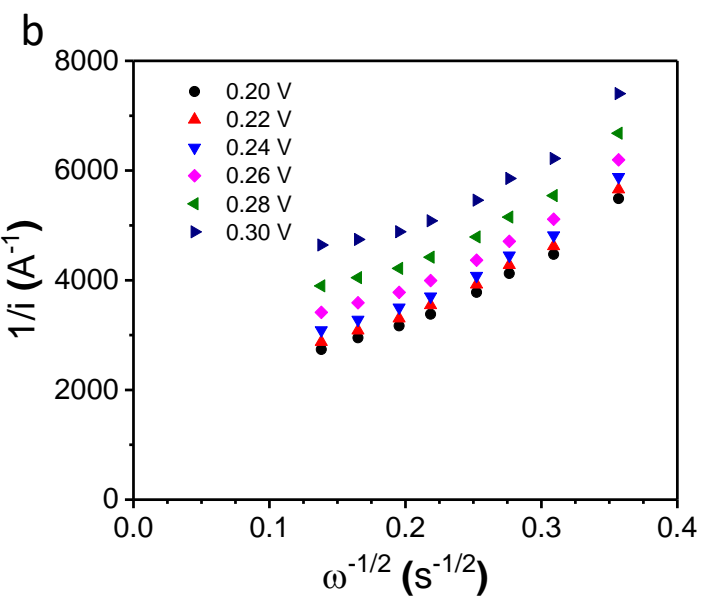

d

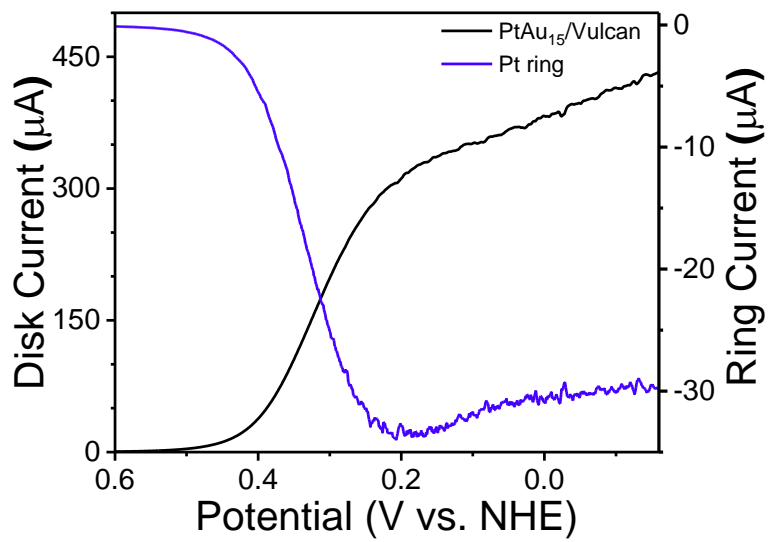

Figure S30: Electrochemical measurements of $\mathrm{Pt}_{1} \mathrm{Au}_{15}$ nanoparticles supported on Vulcan XC-72 using a rotating ring disk electrode (RRDE). (a) Disk current of the oxygen reduction reaction (ORR) as a function of potential (-0.2-0.6 V vs NHE) at rotation rates between 150-1250 RPM. (b) The inverse of these disk currents (1/i) as a function of the inverse squared rotation rate $\left(\omega^{-1 / 2}\right)$, which were used to extrapolate ORR current densities in the absence of mass transfer limitations at the y-intercept. (c) Apparent rate constants of the ORR as a function of the potential difference $\left(\Phi-\Phi^{0}\right)$ in the absence of mass transfer. (d) Disk and ring currents of the ORR as a function of potential (-0.2-0.6 V vs NHE) at a rotation rate of $500 \mathrm{rpm}$, which shows the relative rate of $\mathrm{H}_{2} \mathrm{O}_{2}$ and $\mathrm{H}_{2} \mathrm{O}$ formation. All RRDE measurements were conducted in an aqueous $0.1 \mathrm{M}$ $\mathrm{NaClO}_{4}$ solution sparged with $\mathrm{O}_{2}$ gas $(101 \mathrm{kPa}, 298 \mathrm{~K})$. 

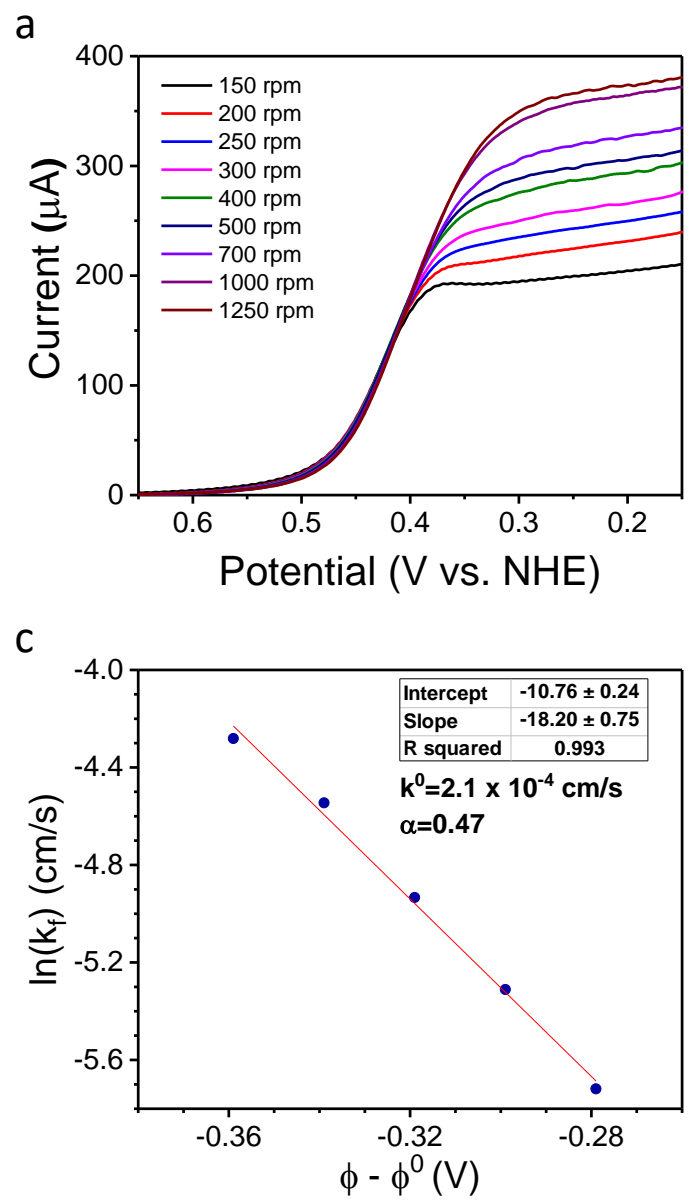

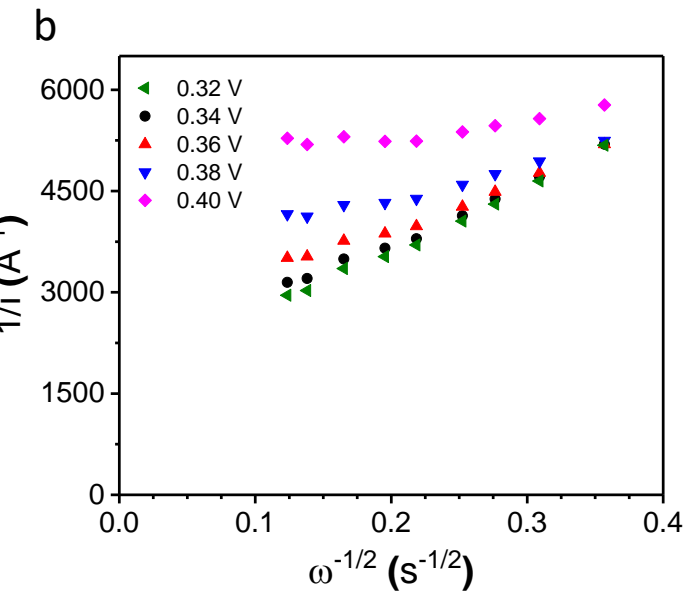

d

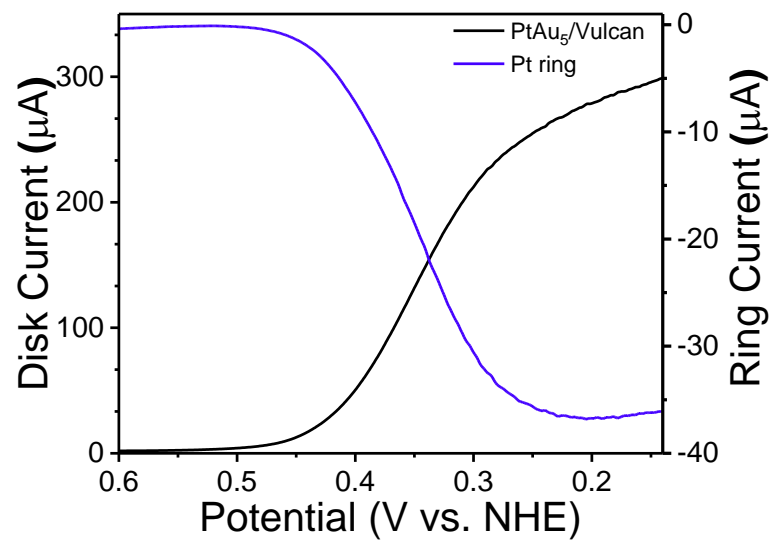

Figure S31: Electrochemical measurements of $\mathrm{Pt}_{1} \mathrm{Au}_{15}$ nanoparticles supported on Vulcan XC-72 using a rotating ring disk electrode (RRDE). (a) Disk current of the oxygen reduction reaction (ORR) as a function of potential (-0.2-0.7 V vs NHE) at rotation rates between 150-1250 RPM. (b) The inverse of these disk currents (1/i) as a function of the inverse squared rotation rate $\left(\omega^{-1 / 2}\right)$, which were used to extrapolate ORR current densities in the absence of mass transfer limitations at the $y$-intercept. (c) Apparent rate constants of the ORR as a function of the potential difference $\left(\Phi-\Phi^{0}\right)$ in the absence of mass transfer. (d) Disk and ring currents of the ORR as a function of potential (-0.2-0.7 V vs NHE) at a rotation rate of $500 \mathrm{rpm}$, which shows the relative rate of $\mathrm{H}_{2} \mathrm{O}_{2}$ and $\mathrm{H}_{2} \mathrm{O}$ formation. All RRDE measurements were conducted in an aqueous $0.1 \mathrm{M}$ $\mathrm{NaClO}_{4}$ solution sparged with $\mathrm{O}_{2}$ gas $(101 \mathrm{kPa}, 298 \mathrm{~K})$. 

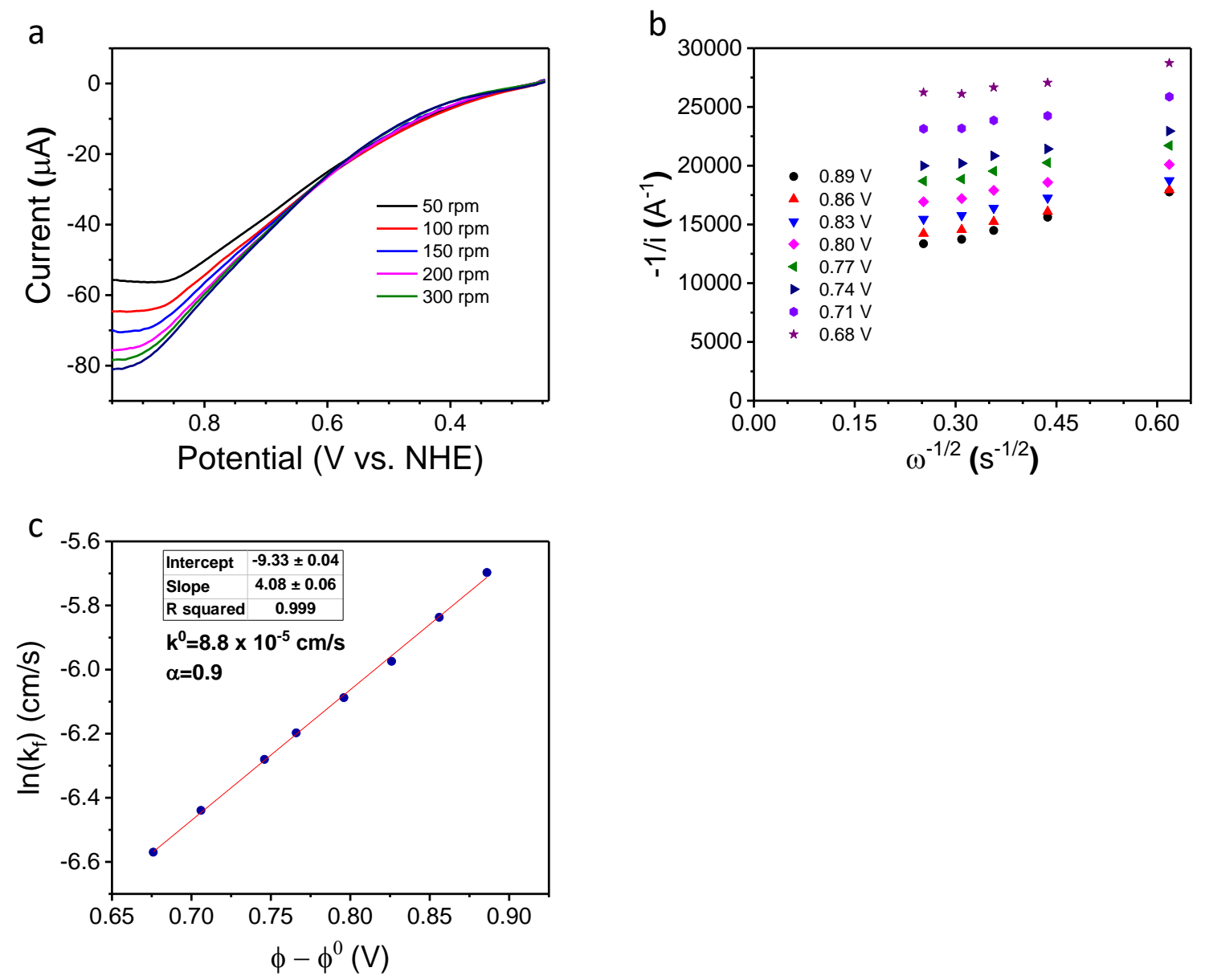

Figure S32: Electrochemical measurements of Pd nanoparticles supported on Vulcan XC-72 using a rotating ring disk electrode (RRDE). (a) Disk current of the hydrogen oxidation reaction (HOR) as a function of potential (0.2-1.0 V vs NHE) at rotation rates between 50-300 RPM. (b) The inverse of these disk currents $(1 / \mathrm{i})$ as a function of the inverse squared rotation rate $\left(\omega^{-1 / 2}\right)$, which were used to extrapolate HOR current densities in the absence of mass transfer limitations at the y-intercept. (c) Apparent rate constants of the HOR as a function of the potential difference $(\Phi-$ $\left.\Phi^{0}\right)$ in the absence of mass transfer. All RRDE measurements were conducted in an aqueous 0.1 $\mathrm{M} \mathrm{NaClO}_{4}$ solution sparged with $\mathrm{H}_{2}$ gas $(101 \mathrm{kPa}, 298 \mathrm{~K})$. 

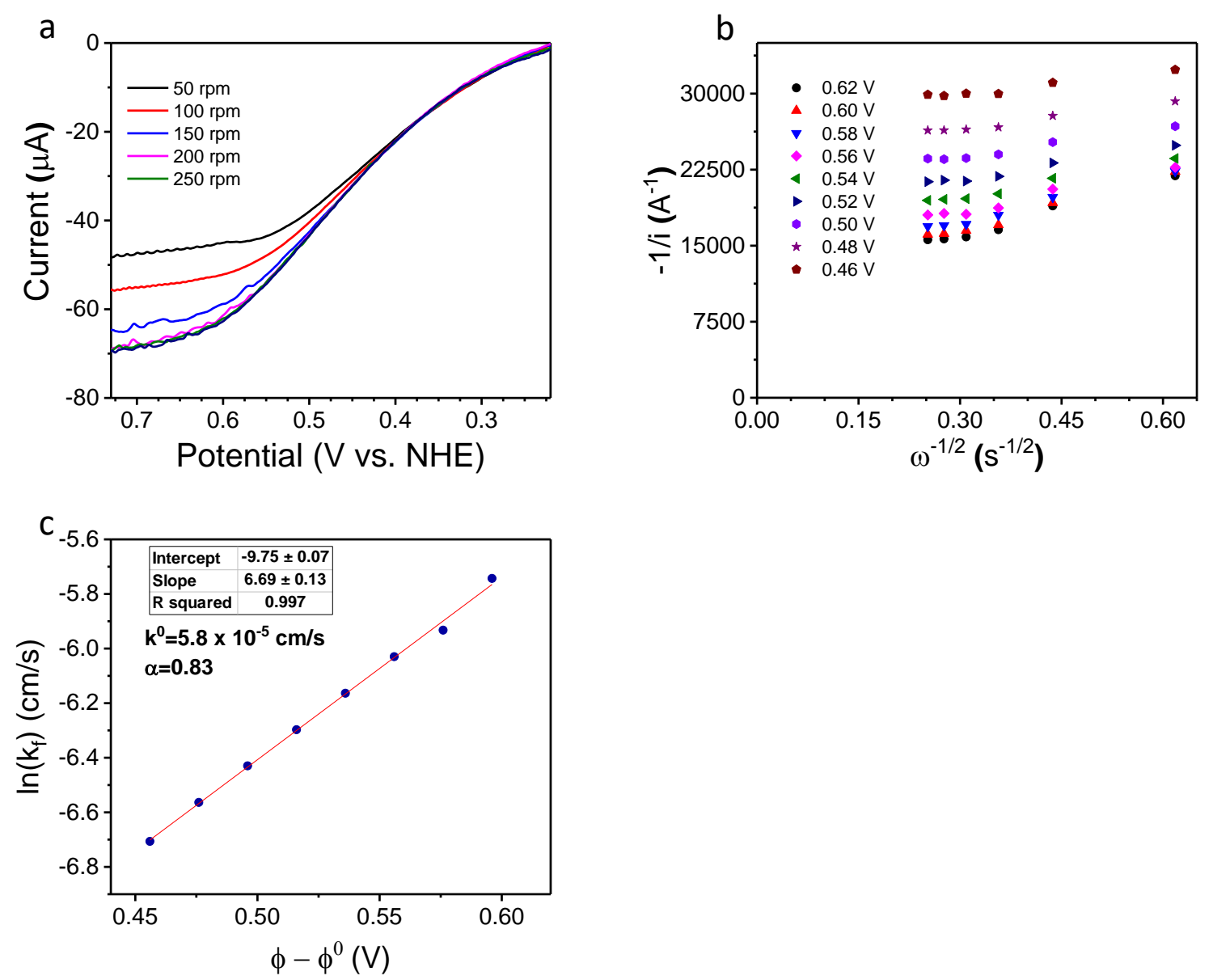

Figure S33: Electrochemical measurements of PdCo nanoparticles supported on Vulcan XC-72 using a rotating ring disk electrode (RRDE). (a) Disk current of the hydrogen oxidation reaction (HOR) as a function of potential (0.2-0.7 V vs NHE) at rotation rates between 50-250 RPM. (b) The inverse of these disk currents $(1 / \mathrm{i})$ as a function of the inverse squared rotation rate $\left(\omega^{-1 / 2}\right)$, which were used to extrapolate HOR current densities in the absence of mass transfer limitations at the y-intercept. (c) Apparent rate constants of the HOR as a function of the potential difference $\left(\Phi-\Phi^{0}\right)$ in the absence of mass transfer. All RRDE measurements were conducted in an aqueous $0.1 \mathrm{M} \mathrm{NaClO}_{4}$ solution sparged with $\mathrm{H}_{2}$ gas $(101 \mathrm{kPa}, 298 \mathrm{~K})$. 

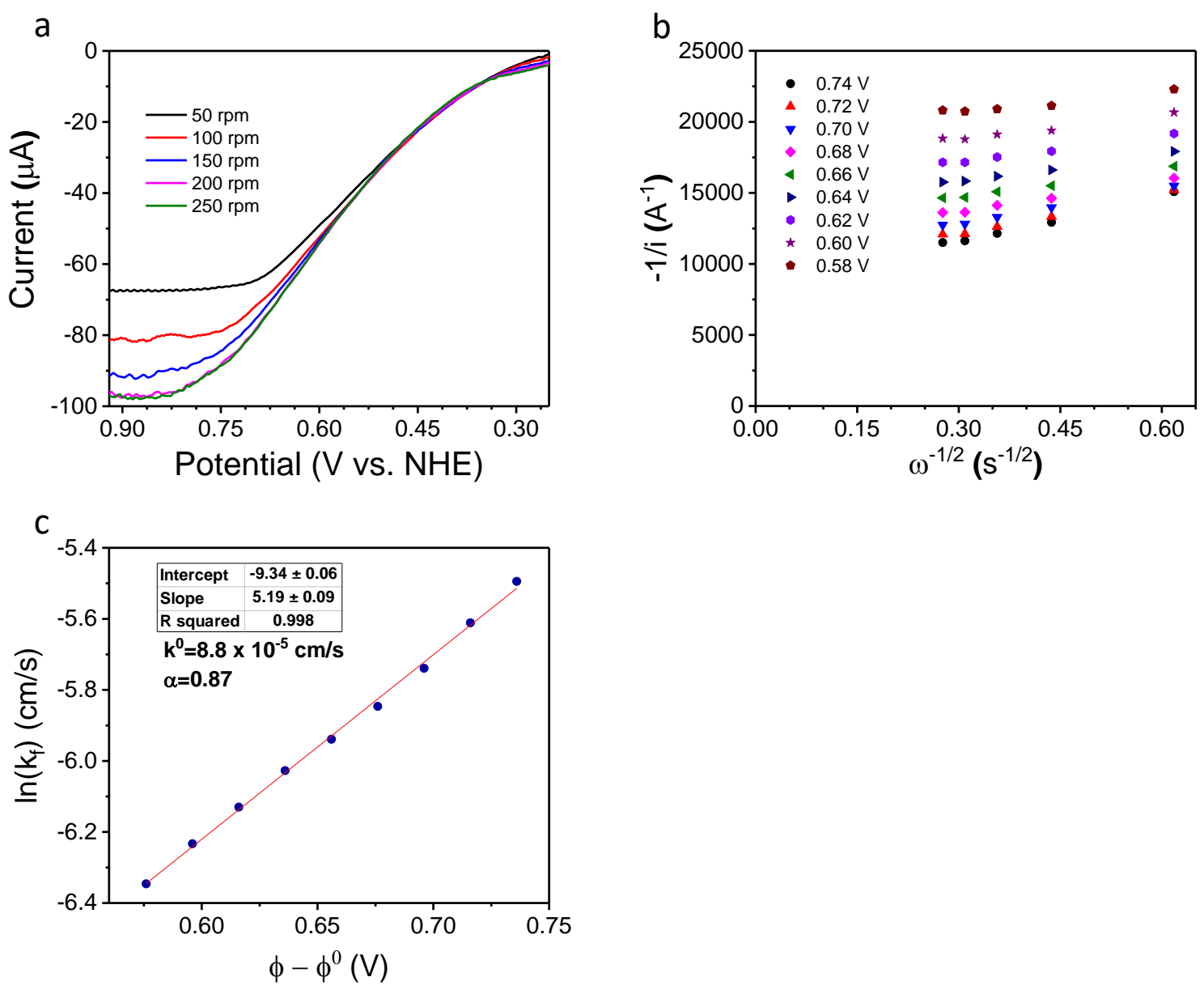

Figure S34: Electrochemical measurements of PdNi nanoparticles supported on Vulcan XC-72 using a rotating ring disk electrode (RRDE). (a) Disk current of the hydrogen oxidation reaction (HOR) as a function of potential (0.2-0.9 V vs NHE) at rotation rates between 50-250 RPM. (b) The inverse of these disk currents $(1 / \mathrm{i})$ as a function of the inverse squared rotation rate $\left(\omega^{-1 / 2}\right)$, which were used to extrapolate HOR current densities in the absence of mass transfer limitations at the y-intercept. (c) Apparent rate constants of the HOR as a function of the potential difference $\left(\Phi-\Phi^{0}\right)$ in the absence of mass transfer. All RRDE measurements were conducted in an aqueous $0.1 \mathrm{M} \mathrm{NaClO}_{4}$ solution sparged with $\mathrm{H}_{2}$ gas $(101 \mathrm{kPa}, 298 \mathrm{~K})$. 

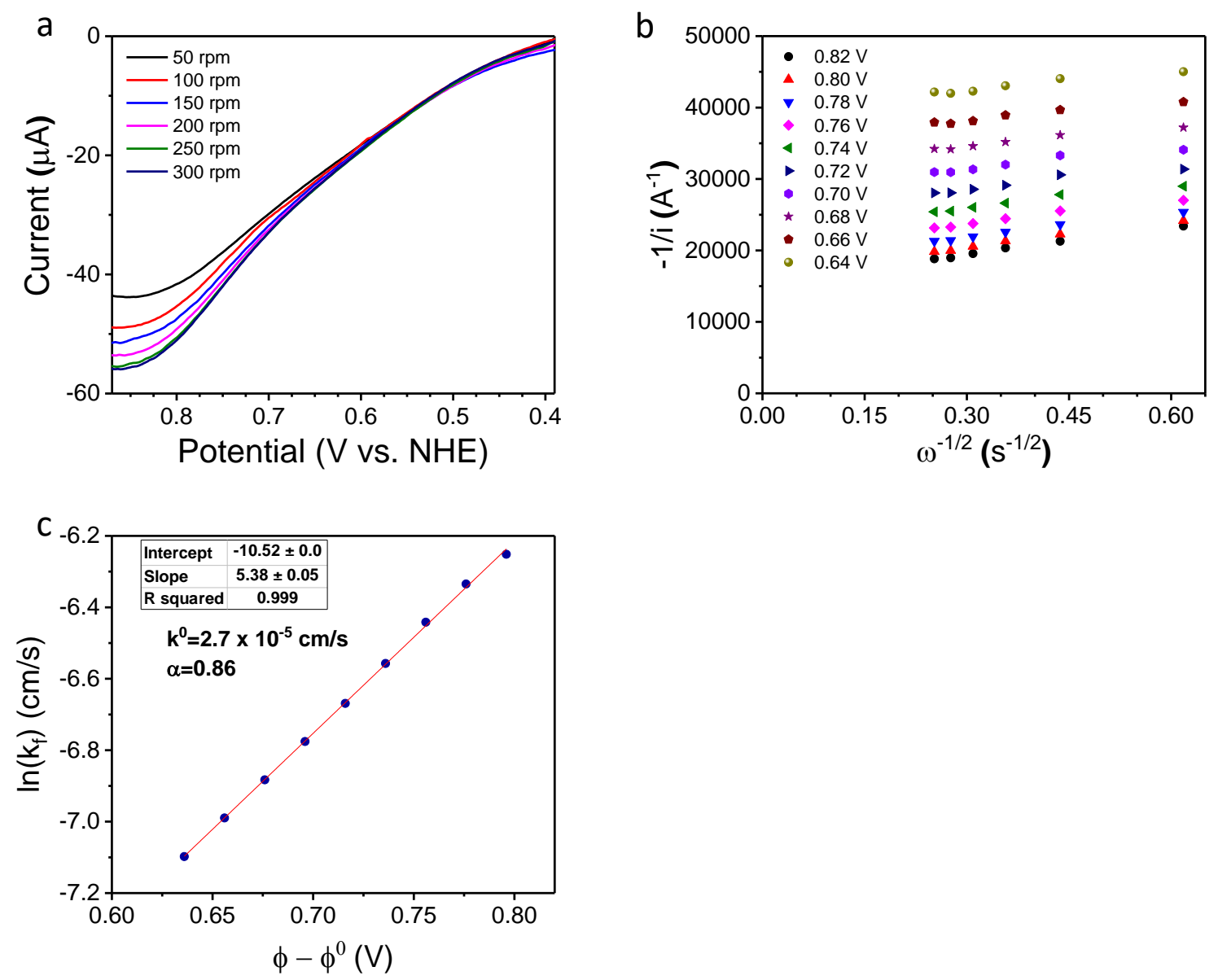

Figure S35: Electrochemical measurements of PdZn nanoparticles supported on Vulcan XC-72 using a rotating ring disk electrode (RRDE). (a) Disk current of the hydrogen oxidation reaction (HOR) as a function of potential (0.4-0.9 V vs NHE) at rotation rates between 50-300 RPM. (b) The inverse of these disk currents $(1 / \mathrm{i})$ as a function of the inverse squared rotation rate $\left(\omega^{-1 / 2}\right)$, which were used to extrapolate HOR current densities in the absence of mass transfer limitations at the y-intercept. (c) Apparent rate constants of the HOR as a function of the potential difference $\left(\Phi-\Phi^{0}\right)$ in the absence of mass transfer. All RRDE measurements were conducted in an aqueous $0.1 \mathrm{M} \mathrm{NaClO}_{4}$ solution sparged with $\mathrm{H}_{2}$ gas $(101 \mathrm{kPa}, 298 \mathrm{~K})$. 

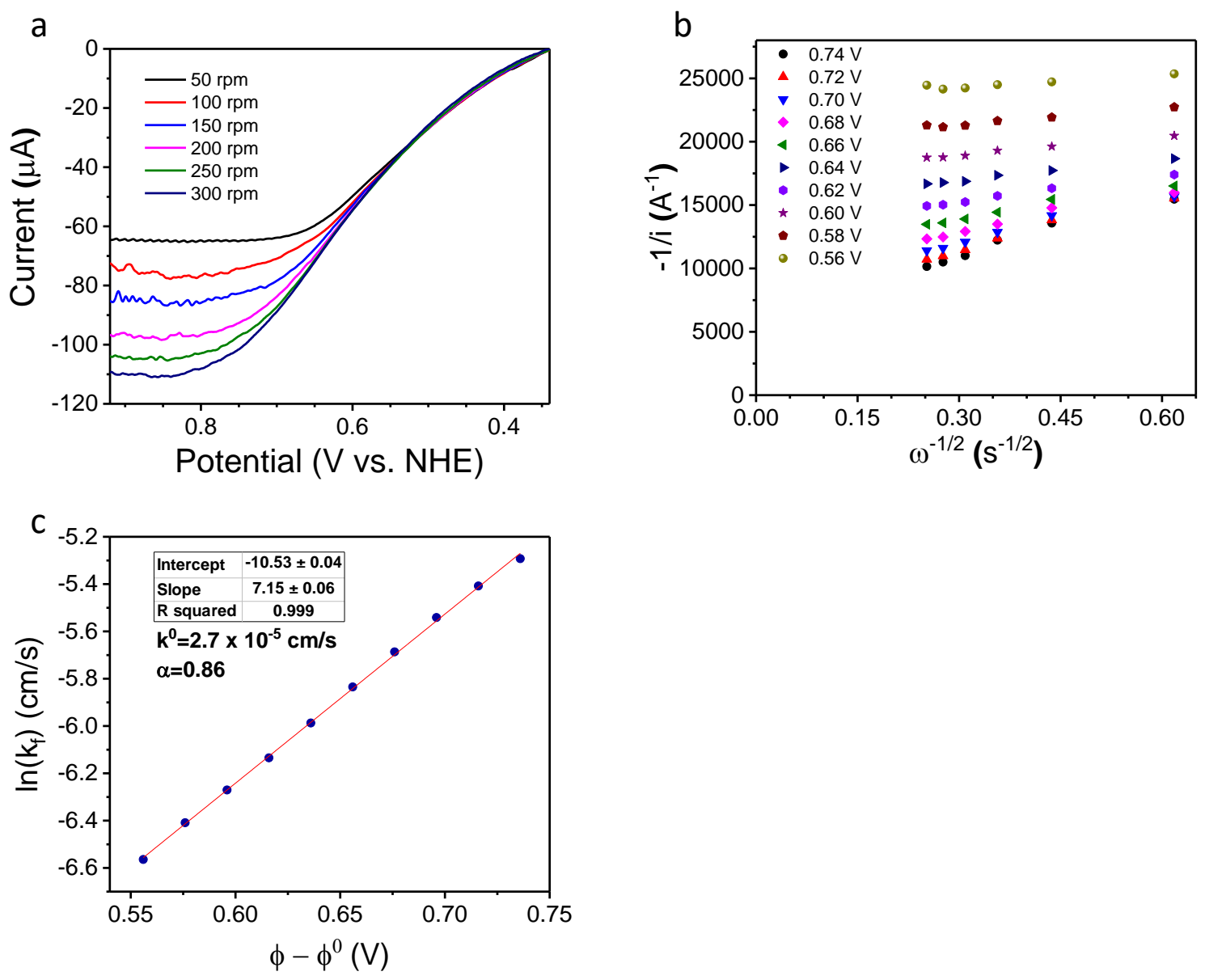

Figure S36: Electrochemical measurements of $\mathrm{PdCu}$ nanoparticles supported on Vulcan XC-72 using a rotating ring disk electrode (RRDE). (a) Disk current of the hydrogen oxidation reaction (HOR) as a function of potential (0.2-1.0 V vs NHE) at rotation rates between 50-250 RPM. (b) The inverse of these disk currents $(1 / \mathrm{i})$ as a function of the inverse squared rotation rate $\left(\omega^{-1 / 2}\right)$, which were used to extrapolate HOR current densities in the absence of mass transfer limitations at the y-intercept. (c) Apparent rate constants of the HOR as a function of the potential difference $\left(\Phi-\Phi^{0}\right)$ in the absence of mass transfer. All RRDE measurements were conducted in an aqueous $0.1 \mathrm{M} \mathrm{NaClO}_{4}$ solution sparged with $\mathrm{H}_{2}$ gas $(101 \mathrm{kPa}, 298 \mathrm{~K})$. 

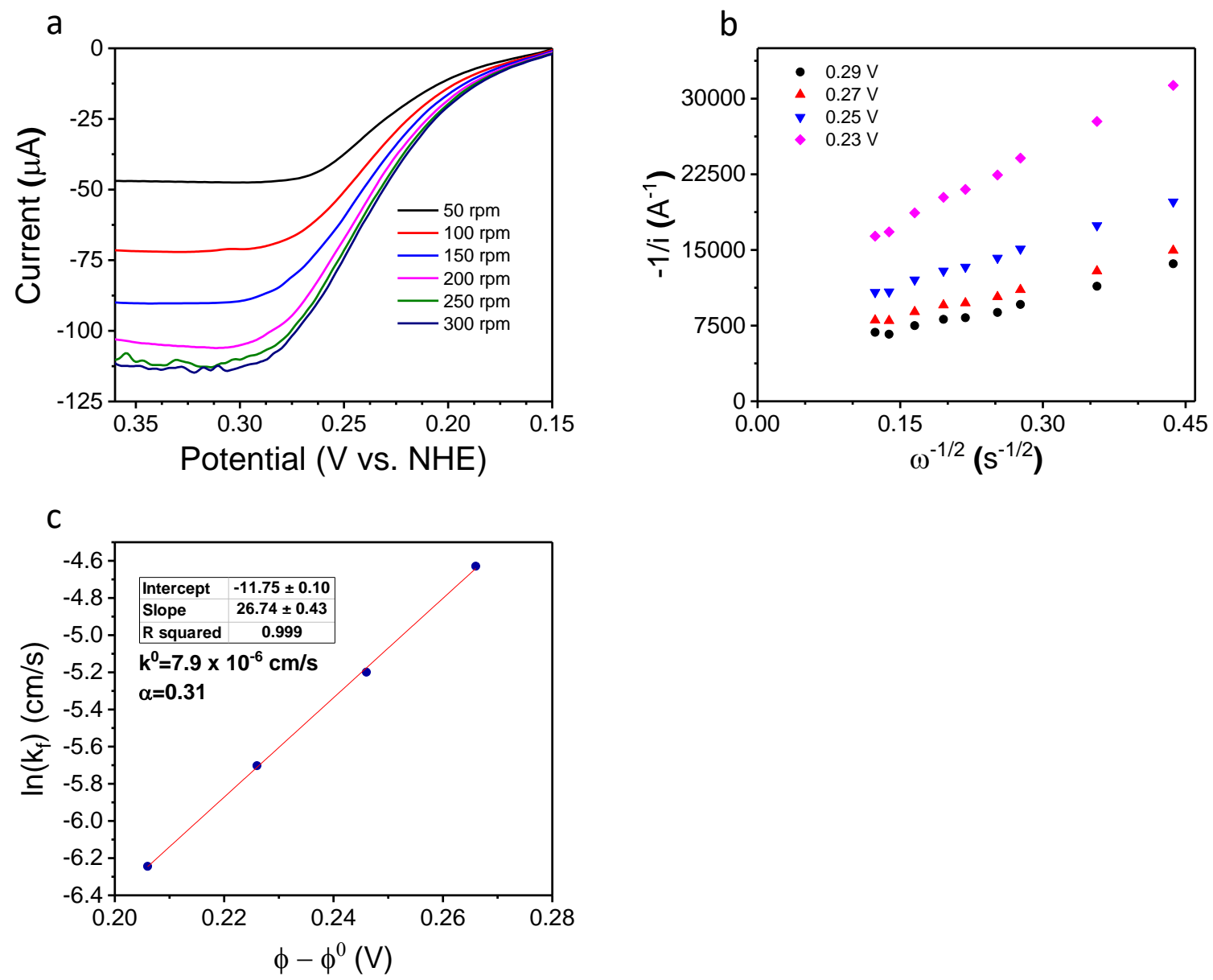

Figure S37: Electrochemical measurements of Pt nanoparticles supported on Vulcan XC-72 using a rotating ring disk electrode (RRDE). (a) Disk current of the hydrogen oxidation reaction (HOR) as a function of potential (0.15-0.35 V vs NHE) at rotation rates between 50-300 RPM. (b) The inverse of these disk currents $(1 / \mathrm{i})$ as a function of the inverse squared rotation rate $\left(\omega^{-1 / 2}\right)$, which were used to extrapolate HOR current densities in the absence of mass transfer limitations at the $y$-intercept. (c) Apparent rate constants of the HOR as a function of the potential difference ( $\Phi-$ $\left.\Phi^{0}\right)$ in the absence of mass transfer. All RRDE measurements were conducted in an aqueous 0.1 $\mathrm{M} \mathrm{NaClO}_{4}$ solution sparged with $\mathrm{H}_{2}$ gas $(101 \mathrm{kPa}, 298 \mathrm{~K})$. 

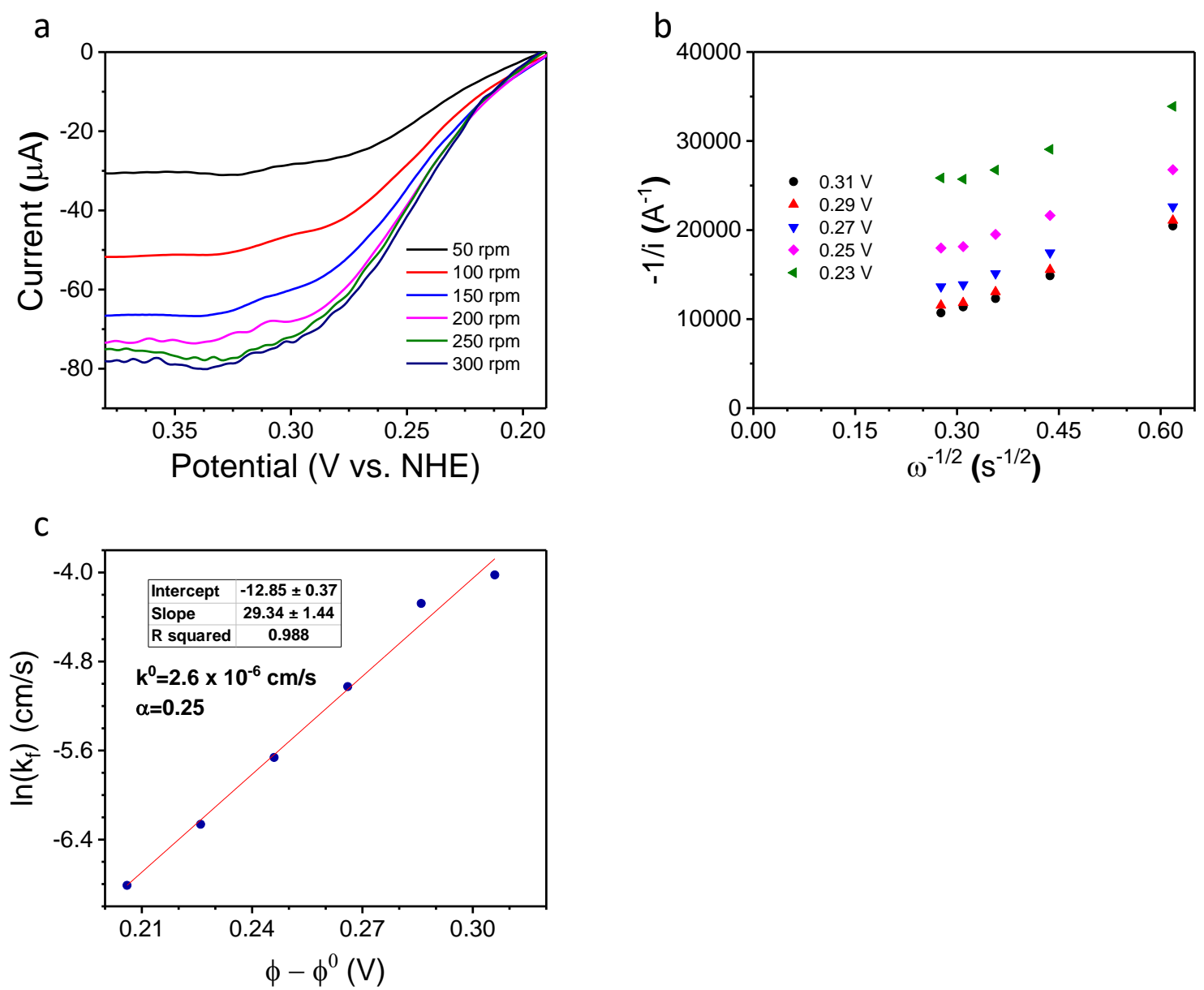

Figure S38: Electrochemical measurements of PdPt nanoparticles supported on Vulcan XC-72 using a rotating ring disk electrode (RRDE). (a) Disk current of the hydrogen oxidation reaction (HOR) as a function of potential (0.2-0.4 V vs NHE) at rotation rates between 50-300 RPM. (b) The inverse of these disk currents $(1 / \mathrm{i})$ as a function of the inverse squared rotation rate $\left(\omega^{-1 / 2}\right)$, which were used to extrapolate HOR current densities in the absence of mass transfer limitations at the y-intercept. (c) Apparent rate constants of the HOR as a function of the potential difference $\left(\Phi-\Phi^{0}\right)$ in the absence of mass transfer. All RRDE measurements were conducted in an aqueous $0.1 \mathrm{M} \mathrm{NaClO}_{4}$ solution sparged with $\mathrm{H}_{2}$ gas $(101 \mathrm{kPa}, 298 \mathrm{~K})$. 

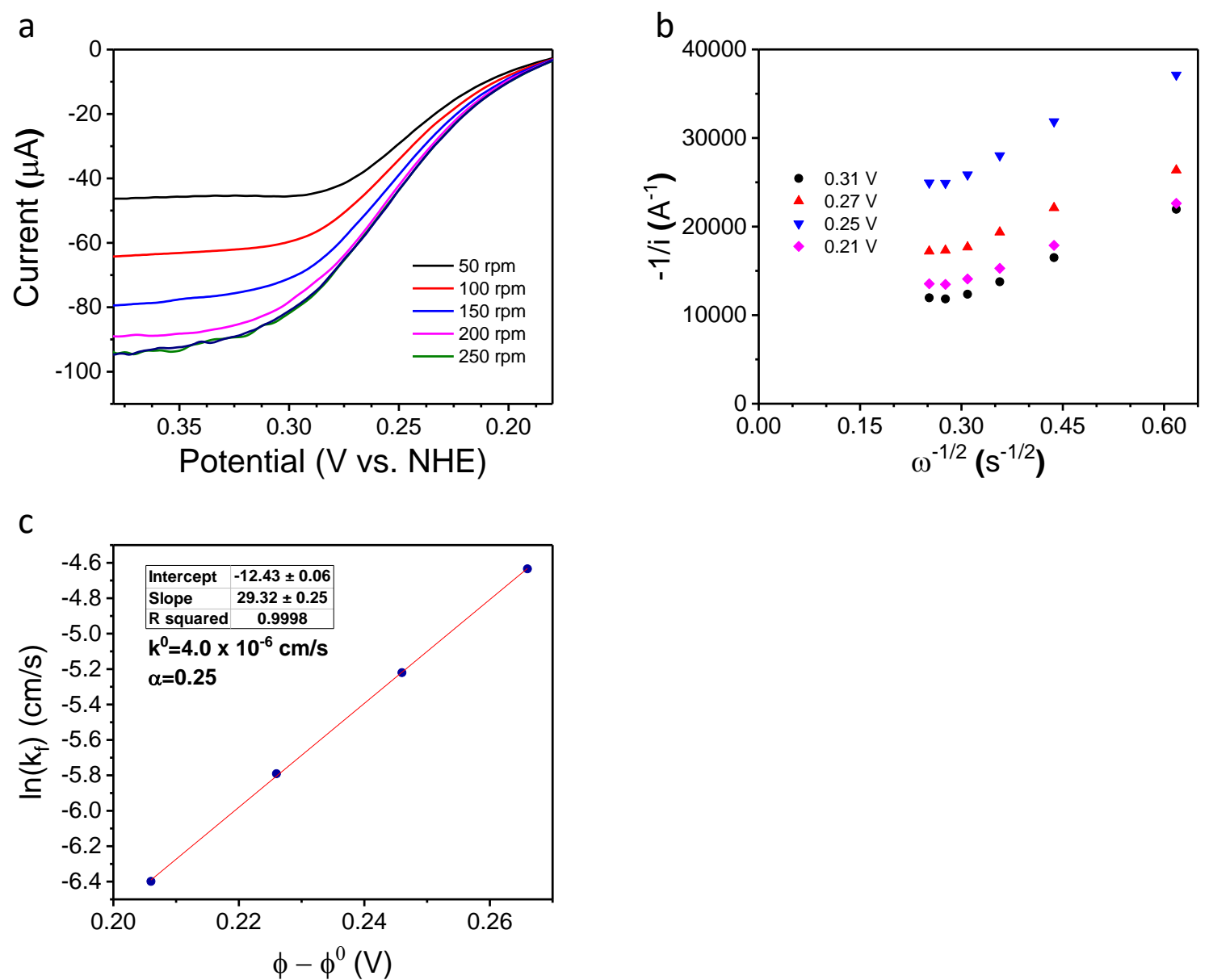

Figure S39: Electrochemical measurements of PtCo nanoparticles supported on Vulcan XC-72 using a rotating ring disk electrode (RRDE). (a) Disk current of the hydrogen oxidation reaction (HOR) as a function of potential (0.2-0.4 V vs NHE) at rotation rates between 50-250 RPM. (b) The inverse of these disk currents $(1 / \mathrm{i})$ as a function of the inverse squared rotation rate $\left(\omega^{-1 / 2}\right)$, which were used to extrapolate HOR current densities in the absence of mass transfer limitations at the y-intercept. (c) Apparent rate constants of the HOR as a function of the potential difference $\left(\Phi-\Phi^{0}\right)$ in the absence of mass transfer. All RRDE measurements were conducted in an aqueous $0.1 \mathrm{M} \mathrm{NaClO}_{4}$ solution sparged with $\mathrm{H}_{2}$ gas $(101 \mathrm{kPa}, 298 \mathrm{~K})$. 

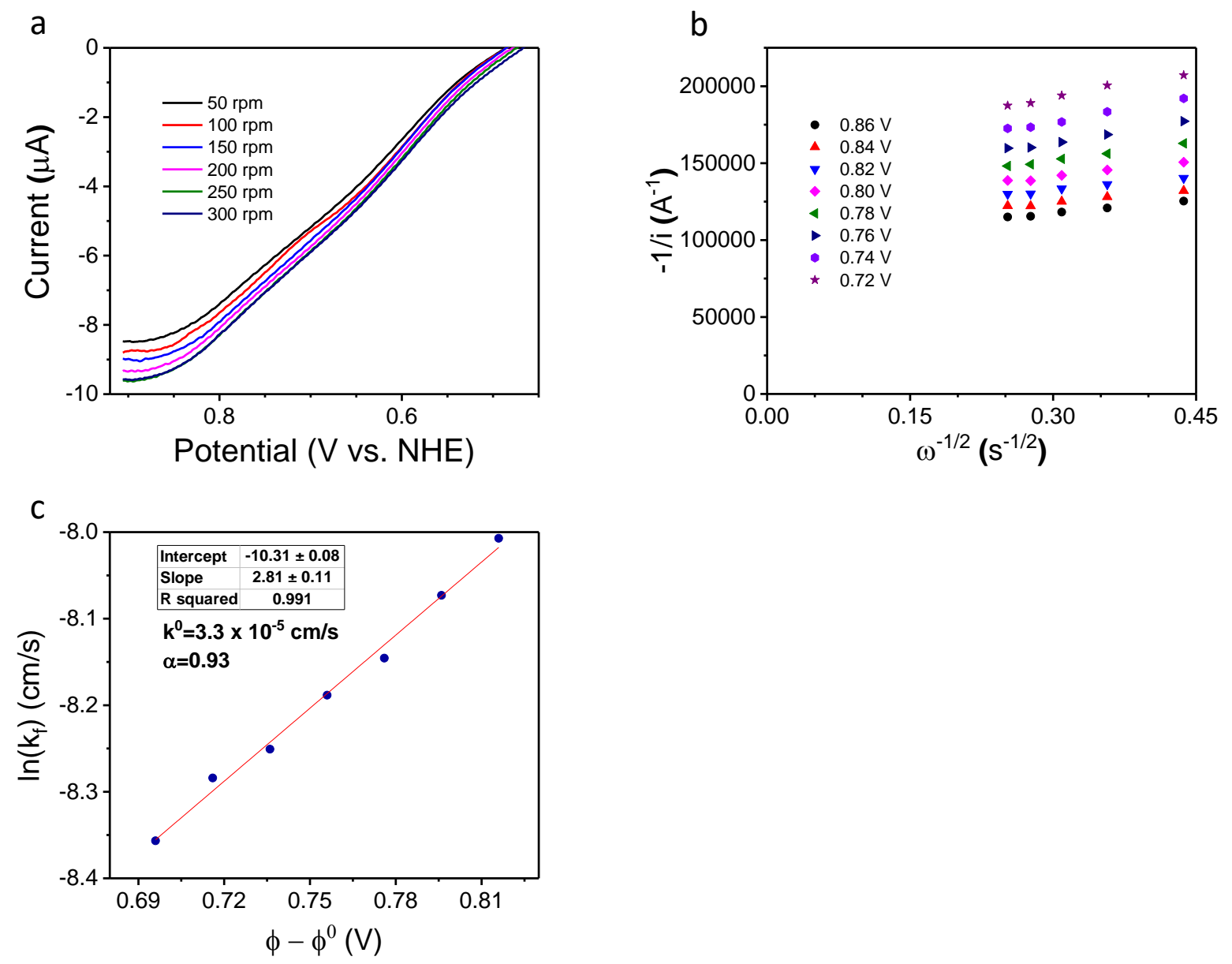

Figure S40: Electrochemical measurements of $\mathrm{Pd}_{1} \mathrm{Au}_{60}$ nanoparticles supported on Vulcan $\mathrm{XC}$ 72 using a rotating ring disk electrode (RRDE). (a) Disk current of the hydrogen oxidation reaction (HOR) as a function of potential (0.2-1.0 V vs NHE) at rotation rates between 50-300 RPM. (b) The inverse of these disk currents $(1 / \mathrm{i})$ as a function of the inverse squared rotation rate $\left(\omega^{-1 / 2}\right)$, which were used to extrapolate HOR current densities in the absence of mass transfer limitations at the y-intercept. (c) Apparent rate constants of the HOR as a function of the potential difference $\left(\Phi-\Phi^{0}\right)$ in the absence of mass transfer. All RRDE measurements were conducted in an aqueous $0.1 \mathrm{M} \mathrm{NaClO}_{4}$ solution sparged with $\mathrm{H}_{2}$ gas $(101 \mathrm{kPa}, 298 \mathrm{~K})$. 

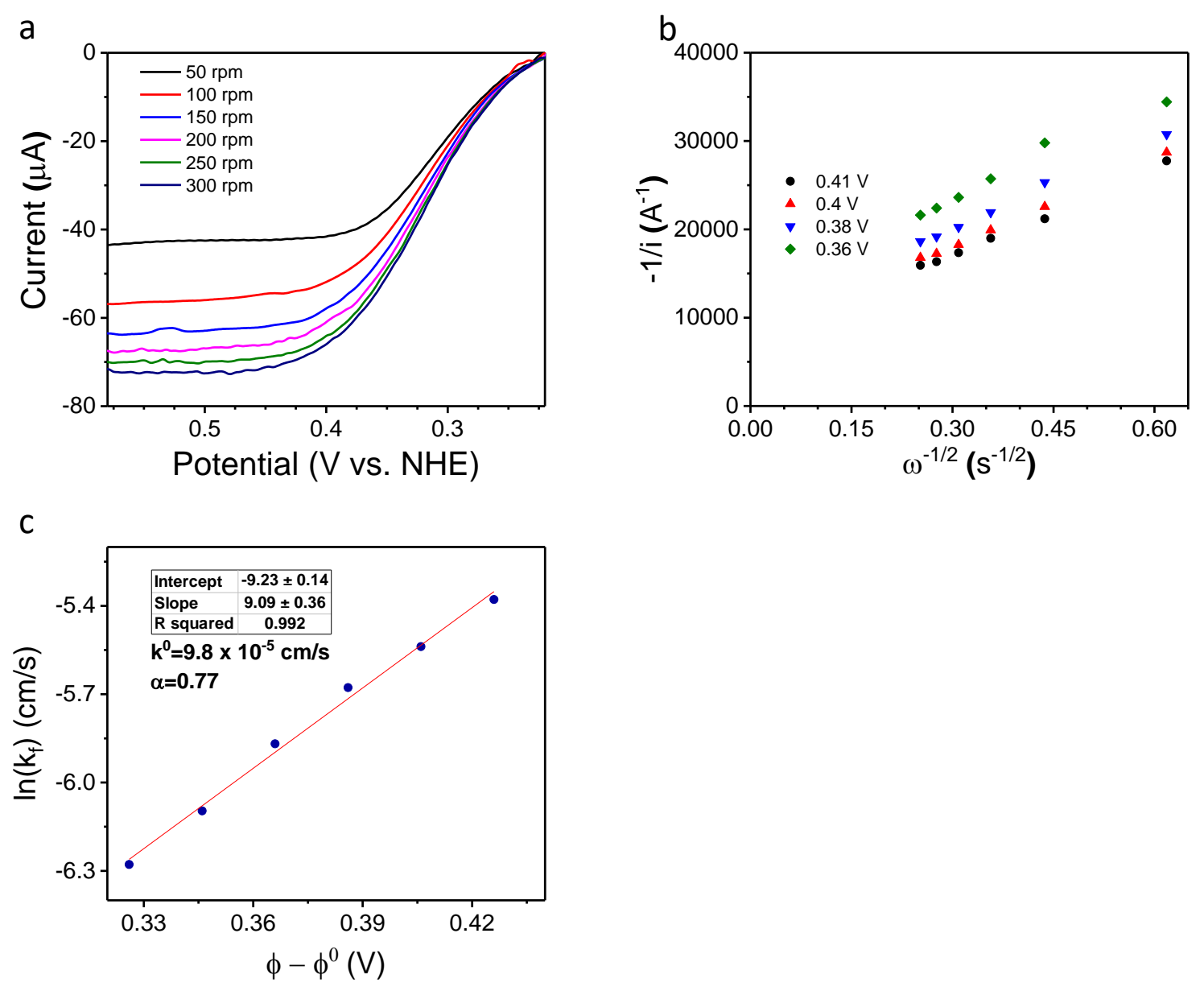

Figure S41: Electrochemical measurements of $\mathrm{Pt}_{1} \mathrm{Au}_{60}$ nanoparticles supported on Vulcan XC-72 using a rotating ring disk electrode (RRDE). (a) Disk current of the hydrogen oxidation reaction (HOR) as a function of potential (0.2-0.6 V vs NHE) at rotation rates between 50-300 RPM. (b) The inverse of these disk currents $(1 / \mathrm{i})$ as a function of the inverse squared rotation rate $\left(\omega^{-1 / 2}\right)$, which were used to extrapolate HOR current densities in the absence of mass transfer limitations at the y-intercept. (c) Apparent rate constants of the HOR as a function of the potential difference $\left(\Phi-\Phi^{0}\right)$ in the absence of mass transfer. All RRDE measurements were conducted in an aqueous $0.1 \mathrm{M} \mathrm{NaClO}_{4}$ solution sparged with $\mathrm{H}_{2}$ gas $(101 \mathrm{kPa}, 298 \mathrm{~K})$. 

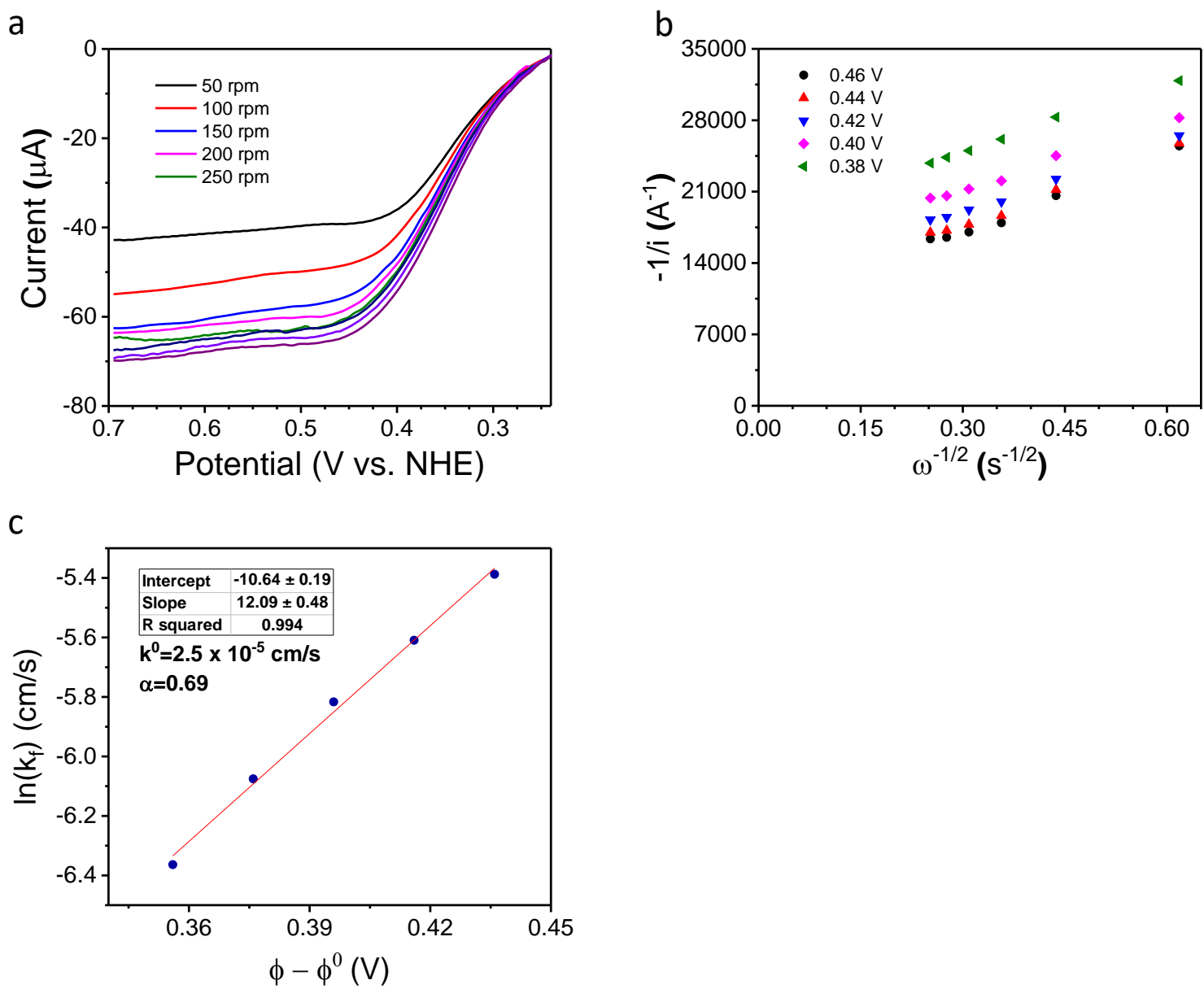

Figure S42: Electrochemical measurements of $\mathrm{Pt}_{1} \mathrm{Au}_{15}$ nanoparticles supported on Vulcan XC-72 using a rotating ring disk electrode (RRDE). (a) Disk current of the hydrogen oxidation reaction (HOR) as a function of potential (0.2-0.7 V vs NHE) at rotation rates between 50-250 RPM. (b) The inverse of these disk currents $(1 / \mathrm{i})$ as a function of the inverse squared rotation rate $\left(\omega^{-1 / 2}\right)$, which were used to extrapolate HOR current densities in the absence of mass transfer limitations at the y-intercept. (c) Apparent rate constants of the HOR as a function of the potential difference $\left(\Phi-\Phi^{0}\right)$ in the absence of mass transfer. All RRDE measurements were conducted in an aqueous $0.1 \mathrm{M} \mathrm{NaClO}_{4}$ solution sparged with $\mathrm{H}_{2}$ gas $(101 \mathrm{kPa}, 298 \mathrm{~K})$. 

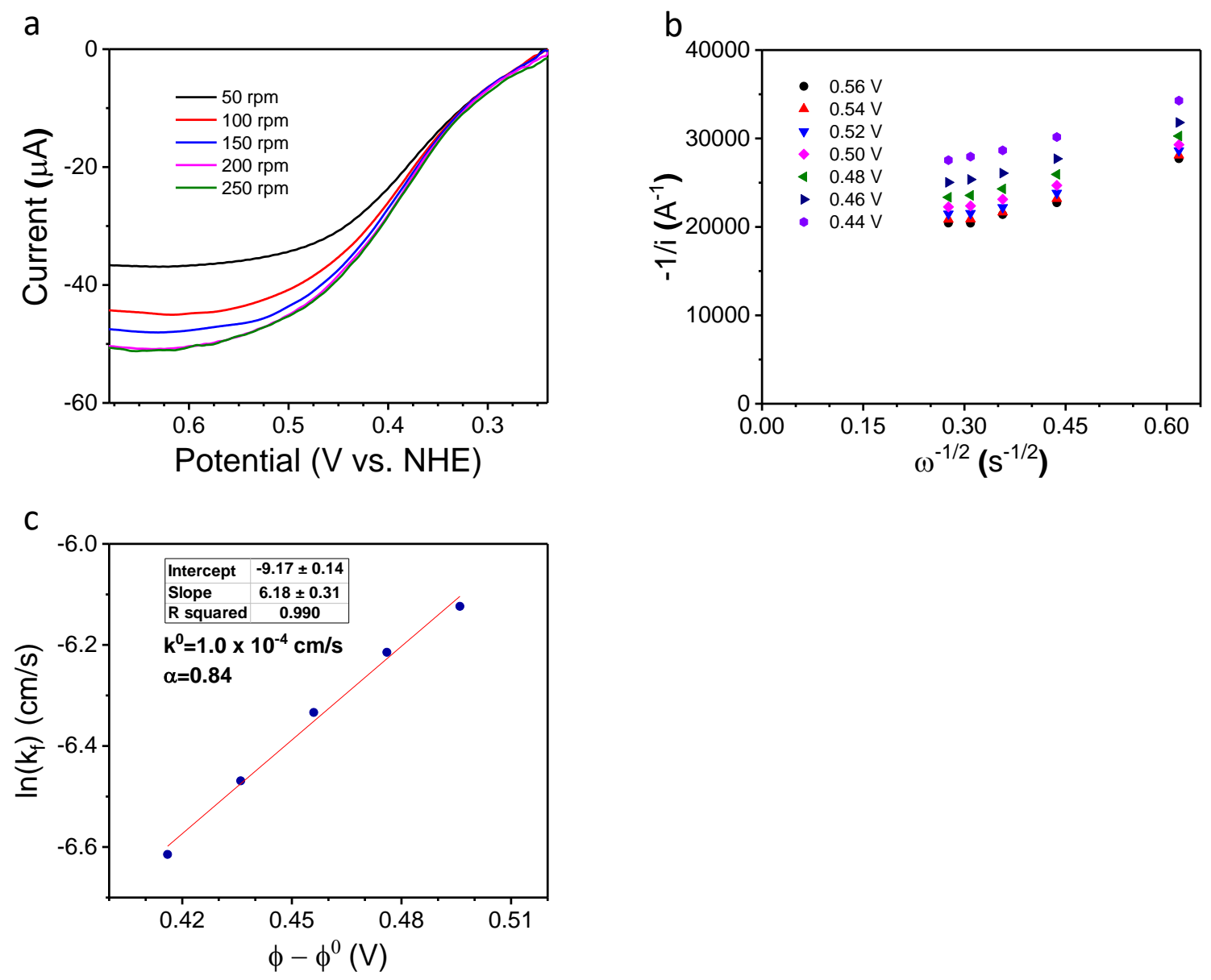

Figure S43: Electrochemical measurements of $\mathrm{Pt}_{1} \mathrm{Au}_{5}$ nanoparticles supported on Vulcan XC-72 using a rotating ring disk electrode (RRDE). (a) Disk current of the hydrogen oxidation reaction (HOR) as a function of potential (0.2-0.7 V vs NHE) at rotation rates between 50-250 RPM. (b) The inverse of these disk currents $(1 / \mathrm{i})$ as a function of the inverse squared rotation rate $\left(\omega^{-1 / 2}\right)$, which were used to extrapolate HOR current densities in the absence of mass transfer limitations at the y-intercept. (c) Apparent rate constants of the HOR as a function of the potential difference $\left(\Phi-\Phi^{0}\right)$ in the absence of mass transfer. All RRDE measurements were conducted in an aqueous $0.1 \mathrm{M} \mathrm{NaClO}_{4}$ solution sparged with $\mathrm{H}_{2}$ gas $(101 \mathrm{kPa}, 298 \mathrm{~K})$. 


\section{S6. Derivation of Hydrogen Coverage by Adsorption, Oxidation, and Reduction Paths}

The adsorption and oxidation of hydrogen on noble metal surfaces are commonly described by Heyrovsky, Tafel, and Volmer kinetics in electrochemical studies of the HOR of platinum-group metals. ${ }^{3}$ In these treatments, hydrogen adsorbs onto the metal surface and reacts with water to form protons and electrons, but the precise molecular actions of these reactions are unclear. Indeed, there is no clear consensus regarding which of these reactions is dominant, and all three steps could be rate-determining depending on the $\mathrm{pH}$, reaction potential, hydrogen coverage, and metal identity ${ }^{4-9}$ Thus, each step may simplify depending on the conditions or material considered. As such, we present each reaction in a general reversible form in Scheme S6.1 below:

$$
\begin{aligned}
\mathrm{H}_{2}+\square+\mathrm{H}_{2} \mathrm{O} & \rightleftarrows \mathrm{H}^{\square}+\mathrm{e}^{-}+\mathrm{H}_{3} \mathrm{O}^{+} \\
\mathrm{H}_{2}+2 \square & \rightleftarrows 2 \mathrm{H}^{\square} \\
\mathrm{H}^{\square}+\mathrm{H}_{2} \mathrm{O} & \rightleftarrows \mathrm{e}^{-}+\square+\mathrm{H}_{3} \mathrm{O}^{+}
\end{aligned}
$$

Scheme S6.1. Elementary reactions for the Heyrovsky (Step 1), Tafel (Step 2), Volmer (step 3) reactions. In this scheme, $\square$ denotes reactive sites that are not occupied by hydrogen, while $\mathrm{H}^{\square}$ denotes hydrogen adsorbed in these sites. The symbols $\rightleftarrows$ indicates that the elementary reaction is reversible depending on the reaction conditions.

The elementary steps shown in Scheme S6.1 show that hydrogen adsorbs to unoccupied sites ( $\square$ ) through concerted adsorption and proton-electron transfer (step 1) or homolytic adsorption (step 2). Water molecules then oxidize adsorbed hydrogen $\left(\mathrm{H}^{\square}\right)$ to generate hydronium ions in solution and electrons in the nanoparticle (step 3). The Heyrovsky (Step 1) and Volmer (step 3) reactions are reversible, and the forward and reverse rates depend strongly on the potential $(\Phi)$ of the nanoparticle. ${ }^{5,7,8,10}$ Note, that this scheme makes no assumptions regarding which reaction dominates, and we will consider how each reaction may change under the conditions investigated in this study.

Under electrocatalytic conditions, an electrode controls the electrical potential of the nanoparticle, and most studies conduct measurements in the absence of oxygen. In such a case, investigators propose that the adsorption steps ( 1 and 2 ) are rate-determining in the HOR since these initial steps can present a greater apparent barrier than the subsequent oxidation step (step 3), which by comparison, has a lower energy reactant state on a clean surface. ${ }^{8}$ Past reports indicate that the potential-dependent Heyrovsky step should dominate at higher overpotentials (greater by $50 \mathrm{mV}$ on Pt electrodes). ${ }^{9,}{ }^{10}$ In contrast, the potential-independent Tafel step should dominate at lower potentials due to its lower intrinsic barrier on Pt group metals. ${ }^{8}$ Still, experimental evidence suggests that the rate of hydrogen oxidation is a strong function of the hydrogen binding energy and the $\mathrm{pH}$, which supports the Volmer step as the kinetically relevant reaction. ${ }^{5}$ Indeed, if the ground state energy of a hydrogen atom is sufficiently high or if the surface is saturated by hydrogen, then step 3 will present the greatest apparent barrier and dominate the reaction rate. ${ }^{10}$ It is also possible that the different facets (e.g., 111,110, and 100) of the nanoparticle favor different reactions, which further complicates the dominant mechanism. ${ }^{11}$ Therefore, each of these mechanisms can be kinetically relevant, and so we consider the implications of each elementary step on the apparent rate expression. 
Under direct synthesis conditions, the operating potential $\left(\Phi^{o p}\right)$ of the material depends on the coupled electron transfer of hydrogen and oxygen species, which results in a narrow range of potentials (0.3-0.65 V vs. NHE) that the material operates (Figure 3). Similarly, the catalytic surfaces likely contain significant coverage of oxygen-derived intermediates that may influence the reaction barriers in ways that typical studies of the HOR do not capture. ${ }^{12}$ In this work, we observe that each material operates at an open circuit potential that is too positive (0.35-0.65 V vs. NHE) to appreciably oxidize hydronium ions in solution (-0.1 V vs. NHE on Pd, Figure S58). Similarly, high coverages of oxygen-derived intermediates will destabilize the ground states of adsorbed hydrogen species. ${ }^{12}$ Therefore, steps 1 and 3 are likely irreversible under direct synthesis conditions at low coverages of hydrogen and a neutral $\mathrm{pH}(\sim 7)$. In contrast, the Tafel step (step 2) is independent of potential, ${ }^{8,10}$ and its reversibility depends on the coverage of hydrogen on the surface. ${ }^{13}$ Specifically, past studies report that the rate of hydrogen-deuterium scrambling on $\mathrm{Pd}$ is quasi-equilibrated at the highest ratios of $\mathrm{H}_{2} / \mathrm{O}_{2}(>3: 1) .{ }^{14}$ At the lowest pressures of $\mathrm{H}_{2}$, however, the adsorption of hydrogen becomes irreversible. Thus, at low coverages of $\mathrm{H}^{\square}$, most of the hydrogen is consumed by electron transfer reactions, while at the highest coverages, there is a greater probability that surface hydrogen reacts with itself to regenerate gaseous $\mathrm{H}_{2}$.

Overall, it is clear that the net rate and direction of these reactions is a strong function of electrical potential, $\mathrm{pH}$, and the activity of hydrogen $\left(\left[\mathrm{H}_{2}\right]\right)$, water $\left(\left[\mathrm{H}_{2} \mathrm{O}\right]\right)$, and hydronium ions $\left(\left[\mathrm{H}_{3} \mathrm{O}^{+}\right]\right)$ in the system. These reactions also depend on the total number of available sites $\left[L_{\square}\right]$, which influences the rate expression depending on whether the most abundant reactive intermediate (MARI) is empty ( $\square$ MARI) or occupied by adsorbed hydrogen ( $\left.\mathrm{H}^{\square} \mathrm{MARI}\right)$. Below we show the complete expression for the pseudo-steady-state hypothesis describing these reactions and the site balance of $L_{\square}$ :

For $\left[H^{\square}\right]$ :

$$
\begin{gathered}
\frac{d\left[H^{\square}\right]}{d t}=0=k_{1}^{0}\left[H_{2}\right][\square] e^{\frac{F \alpha_{1}\left(\Phi^{o p}-\Phi_{1}^{0}\right)}{R T}}-k_{-1}^{0}\left[H_{3} O^{+}\right]\left[H^{\square}\right] e^{-\frac{F \alpha_{-1}\left(\Phi^{o p}-\Phi_{-1}^{0}\right)}{R T}} \\
+\frac{1}{\left[L_{\square}\right]}\left(k_{2}^{0}\left[H_{2}\right][\square]^{2}-k_{-2}^{0}\left[H^{\square}\right]^{2}\right) \\
-k_{3}^{0}\left[H^{\square}\right]\left[H_{2} O\right] e^{\frac{F \alpha_{3}\left(\Phi^{o p_{-}} \Phi_{3}^{0}\right)}{R T}}+k_{-3}^{0}\left[H_{3} O^{+}\right][\square] e^{-\frac{F \alpha_{-3}\left(\Phi^{o p} p_{-} \Phi_{3}^{0}\right)}{R T}}
\end{gathered}
$$

For $\left[L^{\square}\right]$ :

$$
\left[L_{\square}\right]=[\square]+\left[H^{\square}\right]
$$

Where $k_{x}^{0}, \Phi_{\mathrm{x}}^{0}$, and $\alpha_{x}$ are the intrinsic rate constant, reaction potential, and charge transfer coefficients for the respective adsorption and oxidation steps $x$. The $\left[L_{\square}\right]$ is in the denominator of the bimolecular surface reactions to account for the statistical probability of two active intermediates being adjacent to one another to perform this reaction. This expression also implicitly includes a statistical factor that accounts for the number of nearest neighboring sites that 
may bind species or participate in these elementary steps. Here, the value $\left[L_{\square}\right]$ reflects the sum of sites that are either empty or occupied by hydrogen.

These experimental results discussed earlier suggest that equation S6.1 simplifies so that steps 1 and 2 are irreversible at low coverages of hydrogen. The rate of hydrogen adsorption then equals the net rate of oxidation by step 3. In this analysis, we consider the implications of these assumptions through both Tafel-Volmer and Heyrovsky-Volmer kinetics, and we find that both may explain the change in rates as a function of hydrogen pressure (Section S7).

First, we consider an irreversible Tafel-Volmer mechanism (steps 2 and 3 only), which is proposed as the dominant mechanism of hydrogen oxidation at low HOR overpotentials on some noble metals. ${ }^{8,9}$ Below we apply the simplifications discussed above and solve for the general expression of the hydrogen coverage:

$$
\begin{gathered}
\frac{d\left[H^{\square}\right]}{d t}=0=k_{2}^{0}\left[H_{2}\right][\square]^{2}\left(\frac{1}{\left[L_{\square}\right]}\right)-k_{3}^{0}\left[H^{\square}\right]\left[H_{2} O\right] e^{\frac{F \alpha_{3}\left(\Phi^{o p}-\Phi_{3}^{0}\right)}{R T}} \\
{\left[H^{\square}\right]=\frac{k_{2}^{0}\left[H_{2}\right][\square]^{2}\left(\frac{1}{\left[L_{\square}\right]}\right)}{k_{3}^{0}\left[H_{2} O\right] e^{\frac{F \alpha_{3}\left(\Phi^{o p}-\Phi_{3}^{0}\right)}{R T}}}}
\end{gathered}
$$

By combining equations $\mathrm{S} 6.2$ and $\mathrm{S} 6.4$, the coverage of hydrogen $\left(H^{\square}\right)$ assumes a polynomial functional form, which simplifies into different expressions depending on the MARI of $L_{\square}$. For instance, at low coverages of hydrogen (i.e., $\left[L_{\square}\right] \approx[\square]$ ), we derive:

$$
\left[H^{\square}\right]=\frac{k_{2}^{0}\left[H_{2}\right][\square]}{k_{3}^{0}\left[H_{2} O\right] e^{\frac{F \alpha_{3}\left(\Phi^{o p}-\Phi_{3}^{0}\right)}{R T}}}
$$

Where the hydrogen coverage increases in proportion with the $\mathrm{H}_{2}$ activity and decreases with the water activity and operating potential. We derive an analogous expression at the highest coverage of hydrogen (i.e., $\left[L_{\square}\right] \approx\left[H^{\square}\right]$ :

$$
\left[H^{\square}\right]=\left(\frac{k_{2}^{0}}{k_{3}^{0} e^{\frac{F \alpha_{3}\left(\Phi^{o p}-\Phi_{3}^{0}\right)}{R T}}}\right)^{\frac{1}{2}} \frac{\left[H_{2}\right]^{\frac{1}{2}}}{\left[H_{2} O\right]^{\frac{1}{2}}}[\square]
$$

Where the adsorption expression of hydrogen at high coverages equals the square root of equation S6.5. In this case, the coverage of hydrogen depends on the same variables at both high and low coverages, but the dependence is weaker at the highest $\mathrm{H}_{2}$ pressures. 
Alternatively, we consider an irreversible Heyrovsky-Volmer mechanism (steps 1 and 3 only), which suggests that hydrogen is generated or removed by strictly heterolytic reactions. Below we apply similar simplifications discussed in the above derivation, but consider the adsorption through step 1 rather than step 2:

$$
\begin{gathered}
\frac{d\left[H^{\square}\right]}{d t}=0=k_{1}^{0}\left[H_{2}\right]\left[H_{2} O\right][\square] e^{\frac{F \alpha_{1}\left(\Phi^{o p}-\Phi_{1}^{0}\right)}{R T}}-k_{3}^{0}\left[H^{\square}\right]\left[H_{2} O\right] e^{\frac{F \alpha_{3}\left(\Phi^{o p}-\Phi_{3}^{0}\right)}{R T}} \\
{\left[H^{\square}\right]=\frac{k_{1}^{0} e^{\frac{F \alpha_{1}\left(\Phi^{o p}-\Phi_{1}^{0}\right)}{R T}}}{k_{3}^{0} e^{\frac{F \alpha_{3}\left(\Phi^{o p}-\Phi_{3}^{0}\right)}{R T}}}\left[H_{2}\right][\square]}
\end{gathered}
$$

Where $\left[H^{\square}\right]$ depends on the activity of hydrogen and the relative rate of potential-driven hydrogen oxidation by the Heyrovsky and Volmer mechanism. Equation S6.8 shows a similar functional dependence on $\left[\mathrm{H}_{2}\right]$ as equation $\mathrm{S} 6.5$, but equation S6.8 does not depend on the activity of water and is less potential-dependent. Regardless, both equations are consistent with the functional dependence of the $\mathrm{H}_{2} \mathrm{O}_{2}$ and $\mathrm{H}_{2} \mathrm{O}$ rate expressions with $\mathrm{H}_{2}$ pressure, as derived in section $\mathrm{S} 7$. Equation S6.8, however, does not break down at different coverages of hydrogen, which leads to much simpler overall rate expressions as a function of hydrogen pressure. Thus, we use equation S6.8 for the discussion of direct synthesis reactions in the later sections but acknowledge that the complete rate expression likely encompasses steps from each reaction discussed (steps 1-3).

Next, we consider two alternative descriptions of the hydrogen coverage for the case of reversible hydrogen adsorption or highly negative operating potentials. Many of the Pd- and Pt-based materials considered in this study may facilitate reversible hydrogen adsorption when hydrogen is present in large stoichiometric excess compared to reacting oxidants. ${ }^{14}$ Under direct synthesis conditions, the adsorption steps show low barriers $\left(0-5 \mathrm{~kJ} \mathrm{~mol}^{-1}\right.$ on $\mathrm{Pd},{ }^{15-17} 0-3 \mathrm{~kJ} \mathrm{~mol}^{-1}$ on $\left.\mathrm{Pt}^{18}\right)$ and can occur at much higher rates than the competing oxidation pathways. For simplicity, we assume that steps 1 and 3 show a negligible rate and treat the Tafel equation as a quasi-equilibrated expression:

$$
\begin{gathered}
\frac{d\left[H^{\square}\right]}{d t}=0=\left(\frac{1}{\left[L_{\square}\right]}\right)\left(k_{2}^{0}\left[H_{2}\right][\square]^{2}-k_{-2}^{0}\left[H^{\square}\right]^{2}\right) \\
{\left[H^{\square}\right]=\left(\frac{k_{2}^{0}\left[H_{2}\right][\square]^{2}}{k_{-2}^{0}}\right)^{\frac{1}{2}}=K_{2}^{\frac{1}{2}}\left[H_{2}\right]^{\frac{1}{2}}[\square]}
\end{gathered}
$$

Where $\left[H^{\square}\right]$ depends sub-linearly on the activity of hydrogen multiplied by the equilibrium constant of hydrogen adsorption $\left(K_{2}\right)$. Equation $\mathrm{S} 6.10$ is equivalent to traditional treatments of hydrogen adsorption on Pd- and Pt-based materials but fails to describe the rate of $\mathrm{H}_{2} \mathrm{O}_{2}$ and $\mathrm{H}_{2} \mathrm{O}$ formation as a function of hydrogen pressure in section S7. Thus, we neglect equation S6.10 from later discussions of hydrogen coverage in this study. 
Next, we consider the formation of hydrogen from the irreversible reduction of protons in solution, which occurs at low potentials. Here we consider these reactions in terms of the electrode potential $(\Phi)$, since we observe that the operating potentials of direct synthesis are typically much greater than those that enable underpotential deposition of $H^{\square}$. For consistency, we show the reverse Heyrovsky-Volmer mechanism, which is analogous to equation S6.7:

$$
\begin{gathered}
\frac{d\left[H^{\square}\right]}{d t}=0=k_{-3}^{0}\left[H_{3} O^{+}\right][\square] e^{-\frac{F \alpha_{-3}\left(\Phi-\Phi_{-3}^{0}\right)}{R T}}-k_{-1}^{0}\left[H_{3} O^{+}\right]\left[H^{\square}\right] e^{-\frac{F \alpha_{-1}\left(\Phi-\Phi_{-1}^{0}\right)}{R T}} \\
{\left[H^{\square}\right]=\frac{k_{-3}^{0}}{k_{-1}^{0}[\square] e^{-\frac{F \alpha_{-3}\left(\Phi-\Phi_{-3}^{0}\right)}{R T}} e^{\frac{F \alpha_{-1}\left(\Phi-\Phi_{-1}^{0}\right)}{R T}}}}
\end{gathered}
$$

Where $\left[H^{\square}\right]$ depends mostly on the potential of the system but does not depend on the reactant activity. Thus, equation S6.12 indicates that hydrogen saturates the catalyst and evolves at a significant rate at the lowest potentials, which is consistent with our electrochemical RRDE measurements (Figure S58a and S58b). Notably, we derive an analogous expression for the reverse Tafel-Volmer mechanism, but we neglect this discussion since it leads to the same conclusions and is more complicated. Thus, we derive many expressions for the hydrogen coverage as a function of the activity of hydrogen and the operating potential, which we analyze in the context of direct synthesis and ORR reactions. 


\section{S7. Derivation of $\mathrm{H}_{2} \mathrm{O}_{2}$ and $\mathrm{H}_{2} \mathrm{O}$ Rate expressions via Proton-electron Transfer Paths}

\section{S7.1 Theoretical Consideration of Low-barrier Proton-electron Transfer Pathways}

In the previous section, we discuss the various mechanisms involved in the adsorption, activation, and oxidation of hydrogen on a nanoparticle surface. In this discussion, we invoke these descriptions of hydrogen coverage and consider the oxygen reduction reaction (ORR) pathways that lead to the derivation of rate expressions for the formation of $\mathrm{H}_{2} \mathrm{O}_{2}$ and $\mathrm{H}_{2} \mathrm{O}$ under direct synthesis conditions. Traditionally, investigators propose that $\mathrm{H}_{2} \mathrm{O}_{2}$ forms through successive homolytic reactions of hydrogen with dioxygen and hydroperoxyl intermediates on nominally similar reactive sites by invoking Langmuir-Hinshelwood kinetics. ${ }^{14,19}$ In our past work, however, we found that experimental evidence is more consistent with a heterolytic multi-site Eley-Rideal mechanism that is more analogous to the mechanisms proposed for the electrochemical ORR. ${ }^{20-22}$ Moreover, DFT studies of the ORR show that the proton-electron transfer pathways present significantly lower barriers than homolytic Langmuir-Hinshelwood reaction, ${ }^{23,}{ }^{24}$ suggesting the heterolytic mechanism is dominant. Here, we have refined the assumptions and conclusions of the mechanistic and theoretical studies of the ORR and direct synthesis literature in Scheme S7.1 below:

$$
\begin{aligned}
& \mathrm{H}_{2}+\square+\mathrm{H}_{2} \mathrm{O} \rightleftarrows \mathrm{H}^{\square}+\mathrm{e}^{-}+\mathrm{H}_{3} \mathrm{O}^{+} \\
& \mathrm{H}_{2}+2 \square \rightleftarrows 2 \mathrm{H}^{\square} \\
& \mathrm{H}^{\square}+\mathrm{H}_{2} \mathrm{O} \rightleftarrows \mathrm{e}^{-}+\square+\mathrm{H}_{3} \mathrm{O}^{+} \\
& \mathrm{O}_{2}+* \rightleftarrows \mathrm{O}_{2} * \\
& \mathrm{O}_{2} *+\mathrm{e}^{-} \longrightarrow \mathrm{O}_{2}^{-*} \\
& \mathrm{O}_{2}{ }^{-*}+\mathrm{H}_{3} \mathrm{O}^{+} \longrightarrow \mathrm{OOH}^{*}+\mathrm{H}_{2} \mathrm{O} \\
& \mathrm{OOH}^{*}+\mathrm{e}^{-} \longrightarrow \mathrm{OOH}^{-*} \\
& \mathrm{OOH}^{-*}+\mathrm{H}_{3} \mathrm{O}^{+} \longrightarrow \mathrm{H}_{2} \mathrm{O}_{2} *+\mathrm{H}_{2} \mathrm{O} \\
& \mathrm{OOH}^{*}+\mathrm{e}^{-} \longrightarrow \mathrm{OH}^{-}+\mathrm{O}^{*} \\
& \mathrm{O}^{*}+\mathrm{e}^{-} \longrightarrow \mathrm{O}^{* *} \\
& \mathrm{O}^{-*}+\mathrm{H}_{3} \mathrm{O}^{+} \longrightarrow \mathrm{OH}^{*}+\mathrm{H}_{2} \mathrm{O} \\
& \mathrm{O}^{*}+\mathrm{H}_{2} \mathrm{O}^{*} \longrightarrow \mathrm{OH}^{*}+\mathrm{OH}^{*} \\
& \mathrm{OH}^{*}+\mathrm{e}^{-} \longrightarrow \mathrm{OH}^{-*} \\
& \mathrm{OH}^{*-}+\mathrm{H}_{3} \mathrm{O}^{+} \longrightarrow \mathrm{H}_{2} \mathrm{O}^{*}+\mathrm{H}_{2} \mathrm{O} \\
& \mathrm{OH}^{*-}+\mathrm{H}_{3} \mathrm{O}^{+} \longrightarrow \mathrm{H}_{2} \mathrm{O}^{*}+\mathrm{H}_{2} \mathrm{O} \\
& \mathrm{H}_{2} \mathrm{O} * \rightleftarrows \mathrm{H}_{2} \mathrm{O}+* \\
& \mathrm{H}_{2} \mathrm{O}_{2} * \rightleftarrows \mathrm{H}_{2} \mathrm{O}_{2}+* \\
& \mathrm{H}_{2} \mathrm{O}_{2} *+\mathrm{e}^{-} \longrightarrow \mathrm{OH}^{-}+\mathrm{OH}^{*}
\end{aligned}
$$


Scheme 7.1. Elementary reactions for a multi-site proton-electron transfer reaction mechanism in water. In this scheme, $\square$ refers to sites that bind hydrogen species and * refers to sites that bind oxygen-derived species. Here, $X^{\square}$ and $X^{*}$ denote adsorbates bound to these respective sites. Symbols of $\rightleftarrows$, or $\longrightarrow$ denote whether an elementary reaction is quasi-equilibrated, reversible, or irreversible, respectively.

In this scheme, we first consider the relevant adsorption and desorption reactions (steps 1, 2, 4, 11, and 12). In section S6, we discuss in detail the adsorption and oxidation of hydrogen by steps 1-3. In short, we generally assume that each step is reversible depending on the hydrogen activity and electrical potential in the system. However, we revisit the implications of the derivations after deriving the complete form of the oxygen reduction rate expression (vide infra). Next, we assume that the adsorption of $\mathrm{O}_{2}, \mathrm{H}_{2} \mathrm{O}$, and $\mathrm{H}_{2} \mathrm{O}_{2}$ are quasi-equilibrated under most conditions since the Gibbs free energy difference and activation barriers are small relative to competing pathways. ${ }^{15,25}$ Consequently, these steps are highly reversible and occur readily at the operating potentials that direct synthesis occurs (0.65-0.3 V vs. NHE).

For the remaining proton-electron transfer pathways (steps 5a, 5b, 6a, 6b, 7, 8a, 8b, 9a, 9b, 10, and 13), we assume that all oxygen dissociation reactions (steps 7 and 13) are irreversible, as reported by Lunsford et al. ${ }^{26}$ Specifically, they found that reactant mixtures of ${ }^{16} \mathrm{O}^{16} \mathrm{O},{ }^{18} \mathrm{O}^{18} \mathrm{O}$, and $\mathrm{H}_{2}$ gas resulted in the formation of $\mathrm{H}_{2}{ }^{16} \mathrm{O}_{2}$ and $\mathrm{H}_{2}{ }^{18} \mathrm{O}_{2}$, but they did not observe $\mathrm{H}^{16} \mathrm{O}^{18} \mathrm{OH}$. Thus, O-O bonds do not reform under typical reaction conditions due to the high exothermicity of these reactions, which become increasingly favorable at lower electrical potentials. For the remaining electron-transfer reactions (e.g., steps 5a, 6a, and 9), the formation of anionic surface intermediates shows a small change in energy, but the subsequent proton transfer reactions occur spontaneously and exothermically. ${ }^{27}$ Thus, all the coupled proton-electron transfer reactions are effectively irreversible due to their low barriers and favorable thermodynamics that occur more readily at lower potentials.

The last proton transfer reactions we consider here is the disproportionation of $\mathrm{O}^{*}$ and $\mathrm{H}_{2} \mathrm{O} *$ (step $8 \mathrm{c})$, which presents low to intermediate barrier on noble metal surfaces $\left(67,29\right.$, and $13 \mathrm{~kJ} \mathrm{~mol}^{-1}$ on $\mathrm{Pt}, \mathrm{Pd}$, and $\mathrm{Au}$, respectively). ${ }^{28}$ Studies of the direct synthesis of $\mathrm{H}_{2} \mathrm{O}_{2}$ commonly invoke the disproportionation reaction, ${ }^{16,28,29}$ but a proton-electron transfer reaction may also occur (steps $8 \mathrm{a}$ and $8 \mathrm{~b}$ ). The ORR literature has debated which mechanism dominates ${ }^{30}$ but with no clear consensus, we invoke both but find that either assumption leads to the same functional form for the rate expressions for $\mathrm{H}_{2} \mathrm{O}_{2}$ and $\mathrm{H}_{2} \mathrm{O}$ formation. Thus, we focus on the case that PET reactions dominates since this assumption leads to much simpler rate expression.

Above, we present the lowest barrier pathways that affect the reaction network, but we neglect several alternative paths invoked in other mechanistic investigations. ${ }^{16,28}$ For instance, we neglect the direct dissociation pathways for dioxygen reactants (e.g., $\mathrm{O}_{2}^{*}+* \rightarrow \mathrm{O}^{*}+\mathrm{O}^{*}, \mathrm{OOH}^{*}+* \rightarrow$ $\mathrm{OH}^{*}+\mathrm{O}^{*}$, and $\mathrm{H}_{2} \mathrm{O}_{2} *+* \rightarrow \mathrm{OH}^{*}+\mathrm{OH}^{*}$ ) since these reactions exhibit significantly higher barriers than the equivalent hydrogen transfer pathways on an adsorbate-covered surface $\left(\Delta \mathrm{E}_{\text {int }}^{\ddagger}=\right.$ $\left.81-118 \mathrm{~kJ} \mathrm{~mol}^{-1}\right) .{ }^{16}$ As adsorbates like $\mathrm{O}^{*}$ cover the surface, they destabilize the product states of dissociation reactions and destabilize the reactant states of association reactions. ${ }^{16}$ Consequently, we only consider the associative pathways (i.e., proton-electron transfer reactions) due to their 
lower overall barriers. Moreover, these heterolytic pathways become increasingly favorable at the lower potentials considered in the ORR measurements.

\section{S7.2 Derivation of General Current Expressions of ORR and Coverage of Oxygenates}

With the experimental and theoretical evidence for Scheme S7.1, we derive a rate expression that considers each surface reaction and the relevant surface intermediates that participate in the direct synthesis of $\mathrm{H}_{2} \mathrm{O}_{2}$. Here, we develop a general expression for the HOR and ORR and then solve for the relevant coverage expressions for the species shown in this scheme.

First, we evaluate the overall current generated by the HOR, as discussed in Section S6. Electrochemical studies indicate that a combination of the Heyrovsky (step1), Tafel (step 2), and Volmer (step 3) reactions facilitate the HOR on noble metal surfaces depending on the potential and reaction conditions of the system. ${ }^{6,31} \mathrm{On} \mathrm{Pt}$ and Pd materials, it is possible that all of these steps are kinetically relevant, depending on the reaction conditions. For low coverages of hydrogen, either the Tafel or Heyrovsky steps could be kinetically relevant, but the dominant mechanism depends on the electrical potential of the material. Since we find that either reaction leads to a similar functional form of the apparent rate expression, we treat the Heyrovsky step as kinetically relevant to simplify the mathematics (vida infra):

$$
\begin{gathered}
\frac{i_{H O R}}{\left[L_{\square}\right]}=-\frac{F}{\left[L_{\square}\right]}\left(k_{1}^{0}\left[H_{2}\right][\square] e^{\frac{F \alpha_{1}\left(\Phi^{o p}-\Phi_{1}^{0}\right)}{R T}}+k_{3}^{0}\left[H^{\square}\right] e^{\frac{F \alpha_{3}\left(\Phi^{o p}-\Phi_{3}^{0}\right)}{R T}}\right)\left[H_{2} O\right] \\
\approx \frac{F}{\left[L_{\square}\right]}\left(2 k_{1}^{0}\left[H_{2}\right]\left[H_{2} O\right][\square] e^{\frac{F \alpha_{1}\left(\Phi^{o p}-\Phi_{1}^{0}\right)}{R T}}\right)
\end{gathered}
$$

Where $k_{x}^{0}, \Phi_{\mathrm{x}}^{0}$, and $\alpha_{x}$ are the intrinsic rate constant, reaction potential, and charge transfer coefficients for step $\mathrm{x}$, respectively. Here, the overall current of HOR $\left(i_{H O R}\right)$ depends on the operating potential $\left(\Phi^{o p}\right)$, hydrogen coverage $\left(\left[H^{\square}\right]\right)$ and activity of hydrogen $\left(\left[\mathrm{H}_{2}\right]\right)$ and water $\left(\left[\mathrm{H}_{2} \mathrm{O}\right]\right)$.

Next, we consider the likely rate-determining steps for the formation of $\mathrm{H}_{2} \mathrm{O}_{2}$ and $\mathrm{H}_{2} \mathrm{O}$. Most DFT studies of the ORR suggest that electron transfer to $\mathrm{O}_{2} *$ (step 5a) is the kinetically relevant step for the formation of both products since this reaction presents the greatest apparent activation barrier of all elementary steps of the ORR. ${ }^{23}$ Similarly, ORR rates in $\mathrm{H}_{2} \mathrm{O}$ and $\mathrm{D}_{2} \mathrm{O}$ solutions are similar on noble metals catalysts (e.g., Pt and Pd), indicating that the electron transfer step is more kinetically relevant than the subsequent proton transfer steps. ${ }^{32}$ Last, DFT studies of the direct synthesis of $\mathrm{H}_{2} \mathrm{O}_{2}$ show that the reduction of $\mathrm{O}_{2} *$ exerts a degree of rate control equal to 1 , which corroborates the findings in the ORR literature. ${ }^{16}$ Below, we derive the general form of the ORR rate expression for a material that transfers some percentage of electrons $\left(n_{O R R}\right)$ towards either $\mathrm{H}_{2} \mathrm{O}_{2}(\mathrm{n}=2)$ or $\mathrm{H}_{2} \mathrm{O}(\mathrm{n}=4)$ products:

$$
\frac{i_{O R R}}{\left[L_{*}\right]}=\frac{i_{H_{2} O_{2}}+i_{H_{2} O}}{\left[L_{*}\right]}=\frac{F}{\left[L_{*}\right]} n_{O R R} k_{5 a}^{0} \mathrm{e}^{-\frac{\alpha_{5 a} \mathrm{~F}\left(\Phi^{o p}-\Phi_{5 \mathrm{a}}^{0}\right)}{\mathrm{RT}}}\left[O_{2}^{*}\right]
$$


Here, the overall current of ORR $\left(i_{O R R}\right)$ depends on the coverage of $\mathrm{O}_{2} *\left(\left[O_{2}^{*}\right]\right)$, the operating potential, and the net current that results in $\mathrm{H}_{2} \mathrm{O}_{2}\left(i_{H_{2} O_{2}}\right)$ or $\mathrm{H}_{2} \mathrm{O}\left(i_{H_{2} O}\right)$ formation. Although $\mathrm{H}_{2} \mathrm{O}_{2}$ and $\mathrm{H}_{2} \mathrm{O}$ formation involve the same kinetically relevant step, the subsequent reduction reactions determine the selectivity of either product and influence the value of $n_{O R R}$. DFT studies indicate that steps $6 \mathrm{a}$ and 7 show the second-highest apparent barriers to form $\mathrm{H}_{2} \mathrm{O}_{2}$ and $\mathrm{H}_{2} \mathrm{O}$ at low coverages of $\mathrm{H}_{2} \mathrm{O}_{2} *{ }^{*}{ }^{16}{ }^{28}$ For these ORR pathways, all subsequent reactions in Scheme S7.1 (steps $6 \mathrm{~b}, 8-12$ ) show low barriers or are irreversible. Thus, the number of electrons transmitted depends on the fraction of $\mathrm{OOH}^{*}$ that reduces towards either the $2 \mathrm{e}^{-}$or $4 \mathrm{e}^{-}$pathways and the rate of $\mathrm{H}_{2} \mathrm{O}_{2}{ }^{*}$ dissociation.

To complete this current and mass balance, however, equation S7.2 must equal the net current expression for each reacting oxygen-derived intermediate:

$$
\begin{aligned}
\frac{i_{O R R}}{\left[L_{*}\right]}=\frac{F}{\left[L_{*}\right]}( & k_{5 a}^{0} \mathrm{e}^{-\frac{\alpha_{5 a} \mathrm{~F}\left(\Phi^{o p}-\Phi_{5 \mathrm{a}}^{0}\right)}{\mathrm{RT}}}\left[O_{2}^{*}\right] \\
& +\left(k_{6 a}^{0} \mathrm{e}^{-\frac{\alpha_{6 a} \mathrm{~F}\left(\Phi^{o p_{-}} \Phi_{6 \mathrm{a}}^{0}\right)}{\mathrm{RT}}}+k_{7}^{0} \mathrm{e}^{\left.-\frac{\alpha_{5 a} \mathrm{~F}\left(\Phi^{o p_{-}} \Phi_{5 \mathrm{a}}^{0}\right)}{\mathrm{RT}}\right)}\left[O O H^{*}\right]\right. \\
& +k_{8 a}^{0} \mathrm{e}^{-\frac{\alpha_{8 a} \mathrm{~F}\left(\Phi^{o p_{-}} \Phi_{8 \mathrm{a}}^{0}\right)}{\mathrm{RT}}}\left[O^{*}\right]+k_{9}^{0} \mathrm{e}^{-\frac{\alpha_{9} \mathrm{~F}\left(\Phi^{o p}-\Phi_{9}^{0}\right)}{\mathrm{RT}}}\left[O H^{*}\right] \\
& \left.+k_{13}^{0} \mathrm{e}^{-\frac{\alpha_{13} \mathrm{~F}\left(\Phi^{o p}-\Phi_{13}^{0}\right)}{\mathrm{RT}}}\left[H_{2} O_{2}^{*}\right]\right)
\end{aligned}
$$

Where the total current reflects the total number of electron transfer reactions to $\left[\mathrm{O}_{2}^{*}\right],\left[\mathrm{OOH}^{*}\right]$, $\left[\mathrm{O}^{*}\right],\left[\mathrm{OH}^{*}\right]$, and $\left[\mathrm{H}_{2} \mathrm{O}_{2}^{*}\right]$ species. For the remainder of this analysis, we derive analytical expressions for the coverage of each intermediate through the pseudo-steady-state hypothesis.

For $\left[O_{2}^{*}\right]$ :

$$
\frac{d\left[O_{2}^{*}\right]}{d t}=0=k_{4}^{0}\left[O_{2}\right][*]-k_{-4}^{0}\left[O_{2}^{*}\right]-k_{5 a}^{0}\left[O_{2}^{*}\right] \mathrm{e}^{-\frac{\alpha_{5 a} \mathrm{~F}\left(\Phi^{o p}-\Phi_{5 \mathrm{a}}^{0}\right)}{\mathrm{RT}}}
$$

This expression indicates that $\left[\mathrm{O}_{2}^{*}\right]$ depends on the relative rate that $\mathrm{O}_{2}$ adsorbs through step 4 versus the rate of $\mathrm{O}_{2}$ desorption (step -4) or reduction (step 5a). A combination of experimental and DFT evidence indicates that the free energy barriers of dioxygen adsorption and desorption are negligible $\left(-9-11 \mathrm{~kJ} \mathrm{~mol}^{-1}\right)$ on noble metal surface, ${ }^{25}$ while $\mathrm{O}_{2} *$ reduction is kinetically relevant and presents much higher barriers in the absence of an applied potential. ${ }^{23}$ Thus, under most conditions step 5 a does not affect $\left[O_{2}^{*}\right]$, resulting in quasi-equilibrated dioxygen adsorption:

$$
\left[O_{2}^{*}\right]=\frac{k_{4}^{0}}{k_{-4}^{0}}\left[O_{2}\right][*]=K_{2}\left[O_{2}\right][*]
$$

Where $\left[\mathrm{O}_{2}^{*}\right]$ depends on the equilibrium constant of $\mathrm{O}_{2}$ adsorption $\left(\mathrm{K}_{2}\right)$ and the activity of $\mathrm{O}_{2}\left(\left[\mathrm{O}_{2}\right]\right)$ in the system. Notably, the assumptions of equation S7.5 breaks down at low potentials, which would result in an overall rate expression that is limited by the rate of $\mathrm{O}_{2}$ adsorption. Under direct 
synthesis conditions, however, the operating potentials of the studied materials are much more positive (0.3-0.65 V vs. NHE), and the quasi-equilibrated solution likely applies in all cases.

For $\left[\mathrm{O}_{2}^{-*}\right]$ :

$$
\frac{d\left[O_{2}^{-*}\right]}{d t}=0=k_{5 a}^{0}\left[O_{2}^{*}\right] \mathrm{e}^{-\frac{\alpha_{5 a} \mathrm{~F}\left(\Phi^{o p}-\Phi_{5 \mathrm{a}}^{0}\right)}{\mathrm{RT}}}-k_{5 b}^{0}\left[O_{2}^{-*}\right]\left[H_{3} O^{+}\right]
$$

Substituting in equation S7.5 into equation S7.6 with further rearrangement then yields:

$$
\left[O_{2}^{-*}\right]=\frac{k_{5 a}^{0} K_{4}\left[O_{2}\right][*]}{k_{5 b}^{0}\left[H_{3} O^{+}\right]} \mathrm{e}^{-\frac{\alpha_{5 a} \mathrm{~F}\left(\Phi^{o p}-\Phi_{5 \mathrm{a}}^{0}\right)}{\mathrm{RT}}}
$$

Here, the coverage of anionic dioxygen $\left(\left[\mathrm{O}_{2}^{-*}\right]\right)$ increases with the $\mathrm{pH}$ of the solution (i.e., $\left[\mathrm{H}_{3} \mathrm{O}^{+}\right]$) and the value of $\Phi^{o p}$. So, this coverage would increase significantly at sufficiently low potentials. For $\left[O O H^{*}\right]$ :

$$
\begin{aligned}
\frac{d\left[O O H^{*}\right]}{d t}=0 & =k_{5 b}^{0}\left[O_{2}^{-*}\right]\left[H_{3} O^{+}\right] \\
& -\left(k_{6 a}^{0} \mathrm{e}^{-\frac{\alpha_{6 a} \mathrm{~F}\left(\Phi^{o p}-\Phi_{6 \mathrm{a}}^{0}\right)}{\mathrm{RT}}}+k_{7} \mathrm{e}^{-\frac{\alpha_{7} \mathrm{~F}\left(\Phi^{o p}-\Phi_{7}^{0}\right)}{\mathrm{RT}}}\right)\left[O O H^{*}\right]
\end{aligned}
$$

Substituting equation S7.7 into the above expression, we derive:

$$
\left[O O H^{*}\right]=\frac{k_{5 a}^{0} K_{4}\left[O_{2}\right][*] \mathrm{e}^{-\frac{\alpha_{5 a} \mathrm{~F}\left(\Phi^{o p}-\Phi_{5 \mathrm{a}}^{0}\right)}{\mathrm{RT}}}}{\left(k_{6 a}^{0} \mathrm{e}^{-\frac{\alpha_{6 a} \mathrm{~F}\left(\Phi^{o p}-\Phi_{6 \mathrm{a}}^{0}\right)}{\mathrm{RT}}}+k_{7}^{0} \mathrm{e}^{-\frac{\alpha_{7} \mathrm{~F}\left(\Phi^{o p}-\Phi_{7}^{0}\right)}{\mathrm{RT}}}\right)}
$$

Here, the value of $\left[\mathrm{OOH}^{*}\right]$ reflects the relative rate that $\mathrm{O}_{2}$ adsorbs and receives an electron versus the rate that $\left[\mathrm{OOH}^{*}\right]$ receives another electron towards either the $\mathrm{H}_{2} \mathrm{O}_{2}$ or $\mathrm{H}_{2} \mathrm{O}$ formation pathways. For $\left[\mathrm{OOH}^{-*}\right]$ : 


$$
\frac{d\left[O O H^{-*}\right]}{d t}=0=k_{6 a}^{0}\left[O O H^{*}\right] \mathrm{e}^{-\frac{\alpha_{6 a} \mathrm{~F}\left(\Phi^{o p}-\Phi_{6 \mathrm{a}}^{0}\right)}{\mathrm{RT}}}-k_{6 b}^{0}\left[O O H^{-*}\right]\left[H_{3} O^{+}\right]
$$

Substituting equation S7.9 into this expression then yields:

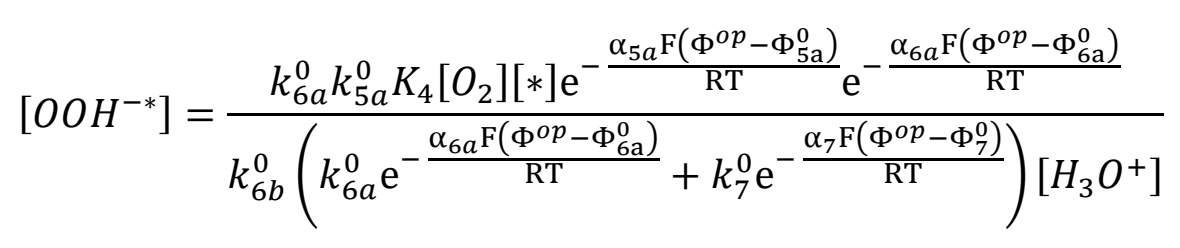

Like $\left[\mathrm{O}_{2}^{-*}\right]$, the average coverage of anionic $\left[\mathrm{OOH}^{-*}\right]$ depends on the rate of electron transfer to $\left[\mathrm{OOH}^{*}\right]$ versus the rate that it protonated by the solution. Thus, the reaction is sensitive to the solution $\mathrm{pH}$ and the operating potential of the nanoparticle.

For $\left[\mathrm{H}_{2} \mathrm{O}_{2}^{*}\right]$ :

$$
\begin{aligned}
\frac{d\left[H_{2} O_{2}^{*}\right]}{d t}=0= & k_{6 b}^{0}\left[O O H^{-*}\right]\left[H_{3} O^{+}\right]+k_{-12}^{0}\left[H_{2} O_{2}\right][*]-k_{12}^{0}\left[H_{2} O_{2}^{*}\right] \\
& -k_{13}^{0}\left[H_{2} O_{2}^{*}\right] \mathrm{e}^{-\frac{\alpha_{13} \mathrm{~F}\left(\Phi^{o p}-\Phi_{13}^{0}\right)}{\mathrm{RT}}}
\end{aligned}
$$

Here, $\left[\mathrm{H}_{2} \mathrm{O}_{2}^{*}\right]$ forms from the reduction of $\mathrm{OOH}^{*}$ and by adsorption from the liquid phase, while dissociation and desorption pathways consume $\left[\mathrm{H}_{2} \mathrm{O}_{2}^{*}\right]$. Under differential conversion during direct synthesis measurements, the concentrations of $\mathrm{H}_{2} \mathrm{O}_{2}$ in solution are negligible $\left(\left[\mathrm{H}_{2} \mathrm{O}_{2}\right] \approx 0\right)$ and so $\mathrm{H}_{2} \mathrm{O}_{2}$ adsorption does not contribute to the value of $\left[\mathrm{H}_{2} \mathrm{O}_{2}^{*}\right]$ at such conditions. Similarly, the secondary decomposition of $\mathrm{H}_{2} \mathrm{O}_{2} *$ is more prevalent at low electrical potentials, while the desorption of $\mathrm{H}_{2} \mathrm{O}_{2} *$ presents a negative free energy barrier $\left(-23 \mathrm{~kJ} \mathrm{~mol}^{-1}\right)$ under most direct synthesis conditions. ${ }^{15}$ Thus, the coverage of $\mathrm{H}_{2} \mathrm{O}_{2}$ simplifies to the following form with the substitution of equation S7.11:

$$
\begin{aligned}
& {\left[H_{2} O_{2}^{*}\right]} \\
& \left(k_{12}^{0}+k_{13}^{0} \mathrm{e}^{-\frac{\alpha_{13} \mathrm{~F}\left(\Phi^{o p}-\Phi_{13}^{0}\right)}{\mathrm{RT}}}\right)\left(k_{6 a}^{0} \mathrm{e}^{-\frac{\alpha_{6 a} \mathrm{~F}\left(\Phi^{o p}-\Phi_{6 \mathrm{a}}^{0}\right)}{\mathrm{RT}}}+k_{7}^{0} \mathrm{e}^{-\frac{\alpha_{7} \mathrm{~F}\left(\Phi^{o p}-\Phi_{7}^{0}\right)}{\mathrm{RT}}}\right)
\end{aligned}
$$

Here, the coverage of $\mathrm{H}_{2} \mathrm{O}_{2} *$ depends on the rate that $\mathrm{OOH}^{*}$ reduces through 2e- pathway versus the rate that it desorbs. Typically, the value of $\left[\mathrm{H}_{2} \mathrm{O}_{2}^{*}\right]$ is low under direct synthesis conditions, but increases at lower potentials as the formation of $\mathrm{H}_{2} \mathrm{O}_{2}$ is favored. ${ }^{23}$ The increased coverage, however, should also increase the probability of $\mathrm{H}_{2} \mathrm{O}_{2}$ dissociation by step 13 , which is favored at lower potentials (discussed in more detail in Section S8). ${ }^{33,34}$ 


$$
\begin{aligned}
\frac{d\left[O^{*}\right]}{d t}=0= & k_{7}^{0}\left[O O H^{*}\right] \mathrm{e}^{-\frac{\alpha_{7} \mathrm{~F}\left(\Phi^{o p}-\Phi_{7}^{0}\right)}{\mathrm{RT}}}-k_{8 a}^{0}\left[O^{*}\right] \mathrm{e}^{-\frac{\alpha_{8 a} \mathrm{~F}\left(\Phi^{o p}-\Phi_{8 \mathrm{~b}}^{0}\right)}{\mathrm{RT}}} \\
& -k_{8 c}^{0}\left[O^{*}\right]\left[H_{2} O^{*}\right]\left(\frac{1}{\left[L_{*}\right]}\right)
\end{aligned}
$$

Where the total site count $\left(\left[L_{*}\right]\right)$ is in the denominator to account for the statistical probability that $\mathrm{O}^{*}$ and $\mathrm{H}_{2} \mathrm{O} *$ are adjacent during the disproportion reaction. Here, the expression can simplify into two forms depending on whether the disproportion (step 8c) or the PET reaction (step 8a) dominates, which we derive by substituting in equations S7.9 into equation S7.14.

If the PET reaction (step 8a) is the dominate pathway:

$$
\left[O^{*}\right]=\frac{k_{7}^{0} k_{5 a}^{0} K_{4} \mathrm{e}^{-\frac{\alpha_{5 a} \mathrm{~F}\left(\Phi^{o p}-\Phi_{5 \mathrm{a}}^{0}\right)}{\mathrm{RT}}} \mathrm{e}^{-\frac{\alpha_{7} \mathrm{~F}\left(\Phi^{o p}-\Phi_{6 \mathrm{a}}^{0}\right)}{\mathrm{RT}}}\left[O_{2}\right][*]}{k_{8 a}^{0}\left(k_{6 a}^{0} \mathrm{e}^{-\frac{\alpha_{6 a} \mathrm{~F}\left(\Phi^{o p}-\Phi_{6 \mathrm{a}}^{0}\right)}{\mathrm{RT}}}+k_{7}^{0} \mathrm{e}^{-\frac{\alpha_{7} \mathrm{~F}\left(\Phi^{o p}-\Phi_{7}^{0}\right)}{\mathrm{RT}}}\right) \mathrm{e}^{-\frac{\alpha_{8 a} \mathrm{~F}\left(\Phi^{o p}-\Phi_{8 \mathrm{~b}}^{0}\right)}{\mathrm{RT}}}}
$$

Here, the coverage of $\left[\mathrm{O}^{*}\right]$ depends on the relative rate that $\left[\mathrm{OOH}^{*}\right]$ is cleaved into $\mathrm{H}_{2} \mathrm{O}$ and $\left[\mathrm{O}^{*}\right]$ by electron transfer versus the rate that $\left[\mathrm{O}^{*}\right]$ receives another electron. This reaction likely more prevalent than the disproportion reaction at sufficiently low potentials.

If the disproportion reaction (step 8c) is the dominate pathway:

$$
\left[O^{*}\right]=\frac{k_{7}^{0} k_{5 a}^{0} K_{4}\left[O_{2}\right][*]}{k_{8 c}^{0}\left[H_{2} O^{*}\right]}\left(\frac{\left[L_{*}\right]}{1}\right) \frac{\mathrm{e}^{-\frac{\alpha_{5 a} \mathrm{~F}\left(\Phi^{o p}-\Phi_{5 \mathrm{a}}^{0}\right)}{\mathrm{RT}}} \mathrm{e}^{-\frac{\alpha_{6 a} \mathrm{~F}\left(\Phi^{o p}-\Phi_{6 \mathrm{a}}^{0}\right)}{\mathrm{RT}}}}{\left(k_{6 a}^{0} \mathrm{e}^{-\frac{\alpha_{6 a} \mathrm{~F}\left(\Phi^{o p}-\Phi_{6 \mathrm{a}}^{0}\right)}{\mathrm{RT}}}+k_{7}^{0} \mathrm{e}^{-\frac{\alpha_{7} \mathrm{~F}\left(\Phi^{o p_{-}} \Phi_{7}^{0}\right)}{\mathrm{RT}}}\right)}
$$

In this case, the coverage of $\left[\mathrm{O}^{*}\right]$ depends on the rate of $\left[\mathrm{OOH}^{*}\right]$ dissociation versus the rate that $\left[\mathrm{O}^{*}\right]$ is protonated by $\left[\mathrm{H}_{2} \mathrm{O}^{*}\right]$. For simplicity we will continue the derivation using equation $\mathrm{S} 7.15$, since both equations for $\left[\mathrm{O}^{*}\right]$ lead to a rate expression that is consistent with the pressure dependence data. Equation S7.15, however, leads to a much simpler functional form for the derived rate expressions.

For $\left[O^{-*}\right]$ : 


$$
\begin{aligned}
\frac{d\left[O H^{*}\right]}{d t}=0= & k_{8 b}^{0}\left[O^{-*}\right]\left[H_{3} O^{+}\right]+k_{13}^{0}\left[H_{2} O_{2}^{*}\right] \mathrm{e}^{-\frac{\alpha_{13} \mathrm{~F}\left(\Phi-\Phi_{13}^{0}\right)}{\mathrm{RT}}} \\
& -k_{9 a}^{0}\left[O H^{*}\right] \mathrm{e}^{-\frac{\alpha_{9 a} \mathrm{~F}\left(\Phi^{o p_{-}} \Phi_{9 \mathrm{a}}^{0}\right)}{\mathrm{RT}}}
\end{aligned}
$$

Substituting in Equation S7.18 into the above expression, we derive:

$$
\begin{aligned}
& {\left[O H^{*}\right]} \\
& =\frac{k_{7}^{0} k_{5 a}^{0} K_{4}\left[O_{2}\right][*] \mathrm{e}^{-\frac{\alpha_{5 a} \mathrm{~F}\left(\Phi-\Phi_{5 \mathrm{a}}^{0}\right)}{\mathrm{RT}}} \mathrm{e}^{-\frac{\alpha_{7} \mathrm{~F}\left(\Phi-\Phi_{7}^{0}\right)}{\mathrm{RT}}}}{k_{9 a}^{0}\left(k_{6 a}^{0} \mathrm{e}^{-\frac{\alpha_{6 a} \mathrm{~F}\left(\Phi-\Phi_{6 \mathrm{a}}^{0}\right)}{\mathrm{RT}}}+k_{7}^{0} \mathrm{e}^{\left.-\frac{\alpha_{7} \mathrm{~F}\left(\Phi-\Phi_{7}^{0}\right)}{\mathrm{RT}}\right)} \mathrm{e}^{-\frac{\alpha_{9} \mathrm{~F}\left(\Phi-\Phi_{9}^{0}\right)}{\mathrm{RT}}}\right.} \\
& +\frac{k_{6 a}^{0} k_{5 a}^{0} K_{4}\left[O_{2}\right][*] \mathrm{e}^{-\frac{\alpha_{5 a} \mathrm{~F}\left(\Phi-\Phi_{5 \mathrm{a}}^{0}\right)}{\mathrm{RT}}} \mathrm{e}^{-\frac{\alpha_{6 a} \mathrm{~F}\left(\Phi-\Phi_{6 \mathrm{a}}^{0}\right)}{\mathrm{RT}}} \mathrm{e}^{-\frac{\alpha_{13} \mathrm{~F}\left(\Phi-\Phi_{13}^{0}\right)}{\mathrm{RT}}}}{k_{9 a}^{0}\left(k_{6 a}^{0} \mathrm{e}^{-\frac{\alpha_{6 a} \mathrm{~F}\left(\Phi-\Phi_{6 \mathrm{a}}^{0}\right)}{\mathrm{RT}}}+k_{7}^{0} \mathrm{e}^{\left.-\frac{\alpha_{7} \mathrm{~F}\left(\Phi-\Phi_{7}^{0}\right)}{\mathrm{RT}}\right)}\left(k_{12}^{0}+k_{13}^{0}\left[e^{-}\right] \mathrm{e}^{-\frac{\alpha_{13} \mathrm{~F}\left(\Phi-\Phi_{13}^{0}\right)}{\mathrm{RT}}}\right) \mathrm{e}^{-\frac{\alpha_{9} \mathrm{~F}\left(\Phi-\Phi_{9}^{0}\right)}{\mathrm{RT}}}\right.}
\end{aligned}
$$

Here, the coverage of hydroxyl species depends on the relative rate that $\left[\mathrm{OOH}^{*}\right]$ and $\left[\mathrm{H}_{2} \mathrm{O}_{2}^{*}\right]$ are dissociated by electron transfer reactions versus the rate that $\left[\mathrm{OH}^{*}\right]$ receives an electron to form water.

For $\left[\mathrm{H}_{2} \mathrm{O}^{*}\right]$ :

$$
\begin{aligned}
\frac{d\left[\mathrm{H}_{2} \mathrm{O}^{*}\right]}{d t}=0= & k_{11}^{0}\left[\mathrm{H}_{2} \mathrm{O}\right][*]-k_{-11}^{0}\left[\mathrm{H}_{2} \mathrm{O}^{*}\right]+k_{9 b}^{0}\left[\mathrm{OH}^{-*}\right]\left[\mathrm{H}_{3} \mathrm{O}^{+}\right] \\
& -k_{8 c}^{0}\left[\mathrm{O}^{*}\right]\left[\mathrm{H}_{2} \mathrm{O}^{*}\right]\left(\frac{1}{\left[L_{*}\right]}\right)
\end{aligned}
$$

Where $\left[\mathrm{H}_{2} \mathrm{O}^{*}\right]$ forms from $\mathrm{H}_{2} \mathrm{O}$ adsorption from the solution phase and the reduction of $\mathrm{OH}^{*}$, while desorption and disproportion reactions remove $\left[\mathrm{H}_{2} \mathrm{O}^{*}\right]$ from the surface. Here, we simplify equation $\mathrm{S} 7.21$ since the free energy barrier of $\mathrm{H}_{2} \mathrm{O}$ desorption is typically negative on noble metal surfaces, ${ }^{15}$ while the disproportion of $\mathrm{O} *$ and $\mathrm{H}_{2} \mathrm{O} *$ can show greater barriers $\left(13-67 \mathrm{~kJ} \mathrm{~mol}^{-1}\right) .{ }^{28}$ Thus, we neglect step $8 \mathrm{c}$ for simplicity since this reaction does not influence the conclusions of our analysis. Similarly, we assume that the formation of $\left[\mathrm{H}_{2} \mathrm{O}^{*}\right]$ depends mostly on the adsorption of solution-phase $\mathrm{H}_{2} \mathrm{O}$ at the more positive potentials of direct synthesis, while step 9a is prevalent only at the most negative potentials. Therefore, the coverage of $\mathrm{H}_{2} \mathrm{O}$ simplifies to the quasiequilibrated solution, since a given water molecule may adsorb or desorb many times before a water molecule is generated or consumed by the other surface reactions: 


$$
\left[\mathrm{H}_{2} \mathrm{O}^{*}\right]=\frac{k_{-11}^{0}\left[\mathrm{H}_{2} \mathrm{O}\right][*]}{k_{11}^{0}}=\frac{1}{K_{11}}\left[\mathrm{H}_{2} \mathrm{O}\right][*]
$$

Where $\left[\mathrm{H}_{2} \mathrm{O}^{*}\right]$ depends on the inverse equilibrium constant of $\mathrm{H}_{2} \mathrm{O}$ adsorption $\left(K_{11}\right)$ and the activity of $\mathrm{H}_{2} \mathrm{O}\left(\left[\mathrm{H}_{2} \mathrm{O}\right]\right)$ in solution. However, this coverage may depend on the reduction of $\mathrm{OH}^{*}$ (step $9 \mathrm{~b}$ ) at the lowest potentials.

With analytical expressions for each intermediate, we restate the site balances for the coverage of oxygen- and hydrogen-derived species below:

$$
\begin{gathered}
{\left[L_{*}\right]=[*]+\left[\mathrm{O}_{2}^{*}\right]+\left[\mathrm{H}_{2} \mathrm{O}_{2}^{*}\right]+\left[\mathrm{OOH}^{*}\right]+\left[\mathrm{O}^{*}\right]+\left[\mathrm{OH}^{*}\right]} \\
{\left[L_{\square}\right]=[\square]+\left[\mathrm{H}^{\square}\right]}
\end{gathered}
$$

Where the total number of sites that bind oxygen species $\left(\left[L_{*}\right]\right)$ mostly depends on the surface coverage of *, $\mathrm{O}_{2}{ }^{*}, \mathrm{OOH}^{*}, \mathrm{O}^{*}, \mathrm{OH}^{*}$, and $\mathrm{H}_{2} \mathrm{O}_{2} *$ intermediates. In contrast, the sites that bind hydrogen $\left(\left[L_{\square}\right]\right)$ include unoccupied $([\square])$ and occupied $\left(\left[H^{\square}\right]\right)$ sites only. For simplicity, we neglect the contribution of anionic surface species $\left(\mathrm{O}_{2}^{-*}, \mathrm{OOH}^{-*}, \mathrm{O}^{-*}, \mathrm{OH}^{-*}\right)$ from this site balance because we expect them to react spontaneously with the protic solvent. Thus, the anionic species likely exist at low coverages under direct synthesis conditions, but equations S7.7, S7.11, and S7.18 indicate that they may contribute to a significant fraction of sites at low potentials and high $\mathrm{pH}$ values. Similarly, we assume that the coverage of $\mathrm{H}_{2} \mathrm{O}^{*}$ is small relative to other oxygenderived intermediates, since such an assumption leads a to rate expression that disagrees with the functional dependence of rates on reactant pressure. ${ }^{27}$ Substituting in equations S7.5, S7.9, S7.13, S7.15, and S7.20 into equation S7.23, we derive the complete expression for the coverage of oxygen-binding sites $\left(\theta_{*}\right)$ :

$$
\begin{aligned}
& \theta_{*}=\frac{[*]}{\left[L_{*}\right]}=\frac{1}{\left(1+K_{a p p, O_{2}}\left[O_{2}\right]\right)} \\
& K_{a p p, O_{2}}=K_{4}\left(1+\frac{k_{5 a}^{0} \mathrm{e}^{-\frac{\alpha_{5 a} \mathrm{~F}\left(\Phi^{o p}-\Phi_{5 \mathrm{a}}^{0}\right)}{\mathrm{RT}}}}{\left(k_{6 a}^{0} \mathrm{e}^{-\frac{\alpha_{6 a} \mathrm{~F}\left(\Phi^{o p}-\Phi_{6 \mathrm{a}}^{0}\right)}{\mathrm{RT}}}+k_{7}^{0} \mathrm{e}^{\left.-\frac{\alpha_{7} \mathrm{~F}\left(\Phi^{o p}-\Phi_{7}^{0}\right)}{\mathrm{RT}}\right)}\right.} K_{O R R}\right)
\end{aligned}
$$




$$
\begin{aligned}
K_{O R R}=1+\frac{k_{6 a}^{0} \mathrm{e}^{-\frac{\alpha_{6 a} \mathrm{~F}\left(\Phi^{o p}-\Phi_{6 \mathrm{a}}^{0}\right)}{\mathrm{RT}}}\left(1+\frac{k_{13}^{0} \mathrm{e}^{-\frac{\alpha_{13} \mathrm{~F}\left(\Phi-\Phi_{13}^{0}\right)}{\mathrm{RT}}}}{\left.k_{9 a}^{0} \mathrm{e}^{-\frac{\alpha_{9} \mathrm{~F}\left(\Phi^{o p}-\Phi_{9}^{0}\right)}{\mathrm{RT}}}\right)}\right.}{\left(k_{12}^{0}+k_{13}^{0} \mathrm{e}^{\left.-\frac{\alpha_{13} \mathrm{~F}\left(\Phi^{o p}-\Phi_{13}^{0}\right)}{\mathrm{RT}}\right)}\right)} \\
+\frac{k_{7}^{0} \mathrm{e}^{-\frac{\alpha_{7} \mathrm{~F}\left(\Phi^{o p}-\Phi_{7}^{0}\right)}{\mathrm{RT}}}}{k_{8 a}^{0} \mathrm{e}^{-\frac{\alpha_{8 a} \mathrm{~F}\left(\Phi^{o p}-\Phi_{8 \mathrm{~b}}^{0}\right)}{\mathrm{RT}}}}+\frac{k_{7}^{0} \mathrm{e}^{-\frac{\alpha_{7} \mathrm{~F}\left(\Phi^{o p}-\Phi_{7}^{0}\right)}{\mathrm{RT}}}}{k_{9 a}^{0} \mathrm{e}^{-\frac{\alpha_{9} \mathrm{~F}\left(\Phi^{o p}-\Phi_{9}^{0}\right)}{\mathrm{RT}}}}
\end{aligned}
$$

These expressions show that the fraction of oxygen-derived intermediates on the surface increases in proportion to the oxygen activity $\left(\left[\mathrm{O}_{2}\right]\right)$ and the apparent adsorption coefficient of these species $\left(K_{a p p, O_{2}}\right) . K_{a p p, O_{2}}$ reflects the relative value of the equilibrium constant of $\mathrm{O}_{2}$ adsorption $\left(K_{4}\right)$ versus the pseudo-steady-state reduction of other oxygen-derived species $\left(K_{O R R}\right)$ on the surface. This $K_{O R R}$ expression depends on the relative rate of $\mathrm{OOH}^{*}$ formation versus its subsequent reduction to either $\mathrm{H}_{2} \mathrm{O}_{2} *$ or $\mathrm{O}^{*}$. Equation $\mathrm{S} 7.27$ also contains terms describing the relative rate of $\mathrm{H}_{2} \mathrm{O}_{2} *$ desorption versus reduction to $\mathrm{OH}^{*}$, which later reduces to $\mathrm{H}_{2} \mathrm{O}$. These equations suggest that changes in these reactive species do not change the dependence of rates as a function of $\mathrm{O}_{2}$ pressure. Still different reactant coverages can significantly affect the value of $K_{a p p, O_{2}}$, which should affect the apparent reaction rate.

Through a similar methodology, we substitute equation S6.8 from section S6 into equation S7.24, to describe the coverage of hydrogen for Heyrovsky-Volmer kinetics:

$$
\begin{aligned}
\theta_{\square} & =\frac{[\square]}{\left[L_{\square}\right]}=\frac{1}{\left(1+K_{a p p, H_{2}}\left[H_{2}\right]\right)} \\
K_{a p p, H_{2}} & =\frac{k_{1}^{0}}{k_{3}^{0}} e^{\frac{F \alpha_{1}\left(\Phi^{o p}-\Phi_{1}^{0}\right)}{R T}} e^{-\frac{F \alpha_{3}\left(\Phi^{o p}-\Phi_{3}^{0}\right)}{R T}}
\end{aligned}
$$

These equations show that $\left[H^{\square}\right]$ saturates the surface in proportion to the activity of hydrogen $\left(\left[\mathrm{H}_{2}\right]\right)$ and its apparent adsorption coefficient $\left(K_{a p p, H_{2}}\right) . K_{a p p, H_{2}}$ reflects the relative rate that hydrogen heterolytically adsorbs onto the surface (step 1) versus the rate that it is consumed (step 3 ) during the formation of protons and electrons. These site balances are substituted into the rate expressions derived in the Section S7.4.

\section{S7.3 Derivation of $\mathrm{H}_{2} \mathrm{O}_{2}$ Selectivity and Average Electrons Transmitted During the ORR}

In this subsection, we use the relevant coverage expressions to determine the selectivity of $\mathrm{H}_{2} \mathrm{O}_{2}$ during the ORR, which is related to the number of electrons transmitted. Here, we define the selectivity of $\mathrm{H}_{2} \mathrm{O}_{2}\left(\mathrm{~S}_{\mathrm{H}_{2} \mathrm{O}_{2}}\right)$ and $\mathrm{H}_{2} \mathrm{O}\left(\mathrm{S}_{\mathrm{H}_{2} \mathrm{O}_{2}}\right)$ as the fraction of $\mathrm{O}_{2}$ that is reduced to either $\mathrm{H}_{2} \mathrm{O}_{2}$ or $\mathrm{H}_{2} \mathrm{O}$, respectively:

$$
\frac{\mathrm{r}_{\mathrm{H}_{2} \mathrm{O}_{2}}}{\left[\mathrm{~L}_{*}\right]}+\frac{\mathrm{r}_{\mathrm{H}_{2} \mathrm{O}}}{\left[\mathrm{L}_{*}\right]}=\left(\mathrm{S}_{\mathrm{H}_{2} \mathrm{O}_{2}}\left(\Phi^{\mathrm{op}}\right)+\mathrm{S}_{\mathrm{H}_{2} \mathrm{O}}\left(\Phi^{\mathrm{op}}\right)\right) \frac{\mathrm{r}_{\mathrm{ORR}}}{\left[\mathrm{L}_{*}\right]}
$$


where the turnover rates of $\mathrm{H}_{2} \mathrm{O}_{2}\left(\mathrm{r}_{\mathrm{H}_{2} \mathrm{O}_{2}} /\left[\mathrm{L}_{*}\right]\right)$ and $\mathrm{H}_{2} \mathrm{O}\left(\mathrm{r}_{\mathrm{H}_{2} \mathrm{O}} /\left[\mathrm{L}_{*}\right]\right)$ formation are proportional to the total rate of ORR and their respective selectivities. Scheme 7.1 suggest the rate of $\mathrm{H}_{2} \mathrm{O}_{2}$ formation should depend on the relative rate that $\mathrm{H}_{2} \mathrm{O}_{2} *$ forms (step 6) and desorbs (step 12) versus the rate that it is over reduced to $\mathrm{H}_{2} \mathrm{O}$ (step 13). In comparison, the rate of $\mathrm{H}_{2} \mathrm{O}$ formation should depend on the rates of $\mathrm{OOH}^{*}$ and $\mathrm{H}_{2} \mathrm{O}_{2}{ }^{*}$ dissociation (steps 7 and 13). Substituting in the appropriate coverage expressions, we derived expressions for the formation of these products:

$$
\begin{aligned}
& \frac{r_{\mathrm{H}_{2} \mathrm{O}_{2}}}{\left[L_{*}\right]}=k_{12}^{0}\left[\mathrm{H}_{2} \mathrm{O}_{2}^{*}\right] \\
& =\frac{k_{12}^{0} k_{6 a}^{0} k_{5 a}^{0} K_{4}\left[O_{2}\right] \mathrm{e}^{-\frac{\alpha_{6 a} \mathrm{~F}\left(\Phi^{o p}-\Phi_{6 \mathrm{a}}^{0}\right)}{\mathrm{RT}}} \mathrm{e}^{-\frac{\alpha_{5 a} \mathrm{~F}\left(\Phi^{o p}-\Phi_{5 \mathrm{a}}^{0}\right)}{\mathrm{RT}}} \theta_{*}}{\left(k_{12}^{0}+k_{13}^{0} \mathrm{e}^{-\frac{\alpha_{13} \mathrm{~F}\left(\Phi-\Phi_{13}^{0}\right)}{\mathrm{RT}}}\right)\left(k_{6 a}^{0} \mathrm{e}^{-\frac{\alpha_{6 a} \mathrm{~F}\left(\Phi^{o p}-\Phi_{6 \mathrm{a}}^{0}\right)}{\mathrm{RT}}}+k_{7}^{0} \mathrm{e}^{-\frac{\alpha_{7} \mathrm{~F}\left(\Phi^{o p}-\Phi_{7}^{0}\right)}{\mathrm{RT}}}\right)} \\
& \frac{r_{H_{2} O}}{\left[L_{*}\right]}=2 k_{7}^{0} \mathrm{e}^{-\frac{\alpha_{7} \mathrm{~F}\left(\Phi^{o p}-\Phi_{7}^{0}\right)}{\mathrm{RT}}}\left[O O H^{*}\right]+2 k_{13}^{0} \mathrm{e}^{-\frac{\alpha_{13} \mathrm{~F}\left(\Phi-\Phi_{13}^{0}\right)}{\mathrm{RT}}}\left[H_{2} O_{2}^{*}\right]=
\end{aligned}
$$

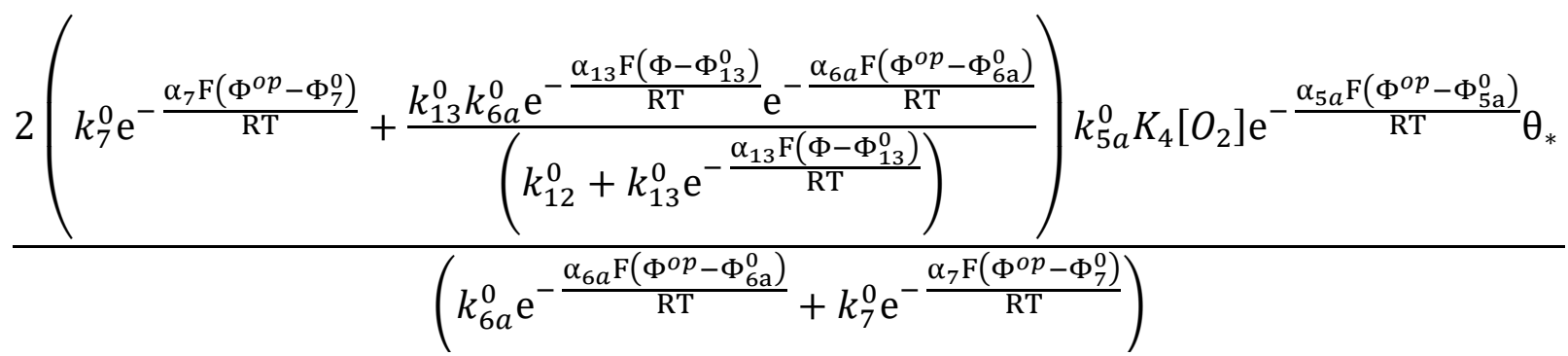

where the stoichiometric formation of $\mathrm{H}_{2} \mathrm{O}_{2}$ and $\mathrm{H}_{2} \mathrm{O}$ depends on the reduction of $\mathrm{OOH}^{*}$ and $\mathrm{H}_{2} \mathrm{O}_{2}$ * species. To simplify the mathematics, we substitute equations S7.31 and S7.32 into equation S7.30 to derive the selectivity of $\mathrm{H}_{2} \mathrm{O}_{2}$ and $\mathrm{H}_{2} \mathrm{O}$ formation:

$$
\begin{aligned}
& \mathrm{S}_{\mathrm{H}_{2} \mathrm{O}_{2}}\left(\Phi^{\mathrm{op}}\right)=\frac{r_{\mathrm{H}_{2} \mathrm{O}_{2}}}{r_{\mathrm{H}_{2} \mathrm{O}_{2}}+r_{\mathrm{H}_{2} \mathrm{O}}} \\
& =\frac{\frac{\mathrm{k}_{12}^{0} \mathrm{k}_{6 \mathrm{a}}^{0} \mathrm{e}^{-\frac{\alpha_{6 \mathrm{a}} \mathrm{F}\left(\Phi^{\mathrm{op}}-\Phi_{6 \mathrm{a}}^{0}\right)}{\mathrm{RT}}}}{\left(\mathrm{k}_{12}^{0}+\mathrm{k}_{13}^{0} \mathrm{e}^{\left.-\frac{\alpha_{13} \mathrm{~F}\left(\Phi^{\mathrm{op}}-\Phi_{13}^{0}\right)}{\mathrm{RT}}\right)}\right.}}{\left(\mathrm{k}_{6 \mathrm{a}}^{0} \mathrm{e}^{-\frac{\alpha_{6 \mathrm{a}} \mathrm{F}\left(\Phi^{\mathrm{op}}-\Phi_{6 \mathrm{a}}^{0}\right)}{\mathrm{RT}}}+2 \mathrm{k}_{7}^{0} \mathrm{e}^{\left.-\frac{\alpha_{7} \mathrm{~F}\left(\Phi^{\mathrm{op}}-\Phi_{7}^{0}\right)}{\mathrm{RT}}\right)}+\frac{k_{13}^{0} k_{6 a}^{0} \mathrm{e}^{-\frac{\alpha_{13} \mathrm{~F}\left(\Phi^{o p}-\Phi_{13}^{0}\right)}{\mathrm{RT}}} \mathrm{e}^{-\frac{\alpha_{6 a} \mathrm{~F}\left(\Phi^{o p}-\Phi_{6 \mathrm{a}}^{0}\right)}{\mathrm{RT}}}}{\left(\mathrm{k}_{12}^{0}+\mathrm{k}_{13}^{0} \mathrm{e}^{-\frac{\alpha_{13} \mathrm{~F}\left(\Phi^{\mathrm{op}}-\Phi_{13}^{0}\right)}{\mathrm{RT}}}\right)}\right.}
\end{aligned}
$$




$$
\mathrm{S}_{\mathrm{H}_{2} \mathrm{O}}\left(\Phi^{\mathrm{op}}\right)=\frac{r_{\mathrm{H}_{2} \mathrm{O}}}{r_{\mathrm{H}_{2} \mathrm{O}_{2}}+r_{\mathrm{H}_{2} \mathrm{O}}}=1-\mathrm{S}_{\mathrm{H}_{2} \mathrm{O}_{2}}\left(\Phi^{\mathrm{op}}\right)
$$

where $\mathrm{S}_{\mathrm{H}_{2} \mathrm{O}_{2}}$ and $\mathrm{S}_{\mathrm{H}_{2} \mathrm{O}}$ are functions of $\Phi^{\mathrm{op}}$ and represent the selectivity towards $\mathrm{H}_{2} \mathrm{O}_{2}$ and $\mathrm{H}_{2} \mathrm{O}$, respectively. Here, the $\mathrm{H}_{2} \mathrm{O}_{2}$ selectivity depends on the rate that $\mathrm{OOH}^{*}$ reduces to $\mathrm{H}_{2} \mathrm{O}_{2}$ (step 6) versus the rate that $\mathrm{OOH}^{*}$ (step 7) or $\mathrm{H}_{2} \mathrm{O}_{2} *$ (step 13) dissociate during $\mathrm{H}_{2} \mathrm{O}$ formation. These expressions also contain terms describing the relative rate that $\mathrm{H}_{2} \mathrm{O}_{2}$ desorbs $\left(r_{12}\right)$ into solution versus the rate that it is reduced to $\mathrm{H}_{2} \mathrm{O}\left(r_{13}\right)$. These equations quantify how selectivities depend on the operating potential and temperature (vide infra). These equations also suggest that the selectivity in electrocatalytic and thermocatalytic measurements will be equivalent if the materials operate at the same potential $\left(\Phi=\Phi^{\mathrm{op}}\right)$, present similar kinetic constants, and possess identical reactant coverages and nanoparticle phase.

Alternatively, we derive $n_{O R R}$ by setting equations S7.2 and S7.3 equal, and substituting in the appropriate coverage expressions each oxygen-derived intermediate:

$$
\begin{aligned}
& =\frac{\left(2 k_{6 a}^{0} \mathrm{e}^{-\frac{\alpha_{6 a} \mathrm{~F}\left(\Phi^{o p}-\Phi_{6 \mathrm{a}}^{0}\right)}{\mathrm{RT}}}+4 k_{7}^{0} \mathrm{e}^{\left.-\frac{\alpha_{7} \mathrm{~F}\left(\Phi^{o p}-\Phi_{7}^{0}\right)}{\mathrm{RT}}\right)}\right.}{\left(k_{6 a}^{0} \mathrm{e}^{-\frac{\alpha_{6 a} \mathrm{~F}\left(\Phi^{o p}-\Phi_{6 \mathrm{a}}^{0}\right)}{\mathrm{RT}}}+k_{7}^{0} \mathrm{e}^{\left.-\frac{\alpha_{7} \mathrm{~F}\left(\Phi^{o p}-\Phi_{7}^{0}\right)}{\mathrm{RT}}\right)}\right.} \\
& +\frac{2 k_{13}^{0} k_{6 a}^{0} \mathrm{e}^{-\frac{\alpha_{13} \mathrm{~F}\left(\Phi^{o p}-\Phi_{13}^{0}\right)}{\mathrm{RT}}} \mathrm{e}^{-\frac{\alpha_{6 a} \mathrm{~F}\left(\Phi^{o p}-\Phi_{6 \mathrm{a}}^{0}\right)}{\mathrm{RT}}}}{\left(k_{12}^{0}+k_{13}^{0} \mathrm{e}^{-\frac{\alpha_{13} \mathrm{~F}\left(\Phi-\Phi_{13}^{0}\right)}{\mathrm{RT}}}\right)\left(k_{6 a}^{0} \mathrm{e}^{-\frac{\alpha_{6 a} \mathrm{~F}\left(\Phi^{o p}-\Phi_{6 a}^{0}\right)}{\mathrm{RT}}}+k_{7}^{0} \mathrm{e}^{-\frac{\alpha_{7} \mathrm{~F}\left(\Phi^{o p}-\Phi_{7}^{0}\right)}{\mathrm{RT}}}\right)}
\end{aligned}
$$

where $n_{O R R}$ reflects the total number of electrons transmitted through the decomposition of $\mathrm{H}_{2} \mathrm{O}_{2}$ * (step 13) and the reduction of $\mathrm{OOH}^{*}$ toward $\mathrm{H}_{2} \mathrm{O}_{2}$ (step 6) and $\mathrm{H}_{2} \mathrm{O}$ (step 7) formation. This expression predicts that the value of $n_{O R R}$ ranges between a value of 2-4, as expected. With some rearrangement of equations $\mathrm{S} 7.33$ and $\mathrm{S} 7.35$, we show how $n_{O R R}$ relates to the selectivity:

$$
n_{O R R}=\frac{4}{1+S_{H_{2} O_{2}}\left(\Phi^{\mathrm{op}}\right)}
$$

This expression shows an intuitive form, which shows that $n_{O R R}$ equals 2 and 4 when $S_{\mathrm{H}_{2} \mathrm{O}_{2}}$ equals 1 and 0 , respectively. Thus, these expressions show what parameters influence the $\mathrm{H}_{2} \mathrm{O}_{2}$ selectivity and correspond number of electrons transferred during ORR.

\section{S7.4 Derivation of Operating Potential and Turnover Rates of ORR During Thermocatalysis}

In this subsection, we relate the rate expressions of the HOR and ORR to approximate the value of $\Phi^{\mathrm{op}}$ and use this term to solve for the total rate of reaction. The current expressions for the HOR 


$$
\begin{gathered}
\frac{i_{H O R}}{\left[L_{\square}\right]}=2 F \frac{r_{H O R}}{\left[L_{\square}\right]}=2 F k_{1}^{0}\left[H_{2}\right]\left[H_{2} O\right] e^{\frac{F \alpha_{1}\left(\Phi^{o p}-\Phi_{1}^{0}\right)}{R T}} \theta_{\square} \\
\frac{i_{O R R}}{\left[L_{*}\right]}=2 F \frac{r_{O R R}}{\left[L_{*}\right]}=n_{O R R} F k_{5 a}^{0} K_{4}\left[O_{2}\right] \mathrm{e}^{-\frac{\alpha_{5 a} \mathrm{~F}\left(\Phi^{O p}-\Phi_{5 \mathrm{a}}^{0}\right)}{\mathrm{RT}}} \theta_{*}
\end{gathered}
$$

Next, we solve for the operating potential of the nanoparticle that is produced by coupled HOR and ORR on the nanoparticle by setting equations S7.37 and S7.38 equal to one another:

$$
\begin{gathered}
\frac{i_{H O R}}{\left[L_{\square}\right]}=-\frac{i_{O R R}}{\left[L_{*}\right]} \\
\Phi^{\mathrm{op}}=\frac{\left(\alpha_{5 \mathrm{a}} \Phi_{5 \mathrm{a}}^{0}+\alpha_{1} \Phi_{1}^{0}\right)}{\left(\alpha_{5 \mathrm{a}}+\alpha_{1}\right)}-\frac{\mathrm{RT}}{\mathrm{F}\left(\alpha_{5 \mathrm{a}}+\alpha_{1}\right)} \ln \left(\frac{2 \mathrm{k}_{1}^{0}\left[\mathrm{H}_{2}\right]\left[\mathrm{H}_{2} \mathrm{O}\right] \theta_{\square}}{\mathrm{n}_{\mathrm{ORR}} \mathrm{k}_{5 \mathrm{a}}^{0} \mathrm{~K}_{4}\left[\mathrm{O}_{2}\right] \theta_{*}}\right)
\end{gathered}
$$

This expression indicates that the number of electrons in the metal (related to $\Phi^{\text {op }}$ ) depends on the relative rate that hydrogen adsorbs and oxidizes into $\mathrm{H}^{+}$and $\mathrm{e}^{-}$versus the rate that oxygen adsorbs and consumes those electrons. This expression also shows that the operating potential depends on the average number of electrons transmitted during the ORR $\left(\mathrm{n}_{\mathrm{ORR}}\right)$. The value of $\mathrm{n}_{\mathrm{ORR}}$ is a function of $\Phi^{\mathrm{op}}$, but for simplicity we treat is as a constant in this evaluation.

Thus, we solve for the total rate of oxygen reduction under thermocatalytic conditions by substituting in expressions for $\theta_{\square}$, and $\theta_{*}$, derived in equations S7.25 and S7.28:

$$
\frac{r_{O R R}}{\left[L_{*}\right]}=\left(\frac{\frac{n_{O R R}}{2} k_{5 a}^{0} K_{4}\left[O_{2}\right]}{1+K_{a p p, O_{2}}\left[O_{2}\right]}\right)^{\frac{\alpha_{1}}{\left(\alpha_{1}+\alpha_{5 a}\right)}}\left(\frac{k_{1}^{0}\left[H_{2}\right]\left[H_{2} O\right]}{1+K_{a p p, H_{2}}\left[H_{2}\right]}\right)^{\frac{\alpha_{5 a}}{\left(\alpha_{1}+\alpha_{5 a}\right)}} e^{\frac{F \alpha_{1} \alpha_{5 a}\left(\Phi_{5 a}^{0}-\Phi_{1}^{0}\right)}{\left(\alpha_{5 a}+\alpha_{1}\right) R T}}
$$

This equation shows that the thermocatalytic rate of the ORR depends on expressions for both the hydrogen oxidation and oxygen reduction reactions. Here, these terms are multiplied by an exponential term, reflecting the difference in equilibrium potentials of the HOR and ORR paths $\left(\Phi_{5 a}^{0}-\Phi_{1}^{0}\right)$. The turnover rate of the ORR also carries an exponential dependence upon parameters that depend on the relative magnitude of the charge transfer coefficients of the ORR and HOR. Empirically, we observe greater values of $\alpha_{\text {ORR }}$ versus $\alpha_{\text {HOR }}$ (Table S2), suggesting that equation S7.41 should simplify:

$$
\frac{r_{O R R}}{\left[L_{*}\right]} \approx\left(\frac{\frac{n_{O R R}}{2} k_{5 a}^{0} K_{4}\left[O_{2}\right]}{1+K_{a p p, O_{2}}\left[O_{2}\right]}\right)^{\frac{\alpha_{1}}{\alpha_{5 a}}}\left(\frac{k_{1}^{0}\left[H_{2}\right]\left[H_{2} O\right]}{1+K_{a p p, H_{2}}\left[H_{2}\right]}\right) e^{\frac{F \alpha_{1}\left(\Phi_{5 a}^{0}-\Phi_{1}^{0}\right)}{R T}}
$$

This expression indicates that rates should increase in proportion with $\left[\mathrm{H}_{2}\right]$ and should show a weak dependence on $\left[\mathrm{O}_{2}\right]$. Similarly, the model predicts that rates should be independent of 
pressure when the surface is saturated with hydrogen- and oxygen-derived intermediates $\left(\left[\mathrm{H}^{\square}\right],\left[\mathrm{O}_{2}^{*}\right],\left[\mathrm{O}^{*}\right],\left[\mathrm{OH}^{*}\right],\left[\mathrm{OOH}^{*}\right]\right)$. The steady-state coverage of such species depends on the apparent adsorption constants of hydrogen $\left(K_{a p p, H_{2}}\right)$ and oxygen $\left(K_{a p p, O_{2}}\right)$, which reflect the relative rate that surface intermediates are generated and consumed. Rearrangement of equations S7.30 and S7.42 yields individual expressions for the formation of $\mathrm{H}_{2} \mathrm{O}_{2}$ and $\mathrm{H}_{2} \mathrm{O}$ :

$$
\begin{aligned}
& \frac{r_{H_{2} O_{2}}}{\left[L_{*}\right]} \approx \mathrm{S}_{\mathrm{H}_{2} O}\left(\Phi^{\mathrm{op}}\right)\left(\frac{\frac{n_{O R R}}{2} k_{5 a}^{0} K_{4}\left[O_{2}\right]}{1+K_{a p p, O_{2}}\left[O_{2}\right]}\right)^{\frac{\alpha_{1}}{\alpha_{5 a}}}\left(\frac{k_{1}^{0}\left[H_{2}\right]\left[H_{2} O\right]}{1+K_{a p p, H_{2}}\left[H_{2}\right]}\right) e^{\frac{F \alpha_{1}\left(\Phi_{5 a}^{0}-\Phi_{1}^{0}\right)}{R T}} \\
& \frac{r_{H_{2} O_{2}}}{\left[L_{*}\right]} \approx \mathrm{S}_{\mathrm{H}_{2} O}\left(\Phi^{\mathrm{op}}\right)\left(\frac{\frac{n_{O R R}}{2} k_{5 a}^{0} K_{4}\left[O_{2}\right]}{1+K_{a p p, O_{2}}\left[O_{2}\right]}\right)^{\frac{\alpha_{1}}{\alpha_{5 a}}}\left(\frac{k_{1}^{0}\left[H_{2}\right]\left[H_{2} O\right]}{1+K_{a p p, H_{2}}\left[H_{2}\right]}\right) e^{\frac{F \alpha_{1}\left(\Phi_{5 a}^{0}-\Phi_{1}^{0}\right)}{R T}}
\end{aligned}
$$

When coverages of hydrogen atoms are low (i.e., $\left[\mathrm{L}_{\square}\right]=[\square]$ ) and the surface is saturated with oxygenates (i.e., $\left[\mathrm{L}_{*}\right] \neq[*]$ ), equation $\mathrm{S} 7.43$ takes the form:

$$
\frac{\mathrm{r}_{\mathrm{H}_{2} \mathrm{O}_{2}}}{\left[\mathrm{~L}_{*}\right]} \approx S_{H_{2} O_{2}}\left(\Phi^{\mathrm{op}}\right)\left(\frac{n_{O R R} k_{5 a}^{0} \mathrm{~K}_{4}}{2 K_{a p p, O_{2}}}\right)^{\frac{\alpha_{1}}{\alpha_{5 a}}}\left(k_{1}^{0}\left[H_{2}\right]\left[H_{2} O\right]\right) e^{\frac{F\left(\alpha_{1}\left(\Phi_{5 a}^{0}-\Phi_{1}^{0}\right)\right)}{R T}}
$$

which predicts that the rate of the ORR increases in proportion with hydrogen pressure at the lowest values of $\left[\mathrm{H}_{2}\right]$, and the overall rate depends mostly on the Heyrovsky step. This rate also depends on the apparent rate constant of electron transfer to oxygen-derived species and the relative charge transfer coefficients of the HOR and ORR.

At the highest hydrogen pressures, hydrogen atoms saturate the available surface sites (i.e., $\left[\mathrm{L}_{\square}\right]=$ $\mathrm{H}^{\square}$ ) and equation $\mathrm{S} 7.3$ simplifies to:

$$
\frac{i_{H O R}}{\left[L_{\square}\right]}=2 F k_{3}^{0}\left[H_{2} O\right] e^{\frac{F \alpha_{3}\left(\Phi^{o p}-\Phi_{3}^{0}\right)}{R T}}
$$

where all terms related to the HOR current are identical but instead depend on reactions related to the Volmer reaction (step 3), which changes the apparent operating potential and resulting rate expression:

$$
\Phi^{\mathrm{op}}=\frac{\left(\alpha_{5 \mathrm{a}} \Phi_{5 \mathrm{a}}^{0}+\alpha_{3} \Phi_{3}^{0}\right)}{\left(\alpha_{5 \mathrm{a}}+\alpha_{3}\right)}-\frac{\mathrm{RT}}{\mathrm{F}\left(\alpha_{5 \mathrm{a}}+\alpha_{3}\right)} \ln \left(\frac{2 K_{a p p, O_{2}} \mathrm{k}_{3}^{0}\left[\mathrm{H}_{2} \mathrm{O}\right]}{\mathrm{n}_{\mathrm{ORR}} \mathrm{k}_{5 \mathrm{a}}^{0} \mathrm{~K}_{4}}\right)
$$




$$
\frac{\mathrm{r}_{\mathrm{H}_{2} \mathrm{O}_{2}}}{\left[\mathrm{~L}_{*}\right]} \approx S_{\mathrm{H}_{2} \mathrm{O}_{2}}\left(\Phi^{\mathrm{op}}\right)\left(\frac{n_{O R R} k_{5 a}^{0} \mathrm{~K}_{4}}{2 K_{a p p, O_{2}}}\right)^{\frac{\alpha_{3}}{\alpha_{5 a}}}\left(k_{3}^{0}\left[H_{2} O\right]\right) e^{\frac{F\left(\alpha_{3}\left(\Phi_{5 a}^{0}-\Phi_{3}^{0}\right)\right)}{R T}}
$$

where the rate of ORR does not depend on hydrogen pressure, and the overall rate is mostly dependent on the Volmer step. Under such conditions, the Volmer step acts as the kinetically relevant step of the HOR, which leads to slight changes in the apparent rate constant and charge transfer coefficients.

These expressions show that the overall rate of reaction depends on both the rate of hydrogen oxidation and oxygen reduction, but the fraction of $\mathrm{H}_{2} \mathrm{O}_{2}$ or $\mathrm{H}_{2} \mathrm{O}$ formed depends on the selectivity factors shown in equations S7.33 and S7.34. Here, equation S7.42 predicts that formation rates increase in proportion with $\left[\mathrm{H}_{2}\right]$ at the lowest $\mathrm{H}_{2}$ pressure before approaching a constant value at the highest pressures. The Tafel-Volmer kinetics (equations S6.5) predicts a similar behavior at the lowest $\mathrm{H}_{2}$ pressure, but we neglect that derivation from this discussion due to its complexity. If we consider an alternative derivation with quasi-equilibrated hydrogen adsorption (equation S6.10), we derive an expression that predicts a sublinear dependence on hydrogen that does not describe the experimental data accurately. Thus, we restrict the discussion of this study to Heyrovsky-Volmer kinetics only. Still, we acknowledge that this rate expression may change if the material facilitates a different pathway for hydrogen oxidation.

\section{S7.5 Considerations of Electron Activity and the Influence of Coupled ORR and HOR}

In this subsection, we more thoroughly evaluate the definition of electron activity on a given nanoparticle and how this term affects its electrical potential. Specifically, we define the thermodynamic activity of electrons on a Pd nanoparticle: ${ }^{1}$

$$
\mu_{e}=\mu_{e}^{0}-F \Phi^{o p}
$$

Here, $\mu_{e}$ is the electron chemical potential on the $\mathrm{Pd}$ nanoparticle and $\mu_{e}^{0}$ is the electron chemical potential in the absence of reactions between hydrogen and oxygen, which is related to the density of states of $\mathrm{Pd}$ near the Fermi level. ${ }^{1}$ This energy should change in proportion to the potential of the nanoparticle phase, which is equal to the operating potential $\left(\Phi^{o p}\right)$ at these conditions:

$$
\mu_{e}=\mu_{e}^{0}-F \frac{\left(\alpha_{5 \mathrm{a}} \Phi_{5 \mathrm{a}}^{0}+\alpha_{1} \Phi_{1}^{0}\right)}{\left(\alpha_{5 \mathrm{a}}+\alpha_{1}\right)}+\frac{\mathrm{RT}}{\left(\alpha_{5 \mathrm{a}}+\alpha_{1}\right)} \ln \left(\frac{2 \mathrm{k}_{1}^{0}\left[\mathrm{H}_{2}\right]\left[\mathrm{H}_{2} \mathrm{O}\right] \theta_{\mathrm{a}}}{\mathrm{n}_{\mathrm{ORR}} \mathrm{k}_{5 \mathrm{a}}^{0} \mathrm{~K}_{4}\left[\mathrm{O}_{2}\right] \theta_{*}}\right)
$$

This equation suggests that the electron chemical potential of a $\mathrm{Pd}$ nanoparticle depends on the relative rate that hydrogen adsorbs and oxidizes into $\mathrm{H}^{+}$and $\mathrm{e}^{-}$versus the rate that oxygen adsorbs and consumes those electrons. Consequently, the operating potential decreases with the activity of hydrogen and increases with the activity of oxygen, which increase or decrease the electron chemical potential, respectively. Next, we differentiate equation S7.40 with respect to the activity of hydrogen at a constant temperature and oxygen pressure and assume a constant selectivity over this range for simplicity: 


$$
\left(\frac{\mathrm{d} \Phi^{o p}}{d\left[H_{2}\right]}\right)_{T,\left[O_{2}\right]} \approx-\left(\frac{R T}{F\left(\alpha_{5 a}+\alpha_{1}\right)}\right)\left(\frac{k_{1}^{0}}{k_{1}^{0}\left[H_{2}\right]^{2}+k_{3}^{0}\left[H_{2}\right]}\right)
$$

Thus, the electrical potential decreases with hydrogen activity as the hydrogen pressure increases until $H^{\square}$ occupies all the available reactive sites. Under such conditions, equation S7.51 no longer depends on the hydrogen pressure and the derivative simplifies to zero:

$$
\lim _{\left[H_{2}\right] \rightarrow \infty}\left(\frac{\mathrm{d} \Phi^{o p}}{d\left[H_{2}\right]}\right)_{T,\left[O_{2}\right]}=0
$$

Here, our model predicts that the change in potential is independent of the activity of hydrogen at the greatest pressures. These conclusions are consistent with the observed open circuit potential as a function of hydrogen pressure on some materials (e.g., PdPt, PdNi, and PdZn), which show a weak dependence on hydrogen pressure at the greatest pressures $\left(200-400 \mathrm{kPa} \mathrm{H}_{2}, 60 \mathrm{kPa} \mathrm{H}_{2}\right.$; Figures S12, S8, and S9). Over a similar range of pressures, however, most materials show rate behavior that is consistent with a hydrogen saturated surface (Figure 5, vide supra). Thus, the observed decrease in potential over this range indicates a reduction in the coverage of oxygenderived intermediates $\left(\left[L_{*}\right]\right)$ or changes in the rate constants or charge transfer coefficients of the elementary steps involved in these reactions. Overall, these interpretations explain why the different materials show diverse changes in operating potential across similar ranges of oxygen and hydrogen pressures (Figure 3). 


\section{S8. Changes in the Selectivity of $\mathrm{H}_{2} \mathrm{O}_{2}$ as a Function of the Electrode Potential}

In this section, we consider an alternative derivation for the selectivity of $\mathrm{H}_{2} \mathrm{O}_{2}$ formation for a purely electrochemical system, in which reactivity changes as a function of the electrode potential $(\Phi)$. We also consider the case that the rate of desorption is comparable or much slower than the rate of secondary $\mathrm{H}_{2} \mathrm{O}_{2}$ decomposition (step 13) at low potentials. ${ }^{33,}{ }^{34}$ Similarly, we investigate how this selectivity changes as a function of potentials and determine what conditions lead to the maximum selectivity towards $\mathrm{H}_{2} \mathrm{O}_{2}$ formation. Overall, these findings give greater insight into why specific the transition state structures lead to differences in selectivities as a function of potential for all the materials investigated.

\section{S8.1 Analysis of $\mathrm{H}_{2} \mathrm{O}_{2}$ Selectivity as a Function of Electrode Potential and Optimization}

In this subsection, we consider the change in the selectivity of $\mathrm{H}_{2} \mathrm{O}_{2}$ as a function of the electrode potential. The analysis in section S7 was solved for some operating potential under direct synthesis conditions, but many of the same expression can be generalized for any potential $\Phi$. Thus, the selectivity in equation $\mathrm{S} 7.33$ can be expressed as:

$$
\begin{aligned}
& \mathrm{S}_{\mathrm{H}_{2} \mathrm{O}_{2}}\left(\Phi^{\mathrm{op}}\right)=\frac{r_{\mathrm{H}_{2} O_{2}}}{r_{\mathrm{H}_{2} O_{2}}+r_{H_{2} O}} \\
& =\frac{\frac{\mathrm{k}_{12}^{0} \mathrm{k}_{6 \mathrm{a}}^{0} \mathrm{e}^{-\frac{\alpha_{6 \mathrm{a}} \mathrm{F}\left(\Phi-\Phi_{6 \mathrm{a}}^{0}\right)}{\mathrm{RT}}}}{\left(\mathrm{k}_{12}^{0}+\mathrm{k}_{13}^{0} \mathrm{e}^{\left.-\frac{\alpha_{13} \mathrm{~F}\left(\Phi-\Phi_{13}^{0}\right)}{\mathrm{RT}}\right)}\right.}}{\left(\mathrm{k}_{6 \mathrm{a}}^{0} \mathrm{e}^{-\frac{\alpha_{6 \mathrm{a}} \mathrm{F}\left(\Phi-\Phi_{6 \mathrm{a}}^{0}\right)}{\mathrm{RT}}}+2 \mathrm{k}_{7}^{0} \mathrm{e}^{-\frac{\alpha_{7} \mathrm{~F}\left(\Phi-\Phi_{7}^{0}\right)}{\mathrm{RT}}}\right)+\frac{k_{13}^{0} k_{6 a}^{0} \mathrm{e}^{-\frac{\alpha_{13} \mathrm{~F}\left(\Phi-\Phi_{13}^{0}\right)}{\mathrm{RT}}} \mathrm{e}^{-\frac{\alpha_{6 a} \mathrm{~F}\left(\Phi-\Phi_{6 \mathrm{a}}^{0}\right)}{\mathrm{RT}}}}{\left(\mathrm{k}_{12}^{0}+\mathrm{k}_{13}^{0} \mathrm{e}^{-\frac{\alpha_{13} \mathrm{~F}\left(\Phi-\Phi_{13}^{0}\right)}{\mathrm{RT}}}\right)}}
\end{aligned}
$$

Where the selectivity of $\mathrm{H}_{2} \mathrm{O}_{2}$ formation changes nonmonotonically with $\Phi$ and reflects fraction of $\mathrm{H}_{2} \mathrm{O}_{2}$ * that forms and desorbs into solution versus the total rate of $\mathrm{OOH}^{*}$ and $\mathrm{H}_{2} \mathrm{O}_{2}$ * reduction. At high potentials, equations S8.1 that the rate of desorption is fast relative to decomposition $\left(r_{12} \gg r_{13}\right)$, and this equation simplifies:

$$
\mathrm{S}_{\mathrm{H}_{2} \mathrm{O}_{2}}\left(\Phi^{\mathrm{op}}\right)=\frac{r_{\mathrm{H}_{2} O_{2}}}{r_{\mathrm{H}_{2} O_{2}}+r_{\mathrm{H}_{2} O} \mathrm{O}}=\frac{\mathrm{k}_{6 \mathrm{a}}^{0} \mathrm{e}^{-\frac{\alpha_{6 \mathrm{a}} \mathrm{F}\left(\Phi-\Phi_{6 \mathrm{a}}^{0}\right)}{\mathrm{RT}}}}{\left(\mathrm{k}_{6 \mathrm{a}}^{0} \mathrm{e}^{-\frac{\alpha_{6 \mathrm{a}} \mathrm{F}\left(\Phi-\Phi_{6 \mathrm{a}}^{0}\right)}{\mathrm{RT}}}+2 \mathrm{k}_{7}^{0} \mathrm{e}^{-\frac{\alpha_{7} \mathrm{~F}\left(\Phi-\Phi_{7}^{0}\right)}{\mathrm{RT}}}\right)}
$$

where the selectivity of $\mathrm{H}_{2} \mathrm{O}_{2}$ increases sigmoidally with the value of $\Phi$ and the secondary decomposition of $\mathrm{H}_{2} \mathrm{O}_{2}$ is treated as negligible. Under typical direct synthesis conditions or at negligible overpotentials of the ORR, the free energy barrier of $\mathrm{H}_{2} \mathrm{O}_{2}$ desorption is small and can be much lower than that of electrochemical $\mathrm{H}_{2} \mathrm{O}_{2}$ dissociation. ${ }^{15}$. At more negative potentials, however, the rate of electron transfer to $\mathrm{H}_{2} \mathrm{O}_{2} *$ species increases significantly, while the rate of 
$\mathrm{H}_{2} \mathrm{O}_{2}$ desorption is independent of potential. Consequently, the apparent $\mathrm{H}_{2} \mathrm{O}_{2}$ selectivity decreases significantly at these lower potential ranges and approaches a value of $0\left(r_{12} \ll r_{13}\right)$.

With a complete expression for the selectivity of $\mathrm{H}_{2} \mathrm{O}_{2}$ selectivity, we evaluated the derivative of this function with respect to $\Phi$ to give better insight as to why a change in potential affects selectivity. Thus, we define the numerator of equation S8.1 as $f(\Phi)$ and its denominator as $g(\Phi)$ to simplify the mathematics:

$$
\begin{aligned}
& f(\Phi)=k_{12}^{0} k_{6 a}^{0} \mathrm{e}^{-\frac{\alpha_{6 a} \mathrm{~F}\left(\Phi-\Phi_{6 \mathrm{a}}^{0}\right)}{\mathrm{RT}}} \\
& g(\Phi)=\left(k_{12}^{0}+k_{13}^{0} \mathrm{e}^{-\frac{\alpha_{13} \mathrm{~F}\left(\Phi-\Phi_{13}^{0}\right)}{\mathrm{RT}}}\right)\left(k_{6 a}^{0} \mathrm{e}^{-\frac{\alpha_{6 a} \mathrm{~F}\left(\Phi-\Phi_{6 \mathrm{a}}^{0}\right)}{\mathrm{RT}}}+2 k_{7}^{0} \mathrm{e}^{-\frac{\alpha_{7} \mathrm{~F}\left(\Phi-\Phi_{7}^{0}\right)}{\mathrm{RT}}}\right) \\
& +k_{13}^{0} k_{6 a}^{0} \mathrm{e}^{-\frac{\alpha_{13} \mathrm{~F}\left(\Phi-\Phi_{13}^{0}\right)}{\mathrm{RT}}} \mathrm{e}^{-\frac{\alpha_{6 a} \mathrm{~F}\left(\Phi-\Phi_{6 \mathrm{a}}^{0}\right)}{\mathrm{RT}}} \\
& \left(\frac{d S_{\mathrm{H}_{2} \mathrm{O}_{2}}(\Phi)}{d \Phi}\right)_{T}=\frac{\frac{d(f(\Phi))}{d \Phi} g(\Phi)-\frac{d(g(\Phi))}{d \Phi} f(\Phi)}{g(\Phi)^{2}}
\end{aligned}
$$

where the derivative of selectivity is described by the quotient rule above. Evaluating these derivatives, we find the following expression from $f$ and $g$ :

$$
\begin{aligned}
& \frac{d(f(\Phi))}{d \Phi}=-\frac{k_{12}^{0} k_{6 a}^{0} \alpha_{6 a} \mathrm{~F}}{\mathrm{RT}} \mathrm{e}^{-\frac{\alpha_{6 a} \mathrm{~F}\left(\Phi-\Phi_{6 \mathrm{a}}^{0}\right)}{\mathrm{RT}}} \\
& \frac{d(g(\Phi))}{d \Phi}=\left(-\frac{\mathrm{F}}{\mathrm{RT}}\left(k_{12}^{0}+k_{13}^{0} \mathrm{e}^{-\frac{\alpha_{13} \mathrm{~F}\left(\Phi-\Phi_{13}^{0}\right)}{\mathrm{RT}}}\right)\left(k_{6 a}^{0} \alpha_{6 a} \mathrm{e}^{-\frac{\alpha_{6 a} \mathrm{~F}\left(\Phi-\Phi_{6 \mathrm{a}}^{0}\right)}{\mathrm{RT}}}\right.\right. \\
& \left.+2 k_{7}^{0} \alpha_{7} \mathrm{e}^{-\frac{\alpha_{7} \mathrm{~F}\left(\Phi-\Phi_{7}^{0}\right)}{\mathrm{RT}}}\right) \\
& +k_{13}^{0} \alpha_{13} \mathrm{e}^{-\frac{\alpha_{13} \mathrm{~F}\left(\Phi-\Phi_{13}^{0}\right)}{\mathrm{RT}}}\left(k_{6 a}^{0} \mathrm{e}^{-\frac{\alpha_{6 a} \mathrm{~F}\left(\Phi-\Phi_{6 \mathrm{a}}^{0}\right)}{\mathrm{RT}}}\right. \\
& \left.\left.+2 k_{7}^{0} \mathrm{e}^{-\frac{\alpha_{7} \mathrm{~F}\left(\Phi-\Phi_{7}^{0}\right)}{\mathrm{RT}}}\right)\right) \\
& -\frac{\mathrm{F}}{\mathrm{RT}} k_{13}^{0} k_{6 a}^{0}\left(\alpha_{6 a}+\alpha_{13}\right) \mathrm{e}^{-\frac{\alpha_{13} \mathrm{~F}\left(\Phi-\Phi_{13}^{0}\right)}{\mathrm{RT}}} \mathrm{e}^{-\frac{\alpha_{6 a} \mathrm{~F}\left(\Phi-\Phi_{6 \mathrm{a}}^{0}\right)}{\mathrm{RT}}}
\end{aligned}
$$

Due to the complexity of this expression, we assume that the rate of $\mathrm{H}_{2} \mathrm{O}_{2}$ desorption is slow relative to decomposition $\left(r_{13} \gg r_{12}\right)$, which is reasonable at the low operating potentials where secondary decomposition is prevalent. Applying this assumption and combining equations S8.37, we derive: 


$$
\begin{aligned}
& \left(\frac{d S_{\mathrm{H}_{2} \mathrm{O}_{2}}(\Phi)}{d \Phi}\right)_{T} \\
& \approx \frac{\frac{k_{12}^{0} k_{6 a}^{0} \mathrm{~F}}{\mathrm{RT}} \mathrm{e}^{-\frac{\alpha_{6 a} \mathrm{~F}\left(\Phi-\Phi_{6 \mathrm{a}}^{0}\right)}{\mathrm{RT}}}\left(\left(\alpha_{6 a}-\alpha_{7}-\alpha_{13}\right) k_{7} \mathrm{e}^{-\frac{\alpha_{7} \mathrm{~F}\left(\Phi-\Phi_{7}^{0}\right)}{\mathrm{RT}}}-\alpha_{13} k_{6 a} \mathrm{e}^{-\frac{\alpha_{6 a} \mathrm{~F}\left(\Phi-\Phi_{6 \mathrm{a}}^{0}\right)}{\mathrm{RT}}}\right)}{2\left(k_{6 a}^{0} \mathrm{e}^{-\frac{\alpha_{6 a} \mathrm{~F}\left(\Phi-\Phi_{6 \mathrm{a}}^{0}\right)}{\mathrm{RT}}}+k_{7}^{0} \mathrm{e}^{\left.-\frac{\alpha_{7} \mathrm{~F}\left(\Phi-\Phi_{7}^{0}\right)}{\mathrm{RT}}\right)^{2}}\right.}
\end{aligned}
$$

Where the change in selectivity as a function of potential depends on the competing charge transfer coefficients of $\mathrm{H}_{2} \mathrm{O}_{2}$ formation $\left(\alpha_{6 a}\right)$ versus the primary $\left(\alpha_{7}\right)$ and secondary $\left(\alpha_{13}\right) \mathrm{H}_{2} \mathrm{O}$ formation pathways. With some simplification, we separate this term into the contributions of the primary formation pathways and the $\mathrm{H}_{2} \mathrm{O}_{2}$ decomposition pathway.

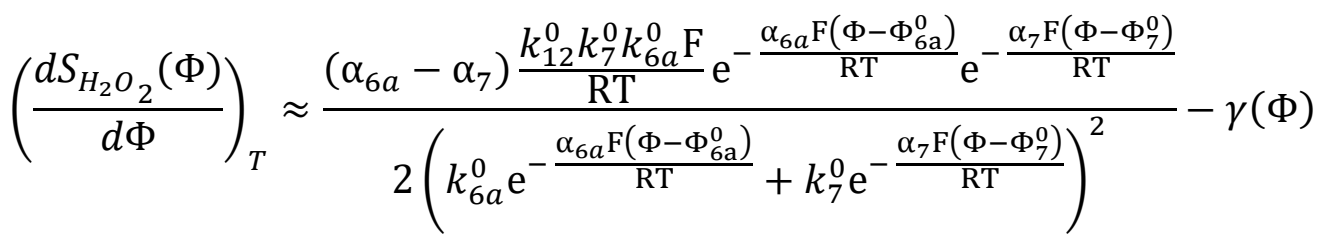

Where the left-hand expression accounts for the change in selectivity from the primary $\mathrm{H}_{2} \mathrm{O}_{2}$ and $\mathrm{H}_{2} \mathrm{O}$ formation pathways while the term $\gamma$ describes the secondary decomposition of $\mathrm{H}_{2} \mathrm{O}_{2}$. The left-hand term tends to dominate at the more positive potentials, at which the rate of $\mathrm{H}_{2} \mathrm{O}_{2}$ desorption is significantly faster than its rate of $\mathrm{H}_{2} \mathrm{O}_{2}$ decomposition. Under such conditions, the expression simplifies further to equation S8.10:

$$
\left(\frac{d S_{H_{2} O_{2}}(\Phi)}{d \Phi}\right)_{T} \approx \frac{2\left(\alpha_{6 a}-\alpha_{7}\right) \frac{k_{7}^{0} k_{6 a}^{0} \mathrm{~F}}{\mathrm{RT}} \mathrm{e}^{-\frac{\alpha_{6 a} \mathrm{~F}\left(\Phi-\Phi_{6 \mathrm{a}}^{0}\right)}{\mathrm{RT}}} \mathrm{e}^{-\frac{\alpha_{7} \mathrm{~F}\left(\Phi-\Phi_{7}^{0}\right)}{\mathrm{RT}}}}{2\left(k_{6 a}^{0} \mathrm{e}^{-\frac{\alpha_{6 a} \mathrm{~F}\left(\Phi-\Phi_{6 \mathrm{a}}^{0}\right)}{\mathrm{RT}}}+k_{7}^{0} \mathrm{e}^{-\frac{\alpha_{7} \mathrm{~F}\left(\Phi-\Phi_{7}^{0}\right)}{\mathrm{RT}}}\right)^{2}}
$$

Here, this expression is equal to the derivative of equation S8.2, which describes the change in selectivity as a function of potential for the primary pathways only. The functional form of equation S8.10 shows that the selectivity increases sharply near a potential of inflection where $d^{2} S_{\mathrm{H}_{2} \mathrm{O}_{2}} / d \Phi^{2}=0$. At this condition, the selectivity shows the greatest change with potential, which is proportional to the difference in charge transfer coefficients between the primary $\mathrm{H}_{2} \mathrm{O}_{2}$ and $\mathrm{H}_{2} \mathrm{O}$ formation pathways. At more extreme potentials (i.e., as $\Phi$ approaches the limit of infinity or negative infinity), equation S8.10 approaches a value of zero, suggesting that the selectivity should approach 0 or $100 \%$. However, the observed function of the selectivity with potential show a parabolic rather than sigmoidal form, which is captured in the $\gamma$, as shown below: 


$$
\gamma(\Phi)=\frac{\alpha_{13} \frac{k_{12}^{0} k_{6 a}^{0} \mathrm{~F}}{\mathrm{RT}} \mathrm{e}^{-\frac{\alpha_{6 a} \mathrm{~F}\left(\Phi-\Phi_{6 \mathrm{a}}^{0}\right)}{\mathrm{RT}}}}{2\left(k_{6 a}^{0} \mathrm{e}^{-\frac{\alpha_{6 a} \mathrm{~F}\left(\Phi-\Phi_{6 \mathrm{a}}^{0}\right)}{\mathrm{RT}}}+k_{7}^{0} \mathrm{e}^{\left.-\frac{\alpha_{7} \mathrm{~F}\left(\Phi-\Phi_{7}^{0}\right)}{\mathrm{RT}}\right)}\right.}
$$

Where the selectivity at lower potentials decreases due to the greater prevalence of secondary decomposition. Here the change in selectivity decreases in proportion to the charge transfer coefficient of step 13. Similarly, this selectivity term depends on the ratio of the rate of $\mathrm{H}_{2} \mathrm{O}_{2}$ desorption (step 12) and $\mathrm{H}_{2} \mathrm{O}_{2}$ decomposition (step 13). Thus, the maximum selectivity occurs at the intersection of $\gamma$ and the region where the primary $\mathrm{H}_{2} \mathrm{O}_{2}$ formation pathway begins to dominate the $\mathrm{H}_{2} \mathrm{O}$ formation pathway at potentials below the potential of inflection. This optimum is determined when the derivative in equation $\mathrm{S} 8.8$ equals zero $\left(d S_{\mathrm{H}_{2} \mathrm{O}_{2}} / d \Phi=0\right)$, which simplifies below:

$$
k_{6 a}^{0} \alpha_{13} \mathrm{e}^{-\frac{\alpha_{6 a} \mathrm{~F}\left(\Phi_{o p t}-\Phi_{6 \mathrm{a}}^{0}\right)}{\mathrm{RT}}} \approx k_{7}^{0}\left(\alpha_{6 a}-\alpha_{7}-\alpha_{13}\right) \mathrm{e}^{-\frac{\alpha_{7} \mathrm{~F}\left(\Phi_{o p t}-\Phi_{7}^{0}\right)}{\mathrm{RT}}}
$$

Then, with some simplification we solve for the approximate form of the optimal operating potential below:

$$
\Phi_{o p t} \approx \frac{\mathrm{RT}}{F\left(\alpha_{7}-\alpha_{6 a}\right)} \ln \left(\frac{k_{7}^{0}\left(\alpha_{6 a}-\alpha_{7}-\alpha_{13}\right)}{k_{6 a}^{0} \alpha_{13}}\right)+\frac{\left(\alpha_{7} \Phi_{7}^{0}-\alpha_{6 a} \Phi_{6 a}^{0}\right)}{\left(\alpha_{7}-\alpha_{6 a}\right)}
$$

This expression shows that $\Phi_{\text {opt }}$ depends on the relative values of the charge transfer coefficients towards $\mathrm{H}_{2} \mathrm{O}_{2}$ formation $\left(\alpha_{6 a}\right)$ versus the extent of charge transfer toward $\mathrm{OOH}^{*}$ dissociation $\left(\alpha_{7}\right)$ or $\mathrm{H}_{2} \mathrm{O}_{2}$ dissociation $\left(\alpha_{13}\right)$.Similarly, this expression depends on the relative value of $k_{6 a}^{0}$ and $k_{7}^{0}$, which reflect the intrinsic selectivity and barriers of the primary $\mathrm{H}_{2} \mathrm{O}_{2}$ and $\mathrm{H}_{2} \mathrm{O}$ formation pathways in the absence of an applied potential. Thus, the value of $\Phi_{\text {opt }}$ depends on several parameters that are critical to defining the $\mathrm{H}_{2} \mathrm{O}_{2}$ selectivity of a catalyst.

\section{S8.2 Experimental Comparisons of Selectivity and Optimal Potentials of Catalytic Materials} In this subsection, we show the empirically measured selectivities of catalytic materials as a function of potential and compare these data to the expectations of our derivations shown in the earlier subsections. Figures S44-S56 show the $\mathrm{H}_{2} \mathrm{O}_{2}$ selectivity of each material as a function of potential with a corresponding fit from equation S8.1. We report the values of the relevant fitted parameters in Table S3.

Generally, each catalyst shows a steep increase in selectivity as the potential decreases before reaching an optimum selectivity between $0.65-0.30 \mathrm{~V}$ vs. NHE, and in some instances, show multiple local maxima. At even lower potentials, the $\mathrm{H}_{2} \mathrm{O}_{2}$ selectivity decreases steeply or gradually, depending on the material. The analysis in section S8.2 suggests that the slope of selectivity with potential reflects the difference in the values of the charge transfer coefficients for the primary $\mathrm{H}_{2} \mathrm{O}_{2}\left(\alpha_{6 a}\right)$ and $\mathrm{H}_{2} \mathrm{O}\left(\alpha_{7}\right)$ formation paths. Here, materials like PdZn and Au show the 
greatest slope, while PdCo and Pt show the smallest slope. Thus, PdZn and Au significantly favor charge transfer towards the formation of $\mathrm{H}_{2} \mathrm{O}_{2}$ versus the formation of $\mathrm{H}_{2} \mathrm{O}$. At lower potentials, the decrease in selectivity depends mostly on the charge transfer coefficient of $\mathrm{H}_{2} \mathrm{O}_{2}$ decomposition $\left(\alpha_{13}\right)$ and the relative rates of the intrinsic constants of $\mathrm{H}_{2} \mathrm{O}_{2}$ dissociation and desorption $\left(k_{12}^{0} / k_{13}^{0}\right)$. Consequently, materials that are unselective towards $\mathrm{H}_{2} \mathrm{O}_{2}$ formation (e.g., $\mathrm{Pt}, \mathrm{PdCu}$ ) tend to show a sharp decrease in selectivity. In contrast, more selective catalysts (e.g., Au-based materials) show a more gradual decrease in selectivity over larger ranges of potential.

Some materials show deviations from the predictions of equation S8.1. For instance, materials like $\mathrm{Pd}_{1} \mathrm{Au}_{60}, \mathrm{Pt}_{1} \mathrm{Au}_{60}, \mathrm{Pt}_{1} \mathrm{Au}_{5}$, and $\mathrm{PdNi}$ show two local maxima, suggesting that these materials may contain multiple types of reactive moieties that are prevalent at distinct ranges of potentials. Alternatively, these materials may develop new structures with unique catalytic behaviors as the potential of the nanoparticles change during the measurement. Regardless, almost all materials deviate from equation S8.1 at the lowest potentials since this equation predicts that the selectivity should approach $0 \%$. This discrepancy likely results from an increase in the ORR activity of the carbon, which shows greater reactivity at the lower range of potentials, as shown by Figure S57. Similarly, we more clearly observe this increase in carbon reactivity on the supported Pd nanoparticle materials reported over a broader range of potentials in Figure S58a. It is also possible that these RRDE measurements are convoluted by other side reactions like the reduction of protons from solution, which results in the hydrogen under potential region and hydrogen evolution region in the voltammograms of Figures S58a and S58b. Finally, the change in potential may result in structural changes to the catalysts that change the values of each fitted kinetic parameter, which may influence the catalyst selectivity in ways that are not captured by equation S8.1.

Table S3. Best fits of the relevant kinetic parameters from Figures S44-S56, which include the ratio of the intrinsic rate constants of primary $\mathrm{H}_{2} \mathrm{O}_{2}$ and $\mathrm{H}_{2} \mathrm{O}$ formation $\left(k_{6 a}^{0} / k_{7}^{0}\right)$, their respective charge transfer coefficients $\left(\alpha_{6 a}, \alpha_{7}\right)$, the ratio of the intrinsic rate constants secondary $\mathrm{H}_{2} \mathrm{O}_{2}$ decomposition and desorption $\left(k_{12}^{0} / k_{13}^{0}\right)$, the charge transfer coefficient of $\mathrm{H}_{2} \mathrm{O}_{2}$ decomposition $\left(\alpha_{13}\right)$, and the optimum electrical potentials $\left(\Phi_{\text {opt }}\right)$ for maximum $\mathrm{H}_{2} \mathrm{O}_{2}$ selectivity. Note that some materials show multiple optimum potentials.

\begin{tabular}{|c|c|c|c|c|c|c|}
\hline Material & $k_{6 a}^{0} / k_{7}^{0}$ & $k_{12}^{0} / k_{13}^{0}$ & $\alpha_{6 a}$ & $\alpha_{7}$ & $\alpha_{13}$ & $\Phi_{\text {opt }}$ (V vs. NHE) \\
\hline $\mathrm{Pt}$ & 0.42 & $9.4 \times 10^{21}$ & 0.75 & 0.35 & 1.10 & 0.63 \\
\hline $\mathrm{Pd}$ & 290 & $5.2 \times 10^{7}$ & 1.60 & 0.64 & 0.33 & 0.43 \\
\hline $\mathrm{PdZn}$ & $3.2 \times 10^{4}$ & $1.5 \times 10^{4}$ & 3.40 & 1.2 & 0.20 & 0.49 \\
\hline $\mathrm{PtCo}$ & 1.8 & $6.3 \times 10^{5}$ & 0.83 & 0.14 & 0.27 & 0.53 \\
\hline $\mathrm{PdPt}$ & 7.7 & $2.5 \times 10^{4}$ & 1.00 & 0.33 & 0.20 & 0.44 \\
\hline $\mathrm{Au}$ & 1100 & 30.0 & 2.70 & 0.86 & 0.05 & 0.44 \\
\hline $\mathrm{PdCu}$ & 26 & $2.0 \times 10^{14}$ & 1.60 & 0.23 & 0.78 & 0.64 \\
\hline $\mathrm{PdCo}$ & 100 & $5.5 \times 10^{9}$ & 0.52 & 0.23 & 0.48 & 0.6 \\
\hline $\mathrm{PdNi}$ & 0.15 & $3.7 \times 10^{13}$ & 0.49 & 0.00 & 0.57 & $0.20,0.44$ \\
\hline $\mathrm{Pd}_{1} \mathrm{Au}_{60}$ & 1100 & 14.0 & 2.20 & 0.68 & 0.04 & $0.51,0.33$ \\
\hline $\mathrm{Pt}_{1} \mathrm{Au}_{60}$ & 1100 & 55.0 & 1.40 & 0.66 & 0.06 & $0.36,0.39$ \\
\hline $\mathrm{Pt}_{1} \mathrm{Au}_{15}$ & 1100 & $1.4 \times 10^{3}$ & 1.60 & 0.65 & 0.10 & 0.32 \\
\hline $\mathrm{Pt}_{1} \mathrm{Au}_{5}$ & 0.02 & 92 & 1.00 & 0.05 & 0.06 & $0.46,0.37$ \\
\hline
\end{tabular}




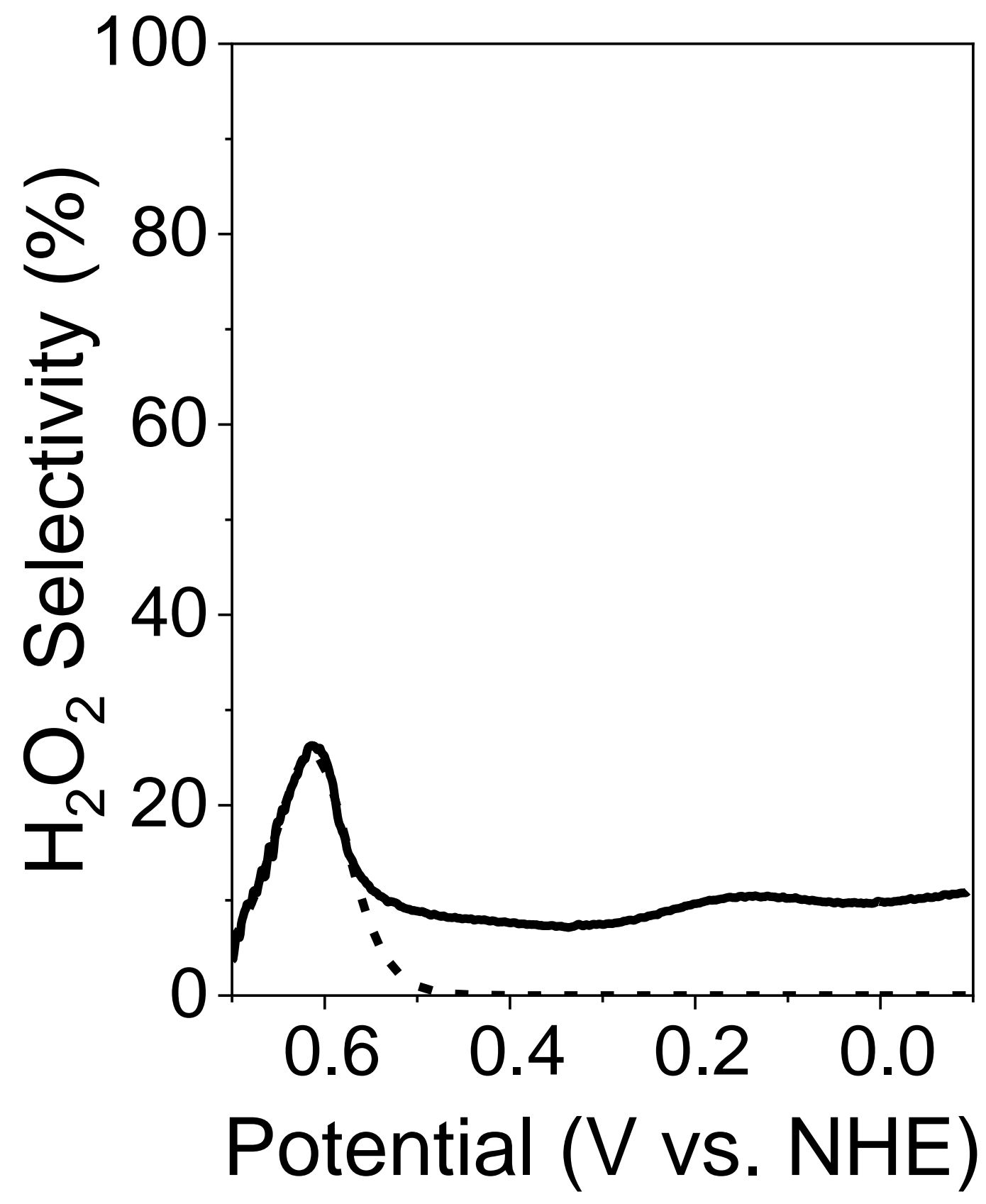

Figures S44. The selectivity of $\mathrm{H}_{2} \mathrm{O}_{2}$ formation on Pt nanoparticles supported on Vulcan XC-72 as a function of potential (-0.1-0.7 V vs. NHE), in which the best fit of equation S8.1 is shown as the dashed line. 


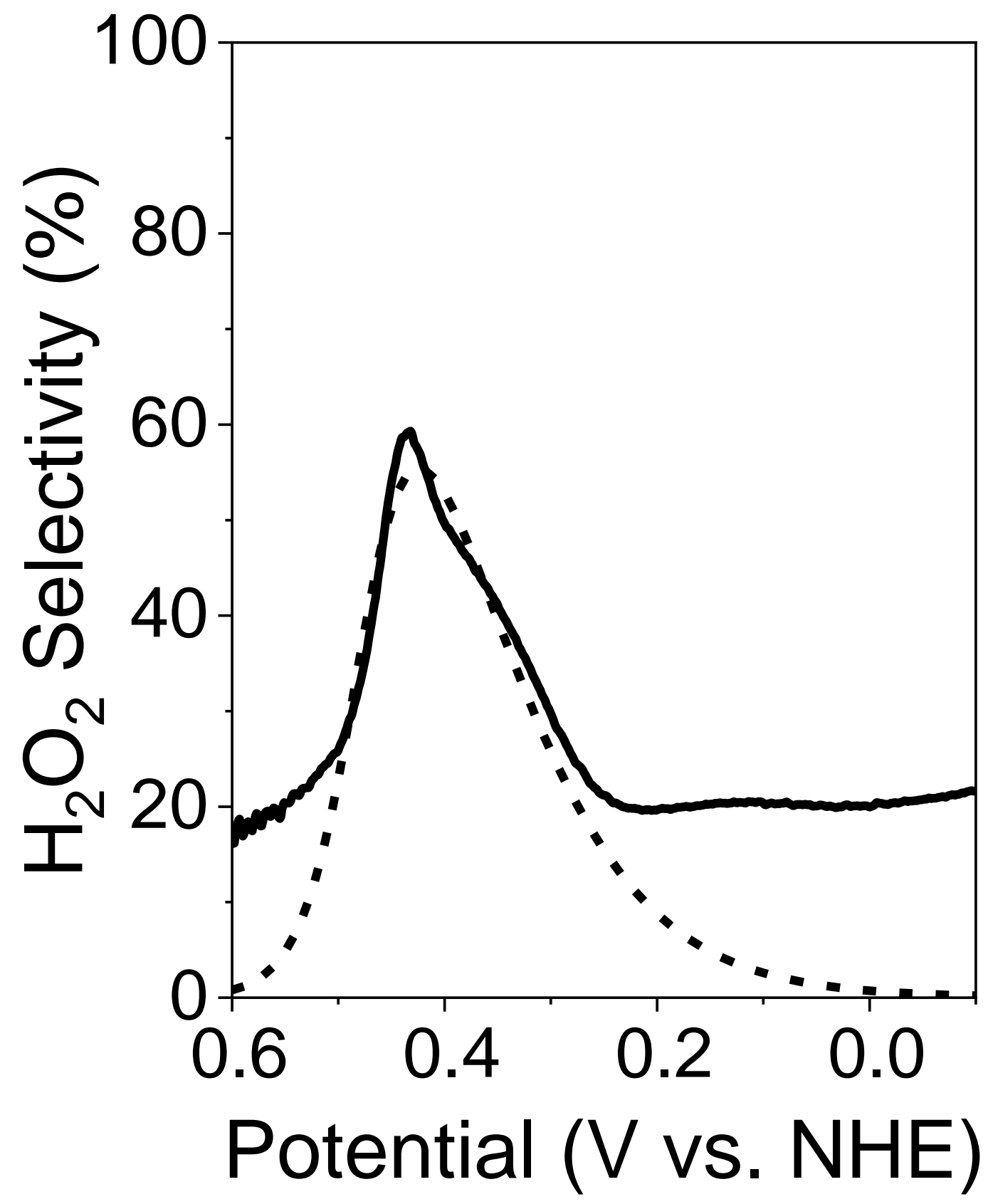

Figures S45. The selectivity of $\mathrm{H}_{2} \mathrm{O}_{2}$ formation on Pd nanoparticles supported on Vulcan XC-72 as a function of potential (-0.1-0.7 V vs. NHE), in which the best fit of equation S8.1 is shown as the dashed line. 


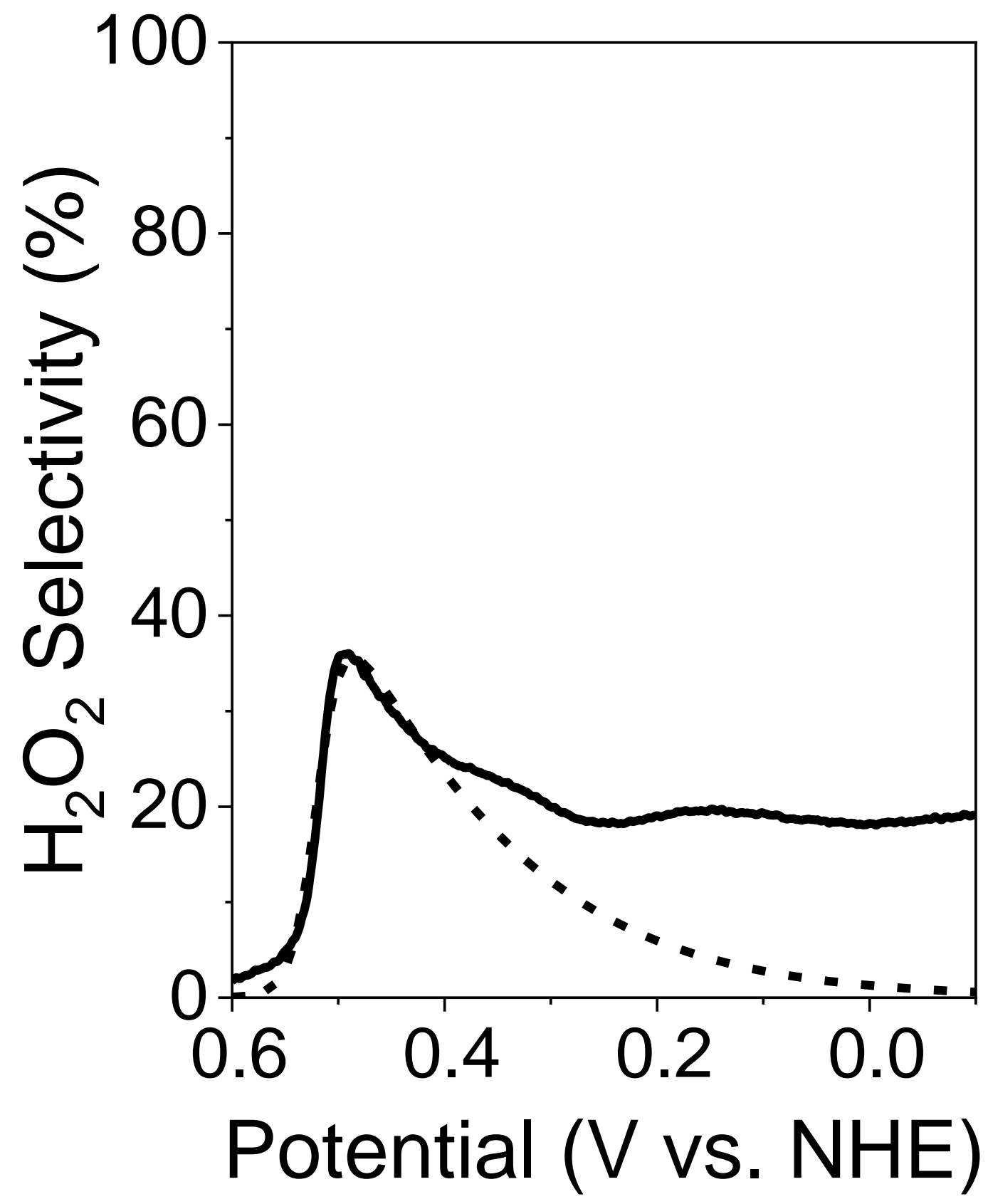

Figures S46. The selectivity of $\mathrm{H}_{2} \mathrm{O}_{2}$ formation on $\mathrm{PdZn}$ nanoparticles supported on Vulcan XC72 as a function of potential (-0.1-0.7 V vs. NHE), in which the best fit of equation S8.1 is shown as the dashed line. 


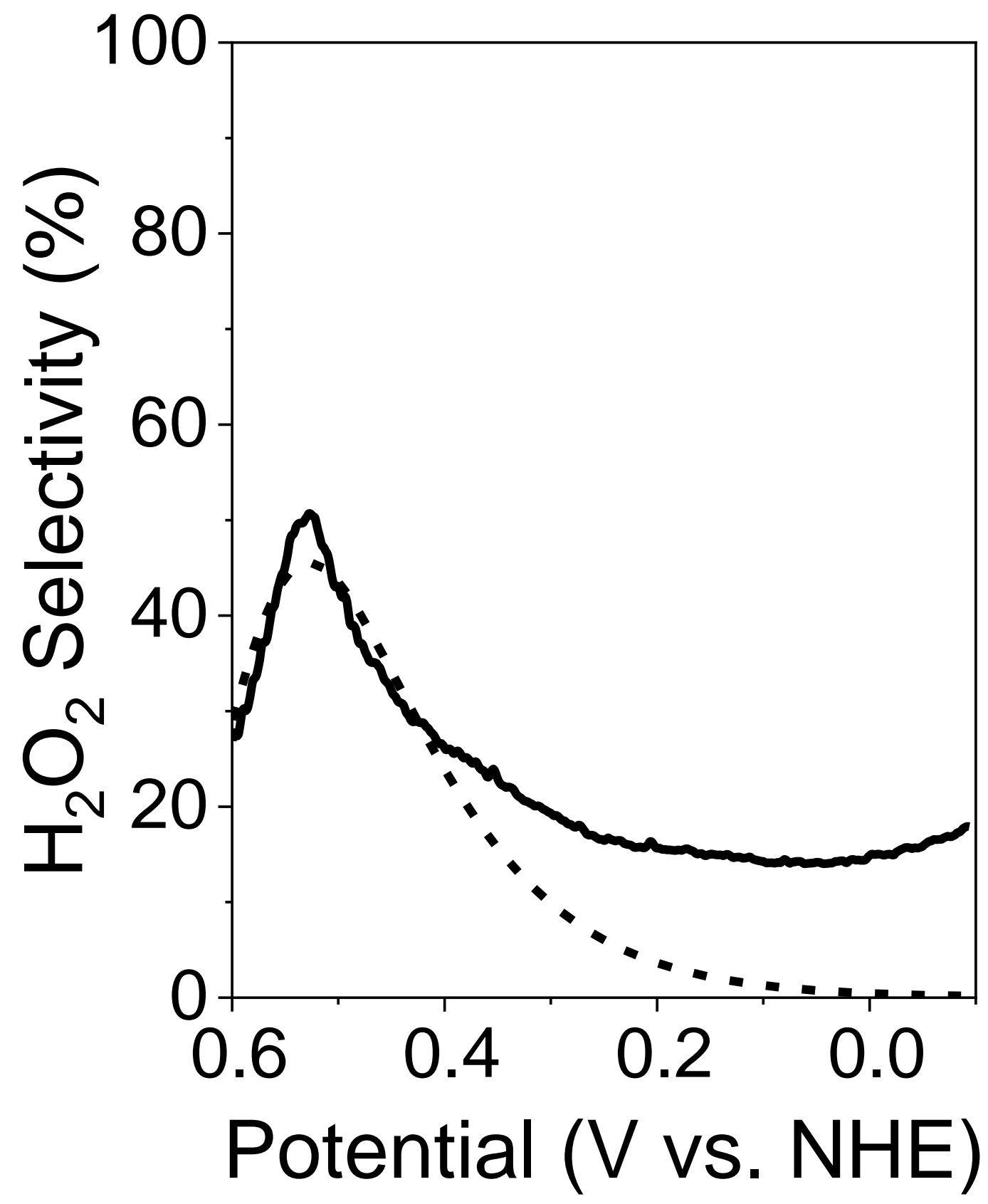

Figures S47. The selectivity of $\mathrm{H}_{2} \mathrm{O}_{2}$ formation on PtCo nanoparticles supported on Vulcan XC72 as a function of potential (-0.1-0.7 V vs. NHE), in which the best fit of equation S8.1 is shown as the dashed line. 


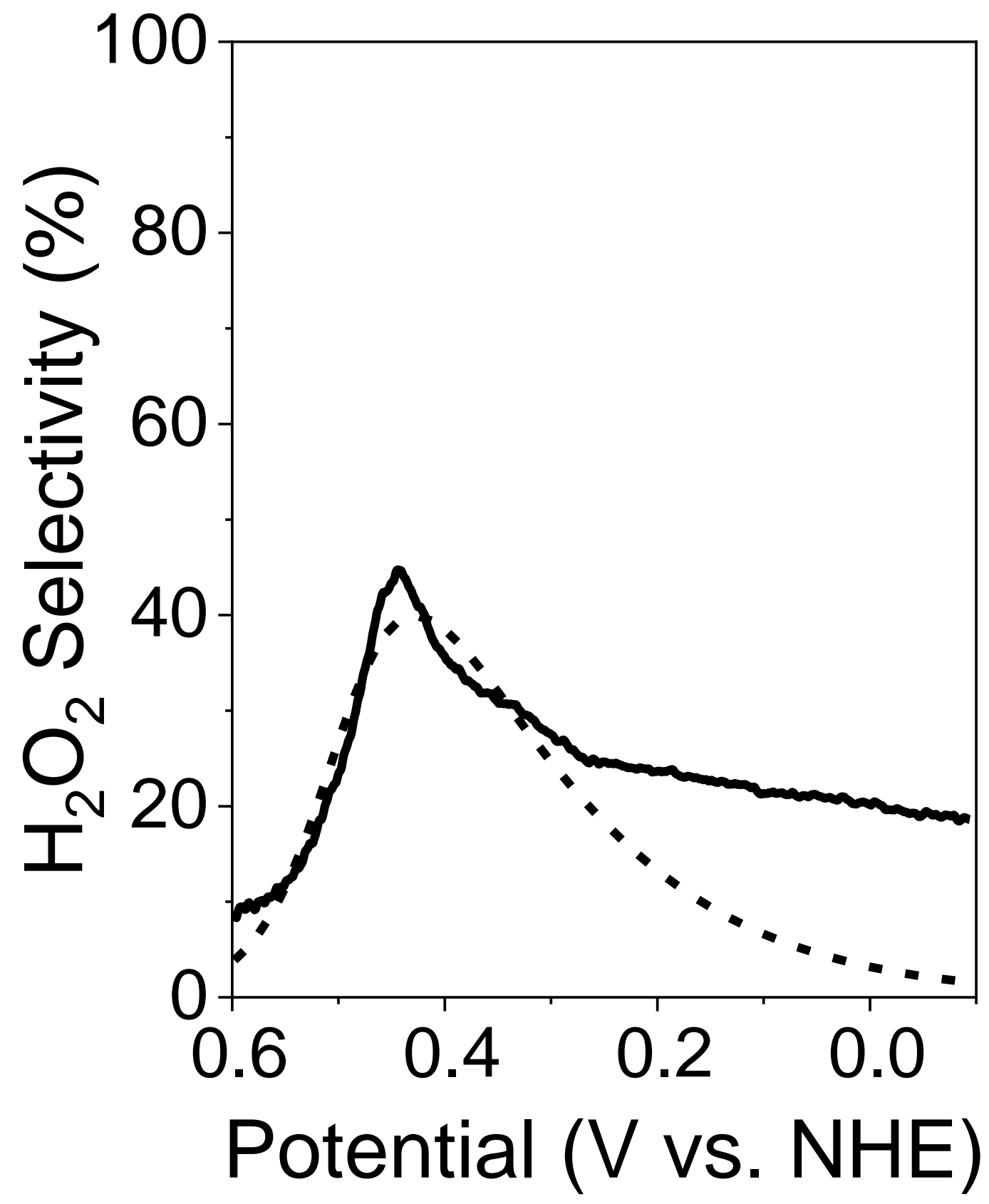

Figures S48. The selectivity of $\mathrm{H}_{2} \mathrm{O}_{2}$ formation on PdPt nanoparticles supported on Vulcan XC72 as a function of potential (-0.1-0.7 V vs. NHE), in which the best fit of equation S8.1 is shown as the dashed line. 


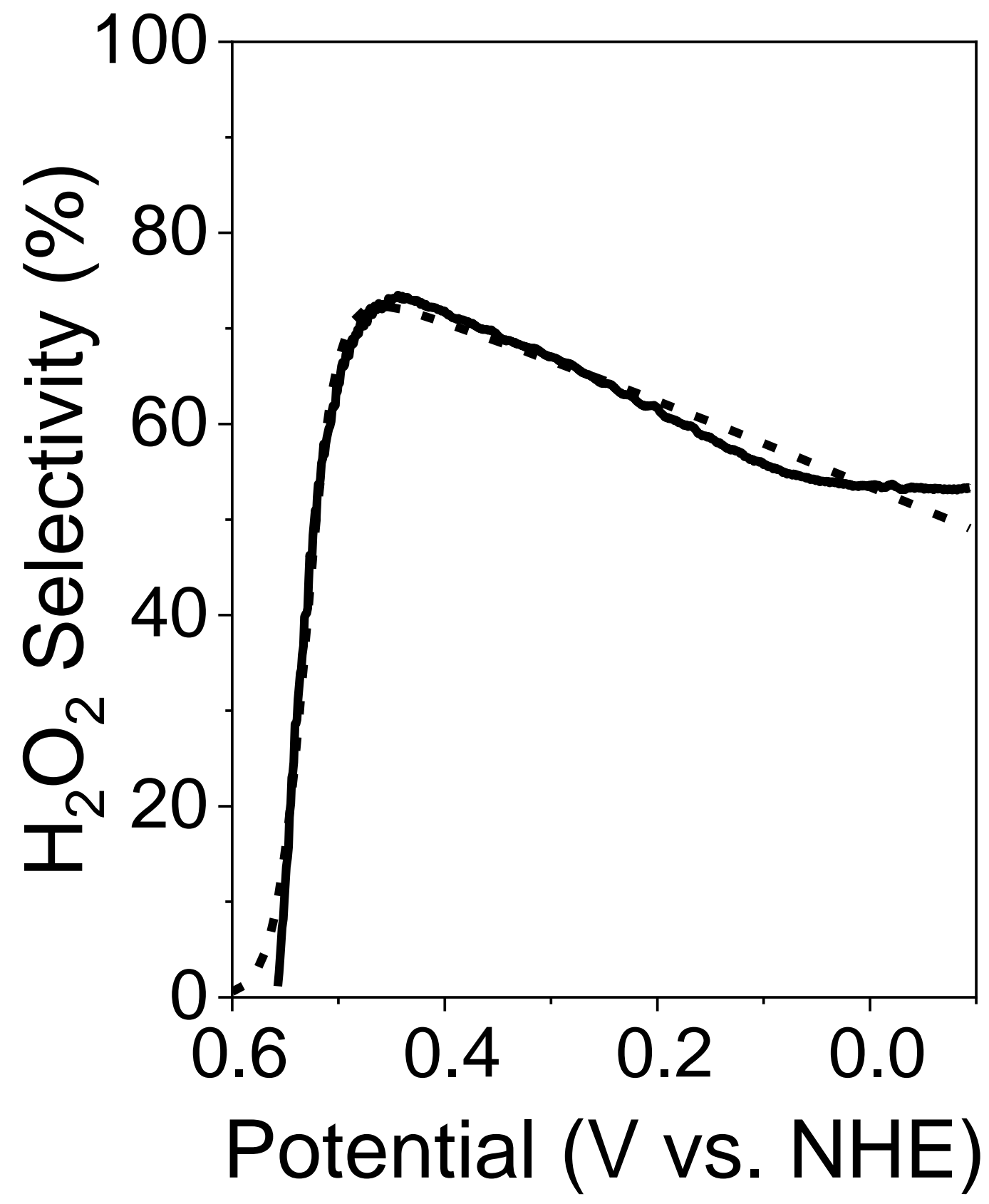

Figures S49. The selectivity of $\mathrm{H}_{2} \mathrm{O}_{2}$ formation on Au nanoparticles supported on Vulcan XC-72 as a function of potential (-0.1-0.7 V vs. NHE), in which the best fit of equation S8.1 is shown as the dashed line. 


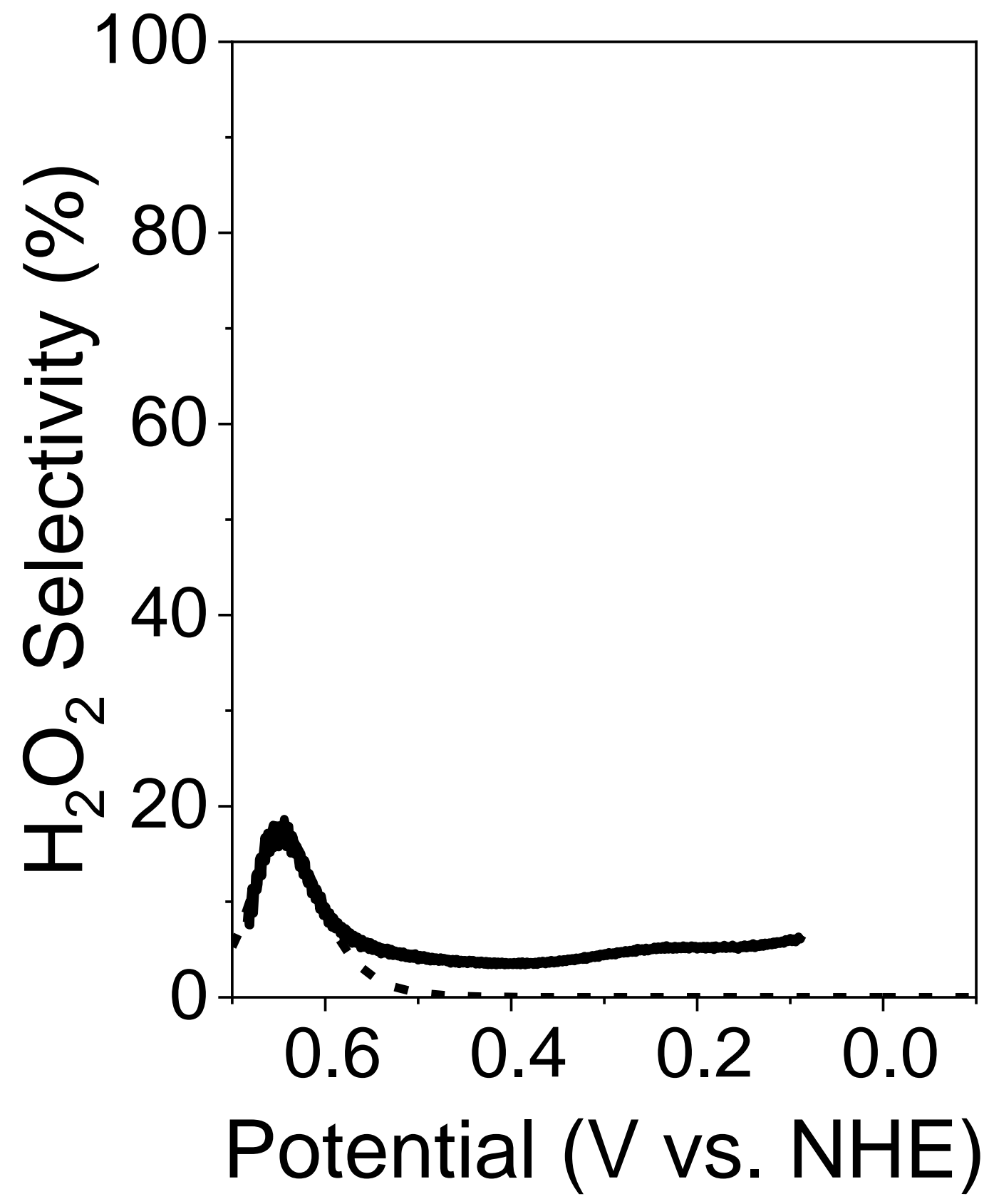

Figures S50. The selectivity of $\mathrm{H}_{2} \mathrm{O}_{2}$ formation on $\mathrm{PdCu}$ nanoparticles supported on Vulcan XC72 as a function of potential (-0.1-0.7 V vs. NHE), in which the best fit of equation S8.1 is shown as the dashed line. 


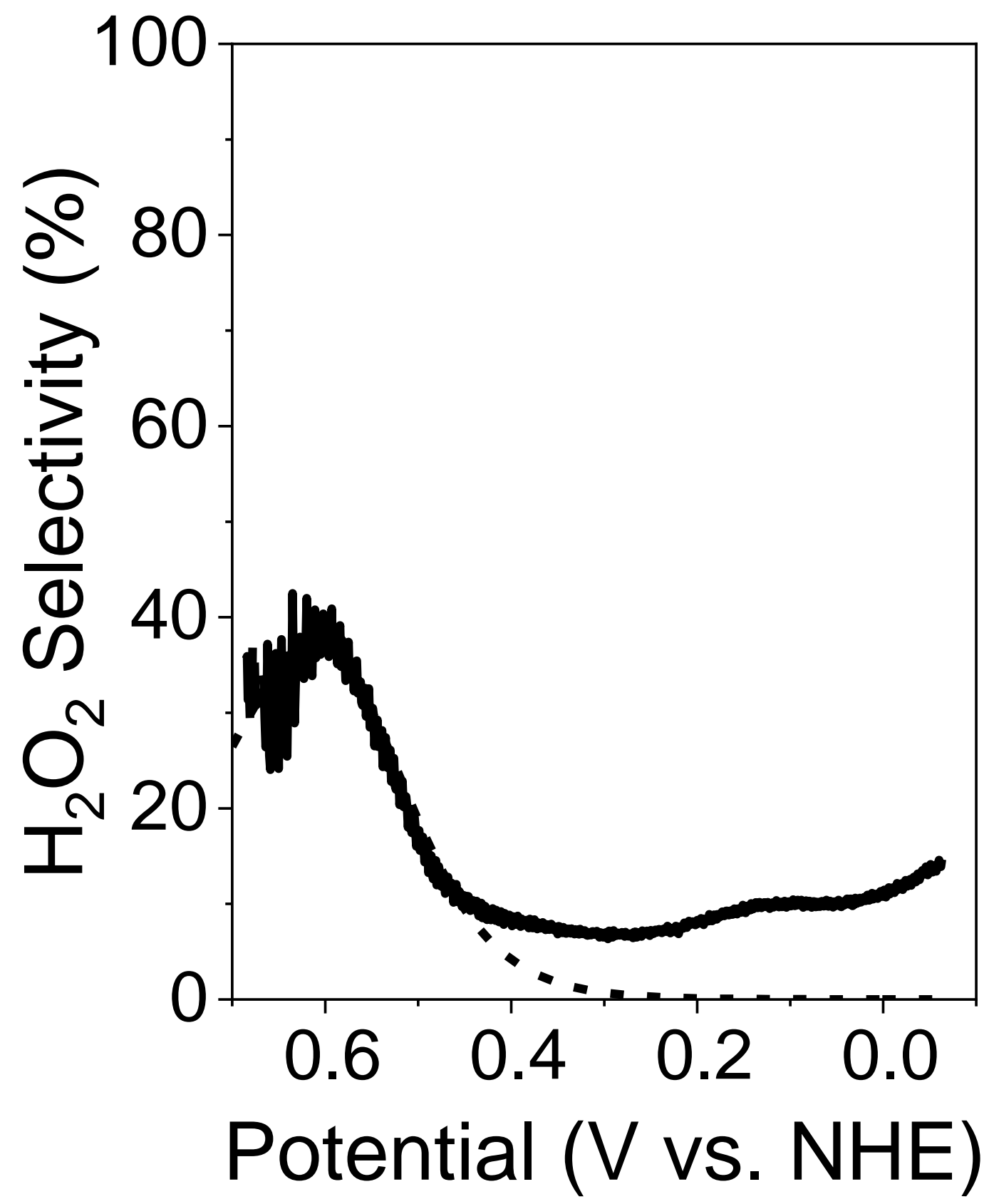

Figures S51. The selectivity of $\mathrm{H}_{2} \mathrm{O}_{2}$ formation on PdCo nanoparticles supported on Vulcan XC72 as a function of potential (-0.1-0.7 V vs. NHE), in which the best fit of equation S8.1 is shown as the dashed line. 


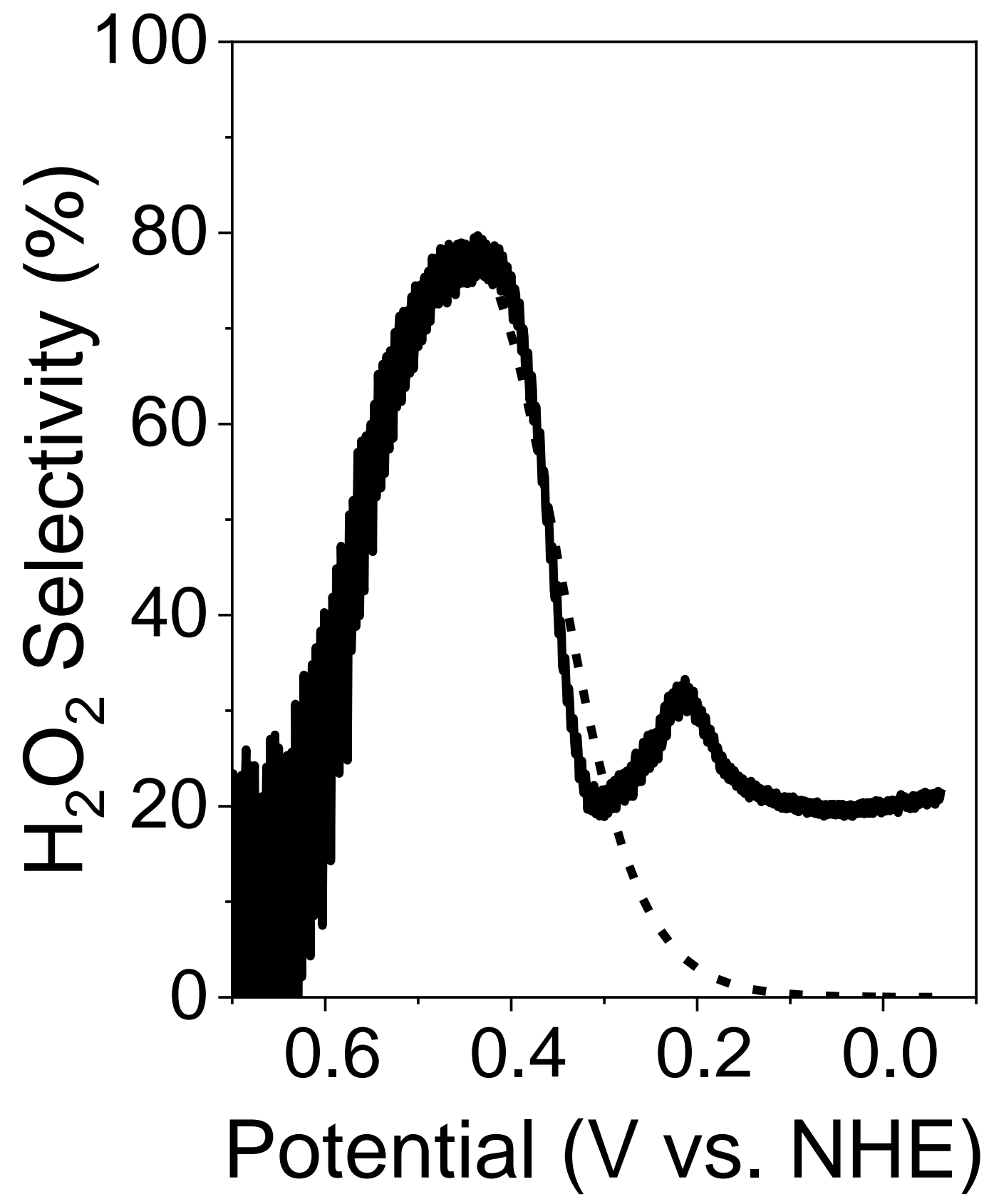

Figures S52. The selectivity of $\mathrm{H}_{2} \mathrm{O}_{2}$ formation on PdNi nanoparticles supported on Vulcan XC72 as a function of potential (-0.1-0.7 V vs. NHE), in which the best fit of equation S8.1 is shown as the dashed line. 


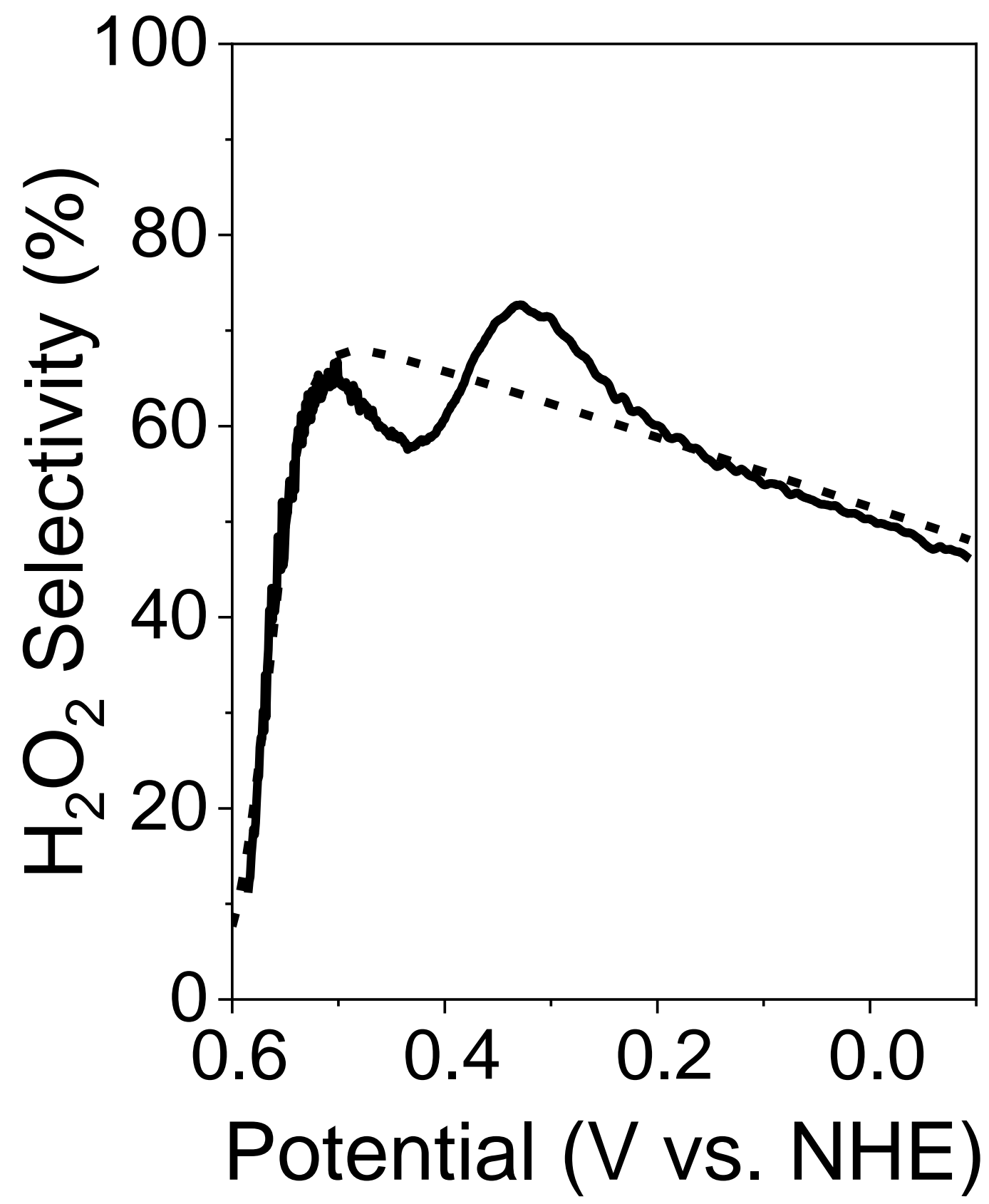

Figures S53. The selectivity of $\mathrm{H}_{2} \mathrm{O}_{2}$ formation on $\mathrm{Pd}_{1} \mathrm{Au}_{60}$ nanoparticles supported on Vulcan $\mathrm{XC}-72$ as a function of potential (-0.1-0.7 V vs. NHE), in which the best fit of equation S8.1 is shown as the dashed line. 


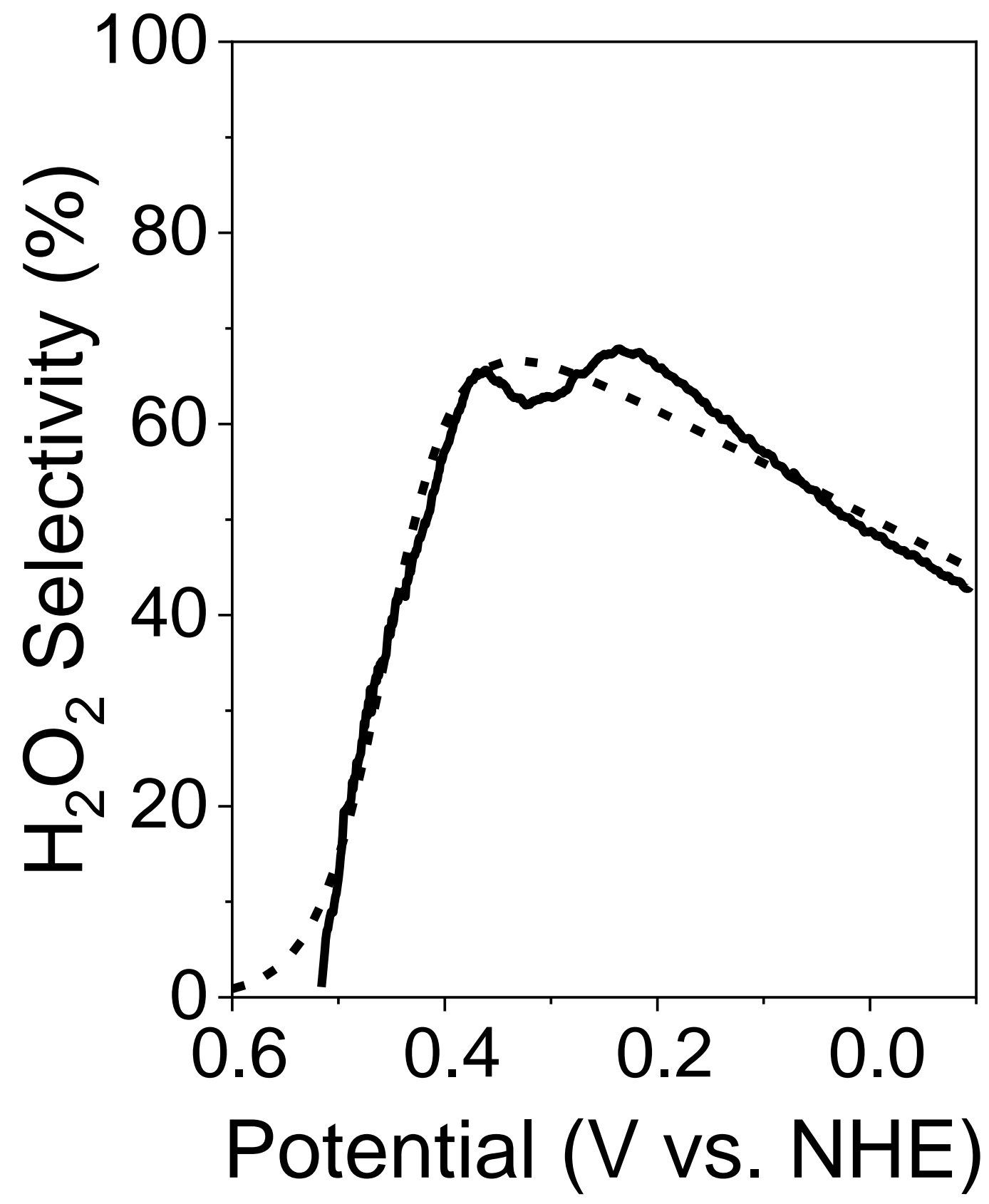

Figures S54. The selectivity of $\mathrm{H}_{2} \mathrm{O}_{2}$ formation on $\mathrm{Pt}_{1} \mathrm{Au}_{60}$ nanoparticles supported on $\mathrm{Vulcan} \mathrm{XC}$ 72 as a function of potential (-0.1-0.7 V vs. NHE), in which the best fit of equation S8.1 is shown as the dashed line. 


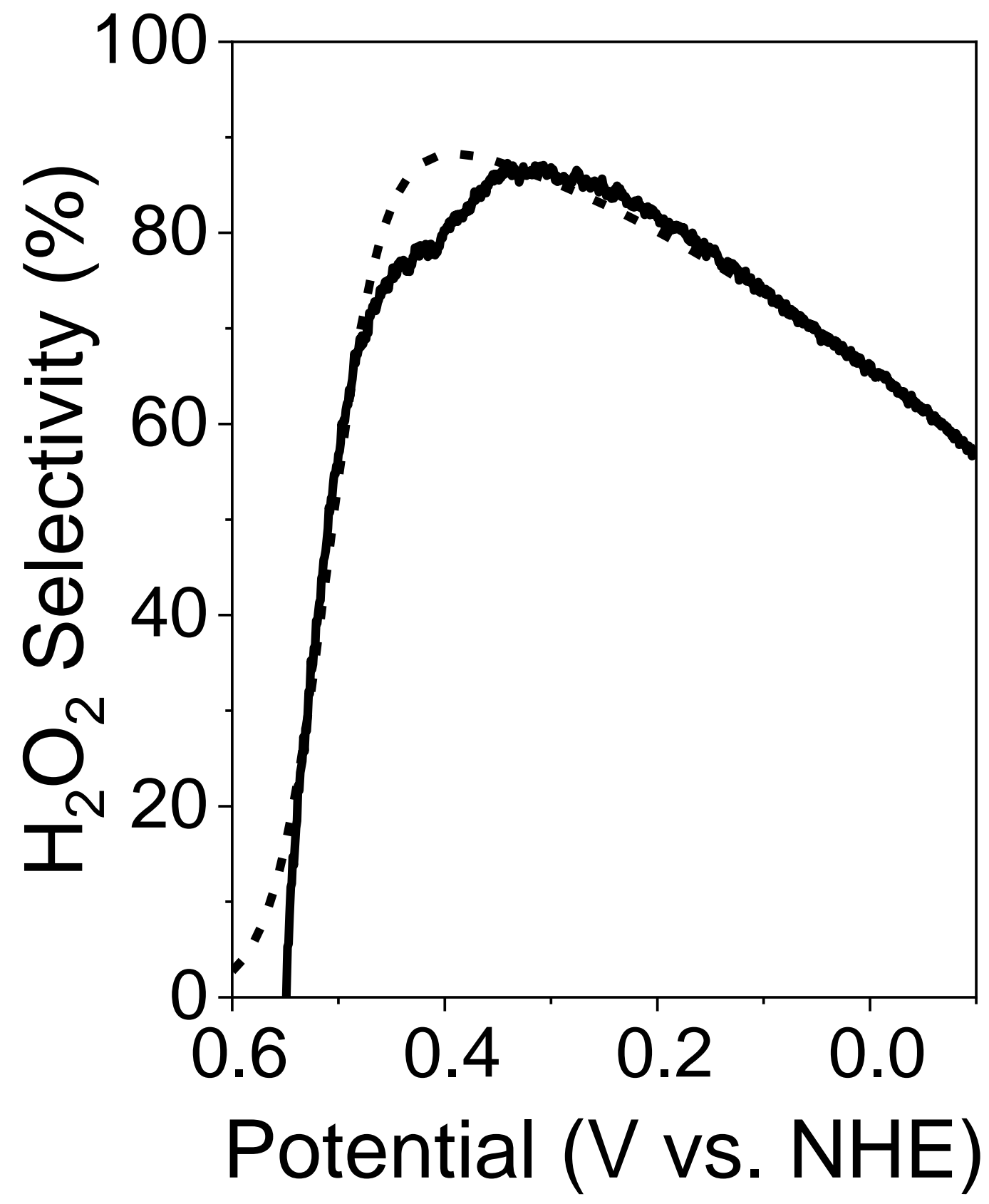

Figures S55. The selectivity of $\mathrm{H}_{2} \mathrm{O}_{2}$ formation on $\mathrm{Pt}_{1} \mathrm{Au}_{15}$ nanoparticles supported on $\mathrm{Vulcan} \mathrm{XC}$ 72 as a function of potential (-0.1-0.7 V vs. NHE), in which the best fit of equation S8.1 is shown as the dashed line. 


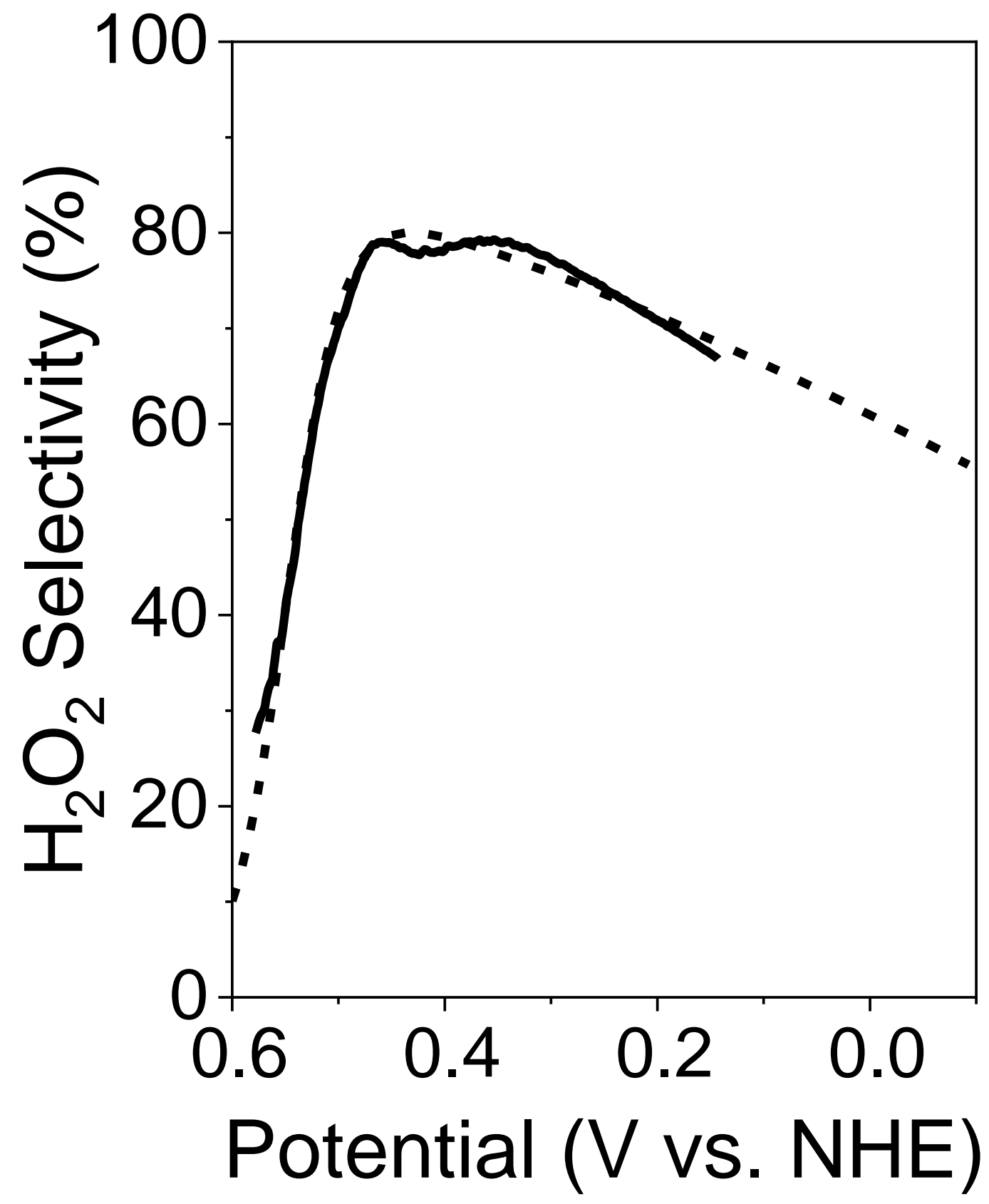

Figures S56. The selectivity of $\mathrm{H}_{2} \mathrm{O}_{2}$ formation on $\mathrm{Pt}_{1} \mathrm{Au}_{5}$ nanoparticles supported on Vulcan XC72 as a function of potential (-0.1-0.7 V vs. NHE), in which the best fit of equation S8.1 is shown as the dashed line. 


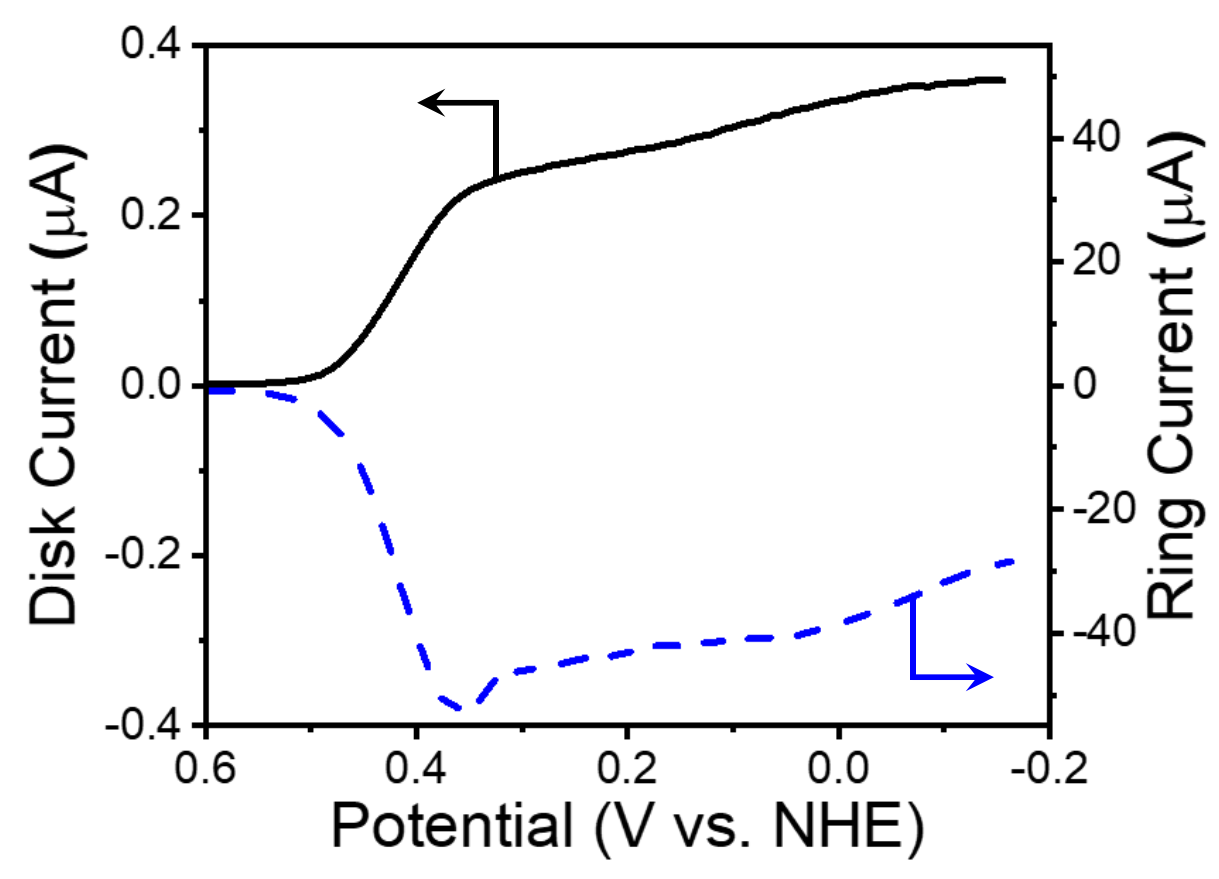

Figure S57. Disk and ring currents of the ORR as a function of potential (-0.2-0.6 V vs. NHE) at a rotation rate of $500 \mathrm{rpm}$, which shows the relative rate of the $\mathrm{H}_{2} \mathrm{O}_{2}$ and $\mathrm{H}_{2} \mathrm{O}$ formation on Vulcan XC-72. All RRDE measurements were conducted in an aqueous $0.1 \mathrm{M} \mathrm{NaClO}_{4}$ solution sparged with $\mathrm{O}_{2}$ gas $(101 \mathrm{kPa}, 298 \mathrm{~K})$. 
a
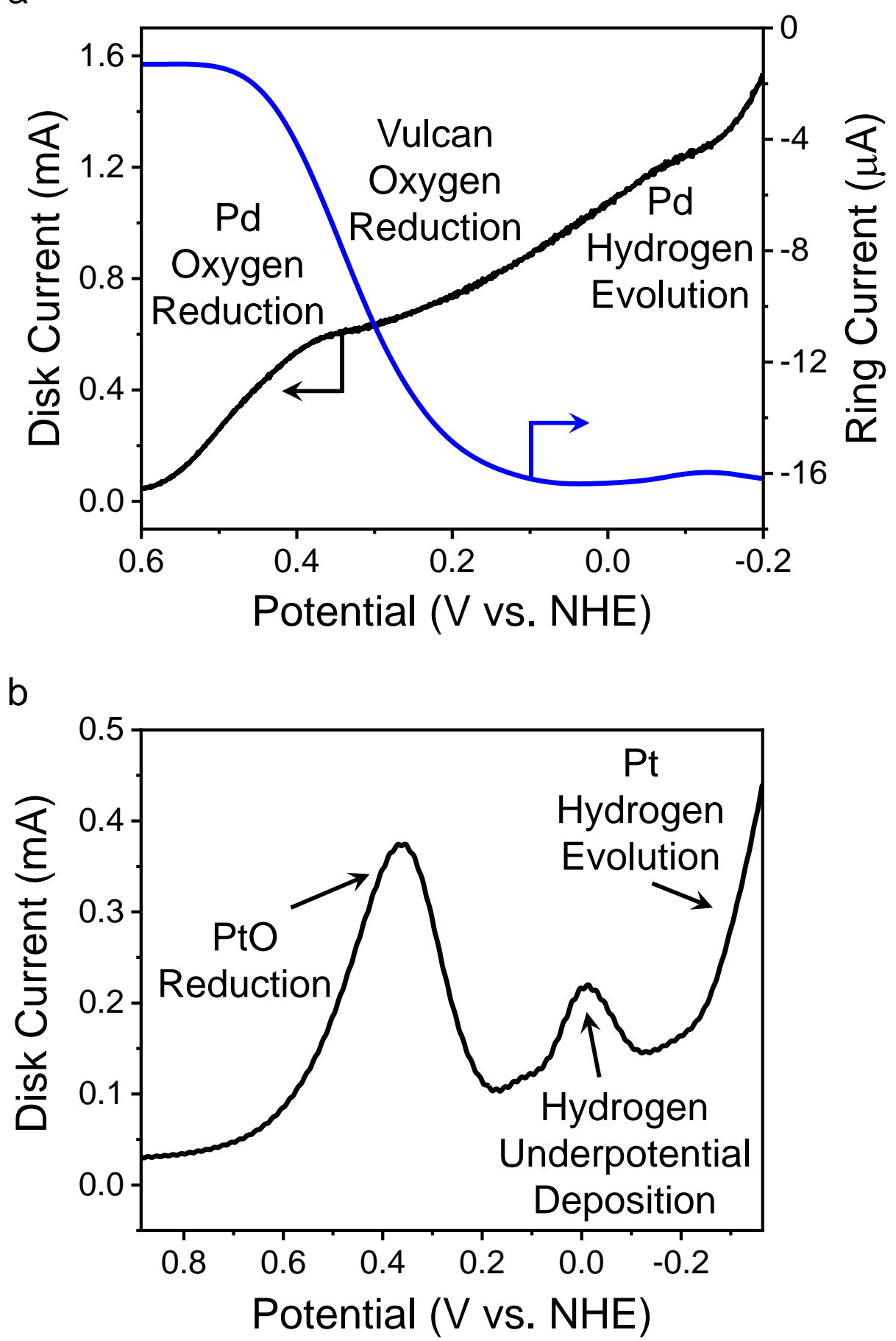

Figure S58. Disk and ring currents of the ORR as a function of potential (-0.3-0.9 V vs. NHE) at a rotation rate of $500 \mathrm{rpm}$, which shows the relative rate of the $\mathrm{H}_{2} \mathrm{O}_{2}$ and $\mathrm{H}_{2} \mathrm{O}$ formation on (a) Pd and (b) Pt nanoparticles supported on Vulcan XC-72. All RRDE measurements were conducted in an aqueous $0.1 \mathrm{M} \mathrm{NaClO}_{4}$ solution sparged with $\mathrm{O}_{2}$ gas $(101 \mathrm{kPa}, 298 \mathrm{~K})$. 


\section{S9. Mathematical Interpretations of Selectivity with Reactant Activity and Temperature}

In the previous section, we discuss how the $\mathrm{H}_{2} \mathrm{O}_{2}$ selectivity changes as a function of potential. In this section, we consider how $\mathrm{H}_{2} \mathrm{O}_{2}$ selectivity changes as a function of hydrogen activity and temperature. Then, we discuss the apparent activation enthalpy barriers that we measure during direct synthesis measurements in the context of these derivations.

\subsection{Selectivity of $\mathrm{H}_{2} \mathrm{O}_{2}$ Formation as a Function of Hydrogen Activity:}

To better understand why the $\mathrm{H}_{2} \mathrm{O}_{2}$ selectivity depends on hydrogen pressure, we multiply the derivative of electrical potential versus hydrogen activity (equation S7.51) by the derivative of selectivity versus electrical potential (equation S8.8):

$$
\begin{aligned}
& \left(\frac{d S_{H_{2} O_{2}}\left(\Phi^{o p}\right)}{d\left[H_{2}\right]}\right)_{T,\left[O_{2}\right]}=\left(\frac{\mathrm{d} \Phi^{o p}}{d\left[H_{2}\right]}\right)_{T,\left[O_{2}\right]}\left(\frac{d S_{H_{2} O_{2}}\left(\Phi^{o p}\right)}{d \Phi}\right)_{T,\left[O_{2}\right]} \\
& \approx \frac{k_{1}^{0} k_{12}^{0} k_{6 a}^{0} \mathrm{e}^{-\frac{\alpha_{6 a} \mathrm{~F}\left(\Phi^{o p}-\Phi_{6 a}^{0}\right.}{\mathrm{RT}}}\left(\left(\alpha_{6 a}-\alpha_{7}-\alpha_{13}\right) k_{7} \mathrm{e}^{-\frac{\alpha_{7} \mathrm{~F}\left(\Phi^{o p}-\Phi_{7}^{0}\right)}{\mathrm{RT}}}-\alpha_{13} k_{6 a} \mathrm{e}^{-\frac{\alpha_{6 a} \mathrm{~F}\left(\Phi^{o p}-\Phi_{6 \mathrm{a}}^{0}\right)}{\mathrm{RT}}}\right)}{2\left(\alpha_{5 a}+\alpha_{1}\right)\left(k_{6 a}^{0} \mathrm{e}^{-\frac{\alpha_{6 a} \mathrm{~F}\left(\Phi^{o p}-\Phi_{6 a}^{0}\right)}{\mathrm{RT}}}+k_{7}^{0} \mathrm{e}^{-\frac{\alpha_{7} \mathrm{~F}\left(\Phi^{o p}-\Phi_{7}^{0}\right)}{\mathrm{RT}}}\right)^{2}\left(k_{1}^{0}\left[H_{2}\right]^{2}+k_{3}^{0}\left[H_{2}\right]\right)}
\end{aligned}
$$

To solve for the complete expression, we must substitute $\Phi^{o p}$ with equation S7.40, but we neglect this step due to the complexity of such an expression. Nevertheless, this expression suggests that the operating potential of the nanoparticle decreases in proportion to the hydrogen chemical potential added to the system. Here, the system behaves similarly to the electrochemical system described in the previous section, in which the nanoparticle shows a parabolic increase in the $\mathrm{H}_{2} \mathrm{O}_{2}$ selectivity as the system operates at more negative potentials. Under direct synthesis conditions, however, the relative activity of hydrogen and oxygen in the system constrains the operating potential of a nanoparticle to a narrow range, whereas an electrode can bias materials to any potential. Thus, we may simplify equation S9.1 in terms of the relevant dimensionless proportionality constant:

$$
\left(\frac{d S_{\mathrm{H}_{2} \mathrm{O}_{2}}\left(\Phi^{o p}\right)}{d\left[H_{2}\right]}\right)=\left(\frac{\mathrm{d} \Phi^{o p}}{d\left[H_{2}\right]}\right)\left(\frac{d S_{\mathrm{H}_{2} O_{2}}\left(\Phi^{o p}\right)}{d \Phi}\right) \propto\left(\frac{\left(\alpha_{6 a}-\alpha_{7}-\alpha_{13}\right)}{\left(\alpha_{5 a}+\alpha_{1}\right)}\right)
$$

Therefore, the change in selectivity with potential is captured by differences charge transfer coefficients for the formation of $\mathrm{H}_{2} \mathrm{O}_{2}\left(\alpha_{6 a}\right)$ versus the primary $\left(\alpha_{7}\right)$ and secondary $\left(\alpha_{13}\right) \mathrm{H}_{2} \mathrm{O}$ formation pathways. The change in potential over this range, however, depends on the combined charge transfer coefficients of the kinetically relevant steps of hydrogen oxidation $\left(\alpha_{1}\right)$ and oxygen reduction $\left(\alpha_{5 a}\right)$. Further interpretation of these mathematics is presented in section S5.2 (main text), while the purpose of this section is to derive the equations therein. 


\subsection{Selectivity of $\mathrm{H}_{2} \mathrm{O}_{2}$ Formation as a Function of Temperature:}

In this subsection, we evaluate selectivity as a function of temperature and probe the intrinsic barriers of reaction for the $\mathrm{H}_{2} \mathrm{O}_{2}$ and $\mathrm{H}_{2} \mathrm{O}$ formation pathways. Figures S59-71 show that the selectivity of each material decreases between $278-308 \mathrm{~K}$ at a constant pressure of $60 \mathrm{kPa} \mathrm{O}_{2}$ and 200 or $60 \mathrm{kPa} \mathrm{H}_{2}$. Catalytic materials show differences in selectivity with temperature over this range. To interpret this behavior, we derive the selectivity as a function of temperature by substituting the enthalpic contribution of the Eyring equation (equation 6 of the main text) into equation S8.1:

$$
\begin{aligned}
& S_{H_{2} O_{2}}(T) \\
& \approx \frac{k_{12}^{\prime 0} \mathrm{e}^{-\frac{\Delta \mathrm{H}_{12}^{\ddagger}}{\mathrm{RT}}} k_{6 a}^{\prime 0} \mathrm{e}^{-\frac{\Delta \mathrm{H}_{6 \mathrm{a}}^{\ddagger}+\alpha_{6 a} \mathrm{~F}\left(\Phi^{o p_{-}} \Phi_{6 \mathrm{a}}^{0}\right)}{\mathrm{RT}}}}{\left(k_{12}^{\prime 0} \mathrm{e}^{-\frac{\Delta \mathrm{H}_{12}^{\ddagger}}{\mathrm{RT}}}+k_{13}^{\prime 0} \mathrm{e}^{-\frac{\Delta \mathrm{H}_{13}^{\ddagger}+\alpha_{13} \mathrm{~F}\left(\Phi^{o p}-\Phi_{13}^{0}\right)}{\mathrm{RT}}}\right)\left(k_{6 a}^{\prime 0} \mathrm{e}^{-\frac{\Delta \mathrm{H}_{6 \mathrm{a}}^{\ddagger}+\alpha_{6 a} \mathrm{~F}\left(\Phi^{o p}-\Phi_{6 \mathrm{a}}^{0}\right)}{\mathrm{RT}}}+2 k_{7}^{\prime 0} \mathrm{e}^{-\frac{\Delta \mathrm{H}_{7}^{\ddagger}+\alpha_{7} \mathrm{~F}\left(\Phi^{o p_{-}} \Phi_{7}^{0}\right)}{\mathrm{RT}}}\right)}
\end{aligned}
$$

Where the selectivity of $\mathrm{H}_{2} \mathrm{O}_{2}$ depends on activation enthalpy of reaction for both the primary $2 \mathrm{e}$ $\left(\Delta \mathrm{H}_{6 \mathrm{a}}^{\ddagger}\right)$ and $4 \mathrm{e}^{-}\left(\Delta \mathrm{H}_{7}^{\ddagger}\right)$ ORR pathways, as well as the $\mathrm{H}_{2} \mathrm{O}_{2}$ decomposition $\left(\Delta \mathrm{H}_{13}^{\ddagger}\right)$ and desorption $\left(\Delta \mathrm{H}_{12}^{\ddagger}\right)$ paths. Here, we factor out the preexponential constants $\left(k_{6 a}^{\prime 0}, k_{7}^{\prime 0}, k_{12}^{\prime 0}\right.$, and $\left.k_{13}^{\prime 0}\right)$ for these reactions, which depend on their activation entropies and the attempt frequency of the reactions. Differentiating equation S9.3 with respect to temperature, we derive an expression for the apparent barrier of reaction by invoking the quotient rule (analogously shown in equation S8.5):

$$
\begin{gathered}
f(\mathrm{~T})=k_{12}^{0} k_{6 a}^{0} \mathrm{e}^{-\frac{\alpha_{6 a} \mathrm{~F}\left(\Phi^{o p}-\Phi_{6 \mathrm{a}}^{0}\right)}{\mathrm{RT}}} \\
g(\mathrm{~T})=\left(k_{12}^{0}+k_{13}^{0} \mathrm{e}^{\left.-\frac{\alpha_{13} \mathrm{~F}\left(\Phi^{o p_{-}} \Phi_{13}^{0}\right)}{\mathrm{RT}}\right)}\right)\left(k_{6 a}^{0} \mathrm{e}^{-\frac{\alpha_{6 a} \mathrm{~F}\left(\Phi^{o p_{-}} \Phi_{6 \mathrm{a}}^{0}\right)}{\mathrm{RT}}}\right. \\
+2 k_{7}^{0} \mathrm{e}^{\left.-\frac{\alpha_{7} \mathrm{~F}\left(\Phi^{o p_{-}} \Phi_{7}^{0}\right)}{\mathrm{RT}}\right)} \\
\left(\frac{d S_{\mathrm{H}_{2} \mathrm{O}_{2}}(\mathrm{~T})}{d \mathrm{~T}}\right)_{\Phi}=\frac{\frac{d(f(\Phi))}{d \mathrm{~T}} g(\mathrm{~T})-\frac{d(g(\Phi))}{d \mathrm{~T}} f(\mathrm{~T})}{g(\Phi)^{2}}=\lambda(T)-\xi(T)
\end{gathered}
$$

Here, the functions $f$ and $g$ represent the numerator and denominator of equation S9.3, respectively. The complete derivative is also separated into two components representing the contributions of the primary $\mathrm{H}_{2} \mathrm{O}_{2}$ and $\mathrm{H}_{2} \mathrm{O}$ formation pathways $(\lambda)$ and the influence of $\mathrm{H}_{2} \mathrm{O}_{2}$ decomposition (step 13) and desorption (step 12) paths ( $($ ). In the following analysis, we assume that the rate of $\mathrm{H}_{2} \mathrm{O}_{2}$ decomposition is much fast than the rate of $\mathrm{H}_{2} \mathrm{O}_{2}$ desorption to simplify the mathematics. Differentiating the functions above, we derive the expressions below: 


$$
\frac{d(f(\Phi))}{d \mathrm{~T}}=\frac{{k^{\prime}}_{12}^{0} k_{6 a}^{\prime 0}\left(\left(\Delta \mathrm{H}_{12}^{\ddagger}+\Delta \mathrm{H}_{6 \mathrm{a}}^{\ddagger}\right)+\alpha_{6 a} \mathrm{~F}\left(\Phi^{o p}-\Phi_{6 \mathrm{a}}^{0}\right)\right) \mathrm{e}^{-\frac{\left(\left(\Delta \mathrm{H}_{12}^{\ddagger}+\Delta \mathrm{H}_{6 \mathrm{a}}^{\ddagger}\right)+\alpha_{6 a} \mathrm{~F}\left(\Phi^{o p}-\Phi_{6 \mathrm{a}}^{0}\right)\right)}{R T}}}{\mathrm{R} T^{2}}
$$

$$
\begin{aligned}
& \frac{d(g(\Phi))}{d \mathrm{~T}}=\frac{k^{\prime}{ }_{13}^{0} \mathrm{e}^{-\frac{\left(\left(\Delta \mathrm{H}_{7}^{\ddagger}+\Delta \mathrm{H}_{6 \mathrm{a}}^{\ddagger}+\Delta \mathrm{H}_{13}^{\ddagger}\right)+\alpha_{6 a} \mathrm{~F}\left(\Phi^{o p_{-}} \Phi_{6 \mathrm{a}}^{0}\right)+\alpha_{7} \mathrm{~F}\left(\Phi^{o p_{-}} \Phi_{7}\right)+\alpha_{13} \mathrm{~F}\left(\Phi^{o p_{-}} \Phi_{13}^{0}\right)\right)}{R T}}}{\mathrm{R} T^{2}} \\
& \left(2 k_{7}^{\prime 0}\left(\Delta \mathrm{H}_{13}^{\ddagger}+\alpha_{13} \mathrm{~F}\left(\Phi^{o p}-\Phi_{13}^{0}\right)\right) \mathrm{e}^{\frac{\Delta \mathrm{H}_{6 \mathrm{a}}^{\ddagger}+\alpha_{6 a} \mathrm{~F}\left(\Phi^{o p}-\Phi_{6 \mathrm{a}}^{0}\right)}{\mathrm{RT}}}\right. \\
& +k_{6 a}^{\prime 0}\left(\Delta \mathrm{H}_{13}^{\ddagger}+\alpha_{13} \mathrm{~F}\left(\Phi^{o p}-\Phi_{13}^{0}\right)\right) \mathrm{e}^{\frac{\Delta \mathrm{H}_{7}^{\ddagger}+\alpha_{7} \mathrm{~F}\left(\Phi^{o p}-\Phi_{7}^{0}\right)}{\mathrm{RT}}} \\
& +k_{6 a}^{\prime 0}\left(\Delta \mathrm{H}_{6 \mathrm{a}}^{\ddagger}+\alpha_{6 a} \mathrm{~F}\left(\Phi^{o p}-\Phi_{6 \mathrm{a}}^{0}\right)\right) \mathrm{e}^{\frac{\Delta \mathrm{H}_{7}^{\ddagger}+\alpha_{7} \mathrm{~F}\left(\Phi^{o p}-\Phi_{7}^{0}\right)}{\mathrm{RT}}} \\
& \left.+2 k_{7}^{\prime 0}\left(\Delta \mathrm{H}_{7}^{\ddagger}+\alpha_{7} \mathrm{~F}\left(\Phi^{o p}-\Phi_{7}^{0}\right)\right) \mathrm{e}^{\frac{\Delta \mathrm{H}_{6 \mathrm{a}}^{\ddagger}+\alpha_{6 a} \mathrm{~F}\left(\Phi^{o p}-\Phi_{6 \mathrm{a}}^{0}\right)}{\mathrm{RT}}}\right)
\end{aligned}
$$

Next, we substitute equations S9.7 and S9.8 into equation S9.6 to derive the two components of the derivative:

$$
\begin{aligned}
& \lambda(T)
\end{aligned}
$$

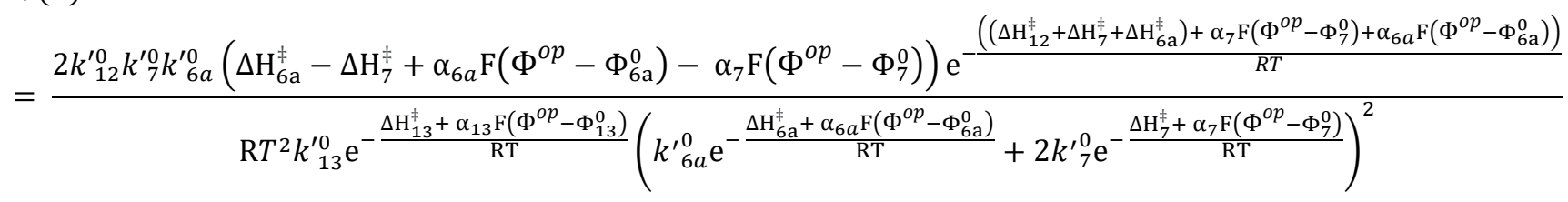

$$
\begin{aligned}
& \xi(T)=\frac{k_{12}^{\prime 0} k^{\prime 0}{ }_{6 a}\left(\Delta \mathrm{H}_{12}^{\ddagger}-\Delta \mathrm{H}_{13}^{\ddagger}-\alpha_{13} \mathrm{~F}\left(\Phi^{o p}-\Phi_{13}^{0}\right)\right) \mathrm{e}^{-\frac{\left(\left(\Delta \mathrm{H}_{12}^{\ddagger}+\Delta \mathrm{H}_{6 \mathrm{a}}^{\ddagger}\right)+\alpha_{6 a} \mathrm{~F}\left(\Phi^{o p}-\Phi_{6 \mathrm{a}}^{0}\right)\right)}{R T}}}{\mathrm{R} T^{2} k^{\prime}{ }_{13} \mathrm{e}^{-\frac{\Delta \mathrm{H}_{13}^{\ddagger}+\alpha_{13} \mathrm{~F}\left(\Phi^{o p}-\Phi_{13}^{0}\right)}{\mathrm{RT}}}\left(k_{6 a}^{\prime 0} \mathrm{e}^{-\frac{\Delta \mathrm{H}_{6 \mathrm{a}}^{\ddagger}+\alpha_{6 a} \mathrm{~F}\left(\Phi^{o p}-\Phi_{6 \mathrm{a}}^{0}\right)}{\mathrm{RT}}}+2 k_{7}^{\prime 0} \mathrm{e}^{-\frac{\Delta \mathrm{H}_{7}^{\ddagger}+\alpha_{7} \mathrm{~F}\left(\Phi^{o p}-\Phi_{7}^{0}\right)}{\mathrm{RT}}}\right)}
\end{aligned}
$$

To simplify the mathematical interpretations of these functions, we consider their proportionality constants: 


$$
\lambda(T) \propto \frac{{k^{\prime}}_{12}^{0}}{{k^{\prime}}_{13}^{0}}\left(\Delta \mathrm{H}_{6 \mathrm{a}}^{\ddagger}-\Delta \mathrm{H}_{7}^{\ddagger}+\alpha_{6 a} \mathrm{~F}\left(\Phi^{o p}-\Phi_{6 \mathrm{a}}^{0}\right)-\alpha_{7} \mathrm{~F}\left(\Phi^{o p}-\Phi_{7}^{0}\right)\right)=-\frac{{k^{\prime}}_{12}^{0}}{{k^{\prime}}_{13}^{0}} \Delta \Delta \mathrm{H}_{4 e-2 e}^{\ddagger}
$$

$$
\xi(T) \propto \frac{k_{12}^{\prime 0}}{k_{13}^{\prime 0}}\left(\Delta \mathrm{H}_{12}^{\ddagger}-\Delta \mathrm{H}_{13}^{\ddagger}-\alpha_{13} \mathrm{~F}\left(\Phi^{o p}-\Phi_{13}^{0}\right)\right)
$$

Here, the change in selectivity with temperature depends on the difference in the intrinsic enthalpy barriers $\left(\Delta \Delta \mathrm{H}_{4 e-2 e}^{\ddagger}\right)$ and charge transfer coefficients towards the primary $\mathrm{H}_{2} \mathrm{O}_{2}\left(\alpha_{6 a}\right)$ and $\mathrm{H}_{2} \mathrm{O}\left(\alpha_{7}\right)$ formation pathways. Equation S9.11 also suggests the difference in transition state energies between the $\mathrm{H}_{2} \mathrm{O}_{2}$ and $\mathrm{H}_{2} \mathrm{O}$ formation pathways changes in proportion with the operating potential of the catalyst. Therefore, a more negative operating potential leads to lower apparent reaction barriers for either ORR pathway and leads to a greater overall $\mathrm{H}_{2} \mathrm{O}_{2}$ selectivity that is sensitive to changes in temperature. At the highest potentials $\lambda$ contributes to much of the change in selectivity with temperature, but $\xi$ becomes more dominant at lower potentials. At such conditions, $\xi$ depends on charge transfer coefficient of $\mathrm{H}_{2} \mathrm{O}_{2}$ decomposition $\left(\alpha_{13}\right)$ and the differences in transition state enthalpies for $\mathrm{H}_{2} \mathrm{O}_{2}$ desorption $\left(\Delta \mathrm{H}_{12}^{\ddagger}\right)$ and decomposition $\left(\Delta \mathrm{H}_{13}^{\ddagger}\right)$. The function $\lambda$ suggests that the apparent value of $\Delta \Delta \mathrm{H}_{4 e-2 e}^{\ddagger}$ should increase with decreasing potential, but the contributions of $\xi$ will lead to a decrease in the apparent value of $\Delta \Delta \mathrm{H}_{4 e-2 e}^{\ddagger}$, particularly when the rate of $\mathrm{H}_{2} \mathrm{O}_{2}$ decomposition is fast (vide infra). Thus, the maximum apparent value of $\Delta \Delta \mathrm{H}_{4 e-2 e}^{\ddagger}$ occurs at the optimal operating potentials $\left(\Phi_{o p t}\right)$, in which the catalyst presents the greatest selectivity towards $\mathrm{H}_{2} \mathrm{O}_{2}$ formation.

On each material, we observe that the $\mathrm{H}_{2} \mathrm{O}_{2}$ selectivity decreases with temperature (vide infra), indicating that the value of $\Delta \Delta \mathrm{H}_{4 e-2 e}^{\ddagger}$ is always positive. This observation suggest that equation S8.1 should approach a value of $100 \%$ as the temperature of the solution approaches zero:

$$
\lim _{T \rightarrow 0} S_{H_{2} O_{2}}(\mathrm{~T})=1
$$

Therefore, to achieve the maximum $\mathrm{H} 2 \mathrm{O} 2$ selectivity in an oxygen reduction system, the catalyst should operate at the lowest possible temperature in the given solvent.

\subsection{Activation Barriers of $\mathrm{H}_{2} \mathrm{O}_{2}$ Formation Compared to Experimental Measurements}

In this subsection, we evaluate the apparent barrier of $\mathrm{H}_{2} \mathrm{O}_{2}$ formation based on the analysis in the previous subsection and evaluate the temperature dependence of rates on each catalytic material in the context of our model. Below we express the Eyring expression for the transition state equilibrium constant of $\mathrm{H}_{2} \mathrm{O}_{2}$ formation $\left(\mathrm{K}_{\mathrm{H}_{2} \mathrm{O}_{2}}^{\ddagger}\right)$ at low pressures of hydrogen (equation S7.45):

$$
\frac{r_{H_{2} O_{2}}}{\left[L_{*}\right]} \approx \frac{k_{B} T}{h} K_{H_{2} O_{2}}^{\ddagger}\left[H_{2}\right]\left[H_{2} O\right]=S_{H_{2} O_{2}}(\mathrm{~T}) k_{1}^{\prime 0}\left[H_{2}\right]\left[H_{2} O\right] e^{\frac{\Delta \mathrm{H}_{1}^{\ddagger}+F \alpha_{1}\left(\Phi^{o p}-\Phi_{1}^{0}\right)}{R T}}
$$


Where the rate of $\mathrm{H}_{2} \mathrm{O}_{2}$ formation $\left(r_{\mathrm{H}_{2} \mathrm{O}_{2}}\right)$ depends on the Boltzmann constant $\left(k_{B}\right)$, Planck's constant $(h)$, temperature $(T)$, and the activity of hydrogen $\left(\left[\mathrm{H}_{2}\right]\right)$ and water $\left(\left[\mathrm{H}_{2} \mathrm{O}\right]\right)$. Below, we show the apparent value of the activation enthalpy of $\mathrm{H}_{2} \mathrm{O}_{2}$ formation $\left(\Delta \mathrm{H}_{\mathrm{H}_{2} \mathrm{O}_{2} \text {,app }}^{\ddagger}\right)$ by invoking the Van't Hoff equations of the transition state enthalpy. Where the apparent barrier depends on the derivative of the equilibrium constant of $\mathrm{H}_{2} \mathrm{O}_{2}$ formation rate $\left(\mathrm{K}_{\mathrm{H}_{2} \mathrm{O}_{2}}\right)$.

$$
\Delta \mathrm{H}_{\mathrm{H}_{2} \mathrm{O}_{2}, \mathrm{app}}^{\ddagger}=\mathrm{R} T^{2} \frac{d}{d T}\left(\ln \left(S_{\mathrm{H}_{2} O_{2}}(\mathrm{~T}) e^{\frac{\Delta \mathrm{H}_{1}^{\ddagger}+F \alpha_{1}\left(\Phi^{o p}-\Phi_{1}^{0}\right)}{R T}}\right)\right)
$$

Where the change in rate with temperature depends on both the change in selectivity and the rate of hydrogen oxidation versus temperature. Substituting equation S8.1 into equation S9.15, we solve for the above derivative:

$$
\begin{aligned}
& \mathrm{R} T^{2} \frac{d}{d T}\left(\ln \left(S_{\mathrm{H}_{2} O_{2}}(\mathrm{~T}) e^{\frac{\Delta \mathrm{H}_{1}^{\ddagger}+F \alpha_{1}\left(\Phi^{o p_{-}}-\Phi_{1}^{0}\right)}{R T}}\right)\right) \\
& =\Delta H_{12}^{\ddagger}+\Delta H_{6 a}^{\ddagger}+\Delta H_{1}^{\ddagger}-\Delta H_{13}^{\ddagger}+\alpha_{6 a} F\left(\Phi^{o p}-\Phi_{6 a}^{0}\right)+F \alpha_{1}\left(\Phi^{o p}-\Phi_{1}^{0}\right)-\alpha_{13} F\left(\Phi^{o p}-\Phi_{13}^{0}\right)
\end{aligned}
$$

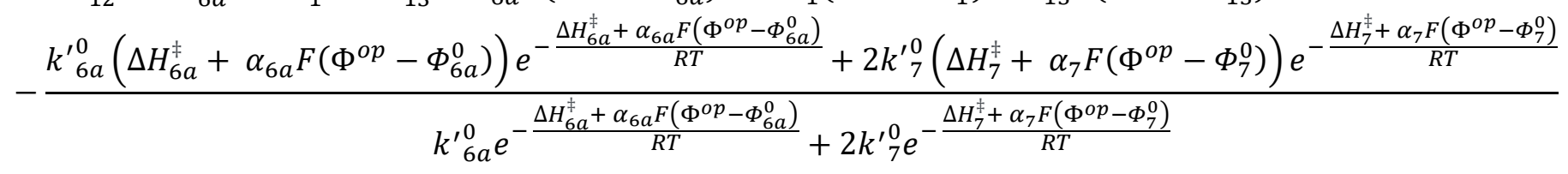

A similar expression also exists for the formation of $\mathrm{H}_{2} \mathrm{O}$, which we neglect for brevity. The complete expression of the above equation is complex, and so we approximate the apparent barriers of $\mathrm{H}_{2} \mathrm{O}_{2}$ and $\mathrm{H}_{2} \mathrm{O}$ formation in terms of their proportionality constants:

$$
\begin{gathered}
\Delta \mathrm{H}_{\mathrm{H}_{2} \mathrm{O}_{2}, \mathrm{app}}^{\ddagger} \approx \Delta \mathrm{H}_{1}^{\ddagger}+\alpha_{1} \mathrm{~F}\left(\Phi^{o p}-\Phi_{1}^{0}\right)-\Delta \Delta \mathrm{H}_{4 e-2 e}^{\ddagger} \\
\Delta \mathrm{H}_{\mathrm{H}_{2} O, \mathrm{app}}^{\ddagger} \approx \Delta \mathrm{H}_{1}^{\ddagger}+\alpha_{1} \mathrm{~F}\left(\Phi^{o p}-\Phi_{1}^{0}\right)+\Delta \Delta \mathrm{H}_{4 e-2 e}^{\ddagger}
\end{gathered}
$$

Thus, the apparent barriers of $\mathrm{H}_{2} \mathrm{O}_{2}$ and $\mathrm{H}_{2} \mathrm{O}$ formation at low coverages of hydrogen depends on the apparent barriers and charge transfer coefficients of $\mathrm{H}_{2}$ adsorption and oxidation by the Heyrovsky step $\left(\Delta \mathrm{H}_{1}^{\ddagger}, \alpha_{1}\right)$. Similarly, this expression will change depending on the coverage of hydrogen, such that the apparent barriers will depend more on the barriers and charge transfer coefficients of the Volmer step $\left(\Delta \mathrm{H}_{3}^{\ddagger}, \alpha_{3}\right)$ at the greatest $\mathrm{H}_{2}$ pressures. This analysis also allows for direct comparisons between the apparent values of measured enthalpy barriers: 


$$
\begin{aligned}
\Delta \Delta \mathrm{H}_{4 e-2 e, a p p}^{\ddagger} & =\Delta \mathrm{H}_{\mathrm{H}_{2} O, \mathrm{app}}^{\ddagger}-\Delta \mathrm{H}_{\mathrm{H}_{2} \mathrm{O}_{2}, \mathrm{app}}^{\ddagger} \approx 2 \Delta \Delta \mathrm{H}_{4 e-2 e}^{\ddagger} \\
& \approx\left(\Delta \mathrm{H}_{7}^{\ddagger}-\Delta \mathrm{H}_{6 \mathrm{a}}^{\ddagger}+\alpha_{7} \mathrm{~F}\left(\Phi^{o p}-\Phi_{7}^{0}\right)-\alpha_{6 a} \mathrm{~F}\left(\Phi^{o p}-\Phi_{6 \mathrm{a}}^{0}\right)\right. \\
& \left.+\xi\left(\Phi^{o p}\right)\right)
\end{aligned}
$$

Here, the change in selectivity with temperature depends on the differences between the apparent activation enthalpies for the four-electron and two-electron ORR $\left(\Delta \Delta \mathrm{H}_{4 e-2 e}^{\ddagger}\right)$. This parameter depends on the difference in the intrinsic activation enthalpies $\left(\Delta \mathrm{H}_{7}^{\ddagger}, \Delta \mathrm{H}_{6 \mathrm{a}}^{\ddagger}\right)$, equilibrium potentials $\left(\Phi_{7}^{0}, \Phi_{6 \mathrm{a}}^{0}\right)$, and charge transfer coefficients $\left(\alpha_{7}, \alpha_{6 a}\right)$ of the elementary steps that form $\mathrm{H}_{2} \mathrm{O}_{2}$ and $\mathrm{H}_{2} \mathrm{O}$ from $\mathrm{OOH}^{*}$. This expression indicates that a more negative operating potential leads to a lower apparent reaction barrier for either ORR pathway. Moreover, equation S7.40 suggests that an increase in temperature leads to a decrease in the operating potential, indicating that these apparent barriers should also decrease with temperature. Therefore, equation S9.19 indicates that $\mathrm{H}_{2} \mathrm{O}_{2}$ selectivity should increase if $\Phi^{o p}$ decreases at a constant temperature (assuming $\alpha_{6 a}>\alpha_{7}$ ). However, Figure $6 \mathrm{c}$ shows that selectivity decreases as temperature increases, indicating that intrinsic activation enthalpies $\left(\Delta \mathrm{H}_{7}^{\ddagger}, \Delta \mathrm{H}_{6 \mathrm{a}}^{\ddagger}\right)$ dictate most of the change in selectivity over the tested range of temperature (i.e., the change $\Phi^{o p}$ with temperature has a weak influence on selectivity). At lower operating potentials, however, the secondary $\mathrm{H}_{2} \mathrm{O}_{2}$ decomposition pathway (step 13) becomes more dominate, and $\xi$ contributes to a significant decrease in the selectivity. Therefore, the value of $\Phi_{o p t}$ coincides with the maximum value of $\Delta \Delta \mathrm{H}_{4 e-2 e}^{\ddagger}$, leading to the maximum selectivity for a material.

In Table S4, we report the apparent activation enthalpy barriers for each of the materials investigated. Figures S59-S70 report the corresponding measurements for the rates of $\mathrm{H}_{2} \mathrm{O}_{2}$ and $\mathrm{H}_{2} \mathrm{O}$ formation as a function of temperature. The interpretations of the above equation explain the trends in the Figures and Figures 6c, in which we empirically measure the apparent values of $\Delta \Delta \mathrm{H}_{4 e-2 e}^{\ddagger}$ as $40 \mathrm{~kJ} \mathrm{~mol}^{-1}$ on the $\mathrm{Pt}_{1} \mathrm{Au}_{15}$ and $7 \mathrm{~kJ} \mathrm{~mol}^{-1}$ on the $\mathrm{Pd}$. The greater value of $\Delta \Delta \mathrm{H}_{4 e-2 e}^{\ddagger}$ results in higher selectivity on $\mathrm{Pt}_{1} \mathrm{Au}_{15}$ than $\mathrm{Pd}$ in Figure 6, which agrees with the fits of $\mathrm{k}_{6 a}$ and $\mathrm{k}_{7}$ by equation $\mathrm{S} 8.1$. Thus, the surface structure of $\mathrm{Pt}_{1} \mathrm{Au}_{15}$ intrinsically favors the formation of $\mathrm{H}_{2} \mathrm{O}_{2}$ versus $\mathrm{H}_{2} \mathrm{O}$ by obstructing the dissociation $\mathrm{O}-\mathrm{O}$ bonds, while $\mathrm{Pd}$ readily dissociates these bonds. Comparisons of the activation barriers at low and high hydrogen pressures also provide greater insight into the electronic differences of these materials at varying coverages of reactant species (Table S4). For instance, the apparent value of $\Delta \Delta \mathrm{H}_{4 e-2 e}^{\ddagger}$ increases from $10 \mathrm{~kJ} \mathrm{~mol}^{-1}$ on $\mathrm{PdNi}$ at $40 \mathrm{kPa} \mathrm{H}_{2}$ to a value of $17 \mathrm{~kJ} \mathrm{~mol}^{-1}$ at $200 \mathrm{kPa} \mathrm{H}_{2}$, which similarly occurs on other Pdbased materials (Table S2). Thus, the $\beta-\mathrm{PdH}_{\mathrm{x}}$ presents an intrinsically more selective surface structure than the metallic phase, as suggested by Figure $6 \mathrm{~b}$. However, some materials deviate form these expectations due to the convolutions of the secondary decomposition reactions $(\xi)$ on some of the materials, which lead to negative apparent activation barriers for some pathways. 


\begin{tabular}{|c|c|c|c|c|}
\hline Material & $\Delta \mathrm{H}_{\mathrm{H}_{2} \mathrm{O}_{2}(40 \mathrm{kPa})}^{\ddagger}$ & $\Delta \mathrm{H}_{\mathrm{H}_{2} \mathrm{O}(40 \mathrm{kPa})}^{\ddagger}$ & $\Delta \mathrm{H}_{\mathrm{H}_{2} \mathrm{O}_{2}(200 \mathrm{kPa})}^{\ddagger}$ & $\Delta \mathrm{H}_{\mathrm{H}_{2} \mathrm{O}(200 \mathrm{kPa})}^{\ddagger}$ \\
\hline $\mathrm{Pt}$ & -3.6 & 5.1 & -5.0 & 9.0 \\
\hline $\mathrm{Pd}$ & -8.7 & 7.2 & 3.7 & 15.5 \\
\hline $\mathrm{PdZn}$ & -2.9 & 7.9 & 3.1 & 9.4 \\
\hline $\mathrm{PtCo}$ & 6.2 & 21.2 & 6.7 & 22.8 \\
\hline $\mathrm{PdPt}$ & 4.5 & 8.7 & 2.0 & 8.4 \\
\hline $\mathrm{PdCu}$ & -12.7 & 8.1 & 2.8 & 11.8 \\
\hline $\mathrm{PdCo}$ & 1.0 & 4.7 & 8.6 & 25.7 \\
\hline $\mathrm{PdNi}$ & 0.4 & 10.0 & 12.7 & 30.0 \\
\hline $\mathrm{Pd}_{1} \mathrm{Au}_{60}$ & 2.8 & 11.8 & 11.8 & 29.8 \\
\hline $\mathrm{Pt}_{1} \mathrm{Au}_{60}$ & 11.0 & 30.9 & 9.3 & 16.0 \\
\hline $\mathrm{Pt}_{1} \mathrm{Au}_{15}$ & 4.0 & 21.9 & 4.0 & 44.0 \\
\hline $\mathrm{Pt}_{1} \mathrm{Au}_{5}$ & 13.8 & 28.5 & 12.4 & 43.3 \\
\hline
\end{tabular}

Table S4: Average values of the apparent activation enthalpies for the formation of $\mathrm{H}_{2} \mathrm{O}_{2}$ and $\mathrm{H}_{2} \mathrm{O}$ formation on each catalyst investigated at $40 \mathrm{kPa} \mathrm{H} 2$ and $200 \mathrm{kPa} \mathrm{H}_{2}$ at a constant $60 \mathrm{kPa} \mathrm{O}_{2}$ measured between 278-308 K. These parameters correspond to data shown in Figures S19-S43. 

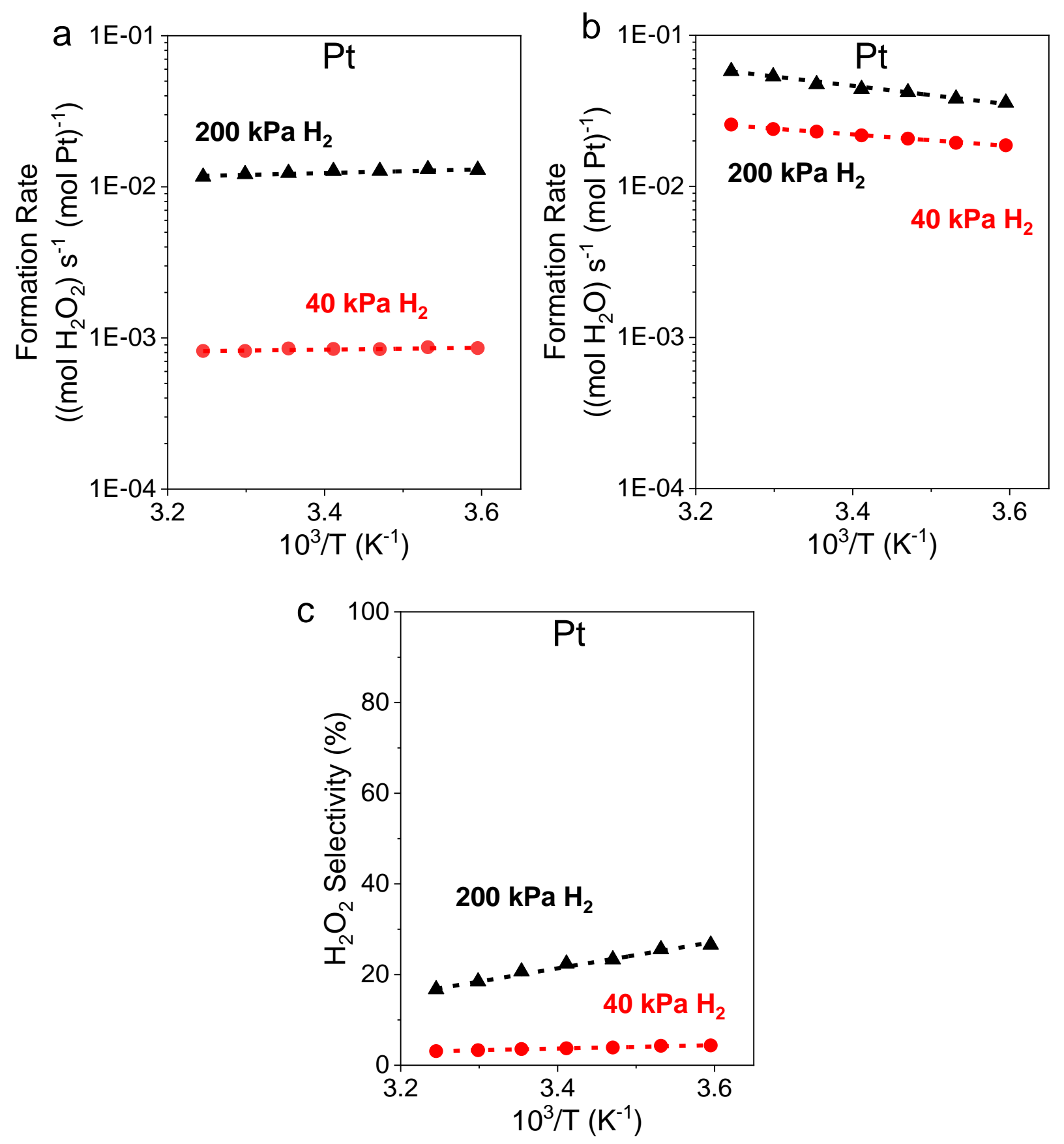

Figure S59. The formation rates of (a) $\mathrm{H}_{2} \mathrm{O}_{2}$ and (b) $\mathrm{H}_{2} \mathrm{O}$ with the corresponding values of (c) $\mathrm{H}_{2} \mathrm{O}_{2}$ selectivity on $\mathrm{Pt}$ nanoparticles as a function of the inverse temperature $(278-308 \mathrm{~K})$. Measurements are reported at a constant $\mathrm{O}_{2}$ pressure $(60 \mathrm{kPa})$ at either $200 \mathrm{kPa}$ or $40 \mathrm{kPa}$ of $\mathrm{H}_{2}$. The linear fit of the apparent activation enthalpy is shown in the dashed lines in part a and $\mathrm{b}$, which correspond to values in Table S4. 

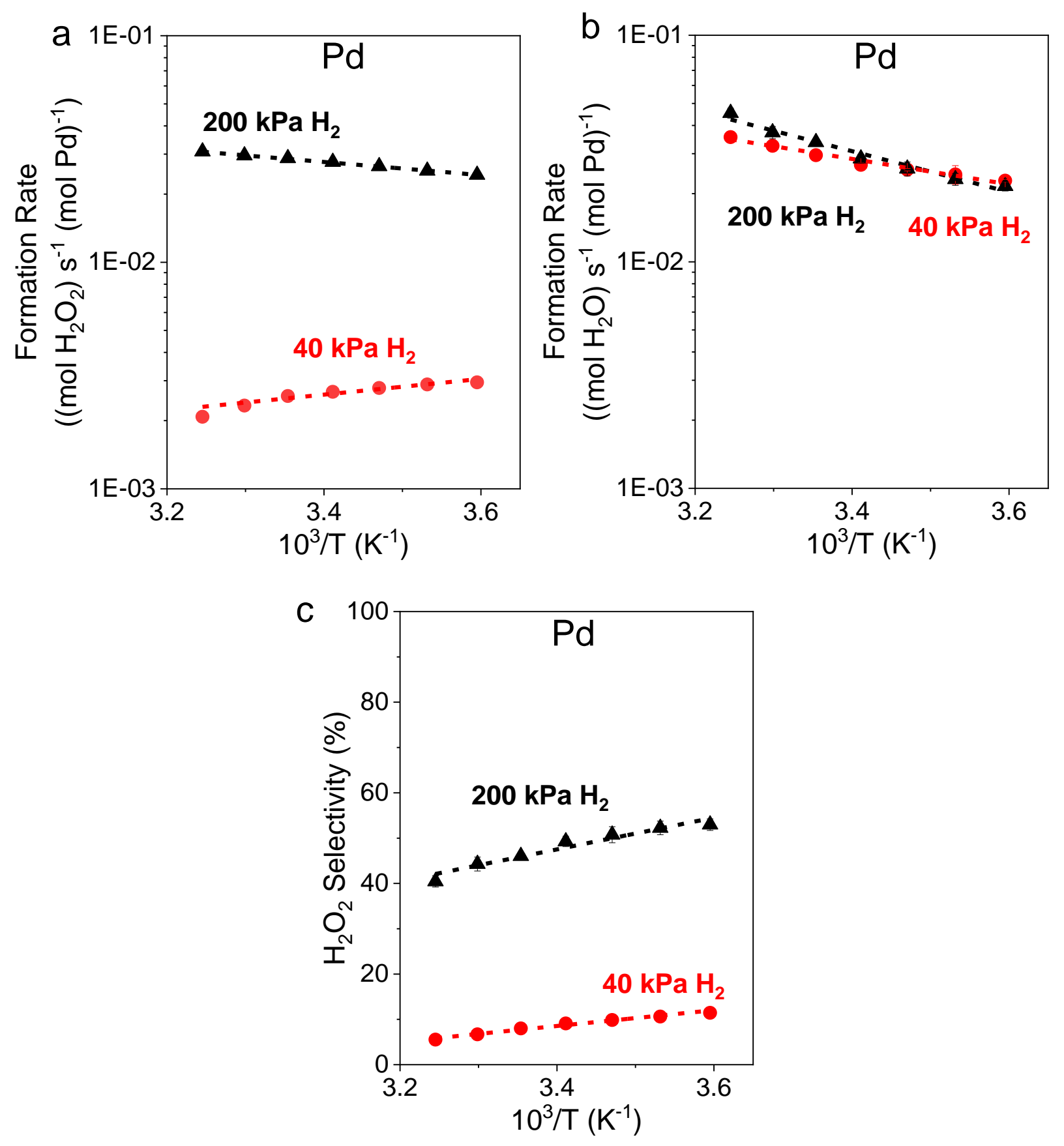

Figure S60. The formation rates of (a) $\mathrm{H}_{2} \mathrm{O}_{2}$ and (b) $\mathrm{H}_{2} \mathrm{O}$ with the corresponding values of (c) $\mathrm{H}_{2} \mathrm{O}_{2}$ selectivity on $\mathrm{Pd}$ nanoparticles as a function of the inverse temperature $(278-308 \mathrm{~K})$. Measurements are reported at a constant $\mathrm{O}_{2}$ pressure $(60 \mathrm{kPa})$ at either $200 \mathrm{kPa}$ or $40 \mathrm{kPa}$ of $\mathrm{H}_{2}$. The linear fit of the apparent activation enthalpy is shown in the dashed lines in part a and b, which correspond to values in Table S4. 

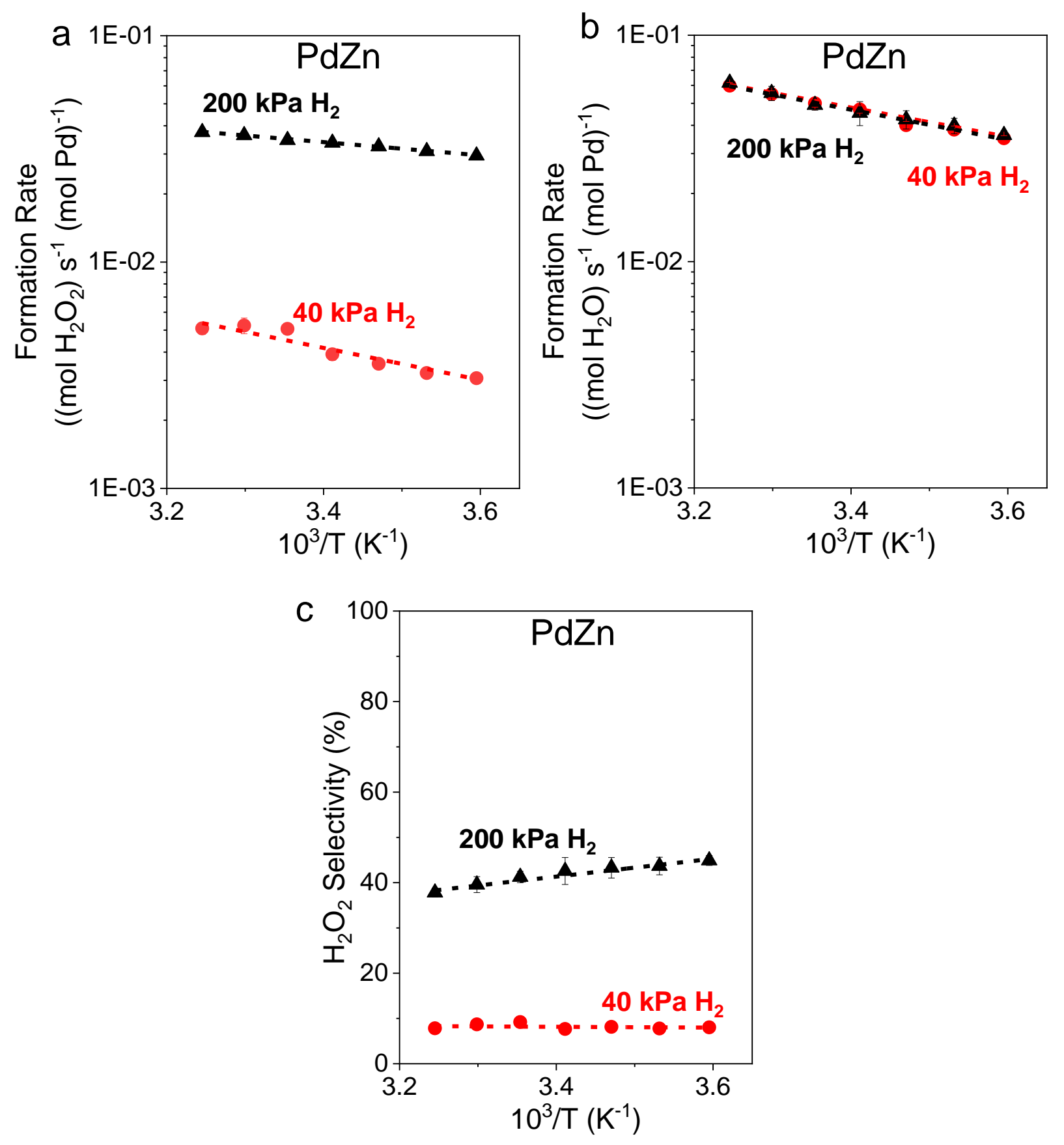

Figure S61. The formation rates of (a) $\mathrm{H}_{2} \mathrm{O}_{2}$ and (b) $\mathrm{H}_{2} \mathrm{O}$ with the corresponding values of (c) $\mathrm{H}_{2} \mathrm{O}_{2}$ selectivity on $\mathrm{PdZn}$ nanoparticles as a function of the inverse temperature $(278-308 \mathrm{~K})$. Measurements are reported at a constant $\mathrm{O}_{2}$ pressure $(60 \mathrm{kPa})$ at either $200 \mathrm{kPa}$ or $40 \mathrm{kPa}$ of $\mathrm{H}_{2}$. The linear fit of the apparent activation enthalpy is shown in the dashed lines in part a and b, which correspond to values in Table S4. 

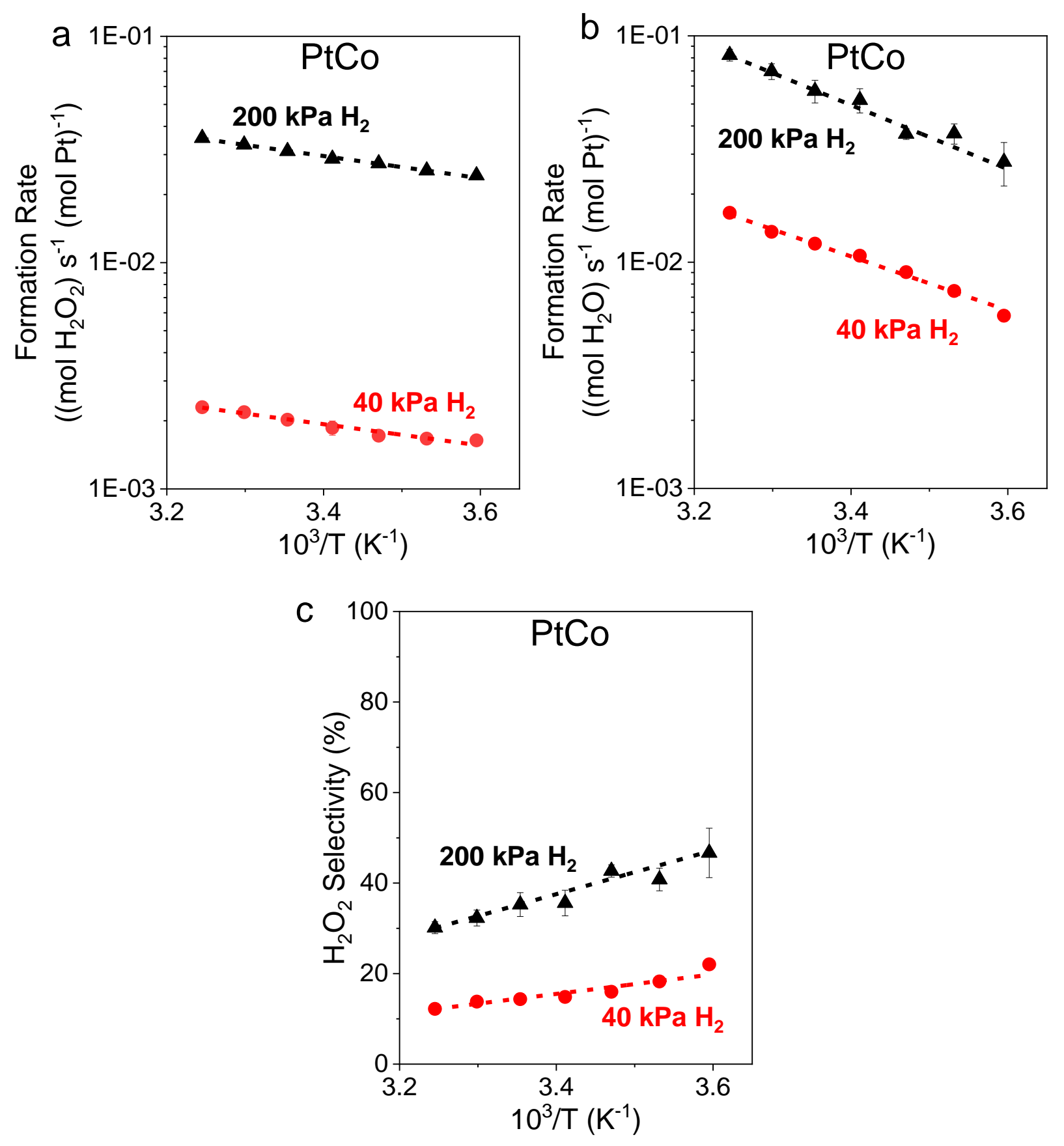

Figure S62. The formation rates of (a) $\mathrm{H}_{2} \mathrm{O}_{2}$ and (b) $\mathrm{H}_{2} \mathrm{O}$ with the corresponding values of (c) $\mathrm{H}_{2} \mathrm{O}_{2}$ selectivity on PtCo nanoparticles as a function of the inverse temperature $(278-308 \mathrm{~K})$. Measurements are reported at a constant $\mathrm{O}_{2}$ pressure $(60 \mathrm{kPa})$ at either $200 \mathrm{kPa}$ or $40 \mathrm{kPa}$ of $\mathrm{H}_{2}$. The linear fit of the apparent activation enthalpy is shown in the dashed lines in part a and b, which correspond to values in Table S4. 

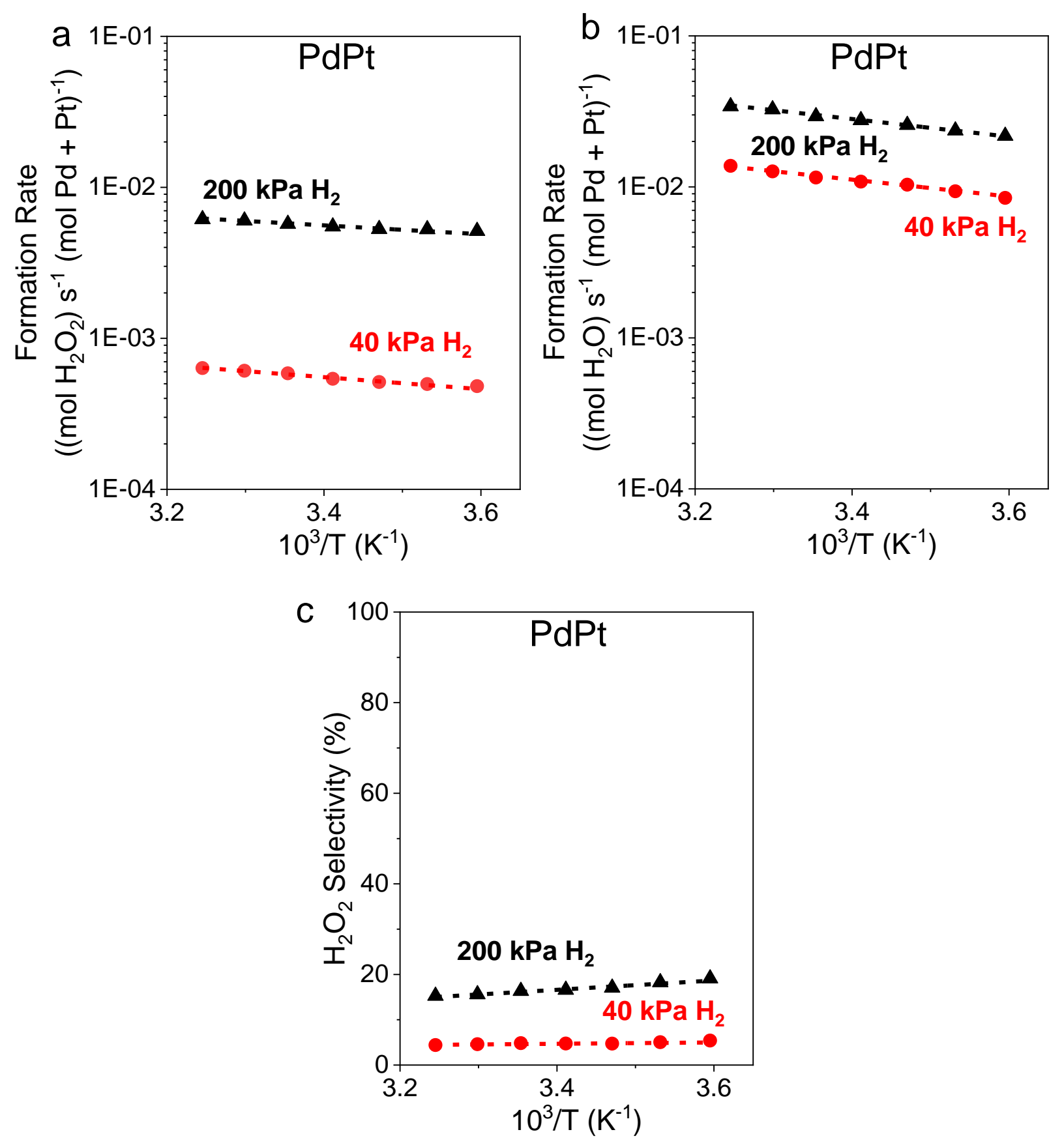

Figure S63. The formation rates of (a) $\mathrm{H}_{2} \mathrm{O}_{2}$ and (b) $\mathrm{H}_{2} \mathrm{O}$ with the corresponding values of (c) $\mathrm{H}_{2} \mathrm{O}_{2}$ selectivity on PdPt nanoparticles as a function of the inverse temperature $(278-308 \mathrm{~K})$. Measurements are reported at a constant $\mathrm{O}_{2}$ pressure $(60 \mathrm{kPa})$ at either $200 \mathrm{kPa}$ or $40 \mathrm{kPa}$ of $\mathrm{H}_{2}$. The linear fit of the apparent activation enthalpy is shown in the dashed lines in part a and $\mathrm{b}$, which correspond to values in Table S4. 

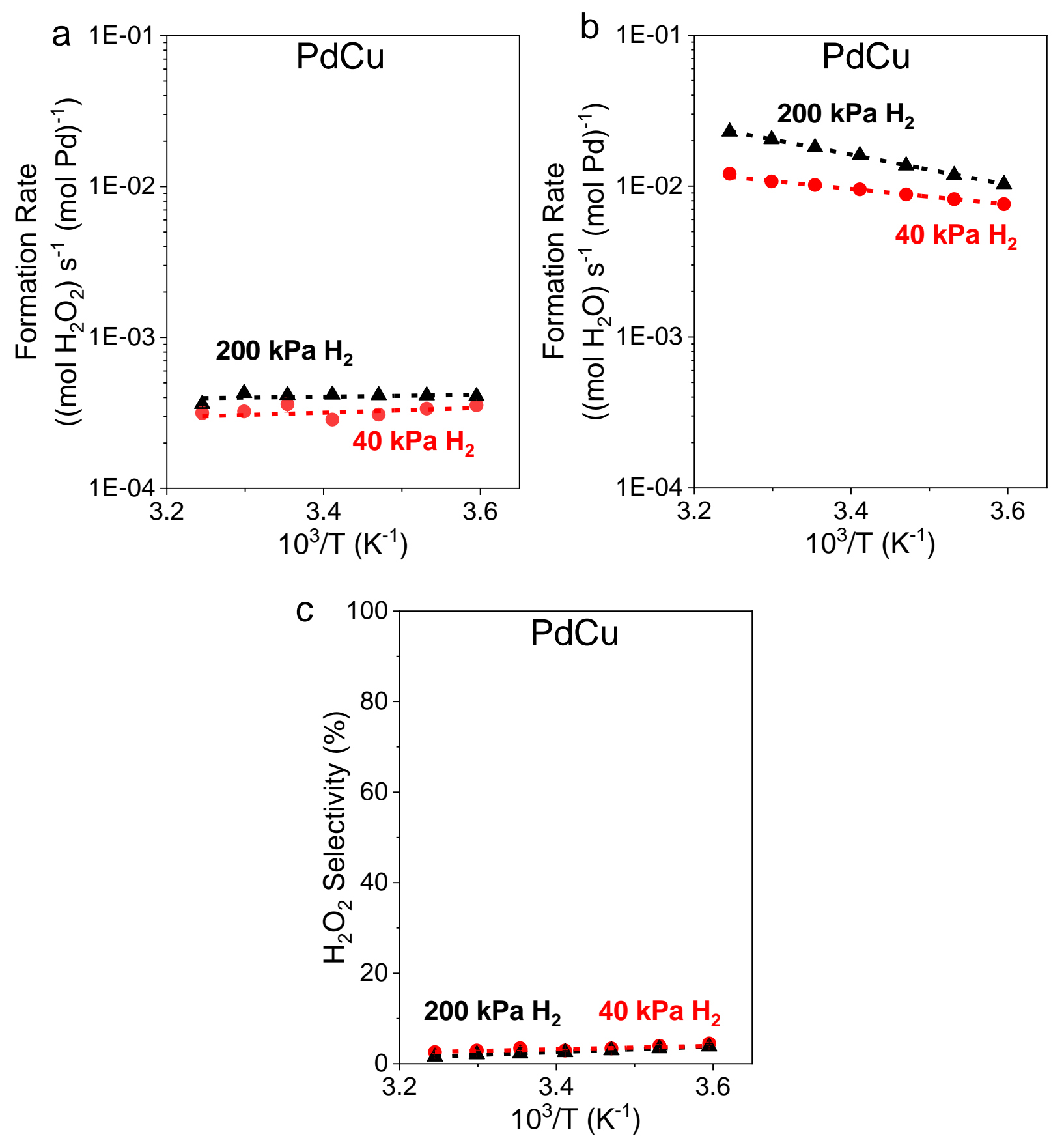

Figure S64. The formation rates of (a) $\mathrm{H}_{2} \mathrm{O}_{2}$ and (b) $\mathrm{H}_{2} \mathrm{O}$ with the corresponding values of (c) $\mathrm{H}_{2} \mathrm{O}_{2}$ selectivity on $\mathrm{PdCu}$ nanoparticles as a function of the inverse temperature $(278-308 \mathrm{~K})$. Measurements are reported at a constant $\mathrm{O}_{2}$ pressure $(60 \mathrm{kPa})$ at either $200 \mathrm{kPa}$ or $40 \mathrm{kPa}$ of $\mathrm{H}_{2}$. The linear fit of the apparent activation enthalpy is shown in the dashed lines in part a and $\mathrm{b}$, which correspond to values in Table S4. 

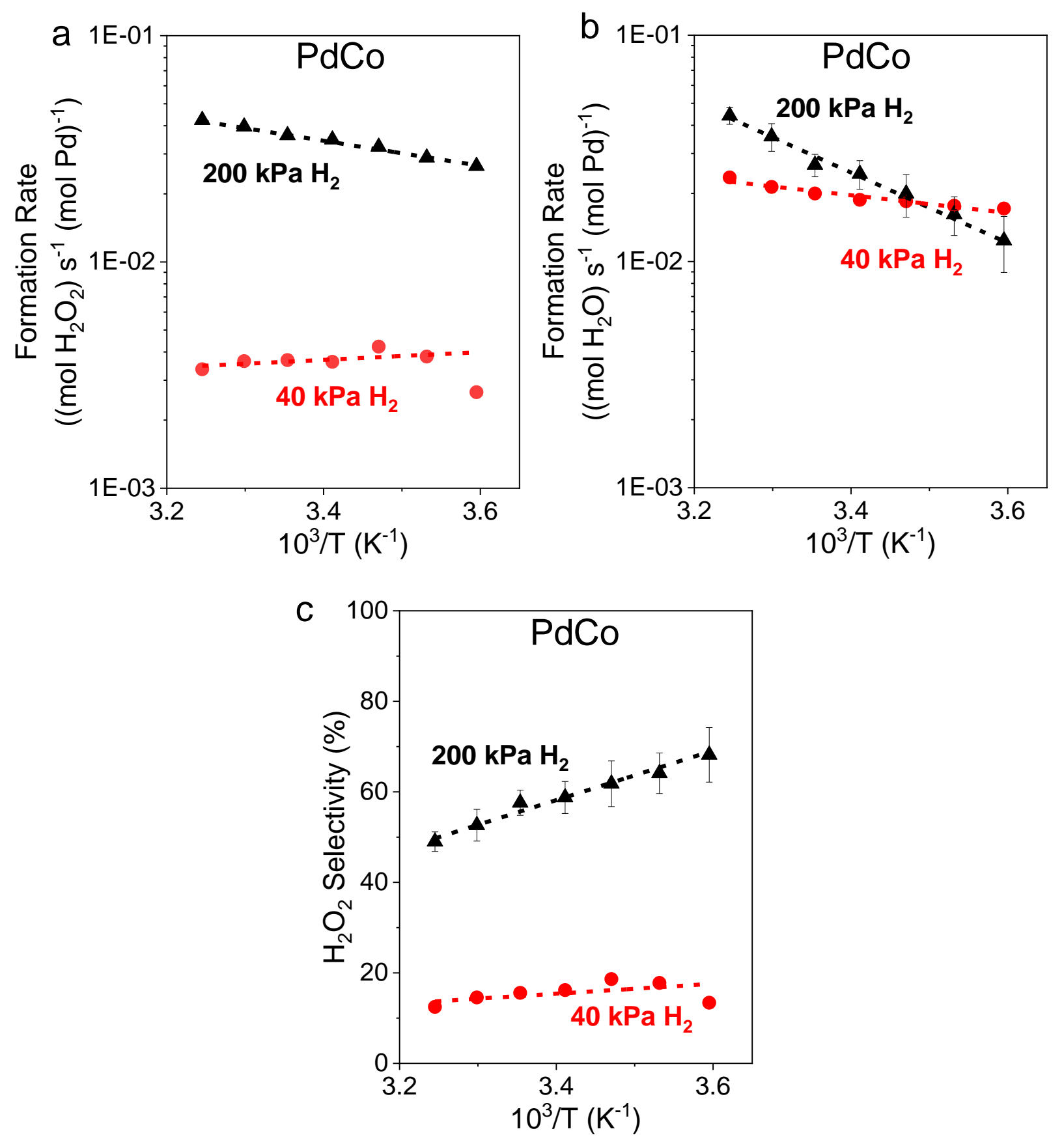

Figure S65. The formation rates of (a) $\mathrm{H}_{2} \mathrm{O}_{2}$ and (b) $\mathrm{H}_{2} \mathrm{O}$ with the corresponding values of (c) $\mathrm{H}_{2} \mathrm{O}_{2}$ selectivity on PdCo nanoparticles as a function of the inverse temperature $(278-308 \mathrm{~K})$. Measurements are reported at a constant $\mathrm{O}_{2}$ pressure $(60 \mathrm{kPa})$ at either $200 \mathrm{kPa}$ or $40 \mathrm{kPa}$ of $\mathrm{H}_{2}$. The linear fit of the apparent activation enthalpy is shown in the dashed lines in part a and b, which correspond to values in Table S4. 

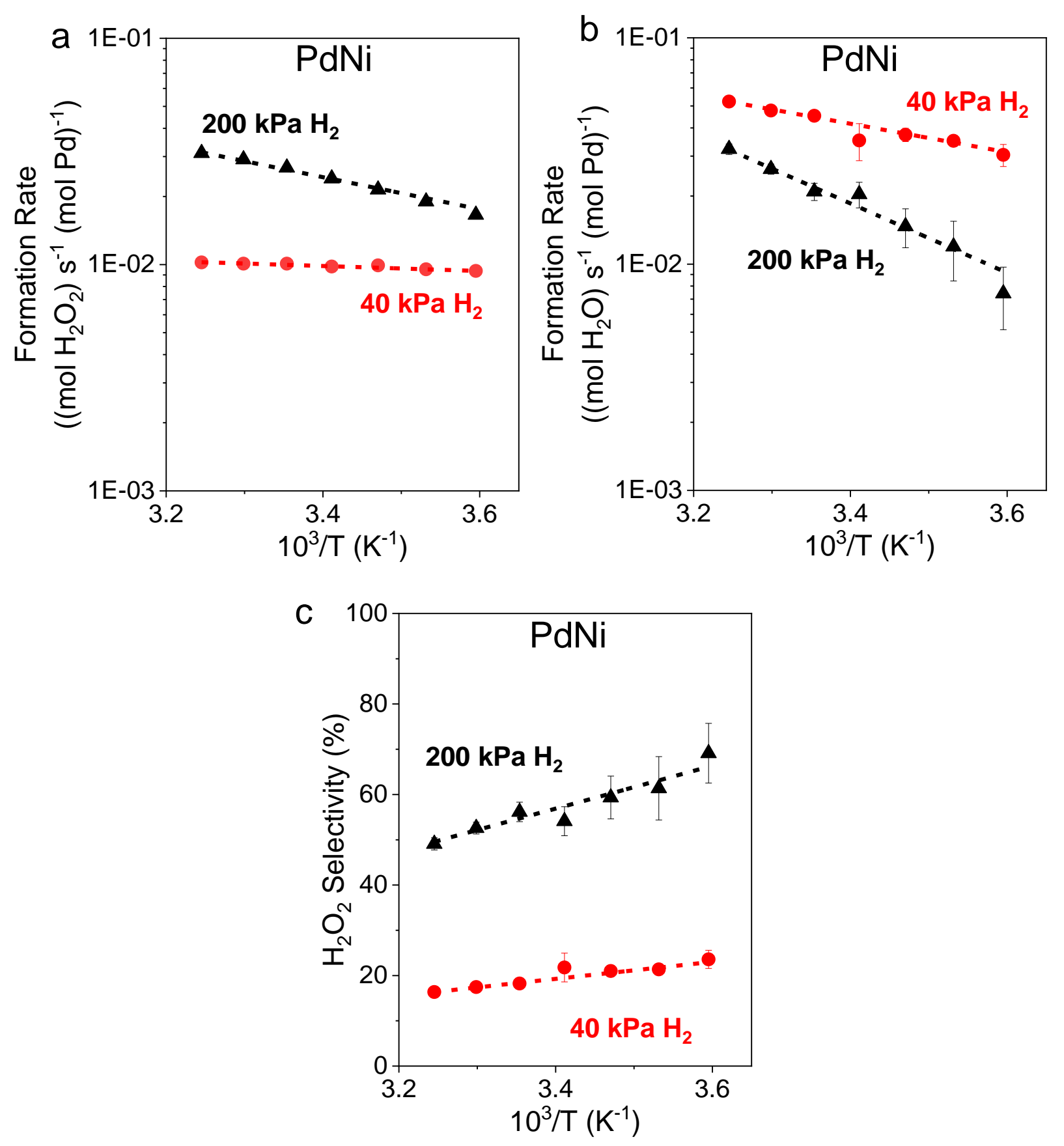

Figure S66. The formation rates of (a) $\mathrm{H}_{2} \mathrm{O}_{2}$ and (b) $\mathrm{H}_{2} \mathrm{O}$ with the corresponding values of (c) $\mathrm{H}_{2} \mathrm{O}_{2}$ selectivity on PdNi nanoparticles as a function of the inverse temperature $(278-308 \mathrm{~K})$. Measurements are reported at a constant $\mathrm{O}_{2}$ pressure $(60 \mathrm{kPa})$ at either $200 \mathrm{kPa}$ or $40 \mathrm{kPa}$ of $\mathrm{H}_{2}$. The linear fit of the apparent activation enthalpy is shown in the dashed lines in part a and $\mathrm{b}$, which correspond to values in Table S4. 

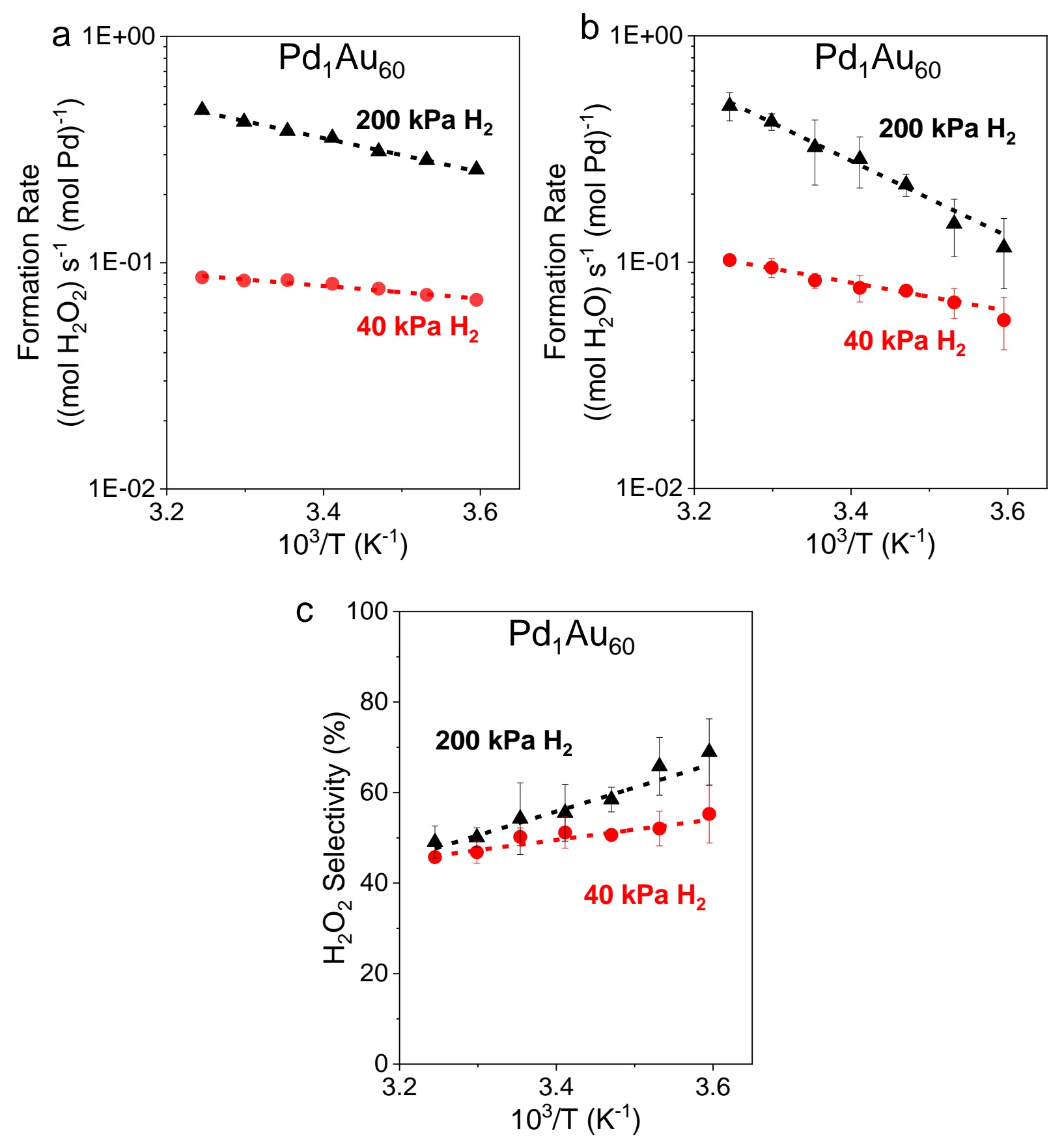

Figure S67. The formation rates of (a) $\mathrm{H}_{2} \mathrm{O}_{2}$ and (b) $\mathrm{H}_{2} \mathrm{O}$ with the corresponding values of (c) $\mathrm{H}_{2} \mathrm{O}_{2}$ selectivity on $\mathrm{Pd}_{1} \mathrm{Au}_{60}$ nanoparticles as a function of the inverse temperature $(278-308 \mathrm{~K})$. Measurements are reported at a constant $\mathrm{O}_{2}$ pressure $(60 \mathrm{kPa})$ at either $200 \mathrm{kPa}$ or $40 \mathrm{kPa}$ of $\mathrm{H}_{2}$. The linear fit of the apparent activation enthalpy is shown in the dashed lines in part a and $\mathrm{b}$, which correspond to values in Table S4. 

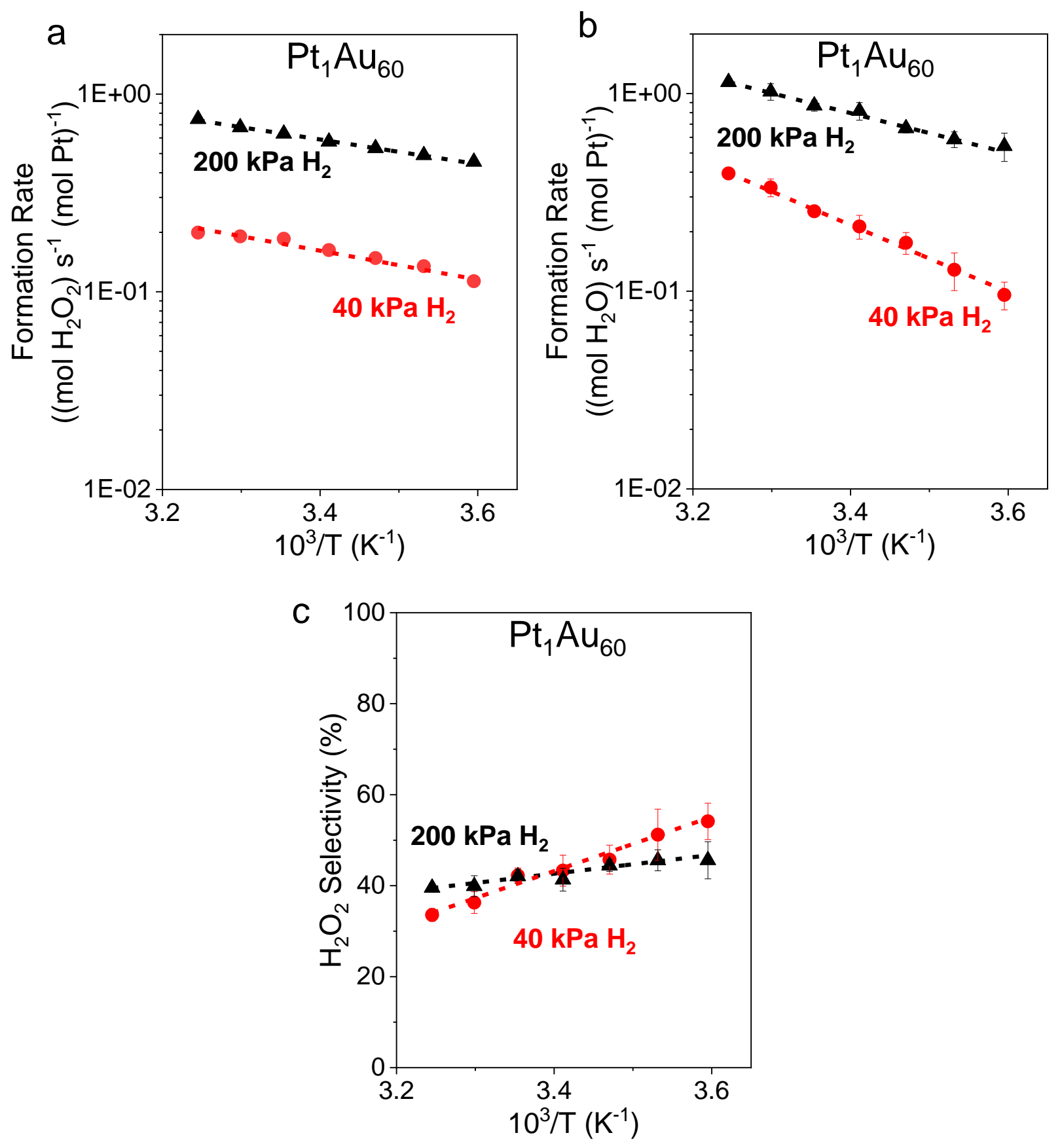

Figure S68. The formation rates of (a) $\mathrm{H}_{2} \mathrm{O}_{2}$ and (b) $\mathrm{H}_{2} \mathrm{O}$ with the corresponding values of (c) $\mathrm{H}_{2} \mathrm{O}_{2}$ selectivity on $\mathrm{Pt}_{1} \mathrm{Au}_{60}$ nanoparticles as a function of the inverse temperature $(278-308 \mathrm{~K})$. Measurements are reported at a constant $\mathrm{O}_{2}$ pressure $(60 \mathrm{kPa})$ at either $200 \mathrm{kPa}$ or $40 \mathrm{kPa}$ of $\mathrm{H}_{2}$. The linear fit of the apparent activation enthalpy is shown in the dashed lines in part a and b, which correspond to values in Table S4. 

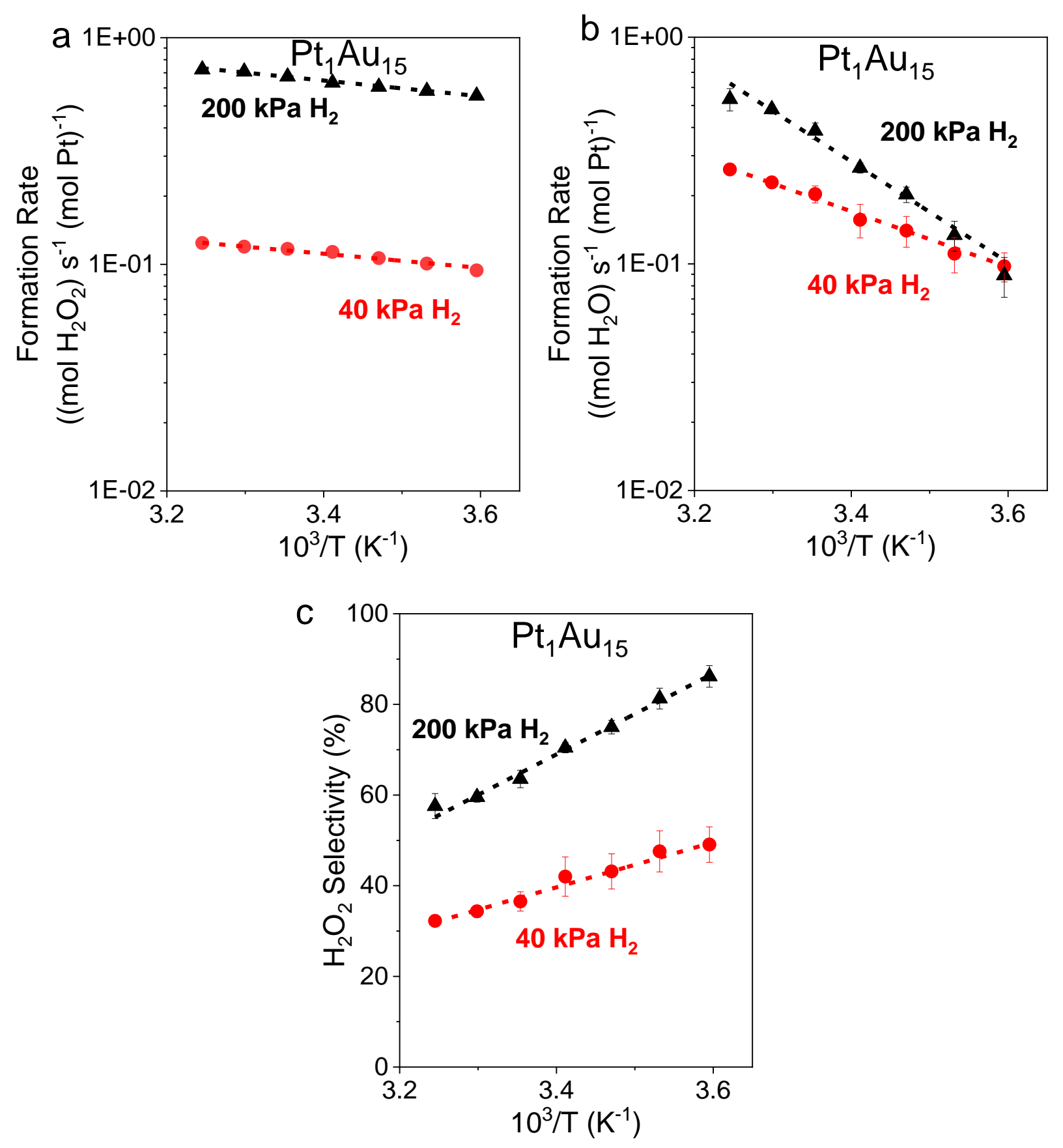

Figure S69. The formation rates of (a) $\mathrm{H}_{2} \mathrm{O}_{2}$ and (b) $\mathrm{H}_{2} \mathrm{O}$ with the corresponding values of (c) $\mathrm{H}_{2} \mathrm{O}_{2}$ selectivity on $\mathrm{Pt}_{1} \mathrm{Au}_{15}$ nanoparticles as a function of the inverse temperature $(278-308 \mathrm{~K})$. Measurements are reported at a constant $\mathrm{O}_{2}$ pressure $(60 \mathrm{kPa})$ at either $200 \mathrm{kPa}$ or $40 \mathrm{kPa}$ of $\mathrm{H}_{2}$. The linear fit of the apparent activation enthalpy is shown in the dashed lines in part a and b, which correspond to values in Table S4. 

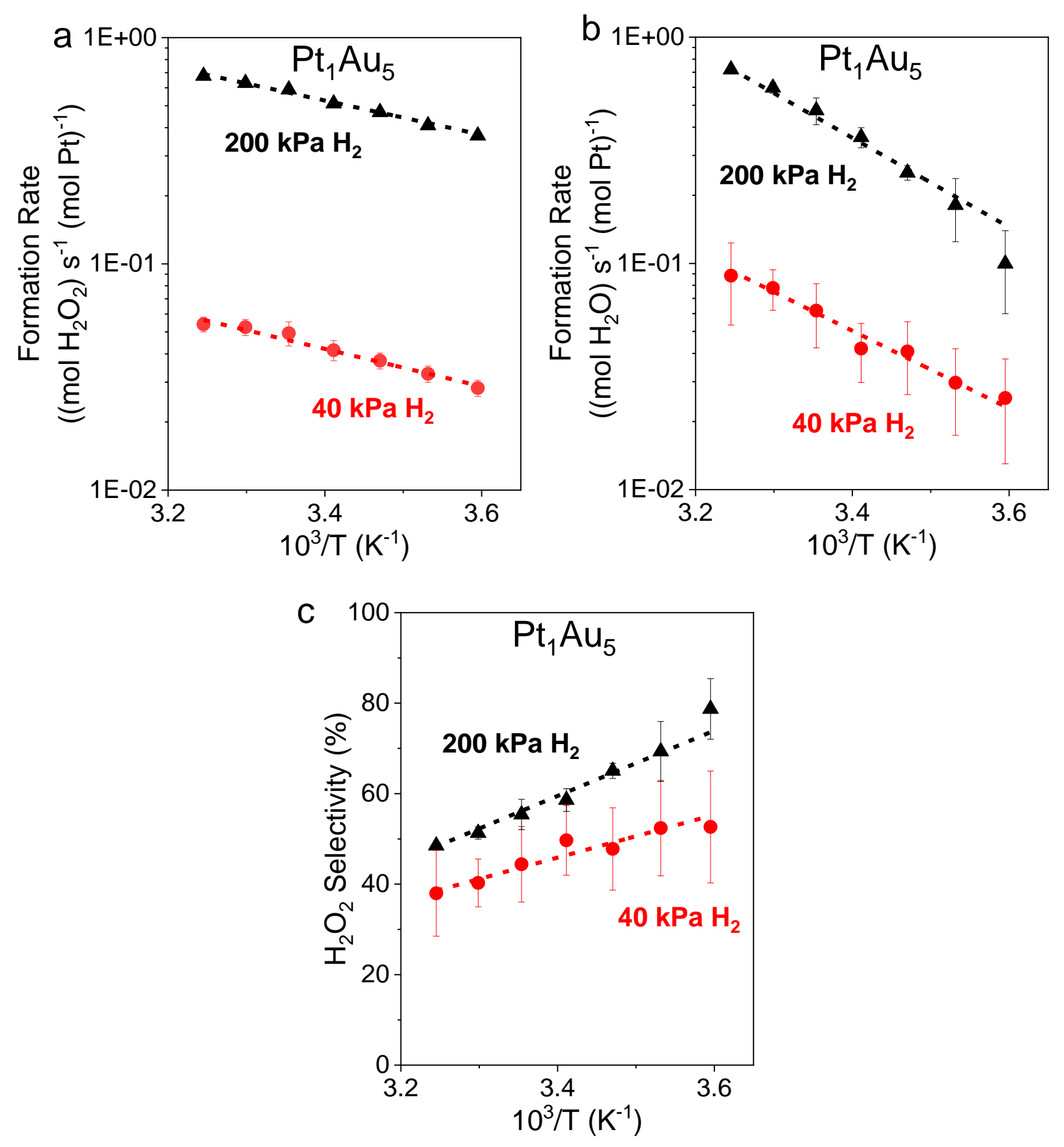

Figure S70. The formation rates of (a) $\mathrm{H}_{2} \mathrm{O}_{2}$ and (b) $\mathrm{H}_{2} \mathrm{O}$ with the corresponding values of (c) $\mathrm{H}_{2} \mathrm{O}_{2}$ selectivity on $\mathrm{Pt}_{1} \mathrm{Au}_{5}$ nanoparticles as a function of the inverse temperature $(278-308 \mathrm{~K})$. Measurements are reported at a constant $\mathrm{O}_{2}$ pressure $(60 \mathrm{kPa})$ at either $200 \mathrm{kPa}$ or $40 \mathrm{kPa}$ of $\mathrm{H}_{2}$. The linear fit of the apparent activation enthalpy is shown in the dashed lines in part a and b, which correspond to values in Table S4. 


\section{S10. Comparisons of Rates and Selectivities between Themo- and Electrochemical Systems}

In this section, we show how to compare rates and selectivities measured during electrode and flow-reactor measurements. First, we use the mathematics developed in Sections S7 and S8, to extract fundamental rate constants and rate ratios (e.g., selectivities) from thermo- and electrochemical measurements of $\mathrm{H}_{2} \mathrm{O}_{2}$ formation. Then, we evaluate error propagation and discuss the agreement of the data with the expectations of these models. Generally, comparisons of selectivity and potentials agree well with the expectations of the models while comparisons of rates show less parity.

\section{S10.1 Comparisons of $\mathrm{H}_{2} \mathrm{O}_{2}$ Selectivity Under Thermo- and Electrocatalytic Conditions}

In this subsection, we consider comparisons of $\mathrm{H}_{2} \mathrm{O}_{2}$ selectivity under electrocatalytic and thermocatalyic conditions, as derived in sections $\mathrm{S} 7$ and $\mathrm{S} 8$ :

$$
\begin{aligned}
& \mathrm{S}_{\mathrm{H}_{2} \mathrm{O}_{2}}\left(\Phi^{\mathrm{op}}\right)=\frac{\mathrm{k}_{6 \mathrm{a}}^{0} \mathrm{e}^{-\frac{\alpha_{6 \mathrm{a}} \mathrm{F}\left(\Phi^{\mathrm{op}}-\Phi_{6 \mathrm{a}}^{0}\right)}{\mathrm{RT}}}}{\left(1+\frac{\mathrm{k}_{13}^{0}}{\mathrm{k}_{12}^{0}} \mathrm{e}^{-\frac{\alpha_{13} \mathrm{~F}\left(\Phi^{\mathrm{op}}-\Phi_{13}^{0}\right)}{\mathrm{RT}}}\right)\left(\mathrm{k}_{6 \mathrm{a}}^{0} \mathrm{e}^{-\frac{\alpha_{6 \mathrm{a}} \mathrm{F}\left(\Phi^{\mathrm{op}}-\Phi_{6 \mathrm{a}}^{0}\right)}{\mathrm{RT}}}+2 \mathrm{k}_{7}^{0} \mathrm{e}^{-\frac{\alpha_{7} \mathrm{~F}\left(\Phi^{\mathrm{op}}-\Phi_{7}^{0}\right)}{\mathrm{RT}}}\right)} \\
& \mathrm{S}_{\mathrm{H}_{2} \mathrm{O}_{2}}(\Phi)=\frac{\mathrm{k}_{6 \mathrm{a}}^{0} \mathrm{e}^{-\frac{\alpha_{6 \mathrm{a}} \mathrm{F}\left(\Phi-\Phi_{6 \mathrm{a}}^{0}\right)}{\mathrm{RT}}}}{\left(1+\frac{\mathrm{k}_{13}^{0}}{\mathrm{k}_{12}^{0}} \mathrm{e}^{-\frac{\alpha_{13} \mathrm{~F}\left(\Phi-\Phi_{13}^{0}\right)}{\mathrm{RT}}}\right)\left(\mathrm{k}_{6 \mathrm{a}}^{0} \mathrm{e}^{-\frac{\alpha_{6 \mathrm{a}} \mathrm{F}\left(\Phi-\Phi_{6 \mathrm{a}}^{0}\right)}{\mathrm{RT}}}+2 \mathrm{k}_{7}^{0} \mathrm{e}^{-\frac{\alpha_{7} \mathrm{~F}\left(\Phi-\Phi_{7}^{0}\right)}{\mathrm{RT}}}\right)}
\end{aligned}
$$

From these expressions, it is apparent that the selectivity of the $\mathrm{H}_{2} \mathrm{O}_{2}$ formation should be equivalent if the nanoparticle operates at equivalent potentials $\left(\Phi=\Phi^{\mathrm{op}}\right)$ in the thermo- and electrocatalytic systems. So, we evaluated the electrochemical selectivities (Figures S44-S56) at the relevant operating potentials ( $\Phi^{\mathrm{op}}$, Figures S6-S17), determined empirically under thermocatalytic conditions. We then compared these selectivities to those measured under direct synthesis conditions at equivalent operating potentials $\left(\Phi=\Phi^{\mathrm{op}}\right.$, Figure 5). Using such comparisons of equations S10.1 and S10.2, we constructed Figures 7a and 7b in the main text.

\section{S10.2 Comparisons of Oxygen Reduction Rates and Considerations of Error Propagation} In this subsection, we consider comparisons of the total ORR rate under electrocatalytic and thermocatalytic conditions, as derived in sections S7. Here, the predicted ORR rate takes the following functional form under the relevant reaction conditions of direct synthesis:

$$
\frac{r_{O R R}}{\left[L_{*}\right]} \approx\left(\frac{\frac{n_{O R R}}{2} k_{5 a}^{0} K_{4}\left[O_{2}\right]}{1+K_{a p p, O_{2}}\left[O_{2}\right]}\right)^{\frac{\alpha_{1}}{\alpha_{5 a}}}\left(\frac{k_{1}^{0}\left[H_{2}\right]\left[H_{2} O\right]}{1+K_{a p p, H_{2}}\left[H_{2}\right]}\right) e^{\frac{F \alpha_{1}\left(\Phi_{5 a}^{0}-\Phi_{1}^{0}\right)}{R T}}
$$


Here, the rate of reaction depends on the rate expressions related to the ORR and HOR, which depend on the coverage of oxygen- and hydrogen-derived intermediates. For simplicity, this analysis compares rates in the regime where the rates show a first order dependence on $\mathrm{H}_{2}$ pressure (60 $\mathrm{kPa} \mathrm{O}_{2}, 20-60 \mathrm{kPa} \mathrm{H}_{2}$ ). Under similar conditions, mechanistic studies of the direct synthesis of $\mathrm{H}_{2} \mathrm{O}_{2}$ suggest that the rate of $\mathrm{H}_{2} \mathrm{O}_{2}$ and $\mathrm{H}_{2} \mathrm{O}$ formation increase in proportion to the $\mathrm{H}_{2}$ pressure and are independent of $\mathrm{O}_{2}$ pressure. ${ }^{20-22,27}$ Moreover, we expect that the kinetic parameters $\left(k_{x}^{0}\right.$, $\alpha_{x}, \Phi_{x}^{0}$ ) should show a greater similarity between thermochemical and electrochemical measurements since coverages of hydrogen-derived intermediates should be low while oxygenderived intermediates should show greater coverages (Section 3.3.2). Under such conditions, the $\operatorname{HOR}\left(K_{a p p, H_{2}}\left[H_{2}\right] \ll 1\right)$ and ORR $\left(K_{a p p, O_{2}}\left[O_{2}\right] \gg 1\right)$ terms of equation S10.3 simplify:

$$
\frac{r_{O R R}}{\left[L_{*}\right]} \approx\left(\frac{n_{O R R} k_{5 a}^{0}}{2 K_{a p p, O_{2}}}\right)^{\frac{\alpha_{1}}{\alpha_{5 a}}}\left(k_{1}^{0}\left[H_{2}\right]\left[H_{2} O\right]\right) e^{\frac{F\left(\alpha_{1}\left(\Phi_{5 a}^{0}-\Phi_{1}^{0}\right)\right)}{R T}}
$$

Using this expression, we can relate the total rate of oxygen reduction under direct synthesis conditions to the apparent rate constants of the HOR and ORR if the surface of the nanoparticle is similar under thermocatalytic and electrocatalytic conditions (i.e., $k_{1}^{0}=k_{H O R}, k_{5 a}^{0}=k_{O R R}, \alpha_{1}=$ $\left.\alpha_{H O R}, \alpha_{5 a}=\alpha_{O R R}\right)$. In this case, equation S10.4 takes the following form:

$$
\begin{gathered}
\frac{r_{O R R}}{\left[L_{*}\right]} \approx\left(\frac{n_{O R R} k_{O R R}}{2}\right)^{\frac{\alpha_{H O R}}{\alpha_{O R R}}}\left(k_{H O R}\left[H_{2}\right]\left[H_{2} O\right]\right) \gamma \\
\gamma=e^{\frac{F\left(\alpha_{H O R}\left(\Phi_{5 a}^{0}-\Phi_{1}^{0}\right)\right)}{R T}}
\end{gathered}
$$

Where we assume that the apparent rate constants and charge transfer coefficients of the HOR and ORR measurements reflect elementary steps 1 and 5a, respectively. Here, the values of $n_{O R R}$ are determined as a function of potential from Figures S44-S56. Finally, we empirically determine the value of exponential term $(\gamma)$ from the definition of the of the rate of ORR, discussed in sections S5 and S7.

$$
\frac{r_{O R R}}{\left[L_{*}\right]}=k_{O R R} e^{\frac{F\left(\alpha_{O R R}\left(\Phi^{\mathrm{op}}-\Phi_{0 R R}^{0}\right)\right)}{R T}}
$$

Here, we can solve for the apparent value of $\gamma$ by setting equations $\mathrm{S} 10.5$ equal to equation $\mathrm{S} 10.7$, which we solve using empirically determined values of $k_{O R R}, k_{H O R}, \alpha_{O R R}, \alpha_{H O R}$, and $\Phi^{\mathrm{op}}$ at the relevant hydrogen and oxygen pressures of these measurements $\left(60 \mathrm{kPa} \mathrm{O}_{2}, 20-60 \mathrm{kPa} \mathrm{H}_{2}\right)$. Here, $\gamma$ represents the combined overpotentials of the HOR and ORR reactions at the operating potential of the nanoparticle. The values of this constant are shown in Table S5 below: 


\begin{tabular}{|c|c|}
\hline Material & $\gamma$ \\
\hline $\mathrm{Pt}$ & 3.31 \\
\hline $\mathrm{Pd}$ & $1.20 \times 10^{1}$ \\
\hline $\mathrm{PdZn}$ & $2.58 \times 10^{2}$ \\
\hline $\mathrm{PtCo}$ & $9.66 \times 10^{1}$ \\
\hline $\mathrm{PdPt}$ & 8.11 \\
\hline $\mathrm{PdCu}$ & $5.53 \times 10^{2}$ \\
\hline $\mathrm{PdCo}$ & 9.80 \\
\hline $\mathrm{PdNi}$ & 9.66 \\
\hline $\mathrm{Pd}_{1} \mathrm{Au}_{60}$ & $4.60 \times 10^{1}$ \\
\hline $\mathrm{Pt}_{1} \mathrm{Au}_{60}$ & 9.09 \\
\hline $\mathrm{Pt}_{1} \mathrm{Au}_{15}$ & $5.51 \times 10^{1}$ \\
\hline $\mathrm{Pt}_{1} \mathrm{Au}_{5}$ & $1.73 \times 10^{1}$ \\
\hline
\end{tabular}

Table S5. Values of $\gamma$ on Pt- and Pd-based materials, determined by empirical comparisons of equations S10.5 and S10.7 using data reported Figure S6-S17 and Table S2.

Finally, we compared the predictions of Equation S10.5 to the rate data shown in Figure 5 to compare the empirical rates of oxygen reduction to the predictions of our model in Figures 7c and 7d. Generally, highly reactive catalysts show high reactivity in both the electrocatalytic and thermocatalytic systems, while unreactive catalysts show lower rates in either system. However, the predicted ORR rates show better agreement with the rates measured on Pt materials than on Pd materials. The Pt and Pt-based catalysts offer more straightforward comparisons because the kinetics of the HOR are much faster on these materials, leading to coverages of hydrogen atoms and other surface species that are more similar between thermocatalytic and electrocatalytic reaction conditions. In comparison, $\mathrm{Pd}$ and Pd-based catalysts offer more sluggish HER/HOR kinetics relative to Pt-based catalysts. Therefore, both the hydrogen atom coverage and the phase (metallic or hydridic) differ between the RRDE and trickle bed reactor, particularly at the more negative potentials and high hydrogen pressures. 

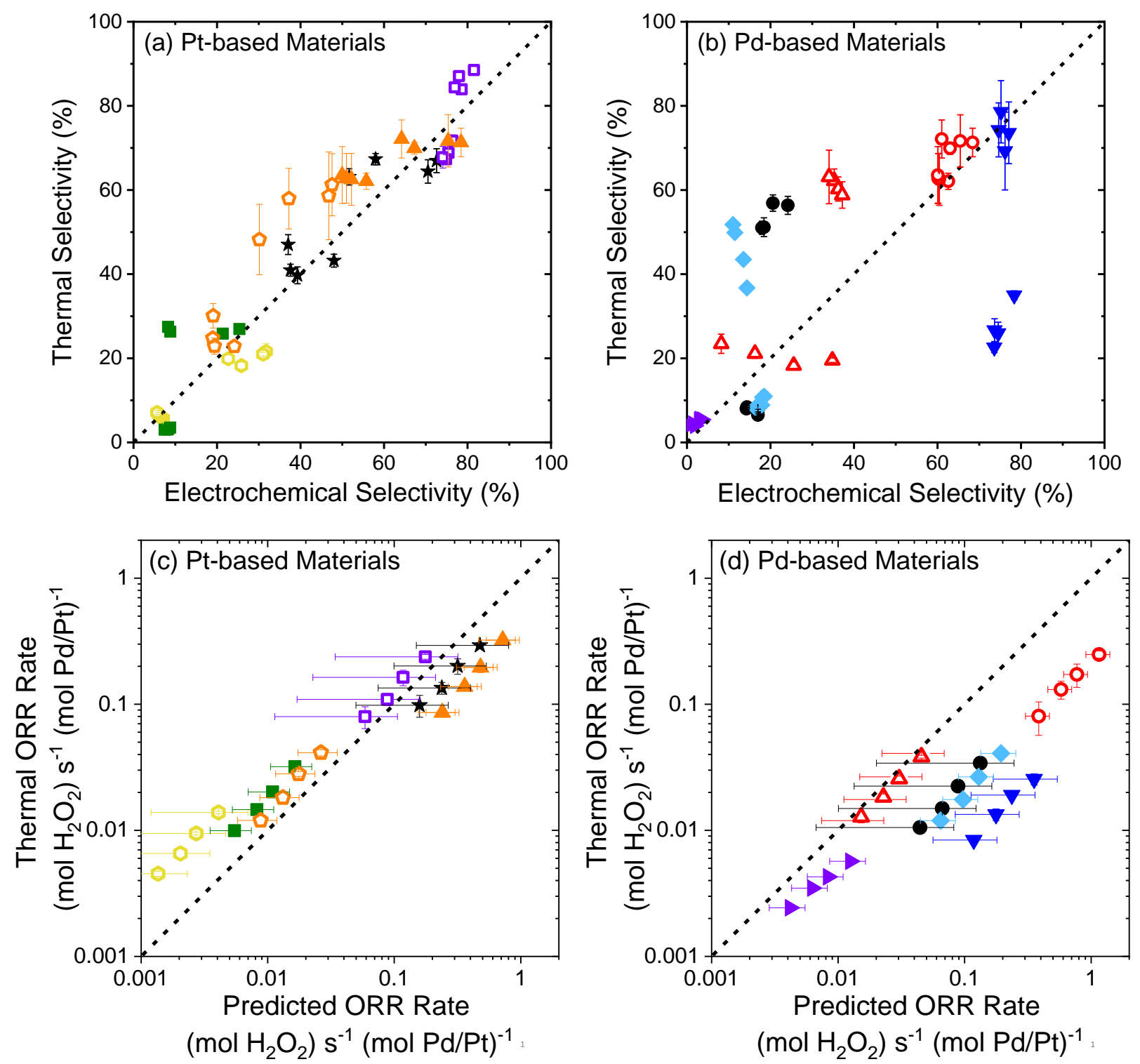

Figure 7. Thermocatalytic $\mathrm{H}_{2} \mathrm{O}_{2}$ selectivities and $\mathrm{ORR}$ rates compared to electrocatalytic selectivities and predicted ORR rates on $(\mathrm{a}, \mathrm{c}) \operatorname{PdPt}(\bullet), \operatorname{Pt}(\bullet), \operatorname{PtCo}(\triangle), \mathrm{PtAu}_{60}(\star), \mathrm{PtAu}_{15}(\triangle)$, and $\mathrm{PtAu}_{5}(\square)$ and (b, d) $\operatorname{Pd}(\bullet), \operatorname{PdCo}(\Delta), \operatorname{PdNi}(\boldsymbol{\nabla}), \operatorname{PdZn}(\diamond), \operatorname{PdAu}(\circ)$, and $\operatorname{PdCu}(\triangleright)$ nanoparticles supported on Vulcan XC-72. Thermocatalytic selectivity was calculated from the $\mathrm{H}_{2} \mathrm{O}_{2}$ formation rate divided by the $\mathrm{H}_{2}$ consumption rate in a trickle-bed reactor (20-400 $\mathrm{kPa} \mathrm{H}_{2}$, $\left.60 \mathrm{kPa} \mathrm{O}_{2}\right)$ at $298 \mathrm{~K}$. Electrocatalytic selectivity was calculated from the ring and disk currents of a rotating ring disk electrode (RRDE). Selectivities were determined at equivalent potentials ( $\Phi=$ $\Phi^{\mathrm{op}}$ ) from open-circuit potentiometry experiments using equation 23. Rates of ORR were predicted from electrochemical rate constants (Table S2) using equation 16. 
In short, the Pd materials show systematically greater rates in the electrocatalytic system compared to the thermocatalytic system, and these deviations probably result from:

(1) Differences in $k_{O R R}, k_{H O R}, \alpha_{O R R}$, or $\alpha_{H O R}$ during thermochemical vs. electrochemical measurements exacerbated by sluggish HER/HOR kinetics on Pd catalysts.

(2) Error propagation resulting from the uncertainty of potentiometric measurements.

(3) Uncertainty in the amount of catalyst on the RRDE electrode, which influences normalized rates.

(4) Differences caused by mass transfer effects.

(1) Our model assumes that the values of $k_{O R R}, k_{H O R}, \alpha_{O R R}$, or $\alpha_{H O R}$ are constant parameters that do not change between thermo- and electrocatalytic measurements. These parameters reflect the apparent value of the kinetically relevant electron transfer steps of HOR and ORR. Consequently, these parameters are a strong function of the coverage of hydrogen- and oxygen-derived intermediates on the catalyst surface (Section S7).

Differences in coverage can stabilize distinct reactive pathways and change the apparent rate expressions to reflect different elementary steps (i.e., the apparent rate changes with the most abundant reactive intermediate). So, if the coverages or reactive intermediates upon the surface are not identical during electrocatalytic and thermocatalytic measurements at equivalent electrode potentials, then the apparent values of $k_{O R R}, k_{H O R}, \alpha_{O R R}$, or $\alpha_{H O R}$ could change significantly between these comparisons. Moreover, these expressions involve exponential functions of $\alpha_{O R R}$ and $\alpha_{H O R}$, which could result in differences in the apparent rate that change by orders of magnitude. Similarly, any non-linearity in the Tafel fitting of the corresponding HOR and ORR expressions can further exacerbate differences in these measured parameters. In separate measurements on related noble metal materials, we observe the emergence of similar nonlinearities over the broad range of potentials used for these comparisons.

Figure 7 suggests that the surface coverage on Pt materials is more similar during electrode and flow reactor measurements than on Pd materials. This conclusion also agrees with the better parity of selectivity measurements on Pt materials versus Pd materials, which is also a strong function of reactant coverage.

From a recent work, form our group we learned that Pd catalysts undergo phase transitions between metallic and hydridic structures within the range of $\mathrm{H}_{2}$ and $\mathrm{O}_{2}$ pressures examined in the trickle bed reactor studied here. ${ }^{27}$ These changes are induced when the coverage of hydrogen atoms on the Pd surface reaches a critical value. During thermocatalysis, these $\mathrm{H}^{*}$-atoms form directly by barrierless adsorption of $\mathrm{H}_{2}$ gas. However, during electrocatalytic measurements of the ORR, the surface coverage of $\mathrm{H}^{*}$-atoms should be low, and the coverage of oxygen-derived species $\left(\mathrm{O}_{2} *\right.$, $\mathrm{OOH}^{*}, \mathrm{O}^{*}$, and $\left.\mathrm{OH}^{*}\right)$ is much greater because the ORR competes with the HER as a destination for protons and electrons. Moreover, differences between the barriers of HER and ORR are greater on Pd than Pt at the relevant operating potentials considered in this work.

These challenges (both phase changes and differences in surface coverages) are less problematic on Pt catalysts due to the intrinsic differences between the electronic structures of Pt and Pd. 
Consequently, the parity of all observable kinetic parameters (operating potentials, selectivities, and normalized rates) are greater for Pt catalysts.

(2) A small amount of error in the measured operating potential or charge transfer coefficients can lead to large changes in the apparent rates. Figures $7 \mathrm{c}$ and $7 \mathrm{~d}$ include the error propagation from the potentiometry measurements, which was determined by equation S10.8:

$$
\begin{gathered}
\delta r_{O R R}=\left(\left(\frac{d r_{O R R}}{d k_{O R R}} \delta k_{O R R}\right)^{2}+\left(\frac{d r_{O R R}}{d k_{H O R}} \delta k_{H O R}\right)^{2}+\left(\frac{d r_{O R R}}{d \alpha_{H O R}} \delta \alpha_{H O R}\right)^{2}\right. \\
\left.+\left(\frac{d r_{O R R}}{d \alpha_{O R R}} \delta \alpha_{O R R}\right)^{2}+\left(\frac{d r_{O R R}}{d \Phi^{\mathrm{op}}} \delta \Phi^{\mathrm{op}}\right)^{2}\right)^{\frac{1}{2}}
\end{gathered}
$$

where $\delta$ is the standard deviation of a given error, and the error propagation from each kinetic parameter is calculated from the derivative of each term times the standard deviation of said term.

Equation S10.5 shows that the thermocatalytic rates are an exponential function of $\alpha_{O R R}$ and $\alpha_{H O R}$, so a small amount of uncertainty in these parameters can cause large differences in the expected rate. While some materials do show large uncertainty, this explanation still does not explain the difference in parity between Pd and Pt materials. Many Pt materials agree with the expectations of the model within the error of the measurement. Many Pd materials, however, overpredict the reaction rate, such that error propagation cannot explain their deviation from parity. In this case the differences between the active phase or surface coverage on the Pd-based catalysts likely lead to the discrepancies (see above).

(3) Proper comparisons of turnover rates require accurate quantification of the number of reactive surface sites that are present on the catalyst material. Thus, the calculated value of rates depends on the assumed number of sites present, and the amount of material used during electrochemical measurements was not quantified precisely. In principle, this value should be an intensive quantity; in practice, we normalize by a surrogate for the number of sites (e.g., CO stripping, CO chemisorption). Therefore, the site count becomes an extensive quantity due to uncertainties in the amount of material used. While measuring the catalyst with the thermocatalytic reactor (on the order of $0.1-2 \mathrm{~g}$ ) is a straightforward task, the determination of the amount of material that remains adhered and in electrical contact with the RRDE is challenging and one additional source of uncertainty.

To better illustrate this idea, we performed additional ORR measurements on our Pt material using complimentary CO stripping and chemisorption measurements. Figure S71a and S71b show the CO stripping data on the carbon-supported Pt nanoparticles), which allowed us to quantify the number of sites deposited on the electrode without requiring an accurate measurement of the mass. Similarly, Figure S71c shows the uptake of CO on the carbon-supported Pt nanoparticles, and analysis of this isotherm indicates a site count of $0.0861 \mathrm{~cm}^{3}$ (STP) per gram of catalyst. We then repeated measurements of the ORR on the same electrode used for CO stripping, and we extracted kinetic parameters of the ORR. Thus, we renormalized the rates measured on Pt under thermo- and electrocatalytic conditions using a consistent internal standard in Figure S71d below: 
a

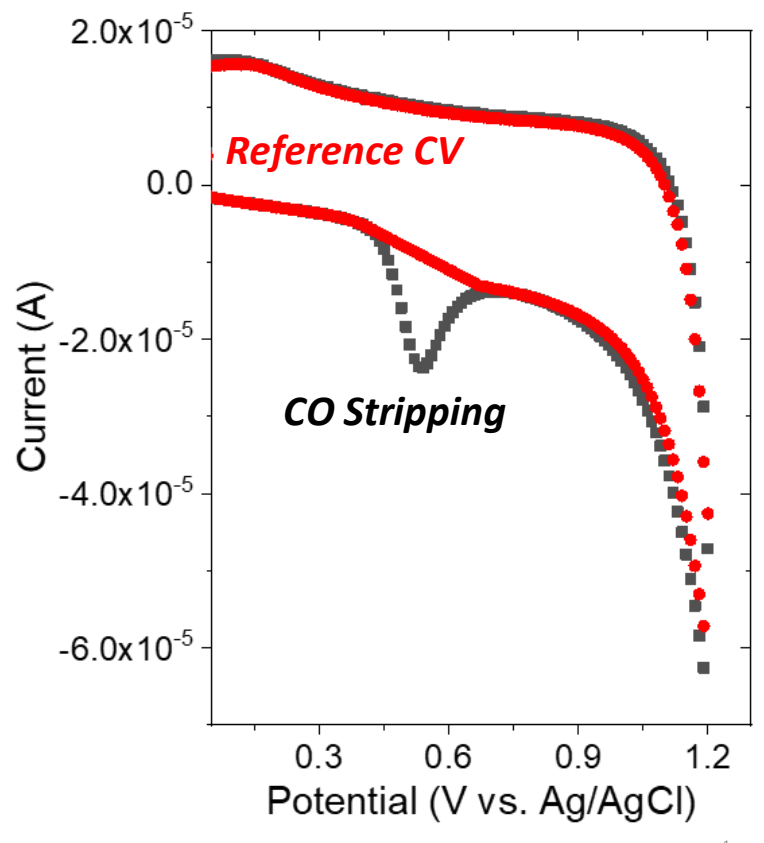

C

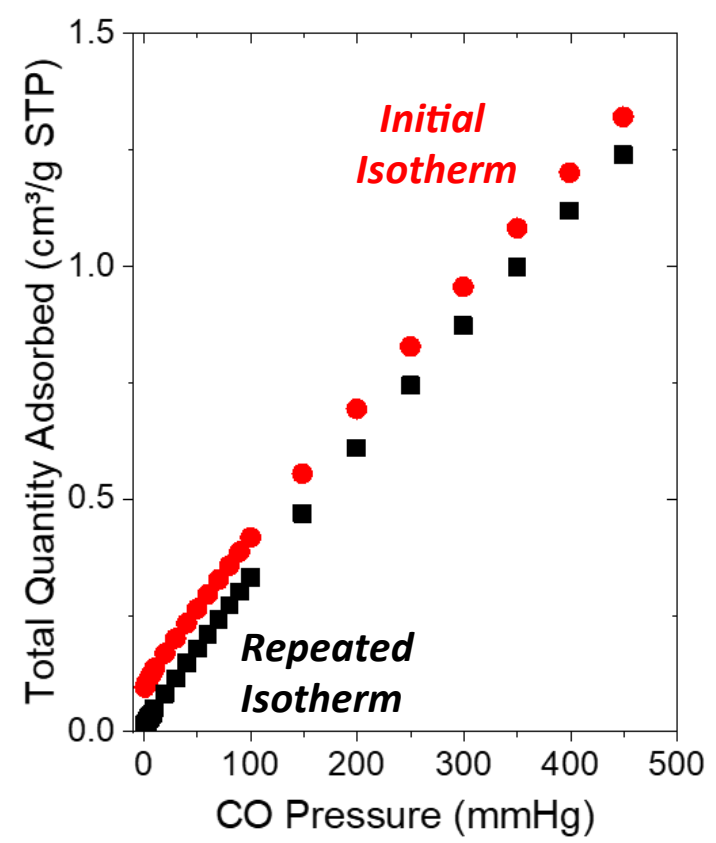

b

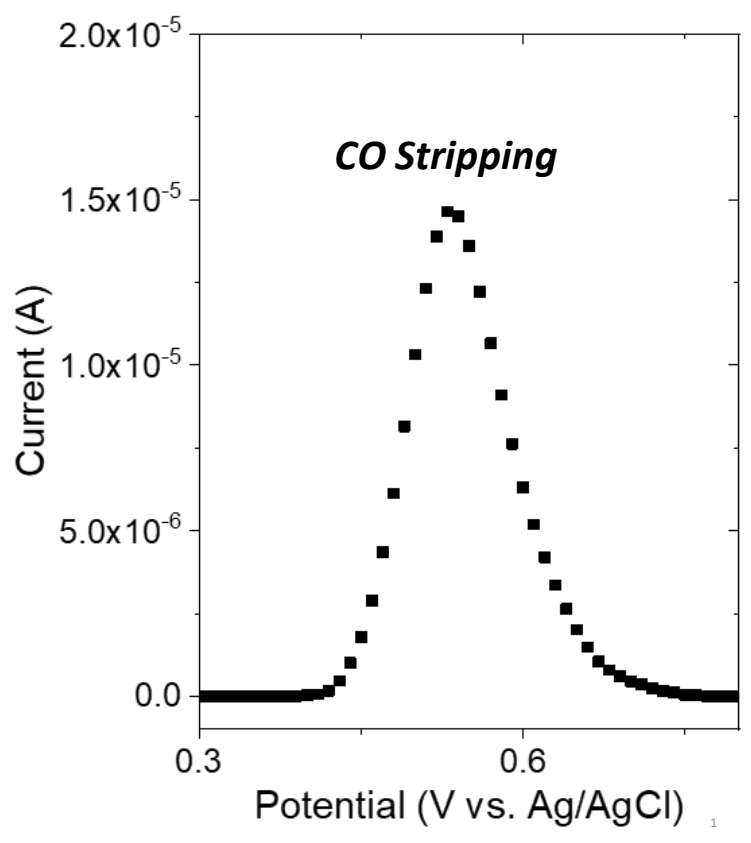

d

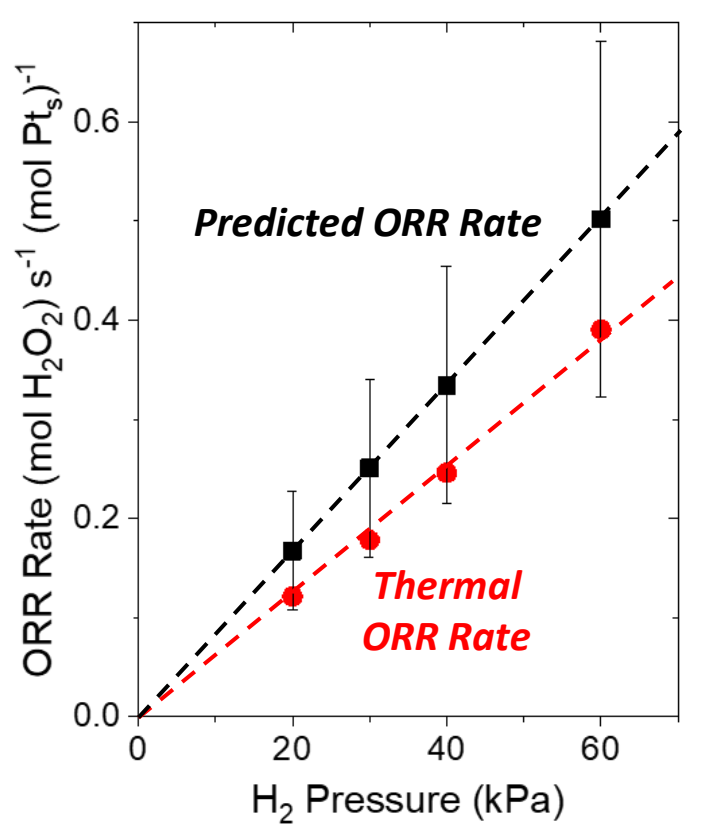

Figure S71. (a) Oxidation and reduction currents as a function of electrode potential in the presence and absence of $\mathrm{CO}$ and (b) the difference of these currents from $\mathrm{CO}$ stripping. (c) gas uptake on $\mathrm{Pt} / \mathrm{C}$ materials as a function of $\mathrm{CO}$ pressure during initial and subsequent isotherms (308 $\mathrm{K})$. (d) Thermocatalytic ORR reaction rates compared to predicted ORR rates using equation S10.5 and parameter renormalized by the moles of surface Pt atoms, determined in a-c. 
Figure S71 shows that the predictions of the rate ORR on Pt agree with thermal measurements of the ORR within error. Thus, proper normalization of rates leads to better agreement between the predicted and observed rates. The conclusions of this $\mathrm{CO}$ stripping analysis likely extends to all of the remaining materials, but such comparisons may become convoluted on the bimetallic alloys that bind $\mathrm{CO}$ on metals other than Pd or Pt and for which the stoichiometry is uncertain. Still, it is unlikely that this approach can explain why the Pd materials show systematically greater predictions of the ORR rate since the methodology of depositing catalysts was the same in all electrochemical measurements.

(4) The different experimental design of the trickle-bed flow reactor and rotating ring disk electrode may introduce subtle differences in mass transport and possibly other factors, which influence comparisons of rates. During flow reactor measurements, water is pumped into the system, where it combines with flowing $\mathrm{H}_{2}$ and $\mathrm{O}_{2}$ gas while under pressure (1000-3000 kPa). The saturated stream flows $\left(35 \mathrm{~mL} \mathrm{~min}^{-1}\right)$ into a reactor loaded with course pellets of catalyst (40-80 mesh), where $\mathrm{H}_{2} \mathrm{O}_{2}$ accumulates across the length of the catalyst bed. In contrast, electrochemical measurements were performed by crushing the catalyst into a fine powder that was deposited onto an electrode, which rotates at rates as high as $1500 \mathrm{rpm}$ within an aqueous solution at atmospheric pressure. This water is sparged with $\mathrm{H}_{2}$ or $\mathrm{O}_{2}$ gas, which diffuses to the electrode while $\mathrm{H}_{2} \mathrm{O}_{2}$ diffuses from the catalyst surface into the solution.

By comparison, the catalyst pellets are much smaller in the electrode measurements, which would improve the internal diffusion of gas relative to the larger pellets used in the flow reactor. Similarly, the difference in the flow geometry and bubbling may lead to other subtle differences that influence the external mass transfer rates in these systems. Last, there are other small differences between these systems that may convolute these comparisons, such as the presence of electrolyte and Nafion during the electrode measurements. This reasoning could explain the overprediction of some rates in the electrochemical system, but it does not explain the difference in parity between $\mathrm{Pd}$ and Pt materials.

Overall, explanation (1) provides the best interpretation for why rates deviate systematically for Pd vs. Pt materials, while explanations (2)-(4) may account for more minor deviations within the Pt materials (Figure 7d and S71d). Thus, this understanding indicates that more accurate predictions of rates would require measurements of charge transfer coefficients under conditions that produce similar surface coverages between electrochemical and thermochemical measurements. 


\section{References}

1. Bard, A. J.; Faulkner, L. R., Electrochemical Methods: Fundamentals and Applications 2nd Edition. John Wiley \& Sons Inc.: New York, 2001; pp 341-344.

2. Maruyama, J.; Minoru, I.; Ogumi, Z., Rotating ring-disk electrode study on the cathodic oxygen reduction at Nafion ${ }^{\circledR}$-coated gold electrodes. . Journal of Electroanalytic Chemistry 1998, $458,175-182$.

3. Cong, Y.; Yi, B.; Song, Y., Hydrogen oxidation reaction in alkaline media: From mechanism to recent electrocatalysts. Nano Energy 2018, 44, 288-303.

4. Davydova, E. S.; Mukerjee, S.; Jaouen, F.; Dekel, D. R., Electrocatalysts for Hydrogen Oxidation Reaction in Alkaline Electrolytes. Acs Catalysis 2018, 8 (7), 6665-6690.

5. Durst, J.; Siebal, A.; Simon, C.; Hasche, F.; Herranz, J.; Gasteiger, H. A., New insights into the electrochemical hydrogen oxidation and evolution reaction mechanism. Energy \& Environmental Science 2014, 7, 2255-2260.

6. Durst, J.; Simon, C.; Hasche, F.; Gasteiger, H. A., Hydrogen Oxidation and Evolution Reaction Kinetics on Carbon Supported Pt, Ir, Rh, and Pd Electrocatalysts in Acidic Media. Journal of the Electrochemical Society 2015, 162 (1), F190-F203.

7. Ishikawam, Y.; Matero, J. J.; Tryk, D. A.; Cabrera, C. R., Direct molecular dynamics and density-functional theoretical study of the electrochemical hydrogen oxidation reaction and underpotential deposition of $\mathrm{H}$ on $\operatorname{Pt}\left(\begin{array}{lll}1 & 1 & 1\end{array}\right)$. Journal of Electroanalytic Chemistry 2007, 607, 3746.

8. Skulason, E.; Tripkovic, V.; Bjorketun, M. E.; Gudmundsdottir, S.; Karlberg, G.; Rossmeisl, J.; Bligaard, T.; Jonsson, H.; Nørskov, J. K., Modeling the Electrochemical Hydrogen Oxidation and Evolution Reactions on the Basis of Density Functional Theory Calculations. Journal of Physical Chemistry B 2010, 114, 18182-18197.

9. Wang, J. X.; Springer, T. E.; Adzic, R. R., Dual-Pathway Kinetic Equation for the Hydrogen Oxidation Reaction on Pt Electrodes. Journal of the Electrochemical Society 2006, 153, 1732.

10. Fang, Y. H.; Liu, Z. P., Tafel Kinetics of Electrocatalytic Reactions: From Experiment to First-Principles. Acs Catalysis 2014, 4 (12), 4364-4376.

11. Conway, B. E.; Jerkiewcz, G., Relation of energies and coverages of underpotential and overpotential deposited $\mathrm{H}$ at $\mathrm{Pt}$ and other metals to the 'volcano curve' for cathodic $\mathrm{H} 2$ evolution kinetics. Electrochimica Acta 2000, 45, 4075-4083.

12. Song, X.; Sun, K. J.; Hao, X. F.; Ma, X. F.; Xu, Y. H., Facet-dependent of catalytic selectivity: the case of $\mathrm{H} 2 \mathrm{O} 2$ direct synthesis on Pd surfaces. . Journal of Physical Chemistry B 2019, 123, 26324.

13. Savara, A.; Ludwig, W.; Schauermann, S., Kinetic evidence for a non-LangmuirHinshelwood surface reaction: H/D exchange over Pd nanoparticles and Pd (111). ChemPhysChem 2013, 14, 1686-1695.

14. Tu, W. F.; Li, X. L.; Wang, R. Q.; Malhi, H. S.; Ran, J. Y.; Shi, Y. L.; Han, Y. F., Catalytic consequences of the identity of surface reactive intermediates during direct hydrogen peroxide formation on Pd particles. Journal of Catalysis 2019, 377, 494-506.

15. Todorovic, R.; Meyer, R. J., A comparative density functional theory study of the direct synthesis of $\mathrm{H} 2 \mathrm{O} 2$ on Pd, Pt and Au surfaces. Catalysis Today 2011, 160, 242-248. 
16. Song, X.; Sun, K. J.; Hao, X. F.; Su, H. Y.; Ma, X. F.; Xu, Y. H., Facet-Dependent of Catalytic Selectivity: The Case of H2O2 Direct Synthesis on Pd Surfaces. Journal of Physical Chemistry C 2019, 123 (43), 26324-26337.

17. Li, J.; Ishihara, T.; Yoshizawa, K., Theoretical revisit of the direct synthesis of $\mathrm{H} 2 \mathrm{O} 2$ on Pd and Au@Pd surfaces: a comprehensive mechanistic study. Journal of Physical Chemistry B 2011, 115, 25359-25367.

18. Olsen, R. A.; Kroes, G. J.; Baerends, E. J., Atomic and molecular hydrogen interacting with Pt(111). The Journal of Chemical Physics 1999, 111, 11155.

19. Voloshin, Y.; Halder, R.; Lawal, A., Kinetics of hydrogen peroxide synthesis by direct combination of $\mathrm{H} 2$ and $\mathrm{O} 2$ in a microreactor. Catalysis Today 2007, 125, 40-47.

20. Wilson, N. M.; Flaherty, D. W., Mechanism for the direct synthesis of $\mathrm{H}_{2} \mathrm{O}_{2}$ on $\mathrm{Pd}$ clusters: heterolytic reaction pathways at the liquid-solid interface. Journal of the American Chemical Society 2016, 138 (2), 574-586.

21. Wilson, N. M.; Priyadarshini, P.; Kunz, S.; Flaherty, D. W., Direct synthesis of H2O2 on $\mathrm{Pd}$ and AuxPd1 clusters: Understanding the effects of alloying Pd with Au. Journal of Catalysis 2018, 357, 163-175.

22. Wilson, N. M.; Schroder, J.; Priyadarshini, P.; Bregante, D. T.; Kunz, S.; Flaherty, D. W., Direct synthesis of $\mathrm{H} 2 \mathrm{O} 2$ on PdZn nanoparticles: The impact of electronic modifications and heterogeneity of active sites. Journal of Catalysis 2018, 368, 261-274.

23. Keith, J. A.; Jacob, T., Theoretical Studies of Potential-Dependent and Competing Mechanisms of the Electrocatalytic Oxygen Reduction Reaction on $\operatorname{Pt}(111)$. Angewandte ChemieInternational Edition 2010, 49 (49), 9521-9525.

24. Keith, J. A.; Jerkiewcz, G.; Jacob, T., Theoretical Investigations of the Oxygen Reduction Reaction on Pt(111). ChemPhysChem 2010, 11, 2779-2794.

25. Guo, X.; Hoffman, A.; Yates, J. T., Adsorption kinetics and isotopic equilibration of oxygen adsorbed on the $\operatorname{Pd}(111)$ surface. The Journal of Chemical Physics 1989, 90, 5787

26. Dissanayake, D.; Lunsford, J. H., The direct formation of $\mathrm{H} 2 \mathrm{O} 2$ from $\mathrm{H} 2$ and $\mathrm{O} 2$ over colloidal palladium. Journal of Catalysis 2003, 214, 113-120.

27. Adams, J. S.; Chemburkar, A.; Priyadarshini, P.; Ricciardulli, T.; Lu, Y.; Maliekkal, V.; Sampath, A.; Winikoff, S.; Karim, A. M.; Neurock, M.; Flaherty, D. W., Solvent molecules form surface redox mediators in situ and cocatalyze $\mathrm{O} 2$ reduction on $\mathrm{Pd}$. Science 2021, in revision.

28. Ford, D. C.; Nilekar, A. U.; Xu, Y.; Mavrikakis, M., Partial and complete reduction of O2 by hydrogen on transition metal surfaces. Surface Science 2010, 604 (19-20), 1565-1575.

29. Plauck, A.; Stangland, E. E.; Dumesic, J. A.; Mavrikakis, M., Active sites and mechanisms for $\mathrm{H} 2 \mathrm{O} 2$ decomposition over Pd catalysts. Proceedings of the National Acadamy of Sciences 2016, 113, 1973-1982.

30. Tripkovic, V.; Skulason, E.; Siahrostami, S.; Rossmeisl, J.; Nørskov, J. K., The oxygen reduction reaction mechanism on $\operatorname{Pt}(111)$ from density functional theory calculations. Electrochimica Acta 2010, 55, 7975-7981.

31. Shinagawa, T.; Garcia-Esparza, A. T.; Takanabe, K., Insight on Tafel slopes from a microkinetic analysis of aqueous electrocatalysis for energy conversion. Scientific Reports 2015, 5.

32. Tse, E. C. M.; Varnell, J. A.; Hoang, T. T. H.; Gewirth, A. A., Elucidating proton involvement in the rate-determining step for $\mathrm{Pt} / \mathrm{Pd}$-based and non-precious-metal oxygen reduction reaction catalysts using the kinetic isotope effect. J Phys Chem Lett 2016, 7 (18), 35423547. 
33. Katsounaros, I.; Schneidar, W. B.; Meier, J. C.; Benedikt, U.; Biedermann, P. U.; Auer, A. A.; Mayrhoger, K. J., Hydrogen peroxide electrochemistry on platinum: towards understanding the oxygen reduction reaction mechanism. Physical Chemistry Chemical Physics 2012, 14, 73847391.

34. Yin, F.; Liu, Y.; Wang, S.; Wang, C.; Liu, H., Validation of H2O2-mediated pathway model for elucidating oxygen reduction mechanism: Experimental evidences and theoretical simulations. Electrochimica Acta 2019, 313, 378-388. 